
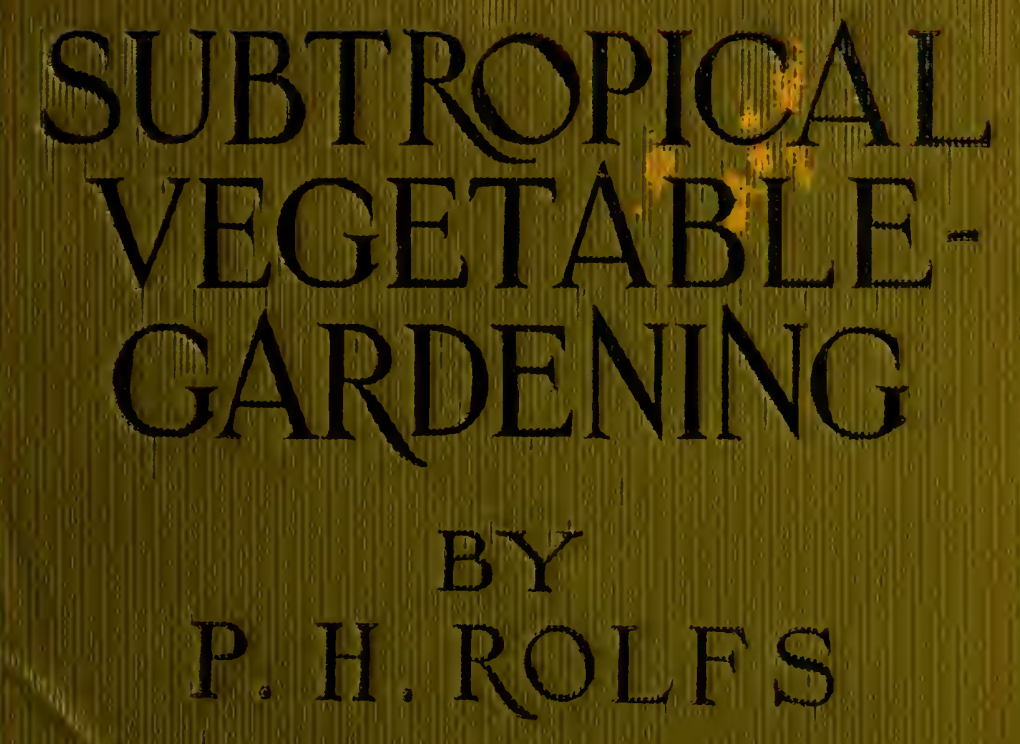

The Rural Science Series L.H. Bailey Editor 


$$
\tilde{\sigma}
$$





\section{Tbe thural Fcience 5eries}

Edited by L, H. BAILEY

SUBTROPICAL VEGETABLE-GARDENING 


\section{The גitural Srience Series}

\section{Edited By L. H. Bailey}

THe SorL. King.

The Spraying of Plants. Lodeman.

Milk and its Products. Wing. Enlarged and Revised.

The Fertility of the Land. Roberts.

The Principles of Fruit-growing. Bailey. 20th Edition, Revised.

Bush-Froits. Card.

Fertilizers. Voorhees. Revised.

The Principles of Agriculture. Bailey. Revised.

Irrigation and Drainage. King.

The Farmstead. Roberts.

Rural Wealth and Welfare. Fairchild.

The Principles of Vegetable-gardening. Bailey.

Farm Podltry. Watson. Enlarged and Revised.

The Feeding of Animals. Jordan.

The Farmer's Business Handbook. Roberts.

The Diseases of Animals. Mayo.

THE Horse, Roberts.

How to Choose a Farm. Hunt.

Forage Crops. Voorhees.

Bacteria in Relation to Country Life. Lipman.

The Nursery-BOok. Bailey.

Plant-Breeding. Bailey and Gilbert. Revised.

The Forcing-Book. Bailey.

The Pruning-book. Bailey.

Fruit-growing in Arid Regions. Paddock and Whipple. Rural Hygiene. Ogden.

DrY-FARMING. Widtsoe.

Law For the AMerican Farmer. Green.

FARM Bors and GirLs, McKeever.

'The Training and Breaising of Horses. Harper.

Sheep-Farming in Norti America. Craig.

Cö̈peration in Agriculture. Povell.

The Farm Woodnot. Cheyney and IVentling.

Household Insects. Herrick.

Citrus Fruits. Coit.

Principles of Rural Credits. Morman.

Beekeeping. Phillips.

Subtropical Vegetable-Gardening. Rolfs. - 


\section{SUBTROPICAL}

\section{VEGETABLE-GARDENING}

BY

P. H. ROLFS

DIRECTOR OF THE EXPERIMENT STATION

OF FLORIDA

Trem 19ark

THE MACMILLAN COMPANY

1916

All rights reserved 


\section{$S_{3} B_{5} 21$ R 6}

COPYRIGHT, 1916,

BY THE MACMILLAN COMPANY.

Set up and electrotyped. Published March, 1916.

Norfonot 损ress

J. S. Cushing Co. - Berwick \& Smith Co.

Norwood, Mass., U.S.A.

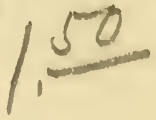

MAK - 91916

(C) Cl.A427204 


\section{PREFACE}

WE may regard the successful growth of the orange tree as marking the outer limit of the subtropical regions, where frosts are of short duration and the year is divided into hot and cool seasons. The coconut palm marks the boundary of the outer tropical belt, which has also more or less distinct cool and hot seasons, but as a rule no frosts. The equatorial belt, on the other hand, has no distinct cool season. In the subtropical regions, tropical vegetables may be grown well in the hot season, and temperate vegetables, which can survive any slight frosts that may occur, can be very successfully raised in the cool season. In the outer tropical or trade-wind belts, some temperate vegetables can be grown fairly well in the cool season. In the subtropical and especially in the tropical lands, an elevation of a few thousand feet produces a remarkable change in the climate; and temperate vegetables can be cultivated at such a height even in the equatorial belt, and still more successfully towards the borders of the tropical belt. Thus the subtropical regions can grow at different times of the year and at different heights, nearly all the vegetables of the world. Except in North India, where numbers of Europeans have resided for a long time, and in certain subtropical countries like peninsular Florida, it is probable that the 
growing of temperate vegetables in the cool season has not been carried to the extent to which it is capable. With a sufficient demand, good crops of many of the improved temperate vegetables can be raised even in the intertropical regions, either in the lowlands in the cool season, or preferably at elevations of a few thousand feet.

The directions in this book are based mainly on Florida practice, but the publications of the United States Experiment Stations, and of the United States Department of Agriculture, together with the horticultural literature of the tropical countries, have been laid under contribution.

The fertilizer formulas given in the book are such as have been successful in certain cases, but must be regarded as tentative only. A vegetable-grower, by trying different mixtures on his own soil and crop, may improve the formulas which the experience of others gives him as a starting point. Exact or definite formulas are to be regarded only as guides or suggestions, and never as prescriptions. There is so much yet to be done in the application of knowledge to the growing of vegetables, that a useful book on this subject must still consist mainly of results based on experience.

Farmer's' Bulletins of the United States Department of Agriculture are sent free on application to the Secretary of Agriculture, Washington, D.C. Other publications of the Department of Agriculture, for which a low price is charged, are obtainable from the Superintendent of Documents, Government Printing Office, Washington, D.C.

The Bulletins of the State Experiment Stations are 
sent free (if not out of print) on application to the Directors of the various Stations.

The Experiment Stations for the southernmost states are at the following places: Texas, College Station; Louisiana, Baton Rouge; Mississippi, Agricultural College; Alabama, Auburn; Florida, Gainesville; Georgia, Experiment; South Carolina, Clemson College. The Experiment Stations at Mayaguez, Porto Rico, Santiago de las Vegas, Cuba, and Honolulu, Hawaii, have published bulletins of special interest.

I am indebted to the Florida Experiment Station for most of the illustrations used in this book. Photographs for Plates IX, XV, and XVI were furnished by Dr. D. G. Fairchild, of the Office of Seed and Plant Introduction, at Washington, D. C.

P. H. ROLFS.

Gainesville, Fla.,

January 1, 1916. 



\section{CONTENTS}

\section{CHAPTER I}

PAGES

$1-4$

Soils for Vegetable-Gardening in Warm Countries .

Soils for vegetable-gardening, 1-Mechanical classification of soils, 2-Composition of soils, 3-Elements necessary for plant growth, 3-Why land becomes poor, 4.

\section{CHAPTER II}

Fertilizers

Complete fertilizer, 6 - Sources of nitrogen, 7 Sources of phosphoric acid, 8 - Sources of potash, 9 Percentage of fertilizer elements, 10 - Mixing fertilizers, 11 - How to compute the amount of fertilizer in a given formula, 12 - Table of fertilizers, 16 - How to use the table, 17 - Lime, 18 - Ground limestone, 18 - Acidity of Florida soils, $20-$ How to test for soil acidity, 20 How to test a field for fertilizer, 21.

\section{CHAPTER III}

Mandres for Vegetable-Gardening in Warm Countries

Compost, 25-Muck, 28.

\section{CHAPTER IV}

Rotation of Crops in Vegetable-Gardening $29-34$

Cover-crops, or plants used to protect and enrich soil, 31 - Plants as a source of nitrogen, 31 - Weeds, 33 .

ix 


\section{CHAPTER V}

\section{WATER AND WATERING}

Irrigation, 36-Overhead irrigation, 37-Surface irrigation, 39-Sub-irrigation, 40.

\section{CHAPTER VI}

\section{Seeds and Seed-Sowing}

How to test a machine, 43 - Choosing the varieties, 44 - Quantity of seed to sow, 44-Table, 45 - Seed-sowing, 46 - How to select plants, 46 - Tropical seeds, 50 .

\section{CHAPTER VII}

\section{Planting}

Coldframes, 52-Selection of a location, 52-Construction, 52-Hotbeds, 55-Plant-sheds, 57-Seedbeds and plant-beds, 58 - Preparation of the land, $59-$ Well-drained land, 60 - Clearing the land, $61-$ Plowing, $61-$ Transplanting, $62-$ Number of plants to the acre, 65 .

\section{CHAPTER VIII}

Pests and Diseases . $\quad . \quad$. $\quad . \quad$.

Poisonous insecticides, 67 - Paris green, 67 - Arsenate of lead, 67 - Zinc arsenite, 68 - Contact insecticides, 68 - Kerosene emulsion, 68-Whale-oil soap or fish-oil soap, 69 - Soda-sulfur spray, 69 - Tobacco-sulfur spray, 69-Commercial lime-sulfur solution, self-boiled, 70 - Bean spray, 71 - Miscible oils, 71 - Poison bait, 72 — Gaseous insecticides, 72 - Bisulfide of carbon, 72 Formalin, 72 - Fungicides, 73 - Bordeaux mixture, $73-$ Ammoniacal solution of copper carbollate, 75 - Spraying machines, 75 - Dry materials, 76 . 


\section{CHAPTER IX}

Marketing

The packing-house, 78 - Honest packing, 80.

\section{CHAPTER X}

Vegetables with Edible Leaves or Stems - Cole Crops

Cabbage, 81 - Seed-bed, 82 - Sowing the seed of cabbage, 82 - Soils for cabbage, 83 - Fertilizers for cabbage, 84 - Preparing cabbage for market, $85-$ Marketing cabbage, 85 - Enemies of cabbage, 86 Varieties of cabbage, 86 - Bulletins, $86-$ Brussels sprouts, 87 - Kale or borecole, 87 - Collards, 88 Cauliflower, 89 - Sowing seed of cauliflower, $90-$ Soil and fertilizer for cauliflower, $92-$ Setting out the plants, 92 - Cultivation of cauliflower, 93 - Cutting, 93 - Crating cauliflower heads, 93 - Seed production, 94 - Varieties of cauliflower, 94-Enemies, 95- Books and bulletins, $95-$ Broccoli, $95-$ Kohlrabi, 97.

\section{CHAPTER XI}

Vegetables with Edible Leaves or Stems - Other Crops

Lettuce, 99 - Seed-bed for lettuce, 100 - Preparing the lettuce field, 102 - Cultivation of lettuce, $102-$ Fertilizer, 102 - Irrigation for lettuce, 103 - Marketing lettuce, 104 - Lettuce seed raising, 104 - Diseases, 105 - Varieties of lettuce, 105-Bulletins, 106 - Endive, 106-Spinach, 107 - Celery, 109 - Soil for celery, 109 - Fertilizer for celery, 111 - Seed sowing, 112 - Transplanting celery, 113 - Irrigation of celery, 116-Preparing celery for market, 118 - Diseases, 118 - Varieties of celery, 119 - Bulletins, 119 - Chicory, $119-$ Parsley, 121 - Cress, 122 - Garden cress, 123 - Upland cress, 123 - Water cress, 123 - Asparagus, 124 - Prep- 
aration of the asparagus plot, 125 - Fertilizer for asparagus, 126 - Planting asparagus, 127 - Cutting, 127 - Bunching and crating asparagus, 128-Marketing, 128 - Blanching, 129 - Raising asparagus plants, 129Canning asparagus, 130 - Enemies, 130 - Varieties of asparagus, 131 - Bulletins, $131-$ Globe artichokes, 132.

\section{CHAPTER XII}

Vegetables with Edible Bulbs

$134-150$

Onions, 134 - Soil for onions, 135 - Fertilizer for onions, 135 - Time to sow onion seed, 137 - Seed-bed for onions, 137 - Setting out onions, 138 - Cultivation of onions, 141 - The large-scale method of onion-growing, 142 - Curing the onion erop, 143 - Crating onions, 144 - Raising onions from sets, 144 -Varieties of onions, $144-$ Costs in onion growing, $146-$ Bulletins, 146 - Leek, 147 - Shallot, 146 - Chive, 149 - Garlic, 150 .

\section{CHAPTER XIII}

Vegetables with Edible Fruits - The Cucurbits

Cantaloupes, 151 - Soil and preparation, 152 - Fertilizer, 152 - Planting and cultivating muskmelons, 153 - Marketing muskmelons, 153 - Saving melon seed, 153 - Enemies, 154 - Varieties of melons, 154 - Bulletins, $154-$ Watermelon, 155 - Soil, $155-$ Fertilizer for watermelons, $155-$ Planting watermelons, 156 - Cultivating, 157 - Marketing watermelons, 158 - Saving seed, 158 - Diseases and insects, $159-$ Varieties of watermelon, 159 - Bulletins and papers, 160 - Cucumber, 160 - Protecting cucumbers from frost, 162 - Soil and preparation of the cucumber field, 163 - Fertilizer for cucumbers, 164 -Cultivating cucumbers, 165- 
Picking and packing, 166 - Saving cucumber seed, 167 PAGEB Varieties, 169-Squash, 169-Choosing the soil for squashes, $170-$ Fertilizers, $170-$ Fertilizers for squashes, 171 - Planting squashes, 172 - Cultivating, 173 - Marketing, 173-Varieties, 174 - Chayote, 174 - Bulletins, 176.

\section{CHAPTER XIV}

Vegetables with Edible Fruits - Solanaceous Plants

Tomato, 177 - Tomato seed, 179 - Seed-beds, 180 Soil for tomatoes, 181 - Fertilizer, 182 - Preparing the tomato field, 182 - Setting out tomato plants, 184 Cultivating, 185 - Pruning tomato vines, 186 - Staking tomatoes, 187 - Trellising, 188 - Picking tomatoes, 188 -Packing-house, 189 — Sorting tomatoes, 190 - Summer and fall crop, 191 - Saving tomato seed, 191 - Canning, 195-Enemies of the tomato in Florida, 193 - Varieties of tomatoes, 194 - Literature, 195-Eggplant, 195 - Hotbeds and coldframes for eggplants, 196 - Using flower-pots, 197 - Soil and preparation, 199 - Fertilizer for eggplants, 199 - Cultivation of eggplants, $200-$ Gathering eggplants, 201 - Marketing, 201 - Seed saving, 201 - Varieties of eggplants, 203 - Pepper, $204-$ Hotbeds and coldframes for peppers, 205-Soil and preparation for peppers, 206 - Fertilizer for peppers, 207 - Cultivation of peppers, 207 - Marketing, 207 - Saving seed, 208-Varieties of peppers, 208.

\section{CHAPTER XV}

Vegetables with Edible Fruits - Other Crops . . 209-221

Roselle, 209 - Propagation, 210 - Cultivation of roselle, 211 - Gathering, 212 - Shipping roselle, $212-$ Productivity, 213-Uses of roselle, 213-Diseases, 214 
- Varieties of roselle, 214 - Bulletin, 214 - Okra, 215PAGES Bulletin, 216 - Plantain, 216-Papaya, 217-Breadfruit, 220 .

\section{CHAPTER XVI}

\section{Vegetables with Edible Seeds}

Peas, 222 - Soil and cultivation, 223 - Fertilizer for peas, 223 - Varieties of peas, 224-Beans, 225 - Bush beans, 226-Soil for bush beans, 226-Fertilizer, 226 - Planting and cultivating bush beans, 227 - Preparing bush beaus for market, 228 - Harvesting bush beans, 229 - Varieties of bush beans, 230 - Pole beans, 230 Varieties of pole beans, 231 - Lima beans, 232-Culture, 232 - Varieties of lima beans, 232 - Runner beans, 232 - Varieties, 233 - Enemies of beans in general, 233 - Bulletins, 233-Broad bean, 234-Cowpea, 235 Bulletin, 235-Peanut, 236-Soil and preparation, 236 -Fertilizer, 237 - Planting peanuts, 237 - Cultivation of peanuts, $239-$ Harvesting peanuts, $240-$ Varieties of peanuts, 242 - Bulletins, 242 - Goober, 242 - Sweet corn, 242.

\section{CHAPTER XVII}

\section{Vegetables with Edible Tubers or Roots}

Irish potato, 244 - Soil and preparation, $245-$ Fertilizer for potatoes, 246 - Seed potatoes, 247 - Planting potatoes, 248 - Cultivation of potatoes, 249- Harvesting, 250 - Storing potatoes, 251 - Varieties of potatoes, 252 - Second crop of potatoes, 252 - Diseases of potatoes, 253 - Bulletins, 253 - Sweet potato, 254 - Soil for the sweet potato, $254-$ Fertilizer, 255 - Propagation of the sweet potato, 255 - Preparation of the land for sweet potato, and transplanting, 256-Cultivation, 257Storing, 258 - Marketing, 259 - Uses, 259-Enemies, 259 - Varieties of sweet potatoes, 260 - Bulletins, 260 - 
Jerusalem artichoke, 261 - Yam, 262 - Radish, 264 Soil and preparation, $264-$ Fertilizer for radishes, 265 — Sowing and cultivation, 265 - Marketing radishes, 266 — Seed raising, 267 - Varieties of radishes, 267 - Comparison of varieties of radish grown in the open garden, 268 - Turnip, 268 - Soil and preparation, 269-Planting and cultivating, 269- Marketing, $270-$ Varieties of turnip, 270-Rutabaga, 270-Beet, 271-Soil and preparation, 271 - Fertilizer for beets, 272 - Seeding and cultivating beets, 272-Marketing, 273 - Varieties of beets, 274 - Carrot, 274 - Soil and preparation, $275-$ Fertilizer for carrots, $275-$ Sowing and cultivation of carrots, 276-Marketing, 276-Varieties of carrots, 276-Parsnip, 277-Soil and preparation, 277 - Fertilizer for parsnips, 277 - Sowing and cultivating parsnips, 278 - Varieties, 278 - Salsify or oyster plant, 279 - Dasheen or Taro, 279 - Uses of dasheen, 281 - Bulletins, 281 - Tanier, 281 - Bulletin, 282- Horse-radish, 283 - Cassava, 283-Bulletins, 285 - Lleren, 285.

\section{CHAPTER XVIII}

Other Vegetables; Pianting-List .

Chenopodium quinoa, 286-Ullucus tuberosus, 286 - Arracacia Xanthorrhiza, 287 - Yam-bean (Pachyrhizus erosus, and $P$. tuberosus), 287-Goa bean (Psophocarpus tetragonololus), 288 - New Zealand spinach (Tetragonia expansa), 288-Basella (Basella rubra), 288-Edible jute (Corchorus olitorius var. edulis), 288-Edible amaranth (Amaranthus oleraceus, A. gangeticus, and A. viridis), 289-Para cress (Spilanthes oleracea), 289-Pigeon pea (Cajanus indicus), 289 - Sword bean and Jack bean (Canavalia), 290Chinese cabbage (Brassica Pe-tsai), 290-Chinese mustard (Brassica juncea), 290 - Roquette (Eruca 
sativa), 290-West India cucumber (Cucumis Anguria), 291 - Ginger (Zingiber officinale), 291 - Dandelion (Taraxacum officinale), 291-Asparagus bean (Dolichos sesquipedalis), 291-Hyacinth bean (Dolichos Lablab), 292-Snake gourd (Trichosanthes Anguina), 292 - Tree tomato (Cyphomandra betacea), 292 Chard (Beta vulgaris var.), 292 - Pepino (Solanum muricatum), 293 - Wax gourd, 293 - Planting-list of vegetables by months, 296 . 


\section{ILLUSTRATIONS}

PLATE

PAG

I. IRRIGATION . . . . . . Opposite

36

Top, wooden sluice for conducting water to cucumbers and other crops, with V-shaped troughs to carry the water and also to be used to protect plants from frost; bottom, sub-irrigation of celery field, showing head-boxes.

II. LetTuCE

Top, lettuce grown on a city lot; bottom, a commercial lettuce field in Florida.

III. Three Good Types of Lettuce . . . Opposite

Left, Hanson ; right, Big Boston ; top, Black-seeded Butter.

IV. Celery

Top, largest one well rooted and ready for transplanting; center, market celery packed in a crate; bottom, celery packing in field.

V. Plant Beds

Opposite

Above, a seed-bed for starting celery plants, with cheesecloth covering; old fertilizer bags on fence were used over the beds to sprout the seeds. Below, a canvas-covered bed in which a cucumber crop is grown.

Vi. Celery

Top left, well-grown celery plants (Golden Selfblanching); top right, foot-press for packing celery; bottom, blanching celery by means of boards. 
ViI. Onions, Red Bermuda (left) and Creole. Also a Hamper of LetTuce . . . . . Opposite $134 \checkmark$

VIII. Melons . • . . . . . . Opposite

Top, Rocky Ford muskmelon; bottom, field marked off for muskmelons.

IX. Twelve Varieties of Chayote (Sechium edule). Onethird Natural Size • . . . . Opposite

X. Eggrlants and Peppers . . . . Opposile

Top, eggplant plantation ; center left, white eggplant; center right, eggplant ready for transplanting to the field; bottom, peppers in the field.

XI. Cucumber Hampers ; and a Plant of Roselle (Victor variety)

XII. Potatoes and Tomatoes - Opposite

Irish potato field above; tomatoes properly staked.

XiII. Lettuce and Sweet Potatoes . . Opposite

Top, Big Boston head lettuce, in longitudinal section ; bottom, using disc cultivator in sweet potatoes.

XIV. Root Vegetables . . . . . Opposite

Left top, French Breakfast radish ; right top, Long Scarlet radish; left bottom, Rose Turnip radish; right bottom, Chantenay carrot.

XV. A Field of Dasheen or Taro as grown in Florida Opposite

XVI. Tubers of Dasheen . . . . . Opposite

A bout natural size. These tubers weigh four or five ounces. 


\section{SUBTROPICAL VEGETABLE-GARDENING}





\section{SUBTROPICAL VEGETABLE- GARDENING}

\section{CHAPTER I}

SOILS FOR VEGETABLE-GARDENING IN WARM COUNTRIES

THE earthy matter in which plants grow is commonly known as soil; it is finely pulverized rock intermixed with more or less organic matter. 'The thin upper stratum in which plants grow is all that we are interested in for the present. The dark color in this stratum is due to the partial oxidation of the vegetable matter here present. The oxygen is mainly derived from the air. The part that is dark is usually called the soil, and that immediately below has been designated the subsoil. The soil is usually more fertile than the subsoil, especially in the South. In some of the alluvial bottoms, the soil is of the same consistency for a considerable depth.

The black vegetable mold in the soil, which we commonly call humus, is an important factor. In it is contained the mineral matter once extracted from the soil by the plants whose rotting produced the humus, in a good condition to be taken up again by other plants. Besides containing food for plants, it keeps the soil in good condition for 
plant growth. A sandy soil, rich in humus, can withstand a drought better than one in which the humus is wanting; but unless there is a more or less compact stratum of subsoil below such a sandy soil, much of the fertilizer will be carried off by frequent rains, and the land will be poor. The rotting of vegetable matter is due to friendly bacteria and fungi in the soil. If there are few of these in the soil, any vegetable or animal substance would be of little use to ordinary plants. The bacteria, as it were, pre-digest it. Hence one must take care of these bacteria and not let the soil be too wet, too close, or too acid for them to multiply.

\section{MECHANICAL CLASSIFICATION OF SOILS}

Owing to the large percentage of sand in many soils and its presence in all soils, it has been suggested that they should be classified according to the amount they contain. Under this classification there are the following divisions:

1. Clay; from which no sand can be removed by washing.

2. Strong clay; from which as much as 5 to 20 per cent of sand can be separated.

3. Clay loam; when washing will remove 20 to 40 per cent of sand.

4. Loam; when the land contains as much as 40 to 70 per cent of sand.

5. Sandy loam; from which 70 to 90 per cent of sand can be separated.

6. Light sand; containing more than 90 per cent of sand. 
When soil contains an easily perceptible amount of carbonate of lime, it is said to be calcareous or marly.

When a very large percentage of vegetable matter is present, the soil is usually called muck or vegetable mold.

\section{COMPOSITION OF SOILS}

Soils that are in good condition for raising crops are made up of about fourteen elements. There are more elements that may occur in soils; but as only about thirteen of these are actually used by plants, we need not regard the others, with the exception of aluminium, which, although not a plant-food, yet is the chief constituent of all clays.

Elements necessary for plant growth.

The essential elements for plant growth are oxygen, hydrogen, nitrogen, carbon, sulfur, phosphorus, potassium, calcium, magnesium, and iron, together with sodium, silicon, and chlorin. Oxygen, hydrogen, and carbon are mainly, and nitrogen partly, derived from the air. They constitute 95 to 99 per cent of the weight of plants. While these four elements are derived from the air, it should not be understood that they are usually taken directly from it by the plant, nor do they usually enter the plant in the condition of a simple element. All parts of plants, however, take oxygen from the air as they respire, and some plants, belonging to the pea family, are able, under certain conditions, to assimilate more or less nitrogen indirectly from the air. Because the abovenamed four elements make up so much of the weight of plants, it should not be inferred that the other nine ele- 
ments that are derived from the soil are of only minor importance. Although their combined weight is only from 1 to 5 per cent of the plant, the absence of any of these may materially interfere with its growth. Most vegetables get all their carbon from the air, and they can only get it in the light. They take in most of the other elements along with water by their roots, and they can only continue to do this when water is evaporating out from their leaves. Hence it is seen why they must have enough sunlight.

\section{WHY LAND BECOMES POOR}

It will be clear from what has been said that if crops are repeatedly removed from the land, some element or elements will be depleted or exhausted, or, as is ordinarily said, the land becomes poor.

Different crops do not remove an equal amount of the different elements, and even different individual plants of the same crop vary considerably in the amount of any one element that they take from the soil. Some crops take much nitrogen from the soil and return only a part of it when their roots and fallen leaves decay; others take only a small amount of nitrogen from the soil and give much back; the former make the land poorer, while the latter make it richer in nitrogen. When a piece of land is "tired" of one crop, it is often able to produce some other crop in fair quantity. To keep soil in such condition that it will produce a crop in paying quantities, we must maintain the necessary elements in sufficient quantity; we must fertilize. 


\section{CHAPTER II}

\section{FERTILIZERS}

ThiRTEen of the eighty and more elements now recognized by chemists are more or less directly concerned in the growth of agricultural plants.

Of the thirteen elements, silicon, chlorin, and sodium are perhaps not essential, and are nearly always abundant enough. Oxygen and hydrogen are the elcments of water. Carbon is derived directly from the air. Sulfur, calcium, magnesium, and iron are contained in most soils in fair amounts. Only nitrogen, phosphorus, and potassium often become scarce, and the plant must have these three. They play such an important part in the plant economy, and are present in such varying quantities, and so often one or more of them is insufficient in amount, that one looks upon them as the essential elements; though they are not more necessary to the plant's welfare than some other elements. A deficiency of any one will cause the plants to look sickly, and make them fit subjects for insect and fungous attacks, to which they then readily succumb. If a field has been producing good crops for a number of years and then gradually fails without visible cause, it is a fair indication that some form of food for that crop is becoming exhausted, and 
one must either stop growing that crop on that particular soil, or in some way supply the wanting plant-foods. This is accomplished by using either home-made or commercial fertilizers. It must not be thought, however, that plants can use up all the mineral food in the soil. They can take only the soluble minerals, and those that happen to come their way. By resting the land, more of the mineral food becomes soluble. The good effects of fertilizers are due mainly to their being soluble plantfood, and to their being put where the plant can get them.

Any substance that will supply the deficient element or elements to the soil, in such a form as to be available to the crop, is considered a fertilizer. It is not uncommon to find an element present in the soil in sufficient quantity, but in such form that the crop cannot make use of it; in other words, the element is not available.

\section{COMPLETE FERTILIZER}

A fertilizer that contains all three elements, nitrogen (as organic nitrogen, nitrate, or ammonia), phosphorus (as phosphoric acid), and potassium (as potash), is said to be complete. The amounts of the elements vary with the different brands of fertilizer, and should be suited to different crops and the different soils for which they are to be used. The amount of an element in a special fertilizer is governed largely by the amount of that element removed from the soil by any particular crop.

An incomplete fertilizer is one which is wanting in any one or more of the three fertilizing elements. These are known either by their chemical name, as acid phosphate, 
muriate of potash, nitrate of soda ; or by some trade name, as kainit, blood and bone, guano.

The fertilizer formulæ employed in this book should not be regarded as the best under all varying soil conditions. They are suggestive of what will probably prove advantageous under average or normal conditions in a sandy soil. Experience with any particular field or region will soon indicate what changes should be made in a formula for a particular crop. Generally speaking, starch-producing crops, such as Irish potatoes and sweet potatoes, will be benefited by a large quantity of potash.

\section{SOURCES OF NITROGEN}

In its natural state, nitrogen occurs as an atmospheric gas, and as such it is not available as a fertilizer. When the amount of nitrogen is mentioned in speaking of a fertilizer, one simply means that it is in some combination with other elements that hold it in the form of a solid.

The different forms in which nitrogen occurs as a fertilizer are: first, as organic matter, either vegetable or animal, for example, cottonseed meal, fish scrap, dried blood, tankage; second, as nitrate, in nitrate of soda, or nitrate of potash; third, in the form of ammonia compounds, as sulfate of ammonia. In the guarantees or analyses of fertilizers, when the amount of nitrogen is given, it is intended to imply how much of it would be present if it were in the form of a gas. Sometimes the amount of nitrogen in a fertilizer is expressed as ammonia, when it is really nitrate or organic matter. It is calculated in this way for ease in comparison. This is the method used in Florida. 
Nitrogen (or ammonia) is the most expensive fertilizer, the one which is most easily lost by leaching, and also the one an excess or deficiency of which may have the most prejudicial effect on a crop. Hence, it behooves the user to be especially careful with his nitrogenous fertilizers. The cheapest way to secure nitrogen (or ammonia) is to get it free from the air by growing velvet beans or other legumes.

\section{SOURCES OF PHOSPHORIC ACID}

A source of phosphoric acid of great commercial importance is the phosphate rock of Florida and South Carolina. This rock contains a varying quantity of phosphoric acid, therefore it is necessary to make an analysis of it before one can know its value. The natural rock becomes soluble only slowly in the soil, so it is customary to grind it and treat with sulfuric acid to make the phosphoric acid readily soluble and available to plants. In this condition it is known as "acid phosphate," or "superphosphate." It has been found of advantage, in some soils, to use the natural rock, finely ground ; this is called "floats."

In the manufacture of steel, the phosphorus of the molten iron is oxidized and absorbed by lime. The resulting slag, called "Thomas slag," contains phosphoric acid and much lime. It is not acid but basic, and so is suitable for acid soils, when finely ground.

Another source of commercial importance was phosphate from the bones of various animals. Before the discovery of phosphate rock, this was a very important source; and while the price of ground bone for fertilizer has not declined much as a result of the discovery of rock 
phosphate, yet it has not increased as it otherwise would have. In their natural state, bones yield phosphoric acid to plants rather slowly; but, being crushed and treated with sulfuric acid, the phosphoric acid is made soluble and so becomes available at once or in a short time. But little bone, however, is now treated with acid, and "dissolved bone" has become a trade name for acid phosphate made from rock.

The packing-houses and slaughter-houses collect the bones and harder part of refuse to grind up for fertilizer. Blood and bone is a trade name given to refuse from slaughtering establishments; its composition is rather indefinite. The bones and refuse of fish in large fisheries, also the carcasses of worthless fish, are used as a supply of this important element of plant-food, as well as nitrogen, under the name of "fish scrap."

\section{SOURCES OF POTASH}

In nature, soluble potash usually occurs as a chloride (muriate), a sulfate, or a carbonate. It is also found as an insoluble silicate in many rocks. It is very widely distributed, occurring in all parts of the world, and is one of the fertilizer ingredients that are left after plants are burned; in other words, it is one of the principal constituents of the ash of plants. Besides this general distribution, it also occurs in large bodies in a very few parts of the earth. The largest and most important of these is located in Stassfurt, Germany, where it is mined, much as salt is in other parts of Europe. In this place it occurs mainly as sulfate mixed with common salt and other sub- 
stances, and is imported to this country under the name of kainit. When refined, it is sold on our market as muriate of potash or sulfate of potash, as the case may be.

\section{Percentage of Fertilizer Elements}

Table showing the approximate amounts of different fertilizer elements in various substances used in growing vegetables

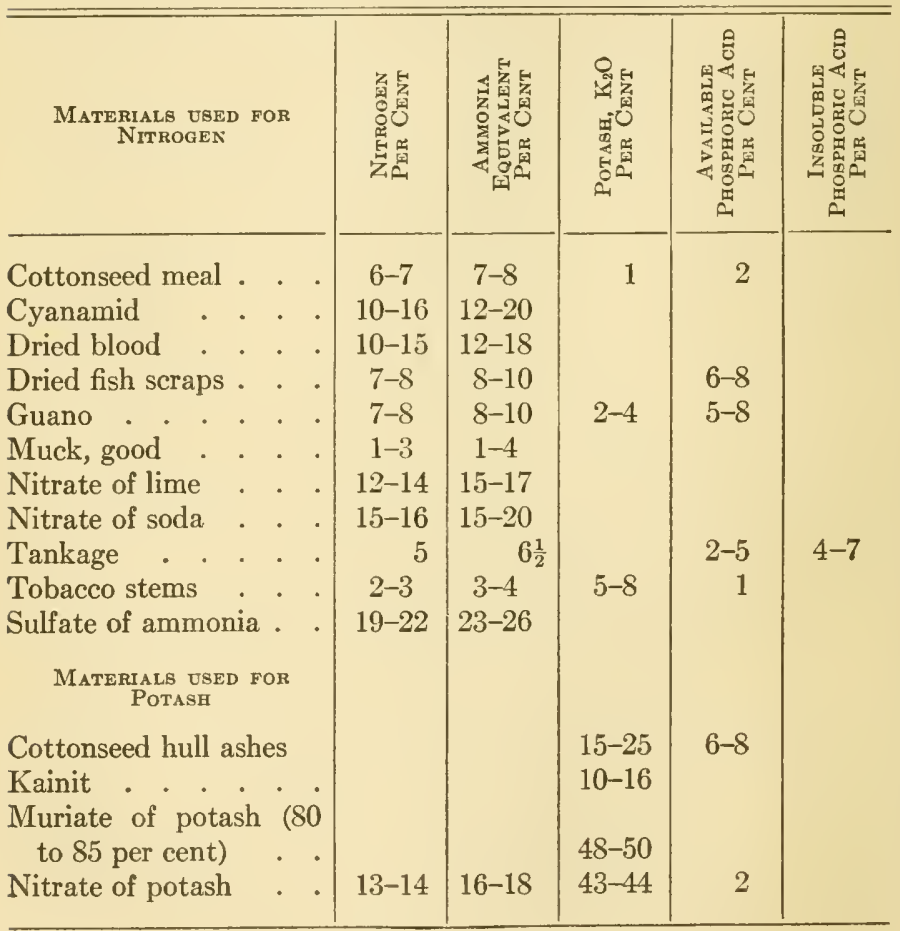




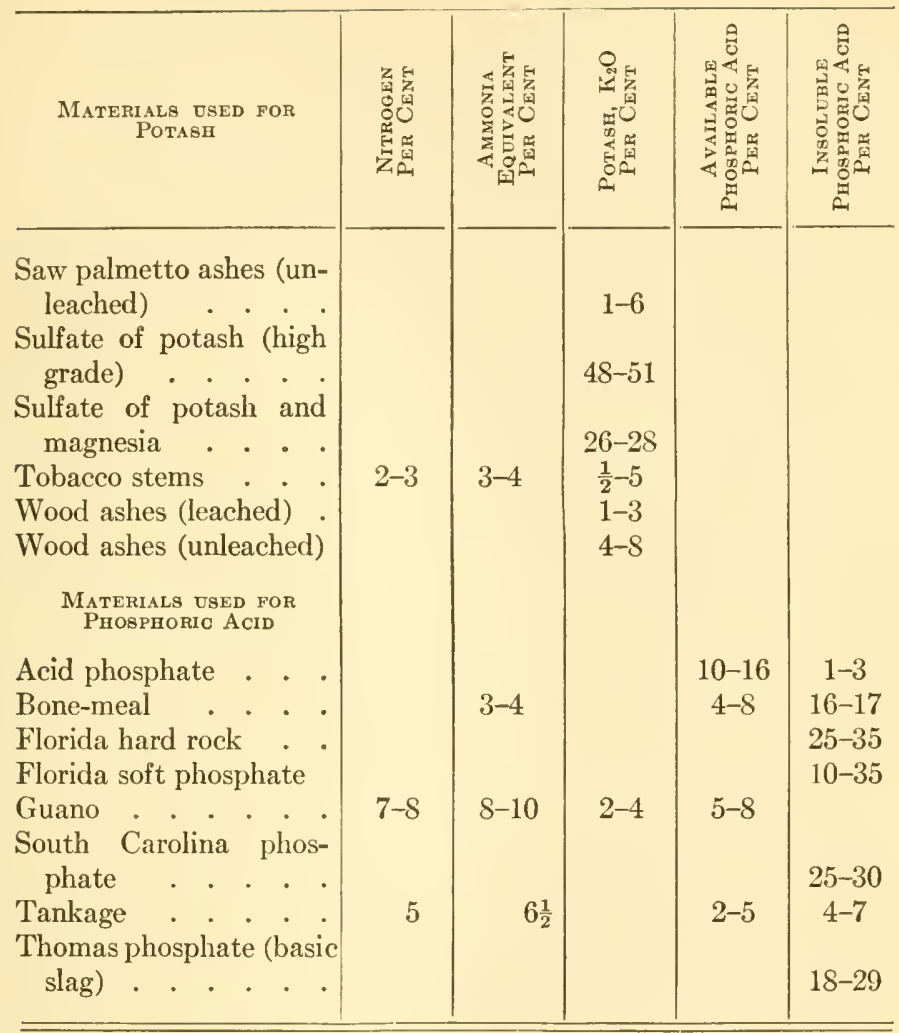

\section{MIXING FERTILIZERS}

Several fertilizer houses in Florida will mix and bag any formula which a grower may desire, at a cost of $\$ 1.50$ a ton more than the value of the materials. This is in excess of what it would cost the grower to do the mixing at home. 
Some combinations, however, cake, and require regrinding, and for such it would be cheaper to have the work done at the factory. Some vegetable-growers do not have a suitable floor, or a plasterer's sieve, and scales at hand. For any who should wish to mix their own fertilizers, and for those who wish to have special combinations prepared, the formulas given in this book are followed by a list of quantities of fertilizing materials.

A method which has been successfully practiced for the home mixing of fertilizers, was to spread the weighed and screened materials on the barn floor, in layers one above the other, the bulkiest at the bottom. The pile was mixed by shoveling together four times, and then bagged. Analysis showed that the mixing was perfect. It is well not to mix lime (or Thomas slag which contains lime) with other fertilizers; for by so doing ammonia may be lost, and phosphoric acid made unavailable, or the mixture may set hard.

HOW TO COMPUTE THE AMOUNT OF FERTILIZER IN A GIVEN FORMULA

It is important that one should be able to compute the amount of any essential fertilizer element contained in a certain formula. Unless one is able to find this out, one cannot make an intelligent use of the substance. Very often a high-grade and a low-grade fertilizer can be purchased on the same market: then it is important that the relative values of these should be secured in order that one may buy intelligently. It does not concern us further than the difference in handling, whether it is necessary to 
use a half ton or a ton of fertilizer to get the requisite amount of an essential element ; therefore, if one cannot get the requisite amount of a certain element in low-grade fertilizer for enough less to pay for its handling and something over, it would be better to buy the high-grade fertilizer.

In Florida and in most other states of the Union, the state chemist publishes every year the approximate values of 20 pounds of nitrogen (or ammonia), 20 pounds of available phosphoric acid, and 20 pounds of potash, at one or more of the principal towns of the state. Thus the Florida state valuations for 1909 were: 20 pounds of nitrogen are worth $\$ 4.01 ; 20$ pounds of potash are worth $\$ 1.10 ; 20$ pounds of available phosphoric acid are worth $\$ 1.00$ - at the sea-ports. Twenty pounds is of course one hundredth, or 1 per cent of a ton, and is taken as a unit. Hence if one has a fertilizer containing 6 per cent nitrogen, 10 per cent available phosphoric acid, and 8 per cent potash, the value of a ton is readily calculated.

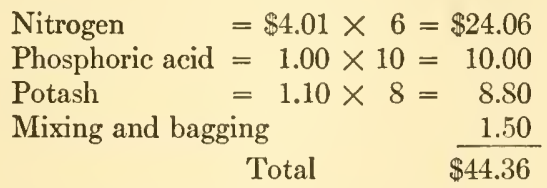

If a second fertilizer contains 4 per cent of nitrogen, 6 per cent of available phosphoric acid, and 6 per cent of potash, it will be worth a ton:

Nitrogen . . . . . . . \$ $\$ 16.04$

Phosphoric acid . . . . . . 6.00

Potash . . . . . . . . . 6.60

Mixing and bagging . . . . . 1.50

Total . . . . . . . $\$ \overline{30.14}$ 
Thus the former fertilizer is worth $\$ 14.22$ a ton more than the latter. Even if the latter fertilizer were offered at $\$ 28.00$ at the depot at Jacksonville, it would be necessary to decide whether one would make anything by buying cheaper and having the extra hauling and handling of so much more useless material.

The Report of the State Chemist of Florida for January, 1909, contains the following comparison of high-grade and low-grade fertilizers, which shows clearly how much money has been lost by purchasing the low-grade fertilizers :

"I again earnestly recommend the use of the high-grade mixed goods as the most economical, and again quote statements made in former reports as follows: The composition, selling price, and valuation of the average brand of each group appear below:

\begin{tabular}{l|c|c|r|r|r|r}
\hline & Nitrooen & $\begin{array}{c}\text { Available } \\
\text { Phos- } \\
\text { Phoric } \\
\text { Acid }\end{array}$ & Potash & $\begin{array}{c}\text { Total } \\
\text { Plant- } \\
\text { Food }\end{array}$ & $\begin{array}{l}\text { Average } \\
\text { Selling } \\
\text { Price }\end{array}$ & $\begin{array}{c}\text { Average } \\
\text { State } \\
\text { Valua- } \\
\text { Tion }\end{array}$ \\
\hline Low Grade & 1.13 & 8.28 & 2.50 & 11.9 & $\$ 24.50$ & $\$ 16.85$ \\
Medium Grade & 2.32 & 8.72 & 3.66 & 14.4 & 30.00 & 24.84 \\
High Grade & 4.00 & 7.00 & 10.00 & 21.0 & 36.50 & 32.70 \\
\hline \hline
\end{tabular}

"It will be noticed how rapidly the relative selling price above state values decreases from the low-grade to the high-grade goods.

Low grade costs above state values . . . . . $\$ 7.65$

Medium grade costs above state values . . . . 5.16

High grade costs above state values . . . . . 3.80 
Again the percentage of cost above state values is as follows, practically :

Low grade . . . . . . . . 45 per cent

Medium grade . . . . . . . . . 20 per cent

High grade . . . . . . . . . 11 per cent

I have urged in previous reports the economy of the highgrade materials, and again call attention to the poor economy of buying fertilizer by the ton 'because it is cheap,' when in fact the 'cheap' fertilizers are the more expensive in first cost, and more costly to handle (value considered) than the higher grade, concentrated goods."

Analyses of commercial fertilizers everywhere show that in many cases the higher grade fertilizer is the cheaper to buy, the higher price for a ton only meaning that there is less worthless material in it. Some vegetable-growers prefer to calculate the value of their mixed fertilizers by the price for a pound of the three plant-food ingredients. The State Chemist of Florida gives the following values for 1909 :

Ammonia. Available phosphoric acid
Potash

Taking a formula recommended for vegetables in Florida, $3 \frac{1}{2}$ per cent ammonia, $7 \frac{1}{2}$ per cent potash, $6 \frac{1}{2}$ per cent available phosphoric acid, let us calculate the value a ton. Here $3 \frac{1}{2}$ per cent is 70 pounds of ammonia, costing $\$ 11.55$; $7 \frac{1}{2}$ per cent is 150 pounds of potash, costing $\$ 8.25$; $6 \frac{1}{2}$ per cent is 130 pounds of phosphoric acid, costing $\$ 6.50$. Therefore, a ton would contain 350 pounds of plant-food, and would be worth, mixed and bagged, $\$ 27.80$. 


\begin{tabular}{|c|c|}
\hline $\begin{array}{l}\% \text { zI HINIVY } \\
\text { WOHA HSVLOd }\end{array}$ & ๘ \\
\hline $\begin{array}{l}\text { \% } 87 \text { HSVLOd } \\
\text { u० aLVATS } \\
\text { wora HSVLOd }\end{array}$ & भु \\
\hline 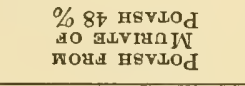 & 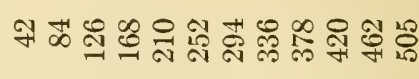 \\
\hline \multirow{2}{*}{ 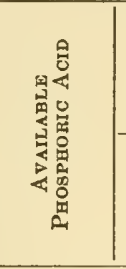 } & ำ \\
\hline & 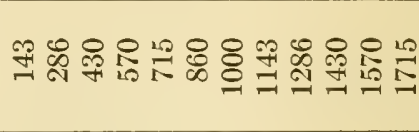 \\
\hline 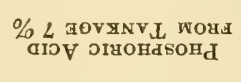 & బ \\
\hline 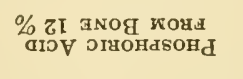 & ๓ \\
\hline 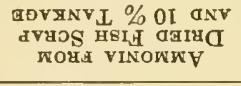 & 유 \\
\hline $\begin{array}{l}\text { \% } 79 \text { MOVসNVL } \\
\text { WOU VINONWV }\end{array}$ & ल \\
\hline 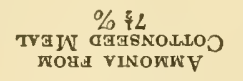 & ल \\
\hline 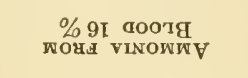 & ผ ำ \\
\hline 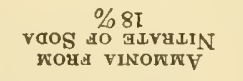 & 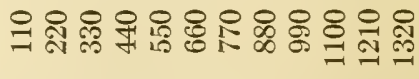 \\
\hline 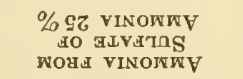 & 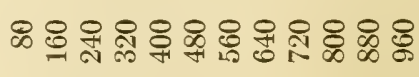 \\
\hline 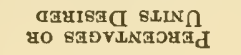 & - \\
\hline
\end{tabular}


HOW TO USE THE TABLE

This table enables one to ascertain the amount of different ingredients that may be used in compounding any normal formula. To secure the amount of plantfood contained in a formula giving 5 per cent ammonia, 6 per cent potash, and 6 per cent phosphoric acid, it will require 550 pounds nitrate of soda, 252 pounds muriate of potash, and 750 pounds 16 per cent acid phosphate. To ascertain the amount of ammonia needed, read down the first column to 5 (the per cent of ammonia the formula calls for), then read across to the column under nitrate of soda where we find 550 pounds as the required amount of nitrate of soda. To get the amount of potash, read down the first column until 6 , the number representing the percentage of potash, is reached, then read across the column until muriate of potash is reached, where we find the number 252. We find the number (6) representing the percentage of phosphoric acid desired, in the same way, and then again read across the columns until the one representing 16 per cent acid phosphate is reached, where we find the number 750 . This combination gives us 1552 pounds. If a ton of material is wanted, one can supply the deficiency by adding soil or other inert material.

Very many combinations can be made. All the materials in this table may safely be mixed. Some combinations may solidify after mixing, and would need to be crushed.

It is frequently advisable to use the ammonia from two sources, for example, nitrate of soda and cottonseed meal. 
Suppose that 2 per cent of the ammonia is wanted from nitrate of soda and 3 per cent from cottonseed meal. We proceed as before to read down the first column to the figure 2, and then across to the nitrate of soda column, where we find the figure 220 , which is the amount of nitrate of soda needed. We then proceed similarly and find 800 pounds to be the amount of cottonseed meal needed to make 3 per cent of ammonia. Then proceed to find the amounts of other elements as before.

\section{LIME}

A plant needs a certain amount of lime. There is often sufficient in the soil as carbonate of lime or limestone. Phosphate and land plaster contain a large percentage of it. But the uses of lime in agricultural soils are usually quite different from its use as a plant-food. It neutralizes the acids which are produced in damp vegetable soils, and is required for the growth of the bacteria which change animal and vegetable matter into soluble salts on which the plants can feed. Lime may be put on the soil as ground limestone or as slaked lime.

\section{Ground limestone.}

The amount of ground limestone to be used will vary greatly according to the acidity of the particular piece of land, even different parts of the same acre showing different degrees of acidity. A soil that is only slightly acid will need from one to two tons of ground limestone; soils that are decidedly acid will require about twice as much; and some of our most acid soils will be benefited by as much 
as 8 to 12 tons to an acre. Many farm crops are benefited by an application of ground limestone, even when the soil does not show acidity. Plants of the legume family are especially benefited by such an application. Celery, lettuce, cabbage, citrous fruits, hay and forage crops, generally prefer a large supply of lime in the soil. Watermelons, on the other hand, do well on an acid soil.

It is best to apply ground limestone to the soil a considerable time before the crop is to be planted. The application should be made before plowing, as this will give an opportunity to incorporate the material more evenly with the soil, and will give the beneficial soil organisms an opportunity to increase to large numbers.

If it has not been possible to apply ground limestone before the soil is broken up, it may be applied before planting time. It is advisable, however, to apply it a considerable time before one wishes to use fertilizer, since the acid phosphate of the fertilizer on coming in contact with the ground limestone is likely to be reverted more quickly than desirable.

Formerly it was considered necessary to have the limestone ground into a very fine powder; later experimentation has shown that a rather more coarsely ground limestone is quite as beneficial and more lasting. Hopkins, of the Illinois Experiment Station, considers that the limestone is ground fine enough if it can pass through a sieve with 10 meshes to the inch. Since there are included in this material all the finer particles that are produced in grinding, a sufficient amount of lime will be available at once for the needs of the plants. 
Acidity of Florida soils.

The soils of Florida are for the most part made up of siliceous particles, and have no available alkali or base to neutralize any acidity. In a few cases in which an abundance of limestone occurs in the surface soil, it is a corrector of acidity, but by far the larger percentage of the sandy soils are acid.

Florida muck soils are nearly all acid, there being very few exceptions. These are not only acid, but very strongly so, and frequently require a very large amount of ground limestone to correct the acidity.

In addition to the fact that most Florida soils are naturally acid, this condition is intensified by some of the fertilizers, especially when large amounts of sulfate of ammonia are used. When such materials are broken up, as they are in the process of being made available to plants, the acid radical is left in the soil.

\section{How to test for soil acidity.}

Soil may be tested readily for acidity. This can best be done in the field. Procure strips of litmus paper from the drug-store, of both kinds, pink and blue. In using this litmus paper, care should be taken that the fingers do not touch it, since the perspiration from the hands is usually acid enough to turn the blue to pink, and in testing soilafter the paper has been handled a false reaction might occur. The soil to be tested must not be too dry. A small amount of soil may be taken up, and if it can be pressed into a good ball it usually contains enough moisture to show the reaction. Break the ball of soil open and place two strips 
of paper (blue and pink) in the break, then press tightly together again. In the course of ten minutes examine, and if the paper has been thoroughly wetted the condition of the soil may be noted. If the blue litmus paper has turned pink, the soil is acid. If the pink paper has turned blue, the soil is alkaline. If no change in color occurs, the soil is neutral. The degree of acidity can be told in a general way by the degree of pinkness if the paper was formerly blue. The subsoil as well as the soil should be tested.

\section{HOW TO TEST A FIELD FOR FERTILIZER}

It is well known to all vegetable-growers that no two fields are exactly alike in their fertilizer requirements. Chemical analyses of the soil will not give sufficiently accurate data to enable us to vary the fertilizer formula. Fortunately the superabundance of any element in the soil rarely proves harmful, but to apply an excess of any element is wasteful and expensive. The only way at our command at present is to ask the particular crop to analyze the field for us.

The sandy soil of Florida is unusually well adapted to work of this kind, as so much of it is deficient in all of the essential fertilizing elements. Any one raising vegetables could withhold one of the three necessary fertilizers for a series of years on three different plots, and thereby learn the effect of such treatment, and then by noting the color of the foliage, form of growth, and other characters, learn to interpret these when observed in other fields.

To test a field to learn whether it really needs all the 
elements of a complete fertilizer, one may proceed as follows: Choose four rows of, say, tomatoes, that run across a typical portion of the field, and withhold from these one of the fertilizer elements, for instance nitrogen. Treat the next four rows the same as the bulk of the field. From the next four rows withhold the potash. Again treat four rows with the usual fertilizer: and withhold the phosphoric acid from the next set of four rows.

While the test rows are being prepared, a number of strong stakes are made ready to mark off each plot by driving them securely into the ground at the first row of each of the three sets of four rows. If a second dressing of fertilizer is given to the crop, care must be exercised not to apply the element that was withheld when the first dressing was made. In making such a test, it is almost useless to employ only one or two rows, as the plants may draw their supply of the wanting element from the neighboring row. After such a test has been made, the crop from this portion should be measured carefully and compared with that of the neighboring rows. If the first four rows produce a decidedly inferior crop, and the other two sets of four rows are of an average production, it is evident that the field needs nitrogen; but if only the first and third sets of four rows have fallen off in yield, the field needs nitrogen and phosphoric acid and not potash.

Another way that has been employed, but one that does not answer the question whether more than one element is deficient, is to use the plots in the way described above; but in the place of two elements in each, to use only one. For example, choose four rows and fertilize these with a nitrogenous fertilizer only, containing neither potash 
nor phosphoric acid; and so on. On vegetables, either of these tests can easily be performed, but on fruit-trees the results are frequently so slow in making themselves manifest that it requires one or two years to answer the question correctly. 


\section{CHAPTER III}

\section{MANURES FOR VEGETABLE-GARDENING IN WARM COUNTRIES}

Manure comprises all forms of partly decomposed vegetable matter in barn-yards, whether animal excrement or other decomposing plant remains. Its value varies greatly, not only with regard to source, but also from the manner in which it has been kept. When kept in the usual way, it is worth from $\$ 2.00$ to $\$ 4.00$ a ton for use on sandy soils in Florida. About 60 to 80 per cent of the whole weight is water; 9 to 15 pounds of each ton is nitrogen; 4 to 9 pounds, phosphoric acid ; and 9 to 15 pounds, potash. From these variations it is evident that it is difficult to state just how much manure is worth. If the manure has decomposed in the open air, there is likelihood of the rain having washed out much of the potash, and the ammonia having passed off as a gas into the atmosphere. Manure that is to be kept for some time should be under a roof where rain cannot wash out any of the soluble fertilizer. It should be kept from becoming too hot by being forked over or stirred in some way, or by using water when becoming dry. While the essential elements in manure may not equal those of a commercial fertilizer at the same price, yet it has an additional worth in supplying humus, the value of which is difficult to estimate, and which is often needed more than the plant-food elements. 
Manure supplies useful bacteria, especially on sandy, worn-out, or occasionally flooded lands, but may distribute weed seeds, and fungi such as Fusarium.

\section{COMPOST}

It has long been known that decomposing vegetable or animal matter causes plants to grow luxuriantly; but that at the same time, the plants are liable to be unfruitful. This is due to an over-abundance of nitrogenous matter. If, to this decomposing organic matter, enough potash and phosphoric acid are added to make a complete fertilizer, the plants do not become "over-grown." The amount of potash and phosphoric acid to be used is learned by experience. Such a mixture is called a compost. This term is often applied to a decomposing heap of organic matter, and also to such heaps when land plaster (gypsum) has been added; but the term is here restricted to decomposed organic matter, to which enough commercial fertilizer elements have been added to make a complete fertilizer.

On any farm, garden, or other place where branches of horticulture or agriculture are carried on, a considerable quantity of coarse and refuse material can be collected without special effort. All offal, as vegetable refuse, kitchen slops, wash-water or soap-suds, the dung of domestic animals, bits of wood, - in fact, anything of animal or vegetable origin, - may be used in this way. The best way to dispose of any animal that has died on the farm is to use it in the compost heap. When any odor is escaping from the compost heap or bin, one may be sure that 
valuable fertilizer is being lost; this may be arrested by mixing with the compost two or three bushels of land plaster to a cart-load of material. If land plaster is not at hand, two or three inches of moist soil thrown over the pile will arrest the escaping ammonia. The decomposition of material may be hastened by adding night-soil or undecomposed manure, but it should be distributed evenly throughout the entire mass.

By the proper use of fresh manure, a compost may be prepared that will be ready for use in four or five weeks.

If any one wishes to compost material rapidly, the following general directions will be found of service: Have on hand about four barrels of manure, such as hen manure, cow manure, horse manure, or night-soil ; and about five bushels of land plaster. This will be found enough to decompose a ton of dry matter, and about eight tons of green matter. Place about six inches of muck on the bottom of the compost shed and wet it down thoroughly. On this put a layer of six or eight inches of material to be decomposed; add a thin layer of manure, and so on, till the required amount of material has been used. The body of the material should be made completely wet; if this is not done it is liable to "burn," and lose one of the important elements of plant-food, nitrogen. Finally, mix the land plaster with enough fresh earth or thoroughly decomposed muck to cover the whole about eight inches thick. The muck in the bottom will catch any surplus moisture and save a waste of soluble fertilizer. The manure furnishes the germs that set up decay, the water distributes these germs and gives them the necessary moisture, while the land plaster arrests 
any escaping ammonia and holds it in an available form. Land plaster may be added to each layer of the compost to take up any gas as it is formed. The time required for decomposition depends largely on the amount of manure used and the completeness of the mixing with the coarse stuff. Caution should be exercised to keep the pile moist, but not wet; if it is so wet that liquid can be pressed out of it by squeezing it in the hand, water must be withheld for several days; when no more water can be pressed out, water may again be applied; if it is too dry much of the nitrogen may be lost. This is made apparent by the rising of steam or the sending off of ammonia gas, and is easily detected by the nostril. If the overheating is due to the lack of water, it may be corrected by supplying the needed moisture, but sometimes it is necessary to fork the pile over to lower the temperature. After a little practice, one is able to prepare a heap so that it will not have to be disturbed until it is to be applied to the field.

If one has determined for what crop the compost is to be used, the proper amount of commercial fertilizer may be added as the pile is prepared; otherwise this must be added when the compost is to be used. There are two advantages in the use of compost: first, it improves the mechanical condition of the soil ; and secondly, the soluble chemical fertilizer is taken up by the vegetable matter and held in suspension much as a sponge holds water, thus keeping the rains from leaching it out of the soil, and as it is in a more finely divided state, the growing plants can absorb it with greater facility. When preparing compost, it must be under shelter to keep the water from washing out the soluble fertilizer. 


\section{MUCK (OR PEAT)}

There has been much said and much written on this subject, and many heated discussions have been engaged in. Much of the discussion would not have occurred if the arguments had been confined closely to the question at issue. Usually the only fertilizing element present in muck is nitrogen, and this varies widely in different samples, from a fraction of 1 per cent in a poor grade to two or three in the best. However, if one is sure that the soil needs this element, nitrogen, and also wants humus, all that is necessary is to get the percentage present in the supply, and calculate whether it is cheaper to use this source or to get it from some other form. It must be remembered that the nitrogen in muck is only slowly available, and the amount available is shown only by experience. The particular crop to be grown on a given piece of land will have much to do with the advisability of hauling muck. It is generally conceded that muck is an important source of nitrogen and will prove of value when properly and intelligently used.

Besides its good qualities as a fertilizer, muck in a dry and powdered form makes one of the best absorbents. It is excellent for use in horse stables, cattle sheds, and similar places. The moisture is taken up quickly and the odor arrested. 'The importance of saving the urine of animals is usually over-looked, mainly because there seems to be no handy way of saving it. By using dry muck, it is as easily handled as a commercial fertilizer.' 


\section{CHAPTER IV}

\section{ROTATION OF CROPS IN VEGETABLE- GARDENING}

When a certain crop has been grown for a number of years in the same field, the yield often decreases with each successive harvest, until, finally, the crop fails to be remunerative. When a different vegetable is planted on such land it usually yields a paying crop, and after a number of years the original crop can again be grown with profit. This phenomenon has given rise to the belief by some persons that the first crop puts something in the soil that is detrimental to itself; others hold that there is something taken out of the soil that is afterward restored. The latter view may be nearer the truth than the former. There are crops, however, that grow "tired" of a certain piece of land, or rather the land grows "tired" of a certain crop. Some of these instances cannot be explained by the exhaustion of certain elements. Certain pieces of land in Germany grew tired of growing beets, and were "rüben-müde" (beet-tired) ; after growing certain other crops on this land, it would again produce beets in the same quantity as at first. Later investigations showed that this "beet-tired" condition was due to the presence of a microscopic worm closely related to the one that causes root-knot on our vegetables. 
Certain crops are able to grow repeatedly on the same land without showing any falling off in quantity or quality of yield. For example, in an onion-raising district, a certain piece of land has grown more than thirty crops of onions, and that plot is preferred to-day to any of the surrounding land. Lawes and Gilbert grew wheat on the same carefully weeded plot for forty consecutive years, and at the end of that time the land seemed about as good for wheat as it was at the beginning of the experiment.

It is always a good practice, however, to change the crop grown in any field from year to year. In making changes of crops, they should be as different as possible. It is well to plant a field that has just received a good green soiling with some gross-feeding crop, as the small grains or corn, and then to follow this with vegetables. To follow a crop of eggplant with a crop of tomatoes could hardly have the force of rotation, inasmuch as the plants use about the same fertilizer and harbor about the same insects and fungi; cabbage following cauliflower could not be considered a rotation for the same reason, but cabbage following tomatoes would be a good rotation.

In the southern United States, near the Gulf, it is possible to have three or even four crops in rotation in a single year. Thus at Hastings, Florida, a crop of Irish potatoes may be planted in February, and immediately after digging the potatoes, corn may be planted. When the corn is cultivated for the last time, cowpeas may be sown. When these have been harvested, a fall crop of Irish potatoes may be planted. These are harvested before Christmas. This rotation has been carried out in practice. If some other crop, such as fall lettuce, be sub- 
stituted for the fall Irish potatoes, we would have a complete four-crop rotation.

A rotation should, as a rule, include a crop of some legume. This will keep the soil in good condition and add to the amount of nitrogen. Otherwise, more nitrogen must be applied, as manure or fertilizer. Legumes used in Florida in a rotation are velvet beans, beggarweed, peanuts, and cowpeas. In other subtropical regions, as Egypt, the broad bean is used as a winter forage crop. In tropical countries, however, the pigeon pea, green gram or woolly pyrol, the jack bean or sword bean, and others are used in rotations.

COVER-CROPS, OR PLANTS USED TO PROTECT AND ENRICH SOIL

The rain that falls on the land during the year leaches out much soluble plant-food or fertilizer, unless there is some way of holding it in the soil. Fertilizer must be in a soluble condition before plants can appropriate it. If there are no plants present to appropriate the soluble part of the fertilizer, it is evident that the rain will carry this portion out of the soil into the waterways; but if plants use it at once when it becomes available, it remains on the land. When these plants decay, they return this stored-up food, and also humus, to the soil.

\section{Plants as a source of nitrogen.}

The primary source of nitrogen is the air. Nitrogen enters plants in different ways; most vegetables take it up from the soil, but a few are known to take it from the 
air indirectly. Plants that do not appropriate it from the air are still important conservators of nitrogen, in that they take it up from the soil and keep it from wasting, and at the end of their life give it back when they decay. This class of plants cannot give to the soil more nitrogen than they draw out, but they can conserve it for subsequent crops. They also accumulate the other soluble elements of plant-food. The nitrogen-assimilating plants store up varying amounts of this element and give it to the soil when they decay, thus actually adding to the supply of this important element, and also keeping the other elements from wasting. By growing a leguminous covercrop on land for a number of years, and utilizing it carefully, the land becomes richer, until finally it will grow full crops.

The best plants for gathering nitrogen now in cultivation in the southern United States are velvet beans, cowpeas, and beggarweed. In tropical countries, green gram or woolly pyrol, jack bean, Manila bean, Bengal bean, pigeon pea, and several other legumes are used. Most varieties of cowpeas are severely attacked by the rootknot-producing nematode. This should be taken into consideration when planting them, as it would mean the failure of a subsequent non-immune crop if the field were infested with these nematodes. Fortunately there is at least one variety of cowpea, the Iron, that seems to be resistant to this disease.

As to the way of using these plants, there is some diversity of opinion. In clay soil, the plants may be plowed under in the green state, but on sandy soils this will not be found good practice. 
According to Director Stubbs of the Louisiana Agricultural Experiment Station, it is a detrimental practice in the South, and the green manure should be allowed to rot before it is plowed under. The decomposition of the green matter is said to create a ferment in the soil detrimental to crops that may follow.

\section{Weeds.}

If the definition that a weed is a plant out of place, is accepted, almost any plant may become a weed. On the other hand, perhaps almost every weed may, in some way, become an economic plant. Most weeds certainly play havoc with a crop; they are ever present, springing up, it seems spontaneously, to take up the available fertilizer that was intended for the crop, thus leaving the seedlings in a sickly and weak condition, unable to withstand insect attacks and diseases.

It has been shown very clearly that many weeds harbor diseases of crops. Some of the plant diseases are carried through the winter by weeds, and in spring produce spores which are disseminated to the crops. Other weeds act simply as harborers of insects, which leave the weed as soon as more refined food can be found. Poke-weed is a prolific source of root-knot ; fire-weed multiplies the sclerotium tomato blight; pepper-grass harbors club-root; and so we might continue a long enumeration of the diseases of crops that will grow on weeds. Another pernicious effect of weeds is the untidy appearance they present when allowed to grow. When dry they invite fire and are often the road to the destruction of much property. 
Weeds remove moisture from the soil and so may cause serious injury to the crop in dry weather. Abundant weeds also prevent the cultivated plants from getting enough light when young, causing them to grow spindly, and the roots of weeds crowd out those of the crop. 


\section{CHAPTER V}

\section{WATER AND WATERING}

IN all branches of vegetable- and fruit-growing, the question of watering is an important one; it is a necessary factor from the time the seed is planted to the time the crop is harvested. A sufficient amount of water must be applied either naturally or artificially. Where water can be supplied either by flowing wells or by pumping, the vegetable-grower has a considerable advantage over his neighbors who have not this supply. In dry seasons his crop will not suffer from drought, and the crop will bring more money in consequence of the lack of water elsewhere. Much of the vegetable land can be supplied with water from artesian wells; their usefulness in this respect has already been demonstrated.

Another source of water for use in vegetable-growing, and one that is not being employed to the extent to which it might be advantageously used, is the flow of streams. In many cases there is enough flowing water to supply all or a great part of the land with water in dry times. Water may be raised to a considerable height by the use of a hydraulic ram. One of these machines will operate without any attention after it has been put in place and set to running. A single discharge may be quite small, yet when it runs twenty-four hours without stopping, a considerable amount of water has been lifted. The amount of water 
that one of these machines will raise depends on the height it is being raised and the amount that is flowing in the stream which supplies the water. Under the most favorable conditions, a ram will raise $\frac{2}{7}$ of the flowing water 4 feet, if there is a fall of 2 feet; or it may raise $\frac{1}{20}$ of the water 120 feet above the source if there is a fall of 12 feet. The amount raised varies inversely as the height to which it is to be elevated. These rams are made in various sizes to suit the conditions; they are made to discharge from $\frac{1}{2}$ to 30 and even more gallons a minute. The cost of these machines varies from $\$ 9$ to over $\$ 100$. Like all other machines they will in time wear out, but their structure is so simple as rarely to get out of order. The manner of placing the tank or reservoir must be modified to suit the individual fields.

Windmills are more largely employed for lifting water to tanks; but they are more difficult to keep in repair and also wear out in a few years. Gasoline engines are now commonly used and are most satisfactory; though they are the most expensive of the various machines used for the purpose of lifting water.

Some method of irrigation is of great use in tropical countries. Indeed without irrigation, vegetables can hardly be raised during the dry season, which often includes most of the cool season. In tradewind regions, an aërmotor usually gives satisfaction as a means of raising water.

\section{IRRIGATION}

Climatic conditions in most tropical and subtropical countries are such that during a part of the year there is 

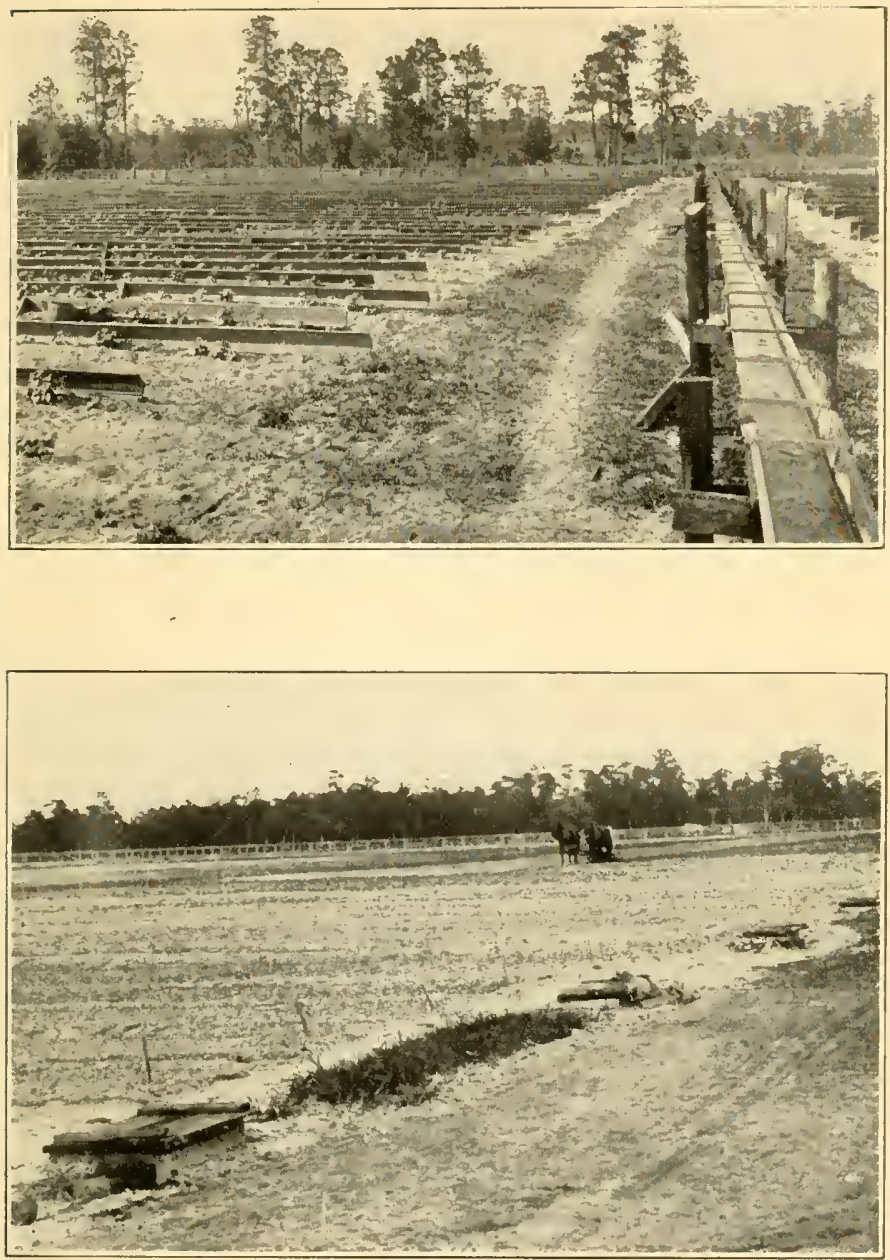

\section{Plate I. - Irrigation.}

Top, wooden sluice for condurting water to cucumbers and other crops, with V-shaped troughs to carry the water and also to be used to protert plants from frost; bottom, sub-irrigation of celery ficld, showing headboxes. 

likely to be an over-supply of moisture, and at another part of the year the rainfall is likely to be deficient. The irrigation plant, of whatever type, becomes extremely useful during the dry part of the year. Many of the vegetables not now grown in these regions will thrive luxuriantly if only a sufficient and constant water supply is at hand. (See Plate I.)

Over-head irrigation.

Under the general head of over-head irrigation are included all kinds of irrigation in which nozzles, pipes, and other appliances are used for distributing water above the surface of the ground. This is not an economical way to use the water, and a considerable quantity is lost by evaporation, since the particles are thrown into the atmosphere in the form of drops of water, and in a windy time much of the moisture is carried away. It has an advantage over the other systems of irrigation in that it is applicable to any kind of soil, no matter whether the surface is uneven or broken. An almost endless variety of nozzles for distributing water by this system may be secured and the variations are as extensive as the ingenuity of the vegetablegrowers.

One essential part of such a plant is the central tank, placed on a tower or elevation of about 60 feet above the field to be irrigated. This gives sufficient pressure to operate the nozzles that are designed for this purpose, or approximately 30 pounds pressure. The size of the tank for holding the water will be determined by the area of the land to be irrigated at one time. The main object of the elevation of the water is to give uniform pressure. 
For a vegetable field of 4 to 6 acres in extent, a 3000-gallon tank is ample. A steel tank and tower, including its erection, costs approximately $\$ 500$.

A second essential part is the pumping plant. A six to eight horse-power gasoline or alcohol engine with pump of suitable capacity will serve for this purpose. The cost of the engine and pump, with cost of installing, will vary according to the location and the make of the machinery, but $\$ 400$ to $\$ 600$ is ample to purchase and install such machinery in first-class condition.

The third essential of this plant is the pipe line. For an area of 4 to 6 acres in extent, it is desirable to have the main line of 3 -inch pipe. This can be reduced to $2 \frac{1}{2}$-inch pipe toward the end of the line. The laterals will be attached to this main line. These should be about 200 to 350 feet in length, starting with a 1-inch pipe at the main line and running at this size for 150 or 200 feet. The remainder of it may be reduced to $\frac{3}{4}$-inch pipe. These laterals may be placed on the tops of posts 7 feet tall, to get the pipe out of the way of laborers and work animals. In the side of this pipe, at 4 foot intervals, are holes drilled with $\frac{1}{16}$-inch bit. This forms a rather crude way of distributing the water, but proves to be serviceable. A better and more serviceable form will be found by using a $\frac{3}{16}$-inch bit for drilling the holes and then inserting brass nozzles manufactured for this purpose. These have a $\frac{1}{16}$-inch opening and deliver the water more evenly than does the rough opening made by a bit. A number of makes of these nozzles may be had on the market. In using this form for distributing the water, the lateral pipes are laid 50 feet apart. A 30-pound pressure from the tank will 
be sufficient to throw the water through one-half the distance between the two lateral lines. The lateral pipe is connected with a universal union near the elbow at the top of the riser from the ground. This enables the operator to turn the pipes resting on the posts in such a way as to distribute the water evenly over a space about 50 feet broad. The cost of installing such a line will vary with the amount and cost of large pipe and other material needed, but $\$ 250$ to $\$ 300$ an acre is a sufficient amount to allow for a 4 - to 6-acre plant.

Many of the plants run the laterals underground and have one-inch risers, on the top of which are placed the distributing nozzles. The distance between the distributing lines and the distance between the various risers on the distributing line will vary with the make of nozzle used and the pressure employed. This nozzle system requires somewhat more piping than does the system with laterals on the tops of posts.

Surface irrigation.

When a surface irrigation system is installed, it is necessary to have the soil of a close compact nature. It must contain a great deal of clay, otherwise the distribution of water in the vegetable field will be somewhat difficult and uneven. The field must also be quite even and have a uniform slope. This system of distributing water has been in vogue for so many centuries and in so many different countries that it is hardly necessary to describe it. The one difficulty to be overcome in the vegetable field is that the water must be applied in furrows rather near the rows of vegetables. For closely-planted vege- 
tables it is sufficient to run one water furrow between the rows.

The length of the laterals for distributing the water will vary with the character of the soil. In a very sandy soil it is difficult to run the water for a distance of more than 300 to 600 feet, where the slope is about 3 inches to the 100 feet. Some considerable experience is necessary to run the water in furrows in a sandy soil, the most important consideration being that of delivering a large volume of water, about 2 inches, and running it quickly down a dry and well-prepared furrow. If the slope is even and the soil has been well prepared, an experienced person has no great difficulty in distributing the water in this way unless he attempts to distribute it for more than 600 feet.

The advantage of this form of irrigation is that it is very economical of the use of water and that it has been in use for many centuries and thus is familiar to many persons; its disadvantages lie in that it is applicable only to lands having a proper slope and consistency, and that it requires experienced laborers when used on sandy lands.

\section{Sub-irrigation.}

The sub-irrigation system which is also used for a drainage system during the rainy season, is one of the most satisfactory that can be employed in the vegetable fields. Its application is limited to lands having an even and very uniform slope. One must also have an impervious substratum as well as a large water supply. It is more adaptable to a loamy or to a sandy soil than to a clay soil.

The essential part of this system is a series of tile drains laid out in proper conformity to the slope of the land. 
Nearly all of the failures connected with the sub-irrigation system can be traced directly to this point. Too frequently the tile line is laid out by crude and inaccurate instruments, such as a spirit level. The line of tile may be laid at varying distances from 16 to 40 feet apart, according to the porousness of the soil.

Such a system should be laid out by means of a surveyor's level and the stakes set as accurately as is done for drainage systems. These various lines of tile are laid out and then run to the main. The length of the laterals will depend upon the convenience of the owner and the character of the vegetables to be grown upon the soil. In laying out such a system, it should be carried out exactly as if it was intended for drainage only. The length of the laterals will vary according to the contour of the land and the desires of the owner. From 200 to 600 feet is usually considered a fair length for a lateral. The tiles are usually made of clay and for the main part porous, though glazed tile may be employed. The 3-inch size is considered most satisfactory.

The depth to which these are laid will vary from a few inches to several feet. If it is necessary to have good drainage during the rainy season, the tile can be laid rather deeply in the soil. If, however, drainage is of secondary importance the tile may be laid higher. In any case they should be laid not less than 12 or 14 inches below the surface, since it frequently becomes necessary to plow to this depth in a vegetable field.

When these tiles are laid in the soil they should be on a perfectly even slope. The joints between the tiles must be protected by the use of some substance such as Spanish 
moss which occurs abundantly in tropical and subtropical regions, cypress shingle tow, or other organic matter of a lasting quality. This strains out the sand and other material that is likely to filter into the tile between the joints and clog the system.

At the point where the laterals join the main distributing pipe, specially prepared boxes are inserted. These boxes may be made of cement, earthenware, or even of durable lumber. These head-boxes are usually about 14 by 18 inches and long enough to reach below the depth of the tile and still protrude several inches above the ground. About midway of these boxes is a partition running from the bottom to the top. Two holes are made through this partition, one even with the holes that receive the ends of the main line and the other as high as the level of the ground. The holes in the head-boxes which receive the laterals are placed on the same side of the partition as the inlet of the main. When the lower hole in the partition is opened, the water flows freely from the end of the main entering the box through the hole in the middle and out of the exit end of the main. When the lower hole in the middle of the box is closed, the water flowing through the main fills the box and runs out into the laterals. This continues until the soil supplied by the laterals is thoroughly saturated. When any surplus water is applied after this, the water continues to flow through the upper hole in the partition in the middle of the hox.

As soon as the field has been sufficiently irrigated to suit the operator, the flow of water is stopped in the main and the stopper taken out of the lower hole and the water run off. (See bottom figure, Plate I.) 


\section{CHAPTER VI}

\section{SEEDS AND SEED-SOWING}

Considerable difficulty is experienced in the matter of seed-sowing, especially if the crop is to be sown in the field. Some small seeds, as turnips, are very difficult to sow evenly by hand; but, fortunately, this has been overcome in a measure by the invention of a machine to do this work. Even with a machine, there is room for exercise of judgment; seeds of the same variety are not all the same size, and the average size varies to a considerable extent.

How to test a machine.

Before sowing with a machine, it is necessary to know just how it will sow. The marks put on by the manufacturer are only approximately correct, on account of the variation in the size of the seed. The machine can be regauged for the particular seed in hand by running it over a piece of canvas that has been spread down for the occasion. The length of the row on the canvas can be measured and the amount of seed also; this reduces the matter to simple computation, and the seed can readily be taken up and returned to the bag unharmed. Seeds obtained from different sources will be found to vary considerably in size; these seeds of different sizes should be planted separately, and it may be necessary to regauge 
the machine. It has been found by experiment that there is a wide difference in the value of the different sizes of seed. If radish seed is taken from a single plant and graded into sizes, the largest will germinate and produce a marketable vegetable first, and nearly all the seed produce good radishes; the second size seed will mature next and so on until the smallest grade is reached, which will produce radishes last, and then only inferior roots.

Choosing the varieties.

In this day of specialization, varieties are almost endless; new ones are brought to notice daily. Sometimes it seems that the prices paid for these are excessive, especially when there are already first-class vegetables of the same general kind. It is misdirected economy, however, to buy an inferior variety. The difference of a few dollars less at seed-time often works a damage of many times that amount at harvest-time. Nurserymen and seedsmen prefer to destroy inferior seed or culls of varieties they hold in esteem. This is a commendable practice to apply to all varieties by those who grow seed, for inferior seed wastes the time of the person giving attention to it, and damages the reputation of the variety.

Quantity of seed to sow.

The following table gives the amount of seed required for an acre, and also the amount to sow on a smaller area. The last column is for the convenience of those who do not wish to grow the vegetable for market. A slight acquaintance with the seeds will make one aware at once that these figures can only be approximately correct. 
Only the leading vegetables are here tabulated; the amount of seed required must be sought in the special discussion of those vegetables :

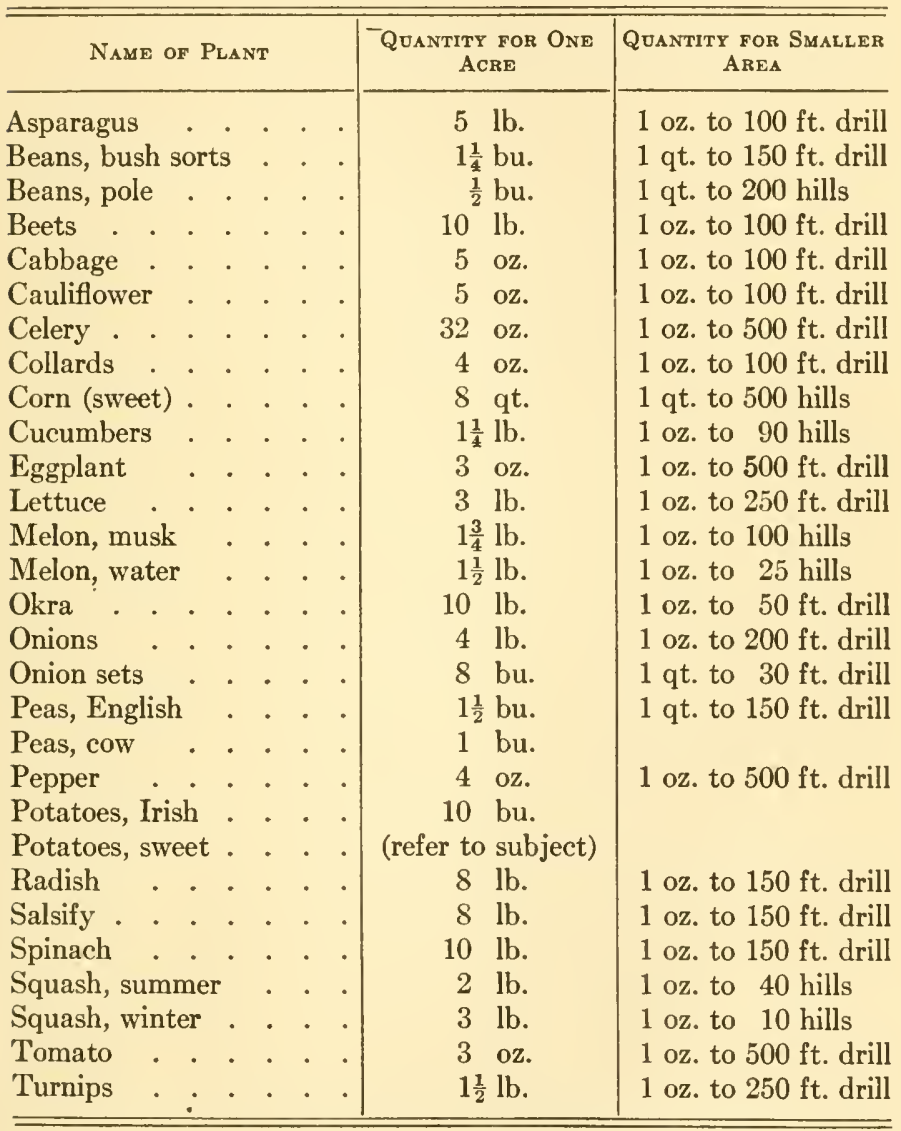




\section{SEED-GROWING}

Seed-growing has not been followed to a decided extent in the South, and yet it is highly commendable. It requires considerable forethought and work to grow the best seed. In some thickly settled countries of Europe, large estates are devoted entirely to the growing of some special seed, either because of some peculiar natural advantage or because of the special skill of the grower. The Netherlands are peculiarly adapted to bulb-raising, Denmark to raising cauliflower seed; and thus we might perhaps continue until nearly all the countries of Europe had been named. The possibilities in this direction for the South, especially the Gulf region, are great; the climatic conditions in many respects are perfect, while labor is fairly cheap. Long experience in India with seeds of onion, cauliflower, kohlrabi, English peas, globe artichoke, turnips, and so on, has shown that for the hotter part, lower Bengal, acclimated seed, that is seed produced in a warm country, produces better plants than seed direct from Europe. The plants from the latter run more to leaf and often do not flower, and are more subject to disease. Also Bermuda onion seed grown in Teneriffe is the best for Florida and the West Indies. Hence it is probable that acclimated seed would often or usually be found best in tropical countries near sea-level and that it is preferable to obtain seed grown in a climate as near as possible to that of the locality where the plants are to be raised.

How to select plants.

In growing for seed, one should never retain a sickly or diseased plant, because these often transmit a tendency to 
invite disease to the product. Only the healthiest and most desirable plants of a variety are good for seed. Some vegetables cannot be raised from home-grown seed; in some cases the seed does not mature, and in others the plants from the home-grown seed are inferior; a striking example of the latter class is the Bermuda onion. After the finest specimens of the variety have been selected, the plant should be allowed to mature the seed thoroughly before gathering. There are two directions in which one may select: first, one may select the best specimens of plants from the standpoint of growth and shape; secondly, one may select the finest specimens of fruit regardless of the growth of the plant. Neither of these methods is perfect alone, for one should select good fruits on good plants. By such selecting, the variety is constantly improved until the improvement finally makes a new strain which will not have the defects of its ancestors.

It sometimes occurs that a plant appears which is strikingly different from the others in the field. Such plants are often designated "sports"; the seed from these will reproduce their peculiarities, and by selecting the typical specimens from the product of such sports, new varieties may be originated.

In tropical and subtropical countries there is much to be done in the way of seed-saving. Experience in India, for example, has shown that the seeds of many vegetables grown in a warm climate will produce plants that bear well when plants from seeds imported from Europe run to leaf only. But in most tropical countries, and even in Florida, nearly all vegetable seed is still imported. There is a neglected field in the improvement of many tropical 
crops such as the pigeon-pea, chayote, Manila bean, jack bean, tropical maize, and the like, which are at present grown from seed only. If the same selection were applied to these as is applied by the nurserymen of the United States and Europe to such plants as the tomato, cabbage, and lettuce, they would, like these latter plants, have visibly improved varieties coming out nearly every year. The vegetable-gardening world greatly needs a few subtropical seed-raisers and one or more tropical plantbreeders.

\section{SEED-TESTING}

As so much depends on having seed that will germinate readily, it is very important to know exactly what to expect in the matter. No vegetable-grower should omit testing the germinating power of his seeds before sowing them on a large scale. He thus saves time and money. The process is simple. A hundred seeds are put between two folds of clean moist cloth between two pans or plates and kept at a proper temperature. The percentage that form roots is counted after a few days. A very simple method is to sow the seed in sand or soil in a pan that can be kept constantly moist and warm. There is considerable risk connected with this method and one needs to exercise much care and jurlgment. The amount of soil in one of these pans will be small, and easily chilled and overheated. A modification of the above is to cover the soil with a cloth, sow the seed on this, cover the seed with another cloth, and put about half an inch of moist sand on this cloth. The advantage of this way is that the seeds can easily be examined and in case of their rotting, there is no delay in 
finding it out. The seed also may be tested in a hotbed or coldframe, using the same precautions as when a pan is used.

Several states have seed-control laboratories under the direction of their agricultural experiment stations. These institutions test the vitality of the seeds offered for sale and examine them as to purity, thus protecting the buyers from frauds and encouraging improvements in these directions. It is to be hoped that much more will be accomplished along this line.

\section{SEED-STORING}

The length of time seeds may be stored without losing their vitality depends largely upon the variety and the condition in which they are kept. To keep well, seeds should be well-matured and preserved in a dry apartment. Much has been said as to the germinating power of seeds that have been kept for hundreds of years, but these reports lack confirmation by scientists. Some seeds that have been kept dry for thirty and forty years have germinated; and recently, there is an accurate account of a few seeds out of many retaining their germinating power for more than eighty years; but in all of these cases this power had been greatly impaired. A few seeds, like those of the cucumber, retain their vitality under proper conditions for ten years; some other seeds lose their vitality during the first year, under the most favorable conditions. In the wet season, especially of subtropical and tropical countries, most seeds lose their vitality much faster than they do in temperate climates. Heat and damp together ruin nearly 
all seeds. In damp climates, between the tropics, one cannot put packets of seeds in a drawer and keep them for years. Most seeds have to be well dried and stored in sealed bottles. Many seeds deteriorate on the voyage from temperate to tropical regions, unless they are specially dried, stored in cans, and soldered up. An easy way to keep valuable seeds in a damp, hot tropical climate is to store them in stoppered jars or tin boxes, sealed with paraffin, and place with them a package of fused calcium chloride or lumps of quick-lime to dry them well. Most seeds will endure such desiccation without injury and are then uninjured by the shade heat of tropical countries, which is rarely over $100^{\circ} \mathrm{F}$. Where cold storage is available, a cheap way is to put the seeds in water-tight boxes in the ice-house. This question of keeping seeds is of great importance to all agriculturists in the hot belt of the earth.

\section{TROPICAL SEEDS}

The tropical vegetable-grower may wish to know, in the absence of nurserymen in the tropics, where he may get new kinds of the different vegetables peculiar to the tropics. In most cases he must go somewhere near the original home of the vegetable in question.

Thus, for new varieties of plantain, recourse should be had to Java especially, and to the neighboring regions; for varieties of taro, to Hawaii and other Pacific Islands; for the tannias, to Porto Rico and other of the Spanish West Indies and the neighboring mainland; for cassava, to tropical and subtropical South America, especially Brazil, Colombia, and Paraguay; for papayas and chayotes, to 
Central America and the West Indies; for different yams, to southeastern Asia, Pacific Islands, and West Indies.

Tropical seeds may he procured from dealers in Ceylon, British India, South Africa, and Australia, or by exchange with the botanical gardens in many tropical countries. Subtropical seeds and roots can be had from nurserymen and seedsmen in California, Florida, Cape Colony, Natal, New South Wales, Queensland, Japan, and the Mediterranean region. 


\section{CHAPTER VII}

\section{PLANTING}

IT is worth while to take much pains to protect young vegetable plants and to give them the very best conditions to get a start in life. Much of the subsequent result will depend on this care in the beginning. Gardeners go to much expense and labor to provide such protection and to secure earliness. The various kinds of frames and seed-beds may therefore be discussed.

\section{COLDFRAMES}

Four points should be borne in mind when one is selecting the place for a coldframe. (1) It must be sheltered from cold winds, that is, it should be in a warm spot; there should be a windbreak of some kind; the bed should be free to the full sun all day (the south side of the barn may be used in some cases). (2) It must be protected from rains; the dripping of eaves must be carried away and the surface drained so that water will not run under. (3) Water must be near at hand, or the needed supply may not be applied. (4) It must be near one's house or near one's daily work, so as to require the least possible time to look after it.

Glazed sashes are of value in using a coldframe successfully, but they are not indispensable. These sashes can 
be purchased set up and glazed in various sizes ; probably the most convenient size is three feet by six feet, which can be obtained in the market for about $\$ 1.50$ apiece. In the colder parts of the subtropics, only a few days occur during the usual winters when the thermometer will remain below freezing if the sun shines. When glazed sashes are not used, some form of cloth will be required. There may be found on the market a cloth prepared for that purpose; this comes in three grades. The best of these grades will be found the cheapest in the end. By using a double thickness of the best cloth, eggplants were carried through a freeze of $14^{\circ} \mathrm{F}$., in a hotbed, when the temperature remained below the freezing point for several days. As eggplants are among the most tender plants, it will readily be understood that other ordinary plants can be carried through easily. During the same freeze, lettuceplants came through safely under a single thickness of cloth over a coldframe.

The best width for a coldframe is 6 feet. At this width, all the cultivating and other attention can be given without entering the frame, and lumber cuts economically to this length. The length of the frame must depend upon individual desire and preparation. Beds made 6 feet wide are run east and west, but if it is desirable to run the beds north and south, they should be made 12 feet wide. In such a frame, the cloth is fastened to a pole along the middle as a ridge-pole, and allowed to unroll roof-shape on each side. All materials used in the construction may be 1 inch thick. The back or north sides should be 26 inches high, and the south sides 10 inches high. When glazed sashes are used, a pitch of 4 inches is sufficient - 
that is, the front is made 10 inches high and the back 14. But experience has taught that this pitch is not sufficient for frames covered with plant-cloth. The sides are nailed to 4 -inch boards that are driven into the ground 6 feet apart. The ends of the frame are trimmed to an even slope. At intervals of 6 feet, 3 -inch pieces are dovetailed into the front and back, to steady the sides, and to hold the protecting cloth from bagging.

The protecting cloth is sewn into a sheet large enough to cover an entire frame. The seams run crosswise for obvious reasons. The sheet is fastened to the back and then stretched over the frame; and just far enough over the front to press the cloth down tightly, a strip is nailed to serve as a roller for a curtain. By turning at one end, the whole curtain may be raised and fastened at the top; when it is wanted for use, the fastening is loosened and the curtain unrolls itself, at the same time shutting the whole frame up for the night. The woodwork and cloth for a frame 6 feet wide and 30 feet long should not cost more than $\$ 2.50$.

The soil in coldframes should be made very fertile by using commercial fertilizer, or, preferably, compost. Make the soil about 6 inches deep, using as much well-rotted compost as soil. The fertilizer if used must be worked in thoroughly, and the frame thus prepared allowed to stand ten days or two weeks, all the time keeping it thoroughly moistened. A coldframe is as valuable in the summer as in the wintcr. In the summer, the cloth is raised to allow the air to pass under, thus protecting small plants from the scorching sun. In the management of a coldframe, and of a hotbed, plenty of water is 
indispensable, and it must be applied in liberal quantities daily.

Cheese-cloth may be put over a frame to screen seedlings from the sun, and mosquito-bar will keep insects away from young cabbages, and the like.

\section{HOTBEDS}

This convenient form of plant-bed is perhaps not as generally used in the almost frostless regions as it merits; probably from the fact that many persons do not understand the principles underlying its successful operation. It is used to grow early plants of eggplant, tomato, and other vegetables which will not endure any frost.

When undecomposed manure, leaves, or other vegetable matter begin to decay, a certain amount of heat is given off ; if the pile is large and in a compact heap, the amount of heat evolved will be considerable. This is due to the breaking down of the vegetable matter through the actions of low forms of life, such as bacteria and molds. This breaking down takes place in the presence of moisture; vegetable matter stored in a dry state will remain undecomposed for an indefinite time. It is possible for every one who keeps a horse or eow to provide himself with a hotbed.

During the early part of the season the manure may be stored away dry, and kept so; and when the time to fix a hotbed arrives, it may be prepared in a similar way to a compost heap.

The same four points should be borne in mind when one is selecting the place for a hotbed as when locating a coldframe. See page 52 . 
The frame for a hotbed is made like that of a coldframe and covered with glazed sash or plant-cloth.

When the frame for the hotbed has been completed, the undecomposed manure is placed in it to the depth of 6 to 10 inches. It is usually necessary to remove some of the earth inside the frame; this can be used to bank it on the outside. As the manure is placed in the frame, it should be thoroughly soaked and tramped down. In two or three days this will begin to heat, and will continue to rise in temperature for eight or ten days, and will often rise high, running considerably over a hundred degrees. If the bed is kept moist (and this can be tested by digging into parts of it), there is no danger of its "burning." This does not mean that there is any danger of its actually generating fire, but the material becomes dry and discharges valuable fertilizing quality in the form of gases, and hence is about destroyed. When large quantities of fresh manure are used, the gardeners dump it in piles and fork it over every day or two to keep it cool enough, and at the end of ten days or two weeks place it in the hotbed.

After the manure has been placed in the frame, an inch of fresh loam should be spread over it, to arrest any gases that may be escaping. After about ten days of fermenting, the manure has reached its highest temperature, and seed can be sown in the loam without danger. From this time on, the temperature falls gradually, until decomposition is complete.

The only advantage of a hotbed over a coldframe is that the decomposing matter gives off heat, and the amount of heat given off will vary with the amount of 
manure used. If one desires to keep a bed especially warm, the frame may be banked outside with fresh manure.

\section{PLANT-SHEDS}

In Florida it has been found advantageous to grow the choicer kinds of pineapples under sheds. These sheds may be made by setting $8 \frac{1}{2}$-foot posts $S$ feet apart north and south, by 14 feet east and west. Stringers 2 by 6 inches and 15 feet long are fastened on the tops of the posts in east and west lines. Across the stringers are nailed the laths or slats, which may be 1 or 3 inches by 16 feet; or laths supported by wires may be used. The spaces between the slats may be once, twice, or thrice the width of a slat. These sheds were first started to give protection from frosts, but it was found that pineapples under sheds grew better and required less fertilizer, and the soil kept moister in dry weather, than was the case with those in the open. Similar sheds are now used in south Florida nurseries to shelter young mangoes, avocadoes, palms, and other tropical plants and fruit-trees. The so-called grass conservatories, used in India for growing plants which do not endure well the full blaze of the sun in the hot season, are made in a similar way, except that they are covered with wire netting on which a reedlike grass is bound so as to give half-light and half-shade. In most tropical and some subtropical countries, bamboos can readily be grown and a plant-shed covered with split bamboo lath can be constructed cheaply. However, most tropical plant-sheds are small, whereas some Florida pineapple sheds cover scores of acres continuously. The 
mistake must not be made of letting creepers grow over the top of the shed, and so shut out nearly all light. With most of the sunlight cut off, plants make a poor growth and may easily become diseased. In fact, one of the advantages of plant-sheds in the tropics, as distinguished from shading by palm leaves, woven coconut leaves, and the like, is that by proper spacing of the laths the plants can be allowed the maximum of sunlight with which they will thrive best. There is often a tendency to use too much shade. In making a plant-shed, it should always be kept in mind that a plant can feed on the carbon dioxide of the air only in the light, and that an amount of shade which is comfortable to a man in the tropics is detrimental to most plants. Certain experiments make it probable that under such large plant-sheds, the culture of many temperate vegetables would be easier in tropical and subtropical lands. This does not seem to have been tried on a large scale, but it appears worth attempting near some tropical towns where there would be a constant demand for fresh temperate vegetables. Such sheds would probably be very successful at an elevation of 1000 or 2000 feet.

\section{SEED-BEDS AND PLANT-BEDS}

Seed-beds should be of porous soil and well drained. After sowing the seeds, protection from the sun may be given by spreading coarse sacking on the soil and keeping it wet until the seedlings become visible above the earth. Then they may be shaded by a properly spaced lath frame, or by cheese-cloth. The latter is especially useful when 
the seedlings are liable to insect attacks, in which case it may be fastened to a plank frame. Lath frames of different spacings may be used gradually to accustom the seedlings to the sun. (See Plate V.)

Scedlings, after growing to a size easily handled, are planted in a bed for further maturing; this is especially so when large quantities of tomato, cabbage, or celery plants are wanted. The advantage of having these plants in as small a space as practicable is apparent to all. The plant-bed must be fertile, and plenty of water must be at hand to be used in case of need. The ground should be raked carefully, the fertilizer applied, and the bed spaded or plowed and then raked again. The bed should lie a week or ten days to allow the fertilizer to be incorporated, when the plants may be set out. Plants should not be allowed to become checked in their growth at any time. It does plants good to be transferred several times, and with some vegetables such transplanting is profitable; but for plants to come to a standstill for want of water or fertilizer works a detriment that is strikingly noticeable in the crop. Hence, in the transplantings, care should be taken as to moisture, temperature, and soil, so that growth may not be checked.

\section{PREPARATION OF THE LAND}

To make vegetable-growing a success, it is necessary to select the proper kind of land. Nearly all vegetables like a sandy loam or some other rather light soil, that is at the same time well drained and yet not thirsty. 
Well-drained land.

It frequently occurs that the very best vegetable land is soggy and sour in its original state. When a piece of land is found that is excellent in all other respects, but needs to be well drained, the problem then is, how shall this be effected. When there is plenty of fall to the land, this may be accomplished in one of two ways - either by surface drainage or by underground drainage. The latter method is preferable and cheaper in the end, though more expensive in the beginning.

The method of surface drainage has the advantage of being cheap and easily accomplished, though it takes some time and attention to keep it in good running order. The method is simple. All that is necessary is to make a ditch from one to three feet deep and to keep this open so that the water will run off.

The advantage of draining has been demonstrated repeatedly in this country and in Europe. Plants on tile-drained land, and to a greater or less degree on land with open ditches, will do better during a rainy season, and, what seems rather contradictory, they will give a larger yield in dry years. Crops are also earlier on drained fields. In a clay country, land that is well drained naturally will be benefited by a well-planned system of tile drains. Where land that is naturally well drained can be obtained, this is of course preferable, as it does away with the initial expense of draining; but, on the other hand, it should be remembered that the land producing the largest and most profitable crop is drained land. 
Clearing the land.

In making a beginning in vegetable-growing, it is best to start aright. The greater part of our unimproved land has to be cleared, and this should be done thoroughly; every stalk, stick, or chunk should be removed from the field. It is a waste of time and money to go into vegetablegrowing as a temporary vocation; it is as deserving of and demands as constant and careful attention as any other branch of horticulture. Therefore if one can only half clear ten acres, it would be better completely to clear five acres. It has been seen repeatedly that a small piece of land well taken care of brings a greater return than double the amount poorly cared for. The familiar adage, "What is worth doing, is worth doing well," has full force in vegetable-growing.

\section{Plowing.}

If the soil is light and sandy, deep plowing may prove detrimental to a field that is to be planted immediately, but some time during the year it should be stirred deeply and well. The subsoil is often so hard that the roots of the plant cannot enter, and so must remain near the surface and be at the mercy of any short drought that may occur; whereas, if the soil were twice as deep, it could stand a much longer drought. Many subsoils do not allow the water to soak through them; other subsoils let the surplus water through slowly. In either case, the mechanical condition of the soil would be improved by an occasional deep plowing. Besides giving the roots a greater feeding space, the tilling of the soil acts as a kind 
of regulator; it makes soggy land drier and dry land to conserve the moisture in time of drought. A cultivated soil can hold more water without being soggy than one not tilled; in a sudden shower a plowed field will retain all the water and give the roots of plants a chance to absorb the fertilizer before it is carried off. Much of our sandy soil allows the fertilizer to be leached out by the rains and retains not even a trace in the soluble form; but if this water were retained in the soil the fertilizer would be retained also. The amount of water a soil can retain depends upon the constituent particles of that soil.

\section{TRANSPLANTING}

Soon after plants that have been sown in a seed-bed begin to show the second or third leaf, they will need to be shifted and set further apart, or they will grow spindly. Then, also, their root system will be developed very poorly, and after transplanting they will either have to change their entire make-up as a plant or die; either one of the two is expensive, as it loses time for the vegetable-grower. Some plants, as cabbage and cauliflower, will do well with one shifting; others, as tomatoes and eggplants, will do better when shifted,two or three times. A very good way is to grow the plants from seed in a hotbed, then shift them to a coldframe; this will have to be many times larger than the hotbed to hold the same plants. It will not take long for the plants to fill the space allowed them (for distance and other special points refer to the accounts of the special crops); then another transfer will have to be made either to a coldframe or to a plant-bed, depending on 
the variety and the time of the year. As mentioned before, the soil should contain much vegetable matter. If this precaution is taken, it will not be necessary to wait for a rain or to use water in transplanting. If paper pots (which can be bought for two or three dollars a thousand) are used, the plant can be transplanted from the plant-bed to the field quickly and without any shock.

In fertilizing the land preparatory to transplanting, the material should be worked in and mixed with the soil thoroughly. No matter how small the particles of fertilizer may be in the soil, the plants will find them. A thorough distribution is very necessary. Plants cannot take in such substances wholesale; while some kinds of fertilizer do not kill a plant when used in big lumps, a very large portion of such doses is not available, or only so after considerable time. Too much fertilizer is rarely used, but it is often used indiscreetly.

The best time to transplant is just before a rain; but when there are ten or twenty acres to be planted, the work must go ahead when the proper time comes, whether there is a rain or not. It is no easy task to put out and water an acre of tomatoes or half an acre of cabbage in a day.

Much of this hard work may be avoided by using a transplanter. Many machines have been constructed and put on the market to do this work. Some are operated by hand, allowing a person to stand in a partially erect position. They do the work more or less efficiently, but for the lack of perfection, none has come into general use. There are also machines that are drawn by horses, but the plants must be put in place by hand. Some of these machines do excellent work, and would be used 
generally except that the prices are so high that many growers cannot buy them. The greatest advantage in the machine drawn by horses is that a regulated quantity of water is emptied wherever a plant is to be placed. To use one of these machines to the best advantage, the land must be free from débris. Stumps and trees are also in the way. The acreage that can be planted in a day depends upon the crop and the condition of the land. It is said that six or seven acres of tomatoes can be set in one day's work.

\begin{tabular}{|c|c|c|c|c|c|c|c|c|c|}
\hline \multicolumn{2}{|c|}{ 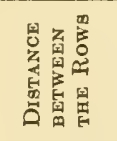 } & \multicolumn{2}{|c|}{ 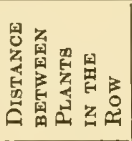 } & \multirow[t]{2}{*}{ 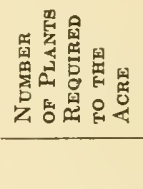 } & \multicolumn{2}{|c|}{ 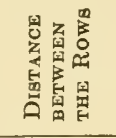 } & \multicolumn{2}{|c|}{ 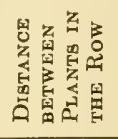 } & \multirow[t]{2}{*}{ 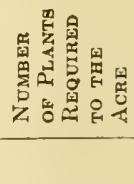 } \\
\hline Ft. & In. & Ft. & In. & & Ft. & In. & Ft. & In. & \\
\hline 0 & 6 & 0 & 6 & 174,240 & 3 & 0 & 1 & 0 & 14,520 \\
\hline 0 & 7 & 0 & 7 & 128,013 & 3 & 0 & 1 & 6 & 9,680 \\
\hline 0 & 8 & 0 & 8 & 98,010 & 3 & 0 & 2 & 0 & 7,260 \\
\hline 1 & 0 & 0 & 1 & 522,720 & 3 & 0 & 2 & 6 & 5,808 \\
\hline 1 & 0 & 0 & 6 & 87,120 & 3 & 0 & 3 & 0 & 4,840 \\
\hline 1 & 0 & 1 & 0 & 43,560 & 4 & 0 & 0 & 6 & 21,780 \\
\hline 1 & 6 & 0 & 1 & 348,480 & 4 & 0 & 0 & 9 & 14,520 \\
\hline 1 & 6 & 0 & 6 & 58,080 & 4 & 0 & 1 & 0 & 10,890 \\
\hline 1 & 6 & 1 & 0 & 29,040 & 4 & 0 & 1 & 6 & 7,260 \\
\hline 1 & 6 & 1 & 6 & 19,360 & 4 & 0 & 2 & 0 & 5,445 \\
\hline 2 & 0 & 0 & 3 & 87,120 & 4 & 0 & 2 & 6 & 4,356 \\
\hline 2 & 0 & 0 & 6 & 43,560 & 4 & 0 & 3 & 0 & 3,630 \\
\hline 2 & 0 & 1 & 0 & 21,780 & 4 & 0 & 3 & 6 & 3,111 \\
\hline 2 & 0 & 1 & 6 & 14,520 & 4 & 0 & 4 & 0 & 2,722 \\
\hline 2 & 0 & 2 & 0 & 10,890 & 5 & 0 & 5 & 0 & 1,742 \\
\hline 3 & 0 & 0 & 6 & 29,040 & 6 & 0 & 5 & 0 & 1,452 \\
\hline 3 & 0 & 0 & 9 & 19,360 & 6 & 0 & 6 & 0 & 1,210 \\
\hline
\end{tabular}


NUMBER OF PLANTS TO THE ACRE

The preceding table gives the number of plants to the acre when they are set out at given distances. If it is desired to find the number of plants required to set an acre at distances not given in the table below, it can be done by a slight amount of thought. The number of plants for 1 inch asunder in the row are given. If, then, plants are set 2 inches apart, the field will require just half as many; if 3 inches, just one-third as many as when 1 inch apart; and if 7 inches apart, just one-seventh the number. 


\section{CHAPTER VIII}

\section{PESTS AND DISEASES}

IN all tropical and subtropical countries, it is as necessary to be prepared for combating insect pests and fungous diseases of plants as to be prepared to till the soil and fertilize the plants.

Insects and fungi are as resistant to cold as are plants which are cultivated, and these multiply with very great rapidity and are present in very large quantities throughout all regions where vegetable crops are grown. There is no escaping these enemies, and hence they must be combated by the best known methods.

Considerable attention has already been paid to developing varieties that are resistant to certain diseases in certain localities. It is not probable, however, that this line of investigation can be carried speedily to the point where the plants will be resistant to all of the numerous diseases. The moment we have plants that are resistant to the wilts diseases, for example, we find that they are still subject to an attack from other enemies.

It is frequently stated that by proper cultivation and fertilization plants will be able to throw off diseases and insects. This is quite incorrect; a plant vigorous and healthy in every respect, is so simply because it has not been attacked or had to endure the disadvantageous con- 
dition of a plant which is not healthy, and frequently a reasonably good crop will be matured on a field that is attacked by one enemy only, while if attacked by two or more, it would fail to give a profitable return.

\section{POISONOUS INSECTICIDES}

The first attempts at protecting plants against insects and diseases were made by combating leaf-feeding insects. Their damage was the more obvious and the method of control required less ingenuity than for handling the sucking insects and for diseases.

Paris green was among the first of the poisonous insecticides to be used and is applicable to all leaf-eating insects and smaller animals. About a teaspoonful should be used to a gallon of water, or a more accurate measure would be to use $\frac{1}{4}$ pound paris green to 50 gallons of water. The mixture must be constantly agitated; otherwise, the poison will settle to the bottom and the application will be uneven, resulting in a scalding of some of the plants and the others not receiving enough poison to protect them. Paris green is now little used, the arsenate of lead and other materials taking its place.

Arsenate of lead usually comes in a paste form, the package usually having printed upon it the formula necessary for its use. Generally speaking, 1 to 5 pounds to 50 gallons of water will be found to be the correct quantity. It is less caustic than paris green and can be used in many places where the latter cannot. It also comes in a powdered form, when it may be mixed with some inert materials such as flour and air-slaked lime and these be 
dusted over the plants in place of being applied as a liquid.

Zinc arsenite is a new arsenical compound that has shown itself to be applicable where lead arsenate may prove too caustic. It usually comes in a powdered form. One pound of zinc arsenite to 50 gallons of water should be used, or it may be mixed with flour or air-slaked lime and dusted on, as in the case of paris green and powdered lead arsenate.

\section{CONTACT INSECTICIDES}

The success attained by using the poisonous insecticides gave a strong impetus to the investigation which had for its purpose the control of insects that feed from the interior of the plants and so are immune from poisonous insecticides.

Kerosene emulsion was the first of the contact insecticides that came into general use. It is rather easy to prepare, and since kerosene (coal oil) is found almost constantly in the farm home, it can be made up without much difficulty. One-half pound of hard soap should be dissolved in 1 gallon of water. This can be done best by chipping the soap and letting it drop into boiling water. The soap solution should be removed from the fire, and 2 gallons of kerosene poured into it. Then the mixture should be thoroughly agitated by means of the spraying pump. In a short time a thick, creamy mass will have formed. The hotter the water, the quicker the emulsion will form. As soon as no free oil forms at the top of the emulsion on straining, the emulsion may be said to be 
formed. One part of this kerosene emulsion should be used to 15 or 20 of water.

Whale-oil soap or fish-oil soap is a commercial article prepared especially for treating insects. The amount to be used will vary with the concentration of the soap and the kind of insect to be treated. For soft-bodied insects, such as aphides, 1 pound to 6 or 8 gallons of water will be found useful. For more resistant insects, such as the plant bugs, a concentration of 1 pound to 4 gallons may be needed.

Soda-sulfur spray will be found especially useful for very soft-bodied insects such as aphides, rust mites, and also for red-spider. For the last named, it is probably the most efficient insecticide known.

Caustic soda (98 per cent), 1 pound.

Flowers of sulfur, 2 pounds.

Water, 2 gallons.

The sulfur should be mixed in cold water to a thick paste, the soda added, and as it boils water added gradually to make 20 gallons. This water should be added fast enough to prevent burning, but not fast enough to stop boiling. The result will be a dark coffee-colored liquid. It should be strained through a fine-meshed cloth or spray-strainer and kept in tightly corked jugs. One-half gallon of this stock solution should be mixed in 40 gallons of water when ready to use.

Tobacco-sulfur spray is especially efficient for treating thrips, particularly when infesting the bloom of vegetables and causing them to drop. 
Commercial lime sulfur solution, $2 \frac{1}{3}$ quarts.

Black-leaf " 40 ”, $3 \frac{1}{2}$ fluid ounces.

Water, 50 gallons.

If the leaf-eating insects are present and need to be treated at the same time, substitute from 1 to 3 pounds of lead aresenate in the place of the lime sulfur solution.

Commercial lime sulfur solution usually can be obtained from seedsmen, fertilizer houses and supply dealers. It may be used in places where the soda sulfur solution is recommended. The usual concentration is such that 1 gallon of this may be used to 25 to 50 gallons of water.

Lime-sulfur solution - self boiled can be used in the place of a soda sulfur solution and will be found to be more or less effective in controlling some of the plant diseases.

Fresh stone lime, 8 pounds.

Flowers or flour of sulfur, 8 pounds.

The lime should be placed in a tub and enough water added to cover. As soon as the lime begins to generate heat enough to cause the water to boil, the sulfur is added by sifting it through a sieve. The mixture should be constantly stirred and more water added at first, making it a thick paste and then more water gradually added to thin it down. The lime will supply enough heat to keep the mixture boiling for several minutes. As soon as it is well slaked, more water is added to keep the mixture from further cooking. If the cooking is allowed to continue for fifteen or twenty minutes, the solution becomes caustic to tender foliage, such as the peach. It is important, therefore, to stop the cooking at the right point. The solu- 
tion is strained and diluted to 50 gallons and applied at once.

Bean spray. - Beans are notably sensitive to scalding from arsenical insecticides. However, it becomes advisable at times to use these poisons on the bean crop. The following formula may be used to good advantage and without much danger of scalding:

Lime sulfur solution, 1 quart.

Lead arsenate paste, $S$ ounces.

Water, 50 gallons.

Miscible oils. - A considerable number of these mixable oils may be obtained on the market. Prominent among them are the Target Brand and Schnarr's Insecticide. Yothers' Formula No. 3 may be easily prepared if it is found advantageous.

Caustic potash whale-oil soap, 8 pounds.

Diamond paraffin oil, $28^{\circ}$ Baumé, 2 gallons.

Water, 1 gallon.

The soap should be heated to melt it to an oily consistency, then the paraffin oil added gradually, beating the soap and oil vigorously while the oil is being added. The beating is continued for some time afterwards and the mixture is thoroughly combined. The gallon of water may then be added. To test the mixture, a small quantity is poured into a glass of water and if free oil floats on the surface, the stirring must be continued or more soap added. One part of the mixture should be used to 200 or 300 parts water. 
Poison bait becomes very useful in combating cutworms, grasshoppers, crickets, and similar pests that are not easily reached by poisoning the foliage or cannot be reached with contact insecticides. A teaspoonful of arsenate of lead, paris green, or zinc arsenite, mixed evenly with a quart of dry bran, shorts, or cottonseed meal should be used. Enough water is added to make it into a paste that can easily be molded in the hands. If a quantity of molasses or sirup is added, it will increase the moistureholding capacity and also make it somewhat more attractive to certain insects.

\section{GASEOUS INSECTICIDES}

Bisulfide of carbon proves very serviceable in destroying insects that are infesting seed and seed-storage rooms. It also proves useful in a limited way in treating seed-beds for destroying ants. One pound of bisulfide of carbon will be needed for about 1,000 cubic feet of tightly closed space. This amount will be almost sure to kill all the animals within the inclosure in twenty-four hours' time. For destroying insects that are infesting seeds, a proportionately smaller amount should be used after placing the seeds in a box that can be tightly closed. For destroying ants' nests, a hole should be punched in the ground with a $\frac{1}{2}$-inch or $\frac{3}{4}$-inch dibber in or near the ants' nest and one to several teaspoonfuls of the carbon bisulfide dropped in the hole, and the hole covered carefully, firming the soil above.

Formalin is useful in combating the root-knot worm in seed-beds, where it is probably more effective than the carbon bisulfide. One part of the commercial formalin is 
needed to 100 parts of water. For a shallow seed-bed, $1 \frac{1}{2}$ gallons of the mixture to a square yard is applied, and for a deep seed-bed a correspondingly larger amount is used.

\section{FUNGICIDES}

There are many fungicides offered by the trade, and in some cases they will be found good, but owing to a large number of inferior materials that are being put on the market, they are not always trustworthy ; it has, therefore, become necessary to depend more largely upon the homemade fungicides and insecticides.

Bordeaux mixture. - For the prevention of fungous diseases, nothing has been discovered that is equal to the standard home-made bordeaux mixture. Unfortunately some difficulties are encountered in making a good home mixture and it is somewhat disagreeable to apply.

Solution No. 1.

Copper sulfate (bluestone), 6 pounds.

Water, 50 gallons.

Solution No. 2.

Caustic lime (quicklime), 4 pounds.

Water, 50 gallons.

It is advisable to have three kerosene barrels of about fifty gallons capacity in the ficld. Six pounds of copper sulfate should be dissolved in a barrel of water (50 gallons). The copper sulfate will be dissolved slowly in cool water if it is suspended near the top of the barrel in a feed sack or other coarse cloth. If it is desirable to dissolve it quickly, this may be done by placing it in a barrel and 
pouring on hot water. After the 6 pounds of copper sulfate have been dissolved, the barrel may be filled to the 50 -gallon mark. Tin or iron vessels should not be used in connection with bordeaux mixture or the copper sulfate solution; always use copper or wooden vessels. The 4 pounds of lime should be slaked in just enough water to cover it, and care should be taken to stir it well and see that it does not burn dry. This is best done in a wooden vessel, as there is considerable heat generated by the lime in slaking. If the stone from which the lime is made contains much sand, it will be necessary to increase the number of pounds of lime used. If there is a quantity of air-slaked lime also present, it will be better to reject this and simply use the part that has not been air-slaked. After the lime has been slaked, water to make 50 gallons is added. The copper sulfate solution (No. 1) should be stirred thoroughly, and about one-half as much as the spraying apparatus will hold taken out. This is poured in the third barrel; the lime water is then stirred thoroughly and just as much lime water (No. 2) taken out as already taken of copper sulfate solution; this is poured into the third barrel and the two stirred together immediately and briskly for a minute or two. A greenish-colored substance will then have been formed which is bordeaux mixture. This mixture is put into the spraying pump and applied at once. Bordeaux mixture is not so good after it has settled, and after it is twenty-four hours old it had better be poured away and a fresh quantity made. The lime water and copper sulfate solution may be kept separately for an indefinite time without deterioration, if evaporation is prevented. 
Ammoniacal solution of copper carbonate will be found applicable in places where the bordeaux mixture would cause a bluish green stain and so cause the product to be less salable, as in the case of maturing tomato fruits, snap beans, and the like. It does not have the lasting qualities of bordeaux mixture, but is much more easily prepared. In addition to this it may be used much more successfully to reach fungi inhabiting the soil, especially those fungi that attack the plants near the surface of the ground.

Copper carbonate, 5 ounces.

Ammonia water $26^{\circ}$ Baumé, 3 pints.

For use the solution should be diluted to 50 gallons. One gallon of water is poured into a wooden or earthen vessel, the 3 pints of ammonia added and stirred so as to mix evenly. The 5 ounces of copper carbonate are shaken in the ammonia water, stirring the liquid all the time. If the copper carbonate all dissolves, an additional amount is put in until a small quantity remains undissolved. When the undissolved copper carbonate has settled to the bottom, the clear, blue liquid is poured off into some vessels that can be tightly corked, such as jugs, or bottles. The writer's experience has been that this stock solution does not keep well for more than a few days to a week or two, even in tightly corked vessels; consequently, the material should be made up just at the time when it is to be used.

\section{SPRAYING MACHINES}

In the last twenty-five years the number of devices that have been invented for applying fungicides and in- 
secticides is almost countless. Machines have been devised for meeting the needs of almost any contingency.

For dry materials.

The simplest device to apply powders is a bag of coarse woven fabric, in which the material is placed and then the bag held over the plant to be treated. By shaking or tapping the bag the powder sifts out and is more or less equally distributed. Hand bellows to accomplish the same purpose have been in use for a considerable time. Machines variously spoken of as powder guns and dust sprayers are also on the market. Some of these are constructed so as to cover a very large area in a small time, and under certain conditions become very efficient.

Where it is practicable to use the dry material, it is usually found more economical than the liquids, owing to the weight of the water which is used in making the liquid sprays.

For liquids.

The simplest forms for applying liquids are the hand atomizers; these work extremely well for small plants and when a small area is to be covered, such as in seedbeds, greenhouses and coldframes.

The bucket sprayer and knapsack sprayer are quite indispensable to the average general trucker, and in some cases the knapsack sprayer only can be used for destroying aphis on cucumbers and watermelons, as well as other garden vegetables. When the work is to be done on a large scale, the labor expense in using a knapsack sprayer becomes too great to make this form of machine profitable. 
For spraying Irish potatoes, cucumbers, and other crops that are grown on extensive areas, the horse spraying machine becomes an economic implement. In spraying Irish potatoes for late blight and early blight, it is rather important to go over the field twice in opposite directions. In this way the foliage is covered better than when the spraying is done only in one direction.

The most perfect of the sprayers now in use is the power sprayer. These develop a pressure of 80 to 100 pounds and make it possible to reduce the spraying mixture to a mist, thus reaching not only the upper surface of the leaves, but the under surface as well to a large extent. 


\section{CHAPTER IX}

\section{MARKETING}

IT is not unusual to find persons who have labored diligently to produce a good crop put it on the market in a slovenly manner. High prices are paid for fancy fruits and vegetables, but it is necessary to have the package fancy from the beginning to the end; any one point neglected in the whole series will cause a decided damage. It requires brains to produce a fine article, hence the supply is limited. It is more profitable to produce the best of everything. If one wishes to succeed in any line of business, one must offer for sale the article that is wanted, and as long as there is a monopoly of that article, the price is considerably above the cost of production. Often, the mere style of label on a package makes a difference of 10 per cent in the selling price. The street venders in our large cities learn to know human nature well; they buy good vegetables and fruits that have been shipped in poor packages and take the time and trouble to repack them, and find it a profitable employment. We must emphasize the matter of doing the very best with the best material at hand. If a crop is all culls, nine times out of ten it will not pay to market it at all.

\section{THE PACKING-HOUSE}

To put vegetables on the market in first-class shape requires certain equipment. One of the indispensables is 78 


\section{Marketing}

a good packing-house. When vegetables and fruit are ready for the market, they must be sent out - they cannot wait. One cannot stop to plan a packing-house after the crop begins to ripen, nor is this the time to build one.

A good packing-house is airy and roomy, and so constructed that all parts can be kept clean. It has been demonstrated repeatedly that vegetables have contracted disease in the packing-house, and arrived in the market in an unsalable condition. In several cases this has led to an annoying controversy, and one in which both parties, being entirely sincere, were severe losers, the buyers in losing a desirable trade, and the vegetable-growers in having to pay for shipping a quantity of worthless vegetables. We cannot say that this was because of carelessness on the part of the vegetable-growers, but rather because of a lack of knowledge on the subject. Diseased vegetables should not be brought into the packing-house, nor should they be left in the field; this is a subject, however, that deserves special attention, and is discussed under the subject of plant diseases, Chapter VIII.

The location of a packing-house must be decided by each individual, as the points to be taken into consideration are of an individual character. When it is possible to place it so that the vegetables can be loaded directly on to the car, this will compensate for considerable disadvantage in other ways, as it saves one handling of full crates. When this is not practicable, the question as to whether it shall be in the field or near one's dwelling has to be considered.

In the planning of a house, a few general principles may be given that will cover all kinds of vegetables; there must 
be more or less variation in detail to suit the kind of vegetable to be packed. The product should enter on one side and be taken out on the other. The driveway to the entrance should be low enough so that the vegetables do not have to be lifted to the floor. The arrangement should be such that the crop does not have to be lifted at each successive handling. It is easier to lift a crate of vegetables from a bench than it is to place it on the bench. Most laborers will do more efficient work when not tired. A tired laborer works to the detriment of the grower, whether the pay is by the box or by the day. The packing season is a busy one, and laborers are often hard to secure; if, therefore, four laborers can do the work of five, there will be that much more margin for profit or for investments.

\section{HONEST PACKING}

The practice of placing poor products in the center of the crate cannot be too severely condemned, and the persons who make a practice of this usually reap the due reward. Too often, also, they do a great injury at the same time to their neighbor. 


\section{CHAPTER X}

VEGETABLES WITH EDIBLE LEAVES OR STEMS - COLE CROPS

THE cole crops are the cabbage tribes, particularly those grown for the leaves or leafy or head-like parts, as cabbage, cauliflower, kale, brussels sprouts, and others. These all require cool weather for best development and they withstand considerable frost at the proper season. The seeds are globular or nearly so, black or blackish, and germinate quickly.

\section{CABBAGE}

This hardy vegetable is grown in Florida and along the Gulf Coast as a winter or cool-season crop. In this way it escapes more or less the many insect enemies which would attack it during the hot season. It is perhaps the commonest temperate vegetable grown in the West Indies and India during the cool season for the benefit of immigrants from colder climates. It matures in three to five months, according to climate and variety.

The season for marketing cabbage from Florida is not long, because the Maine and Nova Scotia cabbage will keep until March or April, while the spring crop of North Georgia and South Carolina begins to reach market in June. In some years the northern crop is small, and in 
such cases late winter cabbage commands a high price. If at the same time the potato crop is light, there will be a demand for southern cabbage. The vegetable-growers can often anticipate such conditions, and put in a large crop of cabbage. There is a large southern market that would depend on this cabbage if the supply were constant.

Cabbage is an excellent feed for cattle. In some of the dairying districts, it is raised as a second crop to feed milch cows.

Seed-bed.

Cabbage is probably the easiest vegetable to grow from seed in the market. It is not necessary to have a coldframe to start the seedlings; but success is more certain by using it, where there is danger from frost. The bed need not be as fertile as for most other seedlings. Where frosts are apt to occur after the plants have been set in the field, the seedlings are often purposely stunted severely in order that they may be more resistant to cold. If it is discovered that the plants are not progressing rapidly enough to bring them to the size desired by transplanting time, they can be stimulated to rapid growth by the use of liquid manure, by giving cottonseed meal, or by an application of nitrate of soda. The cottonseed meal must not come in contact with the plants, as it is liable to cause a "damping-off" in the seed-bed. Four or five ounces of seed should give plants enough for an acre.

Sowing the seed of cabbage.

It is preferable to sow the seed in drills far enough apart to permit working by hoe or hand plow. In Florida, 
September or October or later, depending upon the variety, is the time to sow for the February, March, and April markets of the North. This will bring the crop into market after the northern stored crop has been consumed, and before the early spring crop has matured. The drills are made about $\frac{3}{4}$ of an inch deep. As soon as the seedlings begin to break through the ground, a liberal application of tobacco dust should be given and the dusting repeated every three or four days. This will kill or drive away the insects that are numerous at this time of the year.

If the seeds grow well the plants will become crowded in the drills before they attain their third leaf. Cabbage seedlings may be transplanted at any time in their growth, without losing any plants; hence, they should be transplanted to a new bed as soon as they show signs of too much crowding. They should be transplanted to the field before the height of 6 inches is reached. If the plants grow too rapidly, they may be checked by withholding water or by shifting them to a new bed.

Soils for cabbage.

Cabbage is a gross feeder and will succeed on soil where many other crops fail. Soil used for ordinary gardening is considered excellent for this vegetable. If the land is not level, a northern slope is preferred, as that is cooler and keeps a more nearly constant temperature. Large cabbage will stand $15^{\circ} \mathrm{F}$. without being killed; but that recently set out needs some light protection. Seedlings or plants in the seed-bed can stand about $20^{\circ} \mathrm{F}$., but if they are in rapid growth this temperature makes the leaves look scalded. 
Fertilizers for cabbage.

The fertilizer ingredients necessary for the growth of good cabbage are approximately: ammonia, 6 per cent ; available phosphoric acid, 7 per cent; potash, 8 per cent. Use 1500 to 2500 pounds of the above formula to the acre.

The following table gives the amounts of the different ingredients required :

\begin{tabular}{|c|c|}
\hline & Pounds tO THE ACRE \\
\hline Immonia & $\begin{array}{l}1200 \text { to } 2000 \text { cottonseed meal; or } \\
750 \text { to } 1100 \text { dried blood; or } \\
500 \text { to } 750 \text { nitrate of soda; or } \\
400 \text { to } 600 \text { sulfate of ammonia. }\end{array}$ \\
\hline
\end{tabular}

Phosphoric acid . 1000 to 1500 acid phosphate.

Potash . . $\left\{\begin{array}{l}1200 \text { to } 1800 \text { kainit; or } \\ 300 \text { to } 450 \text { muriate of potash; or } \\ 300 \text { to } 450 \text { high-grade sulfate of potash; or } \\ 600 \text { to } 900 \text { low-grade sulfate of potash. }\end{array}\right.$

Planting and cultivating.

Before transplanting, it is well to harden off the plants, and when ready to remove them, soak the ground thoroughly; this will cause more soil to adhere to the roots. A rainy time is preferable for planting out, and this usually can be waited for, although it is not necessary, as the plants grow very readily. For medium to large varieties, the rows should be made 3 feet apart, and the plants placed 2 to 3 feet apart in the row. They should be planted with a view of doing all the cultivating by horse power. If the season happens to be dry, frequent and 
thorough but shallow cultivation should be given to conserve the moisture of the soil.

Preparing cabbage for market.

It often happens that much rain falls when the heads have become solid, causing them to burst. This may be prevented by running a plow with a long sweep on one side of the row to cut off most of the roots. The bursting is caused by assimilation of too much moisture, and a consequent expansion of the heart while the outer leaves cannot stretch sufficiently.

For shipping, nearly all of the outer leaves are stripped off, leaving just enough to protect the head; the stalk is then cut off about even. The heads should be gathered dry, and kept so until they reach their destination. If somewhat wilted when received by the retail dealer, they may be placed in a cellar or other moist place, when they will become crisp and fresh again.

Cabbage may be classed among the staple products, so the public is not very notional about how it appears on the market. While it is an easy crop to grow, there are, on the other hand, many failures.

\section{Marlieting cabbage.}

There is no settled form of package for cabbages. The smaller early cabbage is usually crated or barreled; the fall cabbage is sometimes shipped in bulk, especially when sold by the carload. Barrels are frequently used when only a few are to be shipped to one address. Crates are often seen on the markets of large cities; they are about 2 by 4 by 4 or 5 feet. In Florida, cabbage crates are made 
to hold 100 pounds - smaller than the dimensions given above.

Enemies of cabbage.

Cabbage insects may be kept away from the seed-beds by screening thoroughly with cheese-cloth or mosquito bar. A spraying with paris green will protect the young plants from caterpillars, and a solution of white hellebore has been found efficacious against the root maggot.

Club-root may be avoided by rotation of crops. Blackrot may be prevented by disinfecting seeds and implements, cleaning out diseased cabbage, and the like, and practicing rotation. Black-mold may be checked by spraying with bordeaux mixture. In some places it is necessary to spray even the small seedlings many times.

Varieties of cabbage.

There is practically no killing frost for cabbage in the lower South; consequently, it is found more profitable to raise the larger kinds. Charleston Wakefield, Premium Flat Dutch, and Louisville Drumhead are favorites in various parts; but these varieties should be grown only to medium size. For family use, when cabbage is wanted in as short time as possible, Jersey Wakefield or Early Winningstadt are desirable varieties.

\section{Bulletins}

Cabbage, U. S. D. A. Farmers' Bulletin 433.

Screening for the Protection of Cabbage, N. Y. Bulletin 301, 1908.

Cabbage Growing, Colo. Bulletin 143, 1909.

Cabbage Experiments and Culture, Maryland Bulletin 133, 1909.

Cabbage Worms, W. Va. Bulletin 120, 1909. 


\section{BRUSSELS SPROUTS}

This form of the cabbage species is distinguished by forming many small heads in the axils of the leaves on a tall stem, instead of one large head at the top. It is a favorite winter vegetable in districts where the winter is sufficiently mild to allow of its growth, for it will stand frosts as well as the cabbage or even better. It is not so much grown in the northern United States, as it is in the west of Europe, because of the rigorous winters. By sowing the seed and transplanting into the field, like cabbage, it can be grown in southern localities during the late fall, winter, and spring, and the sprouts picked from the stem as they develop. The lower leaves are usually removed from the plants in the field to allow the better development of the sprouts. The culture of the plants and their requirements are about the same as for cabbage. There are both tall and dwarf varieties. Brussels sprouts do not appear to succeed in winterless climates.

\section{KALE OR BORECOLE}

This hardy vegetable, which is a variety of the cabbage with open growth and often cut and curled leaves, has not been much grown for the distant market, except at Norfolk, Virginia. It is used rather extensively in New York, Chicago, and several other cities with a large foreign population. The cities named above would consume hundreds of crates of it at a fair price if offered early enough. It should be brought into these markets during March and April, or even earlier. 
The land is prepared as for lettuce and fertilized as for cauliflower. The seed may be sown in drills during October and November, or it may be sown in coldframes like cauliflower during November. When the plants have the fourth or fifth leaf, they may be transplanted in the same way as cauliflower. The working of the field is similar to that for the cauliflower; and it should be remembered that the smaller varieties require less space than the larger.

The large varieties are cut and shipped in barrels; for shipping a long distance or a large amount, crates will be found preferable.

The leading varieties are Scotch Curled and Green Curled. These form only a small part of the varieties grown in Europe.

\section{COLLARD}

The collard is a form of kale; it stands hot weather better than the cabbage, and although it forms no heads, gives a large supply of excellent green leaves. It grows more strongly than the cabbage and is recommended for gardens in subtropical and tropical climates, and even for market-gardening in some of the latter. In winterless climates it may be grown as a perennial, the young leaves only being picked as wanted.

This is decidedly an American vegetable, grown almost exclusively for southern markets by people of the South. As a money crop it is not particularly successful, although it may be marketed when vegetables are usually scarce. Those who have cultivated a taste for it will refuse cabbage and cauliflower at the same price. 
A rich loam should be selected, heavily fertilized, and deeply prepared. The directions given for the preparation of land for cabbage will also apply for collards. 'The seed is sown in a coldframe or in an open seed-bed during February and March in the colder part of the orange belt, and as late as August in the warmer part of the wheat belt. As soon as the plants begin to crowd one another, they are shifted to a new place in the coldframe. When the plants are from 4 to 6 inches high, they are planted in the field, laying the rows off 4 feet apart and putting the plants 3 feet in the row.

The crop may be marketed any time after the first of October. This may be done in crates, in barrels, or in bulk.

\section{CAULIFLOWER}

Many persons prefer the cauliflower to any other vegetable. It has no doubt been derived from the cabbage. The broccoli is a kind of cauliflower, and hardly shows differences enough to deserve a separate name. The cauliflower is remarkable as being one of the few plants whose flower-buds and stalks are eaten. From the swollen colorless state of the flower-buds and flowerstalks, the production of good seed is naturally scanty, and therefore the seed is high-priced. The cauliflower is a monstrosity among cultivated plants, and this may account for several difficulties in its culture. It stands somewhat more warmth than most varieties of its ancestor, the cabbage, and is also more sensitive to frost. Though it can endure some heat and drought when young, it requires moisture and a cooler temperature to head well. If 
checked in growth or not well.fed, it produces a number of buttons instead of solid heads. Cauliflower grows remarkably well in the spring, fall, and winter seasons of subtropical countries, such as Florida, the Gulf Coast, and the Mediterranean region. One variety is grown from acclimated seed in the tropical parts of India. It may be recommended for private or local use in tropical lands where there is a distinct cool season, especially if grown under a slat-shed, or under cheese-cloth on a small scale. The seed for warm climates should be procured, like that of the Bermuda onion, from a warm country. Irrigation is highly beneficial, and a thick mulch of manure or straw has given good results in dry hot weather. The cauliflower takes about five months to mature from seed. The seed may be sown thinly in a seed-bed, or sown in the open field a few together at intervals of 2 feet, in rows 3 feet apart. From $1 \frac{1}{2}$ to $2 \frac{1}{2}$ ounces of seed may be needed for an acre, when sown in a seed-bed.

As a money crop for the southern United States, the cauliflower can be recommended to all sections. It is more difficult to raise than cabbage, and consequently brings a larger profit to those who are able to grow it well. It has been grown successfully in all sections of the lower South, and thousands of acres are raised annually on Long Island. By this it is seen that the difficulties connected with raising it are not obstacles to average gardeners.

Sowing seed of cauliflower.

In sections where the temperature does not go below $18^{\circ} \mathrm{F}$, cauliflower can be relied upon for February and March delivery. If the crop is wanted for these months, 
the seed should be sown in a coldframe shaded with plantcloth at midday during September and October. In Florida, the seed may be sown as early as August, and in South Texas in July.

The soil should be raked off smoothly, and if it is not already fertile, it should receive a liberal application of commercial fertilizer. This should be worked in thoroughly and allowed to stand a week or ten days before the seed is sown. Cottonseed meal or other vegetable matter should not be used in the fall, as it propagates diseases which destroy seedling cauliflowers. In winter this form of fertilizer can be used in the coldframes with safety. Cottonseed meal and other vegetable matter should be composted and thoroughly rotted before using it in the coldframes. The drills are made 3 or 4 inches apart and $\frac{3}{4}$ of an inch deep, and the seed sown by hand very thinly. A seeder may be used with profit if one has much seed to sow. The seed when sown should be covered with about $\frac{3}{4}$ of an inch of soil.

The soil should be kept moist by frequent applications of water, never using enough to soak the bed, and, on the other hand, not allowing the soil to become dry. An open seed-bed may be covered with sacking until the seeds germinate. As soon as the seedlings appear, watering may be less frequent and heavier. The surface of the soil should be allowed to dry, so as to prevent damping-off. If, at any time, it is noticed that some plants are falling over, as if cut off, it is probably due to a fungus. An application of air-slaked lime, dust, or dry sand will often be found of advantage in this case.

As soon as the plants begin to crowd in the rows, they 
may be transplanted to a plant-bed. They are set 4 by 4 inches. In six or eight weeks the plants are ready to go to the field. Care must be exercised that they do not remain in the coldframe too long, as leggy plants are liable to "shoot up" to seed without making fine heads. However, experiments have shown that transplanting decreases the yield, and, if possible, it should be avoided. Soil and fertilizer for cauliflower.

A rather loamy sandy soil, in a warm location, is preferable for winter marketing; but for the late spring market a heavier and cooler soil will give a larger yield. Irrigation is of great value in dry seasons. The land should be prepared deeply and thoroughly. If some crop has been used for soiling, the material should be plowed in early enough to incorporate it well with the soil before planting time. The land should be fertilized heavily as for cabbage. The following ingredients should be used: ammonia, 6 per cent; available phosphoric acid, 7 per cent; potash, 8 per cent. Use about 1500 pounds of the above formula. For table of ingredients to use for an acre, see Cabbage. The fertilizer should be applied along the row, and worked in thoroughly. From several days to two weeks should be allowed to pass before planting out.

Setting out the plants.

The rows should be made $2 \frac{1}{2}$ to 3 feet apart and the plants set 2 feet or so apart in the row. If rain does not occur at the time, it will be necessary to water, for one cannot wait for a rain, as with the cabbage, for the plants 
must be set out, as otherwise they are liable to become too large and a part of the crop to be worthless.

Cultivation of cauliflower.

The general care and cultivation is like that for early cabbage. An application of nitrate of soda at the beginning of heading is advantageous. When the heads reach the size of a teacup, the leaves may be tied over them to keep the heads white. This is not always necessary, nor is the practice always followed.

Cutting.

After cauliflower has begun to head, it requires much judgment to put it into the market properly. The field must be picked over repeatedly and the matured heads removed, or they will spoil. If the weather is warm, they are liable to spot, and this makes them unfit for the market. To examine a head, the leaves are parted to see if the head is beginning to crack; if so, it should be removed. In case the leaves have been tied over the head to blanch it, they must be parted on the side. In cutting, a good, strong knife, with a blade about eight inches long, is needed. The stalk should be cut so as to leave about two circles of leaves. If the product is first-class, it will pay to cut the stalk below the leaves and cart the crop to the packing-house.

Crating cauliflower heads.

Preparatory to crating cauliflowers, all but the inner circle of leaves should be trimmed off, the stalks cut off near the leaves, and wrapped in a thin, white paper. In 
the fancy markets, nearly as much pains is taken with this vegetable as with fancy fruits, and the growing of this class of cauliflower pays best. Before wrapping, each head should be allowed to dry thoroughly. In regard to the package, the customers are not so particular because the product is usually removed from the package before it is sold to the retail dealers. The barrel or box should not contain more than $2 \frac{1}{2}$ bushels, to avoid bruising the lower heads by the weight of the upper ones. For a distant market, it is better to use a crate that will hold about as much as a tomato crate.

Seed production.

The seed is imported from Europe, and some quantity is grown in this country. It is very difficult to grow the seed in the gardening districts of the eastern United States, as the heads have to be kept over winter, and the seeds ripened the next summer. Fine heads cannot be kept from rotting, so half-matured specimens have to be chosen. Is not here a profitable employment for a small capital in the South? Our crop can be manured early so that the seeds can ripen the same season. If an ordinary crop happened to be somewhat late, it might be allowed to go to seed. With a decrease in the price of seed, there would be an increase in consumption. As cauliflower is one of the most delicious vegetables, there need be no fear of over-production.

Varieties of cauliflower.

Good varieties which can be depended upon are, Early Dwarf, Erfurt, Early Snowball, and Extra Early 
Paris. Algiers has been recommended. Large Asiatic is grown in India. The price of the seed is one drawback in cauliflower raising.

\section{Enemies.}

The root-maggot is one of the worst insect enemies of cauliflower. It can be kept away by covering the seedbed with cheap mosquito-bar, and hellebore solution or carbon bisulfide will drive it from mature plants.

The black-rot, caused by bacteria, is a dreaded disease in the southern United States. When a field is once infected, neither cabbage nor cauliflower can be grown on it for some years. The best way to prevent infection of a healthy district is to soak all the seed in a solution of 2 ounces of corrosive sublimate to 15 gallons of water, for a quarter of an hour.

Books and bulletins.

Cauliflower, Fla. Bulletin 59, 1901.

Cabbages and Cauliflowers, by J. J. H. Gregory, Boston, 1908.

\section{BROCCOLI}

Broccoli is a late and coarse form of cauliflower. It is hardier than cauliflower and keeps well, but is not so choice a vegetable, and therefore does not sell as well. It may be grown as a winter crop in some regions where the cauliflower cannot stand the frosts without protection. Thus it is a favorite crop in southern England. Some of the varieties are often confused with cauliflower in new markets. 
The seed should be sown in a coldframe or seed-bed during September, or later. As soon as the seedlings are an inch high, they should be picked out and transferred. The rows are made 4 inches apart and the seedlings set 3 or 4 inches in the row, pressing the soil about their roots lightly and watering thoroughly. A speedy way of setting them out is to make a drill about $\frac{1}{2}$ inch deep and place the seedlings in this in an upright position, then press the soil to them from both sides. After a part of a coldframe has been set out, an abundance of water is applied in a very fine spray. By separating the plants in this way, damping-off, that often causes great losses among plants belonging to the cabbage tribe, is largely checked. When the plants are 4 or 5 inches high, they should be set in the field, or the seed may be sown thinly in drills 4 inches apart, and the plants set out directly in the field.

The soil should be rich sandy loam, deeply prepared and heavily fertilized, using the same fertilizer ingredients as for cauliflower. The rows are laid off 3 feet apart and the plants set 18 inches apart in the row.

As soon as the first seedlings are ready to set out, they should be hardened off for a day or two before planting in the field. If a cold snap is just at hand, the plants may be kept in the frame for a week or two longer. A fresh supply of plants should always be kept under special protection, to be used in case of a hard freeze that may kill the plants in the field.

Cultivation should be practiced frequently, but only to a medium depth. When the heads are maturing, a light band of bast or other cheap material may be used to tie the leaves over the heads for the purpose of blanching. 
When mature, the heads should be cut, leaving only a few leaves on to protect them, and packed tightly in vegetable crates.

The leading varieties are Veitch's Self-protecting, Purple Cape, and Mammoth White.

\section{KOHLRABI}

Cultivated plants belonging to the mustard family have been bred into many striking forms to supply the people of Europe with vegetables. Cabbages store the nourishment in abundant leaves; turnips store the food material in the roots; kohlrabi combines the two and stores the nourishment in the stem at the base of the leaves and above the root. In taste it displays the same adaptation, for, while it partakes of the flavors of cabbage and of turnips, it is distinct from both. It is prepared for eating in the same way as turnip.

The seed should be sown in a coldframe in September, and the sowing repeated every four weeks until the first of February. As soon as the seedlings are an inch high, and before the leaves begin to appear, they should be pricked out in rows 4 inches apart, setting the plants every inch in the row. When they are 4 or 5 inches high, the seedlings are planted out in the field. Kohlrabi may also be treated the same as cabbage plants.

The soil should be a rich loam prepared deeply. The rows are made 2 feet distant, and the plants set a foot apart in the row. Cultivation should be frequent and to a medium depth. As soon as the stems have attained the diameter of 2 inches, they may be used. The Early 
White Vienna and the Early Purple Vienna are ready for table use in about two-and-one-half months.

Some varieties are grown to feed to stock; these will be found to be coarse for table use when full grown, but are good when half grown. Kohlrabi has not been shipped to any extent and will probably not be of value for this purpose. It is a good vegetable to grow in the tropics during the cool season, since it is ready to eat about two months after sowing, and retains a fair flavor. If allowed to grow large, it becomes woody. 


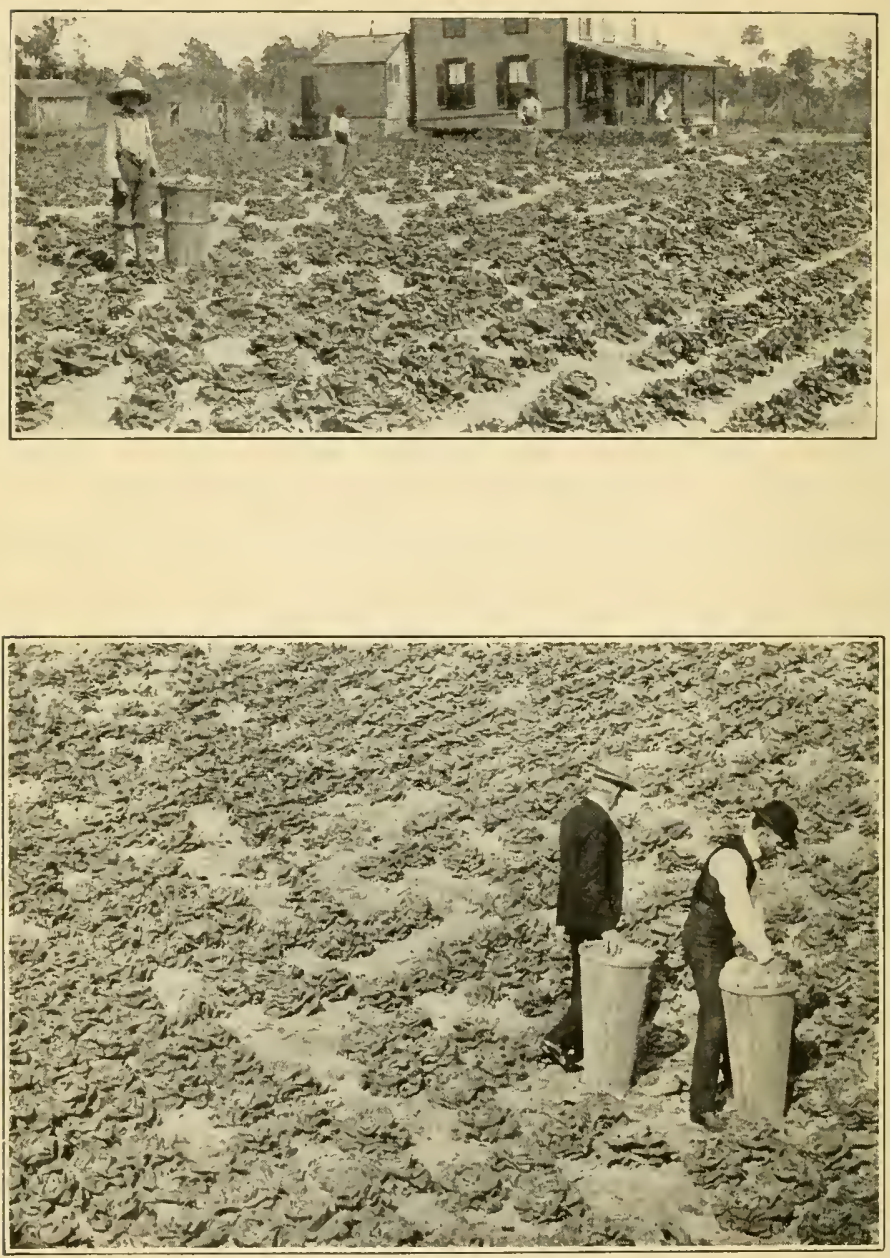

Plate II. - Lettuce.

Top, lettuce grown on a city lot; bottom, a commereial lettuce ficld in Florida. 


\section{CHAPTER XI}

\section{VEGETABLES WITH EDIBLE LEAVES OR}

STEMS-OTHER CROPS

The leaf- and stem-crops other than the cabbages and their kind are not closely related botanically. They belong to different natural families, whereas the cole crops all belong to the mustard family and even to the one genus Brassica. In this chapter are brought together - since the cultural requirements are somewhat similar - such plants as lettuce, endive, spinach, celery, chicory, parsley, cress, asparagus, artichoke.

\section{LETTUCE}

In the outer tropical and in the subtropical lands, lettuce seed may be first sown just before the commencement of the cool season, perhaps in October in northern regions. After this, successional sowings may be made. Lettuce flourishes well in the trade-wind belts at an elevation of 2000 feet or so. As it takes two or three months to mature properly, the first heads will not be ready until about the end of the year. If seed is procurable, lettuce leaves may be grown in partly shaded places within the tropics throughout the hot season, but the plants are often weak and do not head well. Lettuce seed in hot 
countries is often carried off by ants, sometimes to such an extent that it has to be sown in boxes whose supports stand in water.

Lettuce may be grown successfully under extremely varying conditions of climate, but in general it needs a rather cool temperature and humid atmosphere. It is grown very extensively without protection throughout central Florida and along the Gulf Coast, for midwinter and early spring market. To do best, the temperature should not fall below $28^{\circ} \mathrm{F}$. or rise above $85^{\circ} \mathrm{F}$. While the young plants can endure a rather low temperature without being killed, in the heading stage the crop is likely to be ruined by a sudden fall of temperature to $24^{\circ} \mathrm{F}$. Where such freezes are likely to occur, frames that can be covered with a light quality of cotton cloth are prepared. (See lower figure, Plate V.)

Seed-bed for lettuce.

In preparing a coldframe or seed-bed for lettuce, one should select coarse loam and mix with this much vegetable matter, so as to put plenty of humus into the soil. The drainage must be such that any surplus water will draw off rapidly.

The seed is sown in shallow drills about 3 inches apart, and covered lightly with earth. The bed must be covered so as to protect it from the sun or too rapid drying. It is a good policy to sprinkle the bed every morning. From time to time as the seedlings begin to crowd in the row, the weaker ones should be pulled out. Transplanting is done when the leaves are one to three inches long. If delayed until the plants are larger, the work is accom- 
plished more easily; but the chances of getting a good stand are reduced, and the plants may suffer greatly. All inferior plants should be rejected. In setting out in the field the plants are placed in checks 10 by 10 inches according to the size of the variety.

Another method which is not usually practiced, but which gives stronger and better plants, is as follows: As soon as the seedlings are up strongly and before the leaves begin to form, the largest are picked out with the point of a knife or a similar tool. These seedlings are then set out in rows 4 inches apart, and an inch apart in the row. Only firstclass plants should be selected, and the inferior ones destroyed. As soon as the plants are set out, they should be sprinkled thoroughly, and they will grow off without a perceptible check. Before the plants begin to touch in the rows, they should be transplanted again, this time being placed in checks 4 by 4 inches. At this time the largest should again be chosen and the inferior ones destroyed. In a few weeks from this second transplanting, the plants will be ready to go to the field. If they are to remain in a coldframe, they should be planted in checks 10 by 10 inches to 14 by 14 inches, according to the variety. If they are to be planted in the field, the same distances are used.

Nitrate of soda dissolved in water (about an ounce to a gallon) is often sprinkled on young lettuce beds to hasten the growth. It might be worth while to try nitrate of potash instead, as it would perhaps be less likely to induce diseases. Lettuce must make a quick growth and. head well, and to do this it requires more fertilizer than most other garden vegetables. 
Preparing the lettuce field.

All rubbish should be removed from the land before the field is plowed; débris of any sort is not only annoying, but also liable to interfere in cultivation and to cause considerable loss. The soil should be a friable loam, with little silt or fine sand present. It should be rich, but need not be deep. All plowing and preparation may be shallow.

A convenient way to plant in the field is to lay the rows off at proper distances, and then make checks across the rows. A plant is dropped at each check, and afterwards the roots pressed into the ground with a dibber; or the forefinger may be used for this purpose. The soil should be pressed firmly about the plants, and the plants watered thoroughly.

Cultivation of lettuce.

If the weather is dry, frequent shallow plowings by hand should be given. In a wet season, the cultivation should be deeper and more thorough, so as to allow the surplus water to drain off rapidly. It is not sufficient merely to keep the weeds down, but the soil must be kept loose and friable all the time.

Fertilizer.

The fertilizer ingredients for lettuce should be as follows : ammonia, 6 per cent; available phosphoric acid, 9 per cent; potash, 12 per cent. Use 800 to 1000 pounds or more (some growers use over three tons) to the acre of the above formula. If the land is rich is humus, the amount 
of nitrogen may be cut down accordingly. In a coldframe or seed-bed, use a pound for every twelve square feet. The following amounts of materials will give about the quantity of each element called for in the formula :

Pounds to the Acre

Ammonia . . $\left\{\begin{array}{l}600 \text { to } 1200 \text { cottonseed meal; or } \\ 250 \text { to } 500 \text { muriate of soda; or } \\ 200 \text { to } 400 \text { sulfate of ammonia. }\end{array}\right.$

Phosphoric acid . . 600 to 1200 acid phosphate.

Potash . . . $\left\{\begin{array}{l}900 \text { to } 1500 \text { kainit; or } \\ 200 \text { to } 250 \text { muriate of potash; or } \\ 200 \text { to } 250 \text { high-grade sulfate of potash; or } \\ 400 \text { to } 500 \text { low-grade sulfate of potash. }\end{array}\right.$

The general formula is applied broadcast over the field and worked in thoroughly a week or so before planting out. After the plants are nearly half-grown, a liberal application of nitrate of soda or nitrate of potash may be given. The quantity to be used will range from 100 to several hundred pounds to the acre, depending on circumstances. If heavy rains occur, a second application may be necessary.

Irrigation for lettuce.

To make lettuce-growing certain and profitable, it is necessary to have some means of applying water. When conditions permit sub-irrigation, this system is to be preferred; when this is not practicable, an overhead system may successfully be employed. The amount of water to be used will vary greatly with the character of the soil 
and climatic conditions, but frequent and light irrigations are much more profitable than heavy ones at infrequent intervals. Over-watering occurs more frequently in subirrigation than in over-head irrigation. (See Plate I.)

Marketing the lettuce.

The solid head varieties do not remain in a marketable condition as long as the Grand Rapids and those of its type; therefore, if the solid varieties are planted, they will have to be sent forward to the markets as soon as matured. As a whole, the eastern markets are partial to solid head lettuce, while the western markets are more inclined toward loose heads. For local markets, lettuce may be blanched; any simple contrivance that will shut out the sun will do this. (See Plates II, III, VII and XIII.)

For shipping, the crop must be cut when it is dry. It should be packed in a barrel or open crate; in Florida a standard lettuce hamper is used. The heads must be packed in firmly, but the leaves must not be crushed. The packing must be so firm that the material in the crate cannot shake. (See Plate VII.)

Lettuce seed raising.

For raising lettuce seed, the plants should be selected from one variety just as for the market crop. When the plants are matured, all individuals that are not typical should be removed from the field. If any plant contracts disease, it should be removed also. About six weeks after marketing time, the plants will have sent up a seedstalk. A stake should be placed in the ground firmly beside each plant and the plant tied to the stake. This 



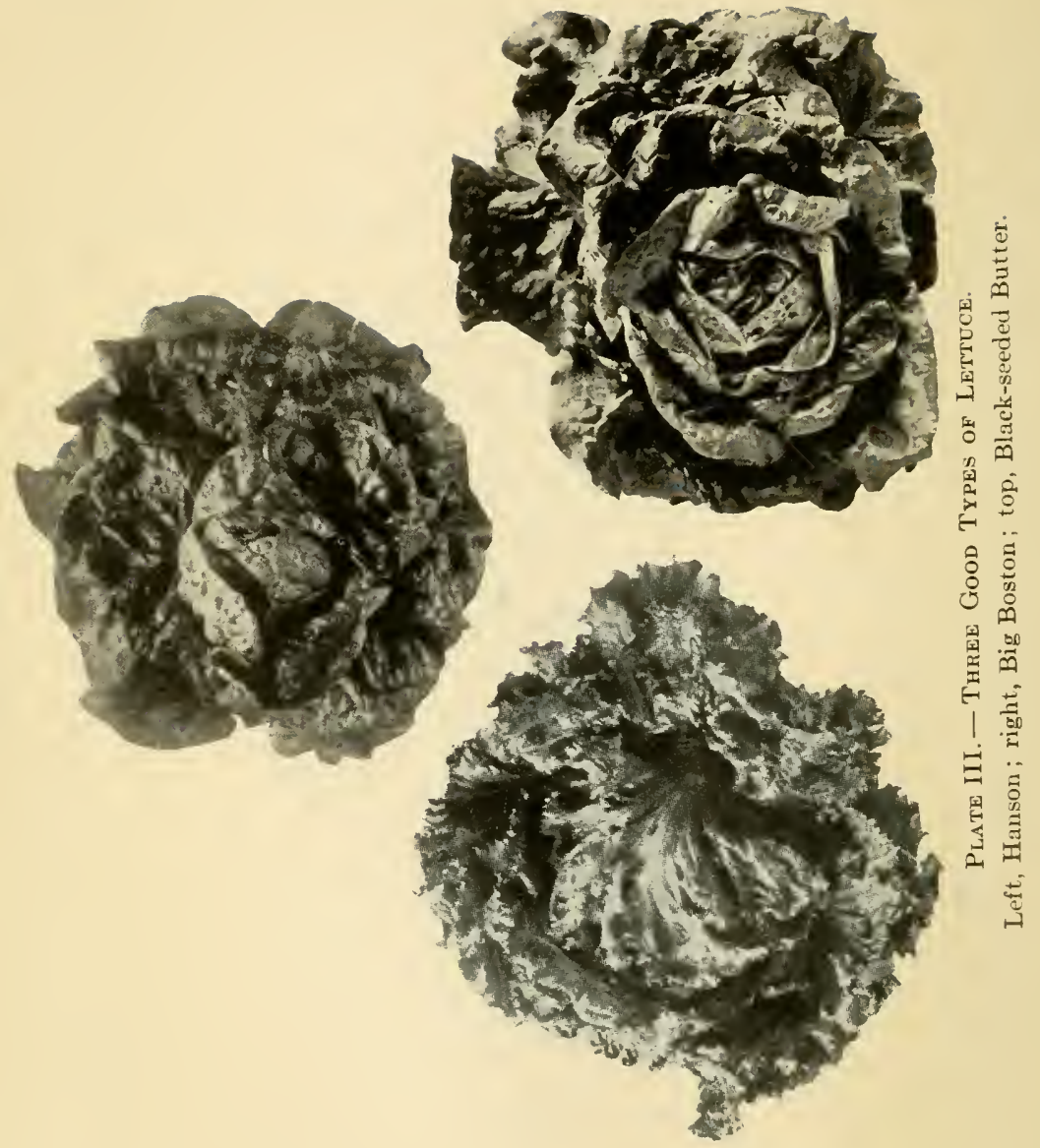


will save many plants from being blown over. The ripening of the seed will be indicated by the feathery pappus on the individual heads. As soon as a good number of heads are ripe, the whole plants may be cut off and bunched, and hung for drying in the packing-house. As soon as dry, the seed should be threshed, as it is very easily blown away. Clean out all chaff and light seed, and pack away from mice and roaches.

\section{Diseases.}

Lettuce-drop is caused by a fungus which lives in the soil. The plants wilt and drop in a few hours. Small black sclerotia may be seen on the dead plants. The remedy is to use fresh soil for seed-beds, which does not contain the fungus, and to clean out all diseased plants. The bacterial disease of lettuce starts as transparent spots, which spread over the leaves, causing them to die. This disease kills the plants slowly.

Varieties of lettuce.

Of the two classes of lettuce, the Cabbage and Cos, the former is regarded as best for tropical countries. Of lettuce varieties grown in Florida for early shipment to northern markets, California Cream Butter perhaps ranks first, Big Boston second, and Black-seeded Simpson third. Other varieties grown are Tennisball Black-seeded, and Mammoth Black-seeded Butter. (See Plate III.)

The Grand Rapids, an open-headed variety, is preferred by some markets, especially for garnishing purposes. There are many other varieties that are claiming attention, but the above will be found reliable. 


\section{Bulletins.}

American Varieties of Lettuce, U. S. D. A. Bur. of Plant Ind. Bulletin 69, 1904.

Lettuce Culture, Cuba Agr. Exp. Sta. Bulletin 8, 1907.

\section{ENDIVE}

Endive is used either as cooked greens (the broad-leaved variety) or in making salads (the curled endive), but it is not demanded in the markets of the southern United States. While it is raised to a considerable extent in some places in the northern states, it receives greater attention in Europe. Endive stands heat and cold better than lettuce. It is easily grown within the tropics from seed sown broadcast or in drills, at the beginning of the cool season, and the curled varieties are readily blanched by tying up. They are of little use for salads unless thoroughly blanched. The plant is very closely allied to chicory. It produces a dense clump or rosette of leaves.

A quick loam is required to make a good crop, but, like spinach, endive is a surface-feeder. The land should be thoroughly prepared and the fertilizer evenly distributed. Of the ordinary vegetable fertilizer 800 to 1200 pounds should be used to the acre. If the nitrogen is in the form of vegetable matter, it should be thoroughly decomposed; if in the form of mineral matter, it had better be applied at different times. The fertilizer should be applied in the drill. The rows should be made about 2 feet apart and the seed sown thickly, thinning out later to about 9 inches in the row. September or October is the best time for sowing. 
About January or February, the crop will be ready to blanch; this is done by tying the outer leaves up over the inner until the green has disappeared from the latter. It depends much upon the condition of the weather as to the length of time that will be required in blanching; if the plants are growing rapidly and the weather is warm, only half as much time will be required as when the weather is cold. As soon as blanching is complete, the leaves must be cut, or decay will set in. Transplanted endive has not yielded as well as when not transplanted; therefore, it is preferable to sow an abundance of seed and then thin out. The marketing is like that of spinach.

There are two classes of curled endive - the yellow and the green; the yellow is probably the more attractive, but there is little choice.

\section{SPINACH}

Spinach leaves are much used as cooked greens. This easily cultivated plant will stand a hard winter, and may be readily grown in the tropics during the cool season, or at elevations of 2000 feet and more. It forms an agreeable change from the cabbage, which is often the only green vegetable procurable, and that with difficulty, in some tropical countries.

In the northern United States spinach is largely grown. It does not stand shipping to a distant market very well, and therefore will not come into general favor with truckgrowers in the lower South, though a large quantity is shipped from Virginia.

A warm loam should be selected and fertilized heavily. 
The following fertilizer ingredients should be used: ammonia, 3-4 per cent; available phosphoric acid, 7 per cent; potash, 5 per cent. Use 800 to 1200 pounds to the acre, and apply in the row. The plowing need not be deep, and a top-dressing of chemical fertilizer after the plants have been started will be found advantageous. The rows should be made 2 feet apart, or less, and a seed dropped about every inch and covered with about an inch of soil. September or October is the best time for sowing. The plants are thinned out to 6 to 12 inches in the row according to the variety. A wheel-hoe or some other shallow-running cultivator is used to stir up the soil. The main work will be to keep the weeds down and the soil moist. If the ground becomes very dry, the plant runs to seed. Like lettuce, it must be kept continuously in active growth.

Marketing may be done in the ordinary vegetable crate, or in ventilated barrels, but the product must be thoroughly dry before it is packed. The plants should be cut so as to leave less than an inch of root, the dirt shaken off well, all dried or otherwise worthless leaves removed, and packed tightly. With the increased facilities for transportation, it may be possible to supply many of the southern markets. In a garden it is usual to pick the outer leaves of the spinach as they mature.

There are not many varieties of spinach to choose from; the one known as Round Leaved is quite common; the Improved Curled American Savoy is also grown extensively. Prickly Seeded spinach is also sold for winter growth.

In raising spinach seed, the barren or staminate plants 


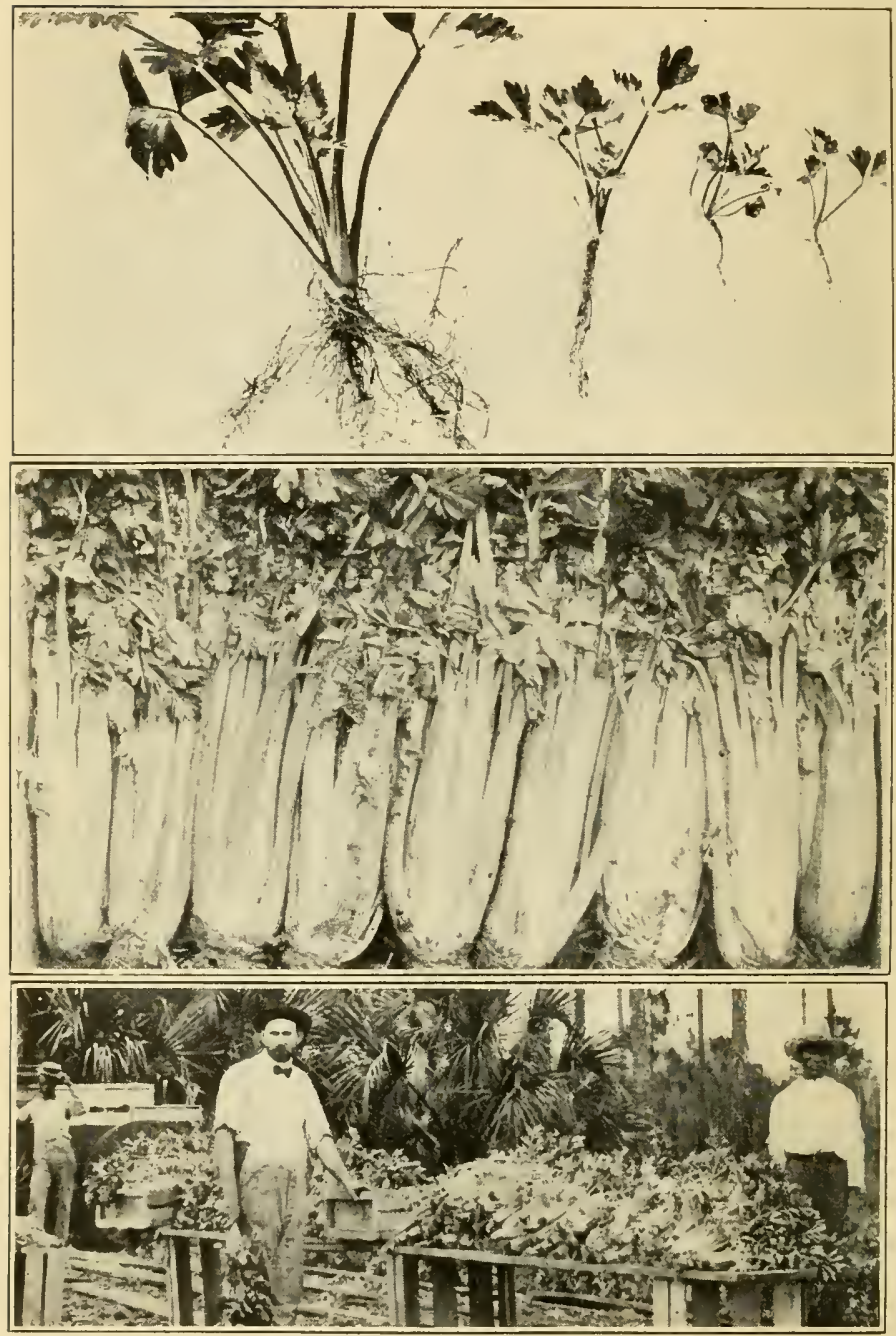

Plate IV. - Celery.

Top, largest plant well rooted and ready for transplanting; center, market celery packed in a crate; bottom, celery packing in field. 
may be rooted out and thrown away as soon as the seed has set. When the seed is ripe, the plants are hung up to dry and the secd threshed out.

\section{CELERY}

Early celery is grown on a commercial scale as far south in Florida as $27 \frac{1}{2}^{\circ}$ north latitude. It can be raised in gardens in northern India and the West Indies during the cool season. It requires five months or more to mature from seed. The profit in this line of vegetable-growing depends largely upon individual skill. In northern sections, as in Michigan and New York, celery is raised as a second crop ; but in Florida it has to be raised as a first or cool-season crop.

Soil for celery.

The South has enough excellent celery land to supply the markets of the United States. In choosing a plot, two points must be kept in mind: first and most important, the soil must be rich, or made rich by heavy fertilizing ; second, the soil must be moist and well drained. Much of the drained muckland has failed to produce celery because it is too dry. Again, some muckland was too new, and caused the crop to "rust" and decay. Celery raising pays, because it takes more skill to raise it than many other crops.

In northern celery-growing sections, a crop of early vegetables is taken from the land, and then the celery is planted. The land having received a heavy application of manure before the early vegetables are planted, need not 
be fertilized again unless some thoroughly rotted compost can be obtained. Fresh or undecomposed manure may cause a rusting of the vegetable that unfits it for market. The old method of growing celery was to prepare the land well and deeply, and then make trenches 6 to 8 inches deep, and set the plants in these trenches. This method is not followed now by the best celery-growers.

If one has a field of drained muckland, one should first make the soil sweet, and then plant the crop. Muckland may not be fit to plant celery for two or three years after it has been reclaimed. It may be best to add lime, ground limestone, or ashes to correct the acidity. One of the best crops to prepare the land for vegetables is corn. This is very exhaustive; but the roots penetrate the soil well, and corn is able to stand more sourness than many other crops. Rye and oats prepare the upper stratum well, but their roots do not penetrate the soil as deeply as those of corn. When the soil has become perfectly homogeneous, and the vegetable matter thoroughly incorporated, one may feel sure that it is in good condition for celery. It is advisable to test the land by planting out a short row of celery on a typical portion the year before; the growth of this will tell for a certainty whether the soil is in good condition. When the soil is in a good condition, the land should be plowed deeply, thoroughly harrowed, and all rubbish removed. Before plowing, all corn-stalks, large weeds, sticks, and anything that may interfere with cultivation, should be removed.

If it is pinewoods land that is to be put into cultivation, it must be cleared of all woody matter. The rows are then laid off, and a double furrow plowed out deeply - 
as is possible with a two-horse plow. In this furrow thoroughly decomposed compost of muck and stable manure is scattered, at the rate of about a two-horse wagon load to 100 feet of furrow. The soil and compost are mixed thoroughly, gradually filling the furrow in doing so. When well-rotted vegetable matter cannot be obtained, humus may be supplied by sowing the field to a rank-growing legume, such as velvet beans. Cowpeas are not so desirable, since most varieties harbor the rootknot - a very serious disease of celery in light sandy soils of subtropical regions.

Fertilizer for celery.

The proportions of fertilizer ingredients should be as follows : ammonia, 6 per cent; available phosphoric acid, 6 per cent; potash, 8 per cent. Use 2000 pounds or more to the acre. The growers in Florida use from two to three tons. If the celery is planted on muckland, the amount of nitrogen should be reduced.

The following fertilizer ingredients will give the proportions of the above formula at the rate of 2000 pounds to the acre:

Pounds to the Acre

1700 cottonseed meal ; or

Ammonia . . . . $\left\{\begin{array}{c}1000 \text { dried blood; or } \\ 700 \text { nitrate of soda; or }\end{array}\right.$

500 sulfate of ammonia.

Phosphoric acid . . . 1200 acid phosphate.

Potash . . . . $\left\{\begin{array}{l}320 \text { muriate of potash; or } \\ 350 \text { high-grade sulfate of potash; or } \\ 700 \text { low-grade sulfate of potash. }\end{array}\right.$ 
In an extensive trial of different fertilizers on sub-irrigated land in Florida, the following mixture gave excellent results :

1. Bone-meal . . . . . . $1500 \mathrm{lb}$. to the acre.

2. Fish scrap . . . . . . $2200 \mathrm{lb}$. to the acre, or

2. Dried blood . . . . . . . $1800 \mathrm{lb}$ to the acre.

3. High-grade sulfate of potash . . . $650 \mathrm{lb}$. to the acre.

Seed-sowing.

The seed is sown in August or September, or later, at intervals of two weeks, in a coldframe or in a seed-bed, where the young plants can be watered easily and protected from the hot sun. If the seed-bed or coldframe has been used before, new fertilizer must be added before seed is sown. If a new seed-bed has to be made, follow the directions given on page 58. Plenty of fertilizer should be used; a pound of the formula given may be used to every 6 square feet as a fair allowance. Lime or ashes should be used to correct any acidity. The bed should not be located near trees to secure shade from them; they will exhaust the soil before the celery is ready to be transplanted.

When the bed is level and smooth, shallow drills are made by drawing a stick across, at intervals of about 6 inches. The seeds should be scattered thinly. They should then have a very light covering of soil scattered over them, or the whole bed may be covered with wet burlap until the seeds have germinated. Sprinkling with water is needed after the sowing. The young seedlings usually require to be shaded from the sun's rays by a cover of slats or cheese-cloth. The plants should be thinned to about an inch apart when the leaves begin to 

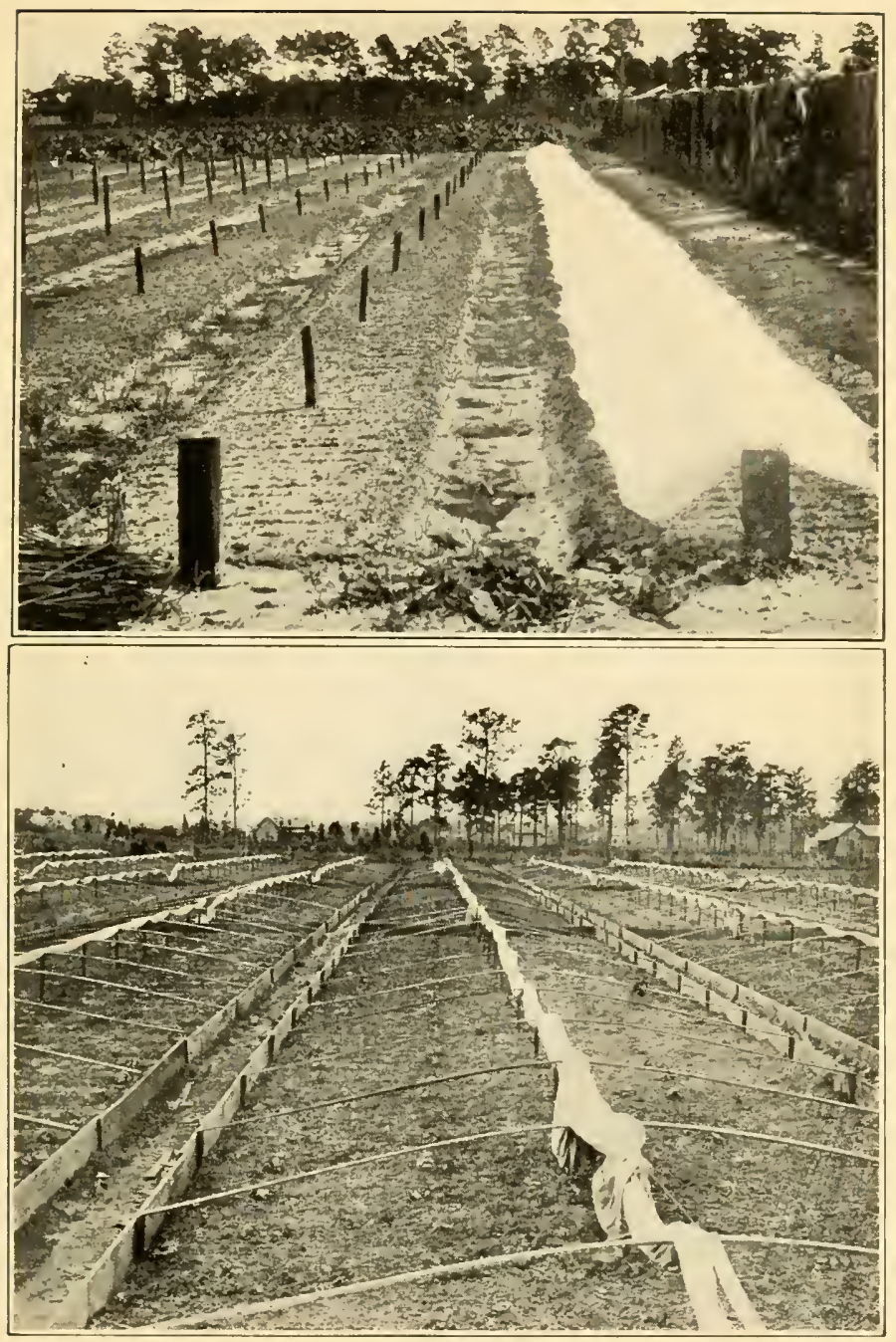

Plate V.- Plant Beds.

Above, a seed-bed for starting eelery plants, with cheesecloth covering; old fertilizer bags on fence were used over the beds to sprout the seeds. Below, a eanvas-eovered bed in which a cucumber erop is grown. 

form. Care should be exercised to keep the weeds out by cultivating and weeding. (See upper figure, Plate V.)

A celery bed should be cultivated at least every week; and while the weeds are still in the seed-leaves, they should be weeded out. If the plants tend to become spindly, the tops should be sheared off and the leaves will grow stocky. Crowding the plants in the row makes them send out a strong down-growing root that might be called a tap-root. If the plants are not crowded, the roots spread out upon the surface, and are constantly subject to slight droughts. In the case of a strong central root system, the plants are nourished from the portion of the soil that is constantly moist. Another decided advantage is that they may be transplanted with less injury to the root system.

\section{Transplanting celery.}

However cheap plants may be in the market, it is preferable to grow one's own plants. However, sometimes it happens that celery plants must be bought or the crop abandoned for that year. If one has to buy plants from a distance, the land must be quite ready to receive them when they arrive. If there happens to be a dry spell, the plants must be put into a bed where they can be shaded, and water in abundance supplied. A number of the plants can then be set out, from time to time, as one is able to take care of them. The setting out must not be delayed, for the plants will soon form roots from the reserve material within them; and if this has to be done the second time, it will be a severe draft on the plant. If one has raised his own plants, he may delay 
transplanting for weeks, awaiting a rain. If the land is in perfect readiness, as soon as the plants are large enough, which will be in six to ten weeks after sowing, they can be set out. 'The time to transplant is when the leaf-stalks are from 3 to 6 inches long. The distance between the rows is about 3 feet or more, according to the variety, putting the plants 3 inches or more apart in the row. The smaller distances will give between 50,000 and 60,000 plants to the acre. The surface of the land should be even and level, and the soil mellow and deep. A line should be stretched and a dibber used for planting. The plant is placed into the hole made by the dibber, and the ground pressed around it firmly. Another method of setting out that is being practiced largely is to set two rows 6 to 10 inches apart, placing the plants 6 to 8 inches apart in the row. The plants in the second row are set so as to come opposite to the spaces in the first row. This allows one to set nearly twice as many plants to the acre as the single-row method, and makes a great saving in lumber at the time of blanching. In setting out, the bud is placed even with the surface of the ground. The work of setting out can be facilitated by cutting the roots and leaves to the proper size before taking to the field. An active boy may be employed to drop the plants for the man doing the setting out. (See upper figure, Plate IV.)

After setting, the plants must be watered, unless the setting out is done immediately after a rain. After watering, as soon as the water has soaked into the ground, a thin layer of dry soil is raked over the soil which has been moistened. If it is after a rain, the ground should be worked lightly to give some loose soil on top. These 


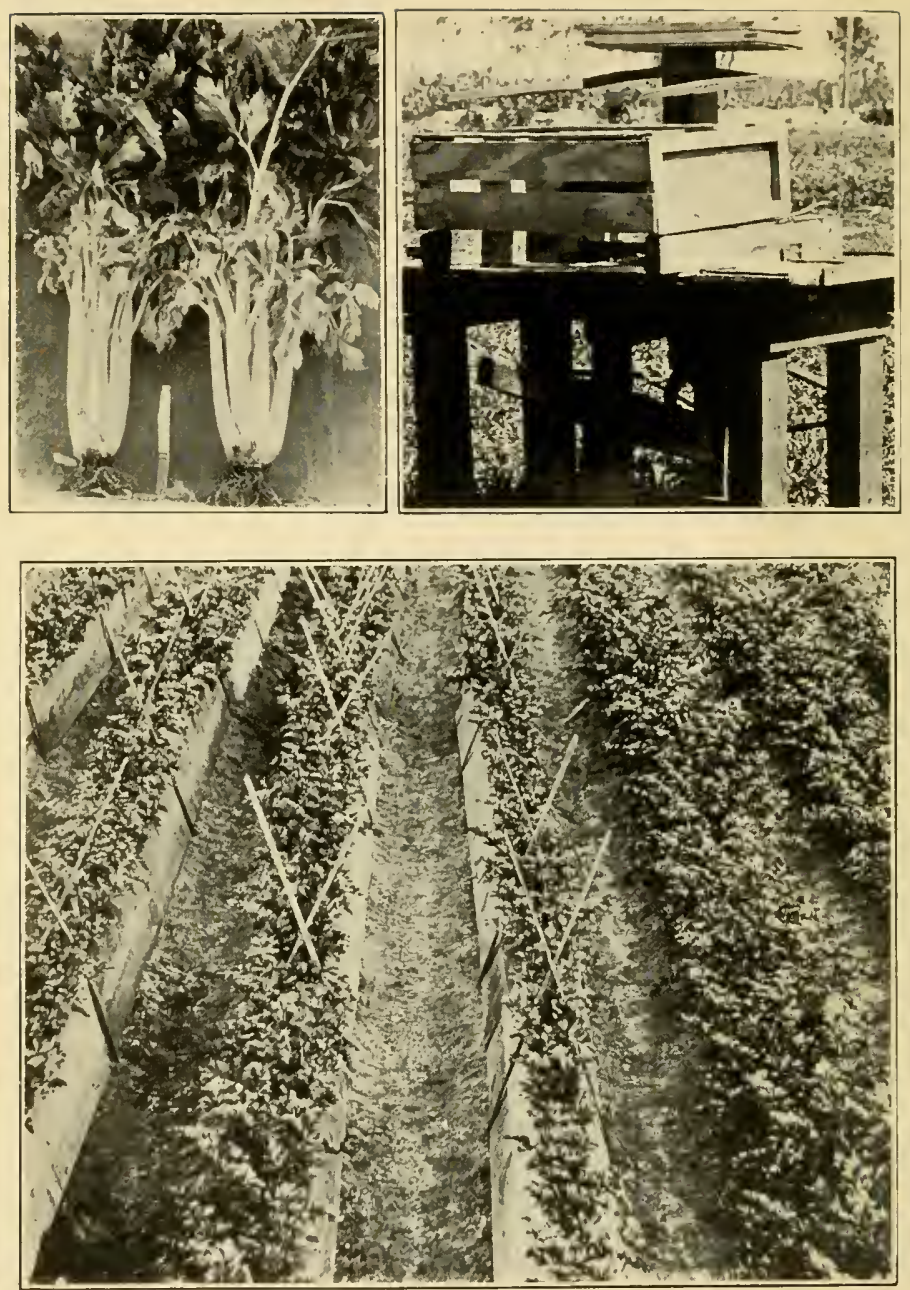

Plate Vi. - Celery.

Top left, well-grown celery plants (Golden Self-blanching); top right, foot-press, for packing celery; bottom, blanching celery by means of boards. 
directions, if followed out, will do much to conserve the moisture.

A few days before transplanting, the plants should be hardened off to lessen the shock of transplanting. After having set the plants out, they may be shaded to accustom them gradually to the field. The best device for this is an 8 - or 10-inch board placed obliquely over the row. The board is secured by stakes, which are driven on the south side of the row, slanting toward the north; by leaning a board against these, the plants will stand in the shade during the hotter part of the day, and be exposed to the sun in the evening and morning. If the plants are exposed to frost, they often run to seed prematurely.

Celery is cultivated five or six times after setting out, and the earth may be gradually drawn up to the row, keeping the foliage on top of a ridge. In the family garden, this is done with a hoe, but on celery farms special plows are used for this purpose, drawn by a team, and hilling both sides at once. This banking is for the purpose of blanching. Shutting out the light in other ways is just as good as banking or hilling, if it keeps the light out as thoroughly. Another way of blanching or bleaching that is employed extensively is to use boards in place of earth. This method has the advantage of causing less discoloration and decay. Eight- to 12-inch boards are used, according to the variety of celery to be blanched, and laid flat alongside the row on each side with one edge next to the plants; the outer edge of the boards is raised up against the plants and the lower edge moved out a few inches, the board pressed down to shut out all light from the bottom, and the work of banking is done. If there is danger of the boards falling, 
they may be fastened by nailing a light strip from one to the other. The upper edges of the boards should be pressed together firmly, but not hard enough to bruise the leaves. The boards may be staked down on each side, upright at first and slanted in later. In two or three weeks the celery will be blanched sufficiently for use.

Among other methods of blanching are those of putting drain tiles around the plants, and of wrapping them with thick paper, or covering with a paper tube; but all of these have failed to meet the wants of celery-growers.

Late in the season, or when celery has attained its full growth, it takes nearly twice as long to blanch. This should be borne in mind when celery is to be prepared for a fixed date. (See lower figure, Plate VI.)

Irrigation of celery.

In following celery culture, it may be necessary to resort to irrigation, for the water supply. This supply may be distributed in one of three ways, - either by open ditches at short intervals, by running tiles below the surface (subirrigation), or by an over-head spray.

When the water is distributed by open ditches, they are cut 3 to 4 feet apart. In watering, these are allowed to flow full until the earth is thoroughly soaked, then the water is turned into another set, and this is continued until the whole area has been treated. These ditches are shallow, only a few inches deep. On a clayey soil, they are run nearly on the level; but on sandy loam, there must be a considerable decline in order that the water may reach the further end. It requires a fall of 1 to 3 inches to 100 feet to make water run well on dry sandy soil. 
Sub-irrigation by the use of drain tiles, or other more or less solid pipes laid into the soil, is the better plan. This is especially advisable when the water supply is large and can be cheaply obtained. To make sub-irrigation a success, it is necessary that the field should have a more or less impervious substratum not more than 5 to 10 feet down, or that the water-table should stand rather near the surface. In this, as in the open ditches, there is a watermain, running from which are the arms that supply the crop. When the land is perfectly level, the lines of tile are laid at regular intervals of 12 to 60 feet. When the land is not level, they must be laid on the contour lines. This is less convenient, since the celery rows must be made parallel to the lines of tile. With a sub-irrigation system, much damage may be done by too free use of water; otherwise it is ideal. In Florida, artesian or flowing wells form a cheap and continuous source of water for irrigating celery. (See lower figure, Plate I.)

The over-head system of irrigation has been used successfully with celery in a number of places. Its main difficulty lies in the fact that it brings about conditions favorable to the propagation of leaf blights. In this system the water is supplied as a spray from small nozzles in over-head lines of pipe.

There is an extensive market for high-grade celery in the late winter and spring; that is, after the crop grown in temperate climates has become exhausted and before a new crop can be produced. The celery must be crisp and have a nutty flavor to sell well. With rapid and certain transportation, celcry can be grown in many subtropical regions to supply the large centers of population. 
Preparing celery for market.

Celery is not grown so generally in the subtropical parts of North America that the local markets are supplied. There are only a few places that produce it, and these do so in quantity. It has been only a few years since gardening for local sale has been profitable in many sections of the southern United States, and in some it is not meeting with success even now. The fault is as much that of the producer as of the buyer. There are many reasons why one should cultivate home markets.

In the matter of preparation for market, there seems to be little choice. The main requirements are to get the celery on sale in a crisp form, and to have it sightly; both ends are often overlooked, however. In the northern markets, there are two distinct ways of preparing this vegetable for market. For the local markets, it is not necessary to use any particular form of package; yet, when one intends to establish a business, some regular form of package or crate should be adopted, as it makes a trademark. The crate should be light and tasty. For longdistance shipping, the celery plants are cut with a celery cutter pushed by a man. The outer leaves are removed and the celery sorted into grades of $2 \frac{1}{2}, 3,4$, or 6 dozen to the crate. The celery is then packed flat into crates 10 by 27 by 27 inches, the root ends together, and shipped in refrigerator cars. (See Plate IV.)

Diseases.

The worst disease of the celery in Florida is that known as rust or blight. This has destroyed many acres, es- 
pecially of the late celery in March and April. The remedy is to spray the plants in the seed-bed and field with bordeaux mixture or sulfur solutions.

Black-heart and foot-rot seem to be led up to by too much moisture. They are infectious, and the fields should be well cleaned of diseased plants.

Varieties of celery.

Golden Self-blanching is the chief variety of celery in Florida. Several other varieties have been grown, such as White Plume, and Giant Pascal, but with less profit.

Bulletins.

Celery, Farmers' Bulletin 282, April, 1907.

Celery Growing in Colorado, Colo. Bulletin 144, March, 1909.

Celery, S. C. Bulletin 144, April, 1909.

\section{CHICORY}

Common chicory is grown for the roots, which are dried and used as a substitute for coffee, or as an addition to it. Other varieties are cultivated for their leaves and leafstalks. It is used largely in France and the Netherlands and to some extent in England.

The roots of chicory are used as a coffee substitute. With this product we are not here concerned, but with the leaves, which are used as a salad product.

The usual garden soil will be found sufficiently rich for this plant, and will need little care in the way of prepara- 
tion. The rows should be prepared in a way similar to that for parsnips and other root crops. The seeds are sown in early spring for late spring or summer crop. By sowing in February, the crop will be ready for use in April or May. Less time will be required for the late summer crop to mature.

The cultivation is simple, merely enough to keep the weeds down, and the ground somewhat loose. Deep cultivation will be found advantageous. A week or ten days before the leaves are wanted for use, some soil should be worked up to the plant to blanch the stalks and leaves. As soon as these are well blanched, they may be taken to the kitchen and cooked or prepared as salad. For winter chicory, the seed should be sown during August or September. It will be necessary to protect it during the summer rains, and also from the hot fall sun. As soon as cold weather comes, the soil may be banked up around it to blanch the leaves, or the leaves may be removed entirely and a mound may be made over the row. In a short time the leaves will force their way through the mound, and the stalks will be blanched and ready for use as salad. Two or three crops may be gathered from strong roots.

Another way to secure well blanched chicory will be to remove the roots from the soil during December and place them in a deep box, working some garden soil among them at the same time. About eight or ten strong roots should be placed to the square foot of box. The box should be about a foot higher than the crown of these plants. By applying a gentle bottom heat, new leaves will be thrown out rapidly, and as soon as these reach a length of eight 
or ten inches they will be ready for use, provided the box has been covered to keep the light out.

\section{PARSLEY}

Parsley can be grown well in Florida, Louisiana, the West Indies, and in India, especially if slightly shaded, as by a roof of slats. This hardy umbellifer is a native of the Mediterranean countries, and has been cultivated for about a thousand years.

The seeds may be sown at almost any time in frostless countries, and leaves ready for picking are produced in less than three months.

Parsley is so easily grown that no garden need be without it, and yet it is rather scarce, especially in the southern markets. Its production scarcely reaches the dignity of a crop, though around New York and Chicago, the entire amount would cover some acres. The Germans use both roots and leaves as flavoring; while Americans use only the leaves, and these mainly as a garnishing.

The seed of parsley is reckoned good if 76 per cent germinates. One ounce of seed is sufficient for 150 feet of drill. It may be sown in Florida in November. Since the seeds often germinate slowly, it is sometimes well to soak them for a day in water and sow them with sand. The drills are a foot apart and $\frac{1}{4}$ inch deep, and the seedlings thinned out to 4 to 6 inches. In case the weather is dry, it may be best to sow the seeds in a seed-bed, where they can be kept damp and shaded for three or four weeks until they have germinated. A good plan and a useful one, is to sow the seed in a broad border row around a flower- 
bed ; this remains green during the severest weather. For this purpose the seed should be sown about the first of November, or in regions north of the lower Gulf region, about the first of October. As the plants grow larger they should be thinned out, so as to have from four to nine plants to the square foot. If the flower-stalks are cut down early, the yield of leaves is prolonged.

Parsley can scarcely be over-fertilized by using manure. If commercial fertilizer is used, an abundance of cottonseed meal should be given as a source of nitrogen. The general directions for fertilizing and the amounts given for parsnips will be found useful for this crop.

Parsley readily produces seed in six months or so after sowing. The plants left for seed should be selected for their leaves and allowed a space of $1 \frac{1}{2}$ feet apart. The seed stalks are dried when the seed is mature and the seed threshed out.

The Plain-leaved variety of parsley is most used for flavoring soups, fish, and the like. The Creole Plainleaved has long been acclimatized in Louisiana. For garnishing, the Moss Curled and the Extra Curled will be found desirable. The variety known as Hamburg or Turnip-rooted has a large root, which is the part used in flavoring or in salads.

\section{CRESS}

Of cresses there are several very different kinds or groups, all belonging to the mustard family. We may here treat only three, as the others are little grown. These three are the common garden cress, Lepidium sativum; the upland 
cress, Barbarea vulgaris and B. procox; and the watercress, Radicula Nasturtium-aquaticum.

Garden cress.

Garden cress is a plant of long cultivation in Asia and Europe, and is used in salads. It produces leaves fit for use in about a month and a half. The leaves are only of use when tender. It may be sown broadcast and thinly, and may be grown in the tropics during the cool season. In England it is often used for salads when the first true leaves are very young; in which case it may be sown thickly in pans or boxes at almost any time of the year, and from the Arctic to the equator. There are varieties with curled and plain leaves.

Upland cress.

Upland cress is an American wild cress (Barbarea) and takes rather longer to grow than the garden cress. It is used in salads and much like water-cress. It is grown in the cool season.

Water-cress.

Water-cress can be grown readily in cool spring water in tropical countries, and may be met with in the West Indies along the banks of the streams. It is not advisable, however, in the tropics, to grow this plant in any water except that which is fit to drink. The best place for planting water-cress is some running stream that has a firm or more or less solid bottom and is supplied by a spring. A small stream that is subject to floods during the rainy weather will not be suitable, as the plants are liable to be 
washed away. A single spring will provide a sufficient area to supply all the cress that a family will want to use. If more is needed, beds may be excavated just below the level of the stream, planted and then flooded. The sowing is very simple; it amounts to nothing but dropping the seed in a moist place. The best time for this is during September, October, or November. A ten-cent package will yield all the cress that several families will care to use. After a little patch is once established it will continue to produce this vegetable for several years, but sooner or later, from various reasons, it will have to be sown or replanted. There is no extensive market for this product, and yet there are hundreds of families in the South who would be glad to have it. All that is necessary in preparing it for the table is to see that the branches that have been cut off are thoroughly washed and freed from dirt. It is usually eaten with salt. It is excellent when prepared as salad. Water-cress is sold to a large extent during the cool months in the large cities of the United States and Europe. The best English water-cress is grown in spring water coming directly from underground, so that it is warm in the winter.

\section{ASPARAGUS}

The edible shoots, which form this vegetable, sprout up in quantities only after the plants have been resting during the cold season; thus in regions where there is no cold, but only a cool season, asparagus does not flourish. Thus, in India, asparagus can only be grown fairly well on the mountains, some thousands of feet high. Asparagus does 
not do well in the greater part of Florida, though it is grown to some extent in other southern states, and extensively in California. In the states where it is grown for the New York markets, it is not uncommon to spend from $\$ 300$ to $\$ 600$ an acre for fertilizer. Manure from the large cities is employed to a considerable extent, and chemical fertilizer may be used with profit. Asparagus will not succeed without proper attention being given to cultivation and fertilization, although the idea has sometimes become current that it will do well under any treatment, and that no attention is required except to gather the crop. It may be grown for home use, to a limited extent, as far south as central Florida.

In selecting the field it should be moist and yet not wet; a water-soaked piece will not grow this crop. While it wants an abundance of mojsture, the soil must not be sour. Wet land that has been drained often makes the best plots.

Preparation of the asparagus plot.

Deep plowing, to loosen up the subsoil, is the first act after the plot has been drained. Among the best growers, the opinion is held that it is difficult to make the land too rich, or have it too well prepared. The roots penetrate the soil deeply and widely, as asparagus is a gross feeder. The fertilizer usually employed contains much organic matter, such as compost and rakings from yards; this is mixed thoroughly with the soil, and is often applied before the plants are set out. After they have started, a top dressing of potash and phosphoric acid is given. When the plantation is made a considerable distance from 
the sea coast, it is customary to give a heavy application of salt; this may be applied without injury at the rate of two pounds to the square yard. The application of salt seems to do benefit chiefly by keeping down weeds, and where the cost of salt is less than the cost of cultivation it may pay to apply it.

Fertilizer for asparagus.

The proportion of fertilizer ingredients for asparagus should be as follows: ammonia, 5 per cent; available phosphoric acid, 7 per cent; potash, 5 per cent. Use 1500 pounds to the acre. When possible, 20 to 40 tons of vegetable material should be applied, such as partially rotted rakings, or barnyard manure. When such vegetable matter is procurable, the quantity of nitrogen may be decreased proportionately. If manure is procurable, allowance may be made for the fertilizer elements contained therein. Ten thousand pounds of asparagus (edible part) contained 21 pounds nitrogen, 10 pounds phosphoric acid, and 26 pounds potash.

The following table indicates the amounts of different fertilizing materials necessary to give the desired quantity of each element:

Pounds to the ACre

Ammonia . . . $\left\{\begin{array}{l}800 \text { to } 1000 \text { cottonseed meal; or } \\ 350 \text { to } 400 \text { nitrate of soda; or } \\ 275 \text { to } 300 \text { sulfate of ammonia; or } \\ 400 \text { to } 600 \text { dried blood. }\end{array}\right.$

Phosphoric acid . . . 750 to 1000 acid phosphate.

Potash . . . $\left\{\begin{array}{l}300 \text { to } 500 \text { kainit; or } \\ 150 \text { muriate of potash; or } \\ 150 \text { sulfate of potash, high-grade; or } \\ 250 \text { to } 300 \text { sulfate of potash, low-grade. }\end{array}\right.$ 
Planting asparagus.

The quickest way to make a beginning in asparagus growing is to buy several hundred or a thousand roots from a seedsman. These are not expensive, and will make a fair test as to whether it will be desirable or not to go into growing asparagus as a business. It is agreed that the cheapest and best way to raise asparagus is to sow the seed in a seed-bed, cultivate for one year, and plant out in the field next spring. One-year-old plants, if well grown, as they would be if at all cared for during the long growing season of the South, - are universally preferred to twoyear-old roots for planting out. Rows 3 feet apart should be laid off and the plants set a foot to 18 inches apart in a row. During the first year the field should be well worked and no weeds allowed to get a start. The second year, less cultivation will do. A top-dressing of fertilizer is applied to an asparagus field every spring.

\section{Cutting.}

While asparagus plants will be found to give a few stems one year from transplanting, it is better practice to let them grow up, and to cut only sparingly in the second year. In gathering, care should be taken to leave some strong shoots to form a leaf system for the plant. In cutting, a little of the soil is removed, and the asparagus knife is then pushed down carefully so as not to injure any of the stems that are just beginning to grow up. A slight twist of the knife will separate the stem from the root.

The green tops are afterwards allowed to grow, so as 
to store up food in the roots for next year's crop of shoots. If cutting goes on too long, the next crop will be small.

\section{Bunching and crating asparagus.}

The stems are usually cut when they are about 6 inches above the ground, and since they are cut 3 or 4 inches below the ground, the shoots are 9 or 10 inches long. The stems are laid into some kind of contrivance, either home-made or bought, that will keep them straight and keep the tips even. A simple buncher is made by using a board 8 by 12 inches; to one end of this a thin board 8 by 8 inches is nailed; three or four U-shaped iron straps are nailed on to the 8 - by 12 -inch piece, so that they will be parallel to the 8- by 8 -inch board, and when the asparagus is laid into these the heads will abut against the board. This 8- by 8-inch board will keep the heads even, and the U-shaped straps make the bunch round. Strings of raffia or soft cord are laid across the buncher, and when enough of the vegetable to make a bunch has been added, the whole is tied tightly. Then with a sharp knife the butts are cut square, and the work is done. A handier buncher may be obtained from dealers in garden implements at a small cost. Such a buncher will be found profitable when much asparagus is to be prepared for market.

\section{Marketing.}

A carrier for shipping to a distant market must be either a half-crate or one divided so as to hold one tier of bunches in a compartment. Some soft moist material, as moss or grass is placed in the bottom, and the bunches set upright on this; a layer of the same soft material is then put on 
and the wooden cover fixed over the tier. Another tier may be put above in the same manner. These crates must be sent to the market right side up. Care must be taken not to bruise or otherwise mutilate the stems, as this is likely to cause them to rot in transit.

Blanching.

Often an asparagus plot is not cultivated, but this may be done with profit. It too often happens that the asparagus plants are allowed to drop their seed. The seedlings spring up between the rows and obliterate them, and also crowd the plants, making the stalks come up slender and too small for market. If all seed-stalks are cut off before the berries are half grown, this difficulty will be obviated. To blanch the product, a furrow is thrown upon the rows from each side and raked level. By so doing the plants are buried several inches deeper than they grew. The light being excluded from the growing shoot, no chlorophyll forms until the tip bursts through the soil, when the cutting should be done. After the winter frosts have killed the plants to the ground, the tops may be removed and composted, and the bed raked, to be ready for early spring cutting. While our markets do not call for blanched asparagus, the blanched articles will sell first when both are on the same market and offered for the same price, indicating that there is a decided preference for the blanched vegetable.

Raising asparagus plants.

In summer, certain of the stalks produce flowers, and later, seed; this is in small berries about the size of peas. 
Only about half of the asparagus plants produce berries, the others having barren or staminate flowers. It has been found that the plants with the barren flowers produce more and better shoots. When the berries are ripe they turn a bright red, and in a short time are liable to fall from the plant. When the seed is desired, it will be necessary to collect the stems bearing the berries for storing. As stated before, if one does not want to save the seed, all plants bearing green berries should be cut off to keep the bed from being crowded by seedlings that would spring up from these seeds if allowed to fall. Another way of getting the seed is to go into the field and strip off the ripe berries by hand. If the plants are cut to obtain the seed, they should be dried, when the berries may be beaten off on a cloth. The seed is so common that there is no sale for it.

For sowing seed, a rich piece of land should be prepared by plowing deeply, and laying off rows about 20 inches apart; the seeds are dropped about an inch apart in a drill and covered an inch deep. When the plants are about 4 or 5 inches high, thin out to one in 4 or 5 inches.

Canning asparagus.

Much of the asparagus used in the South has been canned. The operation is similar to that for other vegetables or fruit. (See Farmers' Bulletin 359 of the U. S. Dept. of Agric.)

\section{Enemies.}

The two chief enemies of asparagus are the asparagus rust and the asparagus beetle. 
The asparagus rust was epidemic in the Atlantic States in 1896 and subsequent years, and caused the transfer of the canning industry to California. The rust reached South Carolina in 1897, and spread to California in 1901. The summer-rust is red and the fall-rust black. The disease affects the tops, and if left uncontrolled finally ruins the crop. It may be stopped by spraying with sulfur and alkali, and by preventing all volunteer or other growths of asparagus until cutting is over.

The blue asparagus beetle and its larvæ work on the shoots first and then on the tops. In 1862 and subsequent years they were epidemic in New York, and some plantations were abandoned in consequence. In 1908 these beetles were found on asparagus in North Carolina. They can easily be kept in check by the application of paris green or arsenate of lead to the tops after cutting is over. The larvæ of the spotted asparagus beetle live in the berries.

Varieties of asparagus.

Connover's Colossal and its related varieties, as Giant Brunswick, are liable to much damage from rust, though they are the best for canning. Palmetto and Argenteuil give far better yields when rust is present. The variation in the different varieties is probably less than in most vegetables. The same variety under different treatment often varies more than different varieties under similar treatment.

Bulletins.

Asparagus Culture, Farmers' Bulletin 61, 1897.

Experiments with Asparagus, N. J. Bulletin 173, 1904. 
Asparagus in California, Cal. Bulletin 165, 1905.

Asparagus and Salt, Ark. Bulletin 86, 1905.

Asparagus Rust Control, Cal. Bulletin 172, 1906.

\section{GLOBE ARTICHOKE}

The globe artichoke (Cynara Scolymus) is native of the country about the Mediterranean. It is a favorite vegetable in France and other parts of Europe. It is well suited to subtropical regions, and is cultivated in India in the cool season, plants from acclimated seed yielding heads even at Calcutta. Its huge flower-heads are cooked and eaten, like asparagus, before the blue florets show, the unopened florets being first removed. This cultivated thistle should not be confused with the Jerusalem artichoke, which is a sunflower.

The seed may be obtained from American houses, but it comes from Europe. The soil and climate of the southern states are much like those of France, and good artichokes can be grown in the South. The Large Green Globe is one of the best varieties.

For growing globe artichoke, a rich soil should be prepared in the ordinary way to the depth of 8 or 10 inches. The seed is sown in rows 3 or 4 feet apart, and the plants thinned to 3 feet apart in the row. When artichokes are grown regularly, sets can be used instead of seeds. The soil must be moist and well drained. During hot, dry weather it may be necessary to supply water so that the young plants may become well established.

The cultivation should be thorough and deep; the roots strike well downward, so there is little danger of mutilating 
them. A liberal supply of asparagus fertilizer should be used. The first year a few heads may be produced; and in the second and following years the regular crop will come in. Care must be taken to remove all heads as they become fit, for to allow any to go to seed will degenerate the plant rapidly. As soon as all the heads have been taken, the stem should be cut close to the ground. These heads will stand shipping to distant markets if the crate is not open enough to allow them to wilt.

Only a certain number of the plants raised from seed are good artichokes, consequently seeds should be used only to start the crop and then the field perpetuated from suckers. All plants in the patch that do not produce good artichokes should be destroyed, and suckers taken only from the best plants. In removing suckers from the old plants, care should be taken that each one has roots, else they may fail to grow.

In the northern part of the southern United States, it will be necessary to protect the field with a deep coat of mulch in winter; this will also be found to be of advantage in the southern part. 


\section{CHAPTER XII}

\section{VEGETABLES WITH EDIBLE BULBS}

The plants herein discussed all belong to the genus Allium, of the lily family. They are the onion tribes, comprising, aside from onions, the leek, shallot, chive, and garlic. They are hardy plants, withstanding considerable frost although growing well in subtropical regions. The seed is mostly slow to germinate.

\section{ONION}

Varieties of onion, especially the Bermuda onion, are grown in subtropical and tropical lands during the cool season. The onion requires a dry period to ripen its bulbs, and this dry period comes, north of the equatorial belt, at the beginning of the year. Onions in hot countries grow best from acclimated seed, the seed of the famous Bermuda onion being chiefly grown in the tropical island of Teneriffe. In tropical India, large onions are grown from acclimated seed around Calcutta. In the West India islands, Bermuda onions are grown to some extent; and there are many acres of this variety in Texas and California. Of all the crops grown, there is none that requires more attention to the preparation of the land previous to planting than docs the onion. 


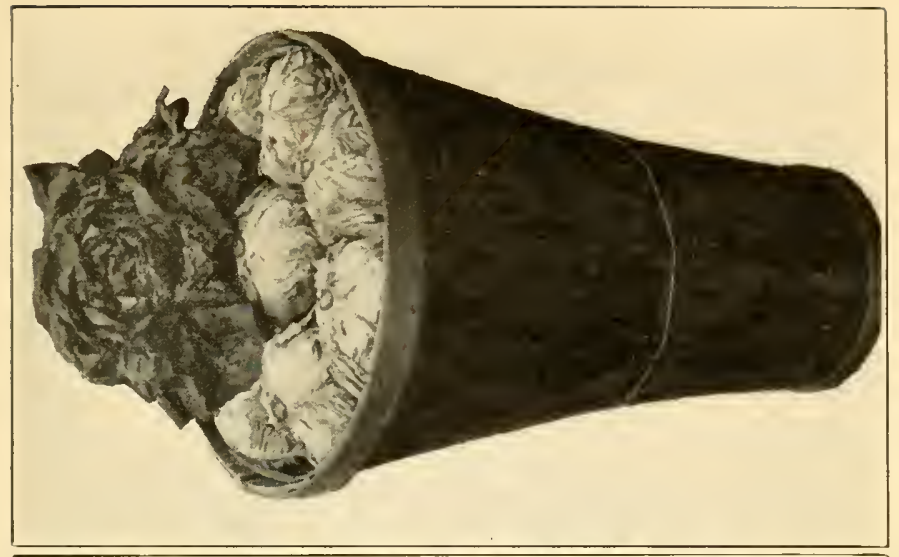

ב
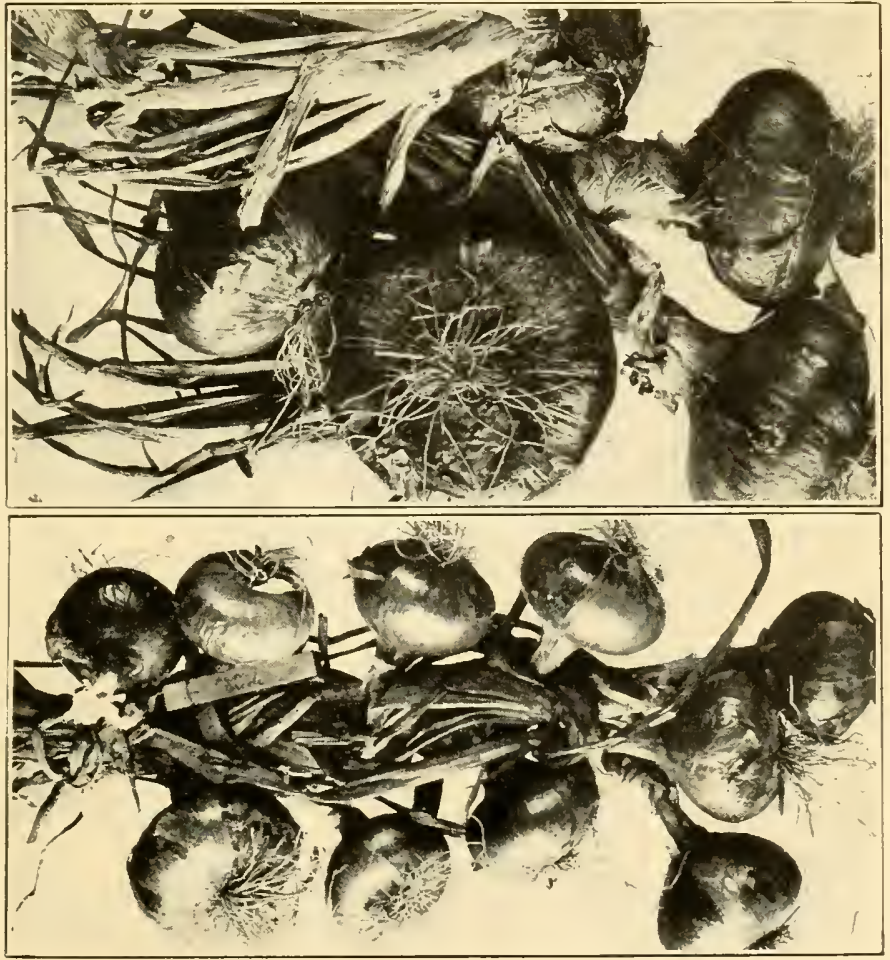

Soil for the onion.

A sandy loam, with a clay subsoil, will give excellent returns, provided there is an abundance of humus or other nitrogenous matter present. Humus may be supplied by turning under leguminous crops. The roots of the onion do not enter the soil deeply, so they are easily affected by changes in the upper stratum. A rotation should be practiced by changes in the upper stratum, or the land may become infested with diseases.

In selecting a plot of land, one should be sure to choose one that does not become soggy in wet weather, nor dry during a drought. One should not go into onion-raising on land not adapted to the crop nor as a temporary employment. Where it is possible to have an artesian well or other constant supply of water, it will be found profitable to irrigate. The land should be well drained, putting the tile drains close together, so as to remove the surplus water quickly.

The land should be plowerl shallow but thoroughly, leaving no particle unturned. All roots or sticks or other débris should be removed before plowing, and again after plowing; the land should then be harrowed thoroughly, removing all sticks or straw; even the roots of last year's grass should be removed. After the land has been thus thoroughly prepared, it should be allowed to remain two weeks or so before fertilizing, when it should be stirred again.

Fertilizer for onions.

Good compost or well-rotted barnyard manure will be found excellent for fertilizing onions. Whatever kind 
is used, it must be sure to contain no weed seeds. It should be applied several weeks before setting out the onions. If both home-made and commercial fertilizer are to be used, the former is plowed in, and after the land has been well worked down, the latter is spread broadcast, and mixed about two weeks before planting time with the soil by using a cutaway harrow. In using fertilizer, "Put on all you think the land can stand, then put on as much more, and you will have about half enough." The proportions should be : ammonia, 6 per cent; available phosphoric acid, 6 per cent; potash, 9 per cent. Use a ton of the above on land that is considered fertile enough for an ordinary crop; two tons may be applied on land that has been cropped for several years. The following table will give the amounts of fertilizer material necessary:

Pounds to the Acre

Ammonia . $\quad\left\{\begin{array}{l}1600 \text { to } 3000 \text { cottonseed meal; or } \\ 700 \text { to } 1400 \text { nitrate of soda; or } \\ 1000 \text { to } 2000 \text { dried blood; or } \\ 500 \text { to } 1000 \text { sulfate of ammonia. }\end{array}\right.$

Phosphoric acid . . 1200 to 2400 acid phosphate.

Potash . . . $\left\{\begin{array}{l}2200 \text { to } 4400 \text { kainit; or } \\ 360 \text { to } 720 \text { muriate of potash; or } \\ 350 \text { to } 700 \text { high-grade sulfate of potash; or } \\ 700 \text { to } 1400 \text { low-grade sulfate of potash. }\end{array}\right.$

Seed.

The Bermuda onion is recommended as being the best variety for a crop in tropical and subtropical regions. The best seed is grown in Teneriffe, and this should be used. 
This is a very important point in the success of oniongrowing. There is probably no other crop in which so much depends on obtaining a good strain of seed. It is not profitable to use old seed. It deteriorates quickly, especially in a warm climate, and should usually be tested before using.

\section{Time to sow onion seed.}

As in the case of potatoes, one should watch the northern markets and crops. If onions are selling at a very low price in the fall, it is clearly not wise to plant a large crop for early spring, but seeding time should be delayed for a month or two. A good crop never fails to bring a fair return; it is unusual to sell any portion of the onion crop in the southern United States for less than a dollar a bushel.

The seed may be sown in the Gulf region, any time from the first of September to the first of January. The last date would bring the onions into competition with the crops raised in the section just north, but the price is not low enough usually to make the crop cease to be profitable. October is a favorite date, and one that brings the onions into market after the stored crop has been consumed. Immediately after the seed has been sown in the coldframe or seed-bed, the preparation of the field should be commenced.

Seed-bed for onions.

The seed should be sown in seed-beds or coldframes, prepared with special care. This will require 3 to 4 pounds of 
seed for each acre to be planted. These beds may be prepared a month or so beforehand, and should be worked over frequently to get the fertilizer incorporated into the soil. They must be constructed so that the moisture in them can be controlled.

If the seed-bed is free from weed seed, as it should be, the rows may be made about 3 inches apart, and the seed sown thick enough to raise about 3000 plants to one linear foot ( 6 square feet) of standard coldframe. This will give 500 to 750 plants to a row 6 feet long. There is considerable variation in the number of plants that can be produced from an ounce of seed; good gardeners are able to produce about 5000 . When the seed-bed is cared for properly, it will give plants in six weeks that are large enough to be set out. They should be set out before they are as large as a thin lead-pencil.

\section{Setting out onions.}

The most expensive operation in the growing of onions in this way is the setting out. This will be found to cost up to $\$ 40$ an acre in Florida. Boys and girls will set out 2000 to 3000 a day, while a good man can set 4000 to 5000 ; and as it takes 160,000 plants to an acre, it will be seen that it is no small task. It is claimed by persons who have set out several acres that they can do so at the cost of $\$ 20$ an acre. In Texas it costs $\$ 15$ to $\$ 25$ an acre. Persons who are not familiar with onion-growing will consider that cost an almost insurmountable obstacle; but when it is remembered that it does away with the early weeding and hoeing, the expense will not be so heavy as is first supposed. Twenty dollars is not sufficient to bring an 
acre of onions to four weeks old by the old method, and have the field free from weeds.

After the seedlings have grown large enough in the seedbed to be handled easily, they should be transplanted into the field. The rows should be marked off about 12 inches apart, if they are to be worked by hand ; if by horse power, the rows must be from 20 to 24 inches apart. A simple rake-like contrivance that has teeth at proper intervals will serve the purpose of a marker. If the marker is wide enough to mark out six or eight rows at once, it will be found steadier than a small one. All that is necessary is to make a mark for a guide, the lines or marks need not be deep or broad. A revolving marker may be made by fastening a thin rope around a wooden roller and inserting pegs at proper intervals in the circumference; it will lay off distances and be a good guide in planting. If the pegs have been put so they will make a dot every 12 inches in the row, all that is necessary is to set a plant on each dot, and then put three between. These dots are especially desirable if one has boys and girls at work. In Texas a sectional roller is used which marks several rows at once, and has conical pins which form the holes in which the plants are to be set.

For setting the plants, a small flat dibber is used; a home-made one will serve the purpose well. A piece of seasoned hard wood, 1 inch square and 6 inches long, should be shaved down to a flat point, and a handle fixed across the top. Such a tool can be made easily and quickly, or one may have steel ones made by a blacksmith ; these will be found better, but where a good many hands are being worked, the expense will be worth considering. 
To set the plant, the dibber is inserted on the line and pressed away from the planter; the plants are set in with the other hand; the dibber is then removed, and set in the ground just beyond, and the soil pressed firmly to the plant. This operation insures that the soil will be pressed firmly about the roots. The plants must be set perpendicularly, or an ill-shaped onion will result. When one has many hands at work, they should be divided into squads, each placed under a careful foreman, who should see that the work is done properly and keep the planters supplied with sets.

The seedlings may be removed from the seed-bed by passing a trowel under the row and lifting a number of them at once; then separate them from the soil and trim off the long roots and leaves. The leaves are in the way of later cultivation, and the roots bother in planting.

If the young onion plants do not start off readily, and the conditions of temperature and moisture are correct, a light dressing of nitrate of soda will be found valuable. One grower advises the use of 75 pounds of nitrate of soda to the acre. An application is made as soon as the field has been set out; and a repetition of this is made about every ten days, until five applications have been given. If this is done when the plants are free from dew and rain, there will be no difficulty from scalding the foliage. It should not be carried on too long, as it will keep the onions growing after they should have ripened; this same diffculty will be experienced if one uses a fertilizer containing an unusual amount of nitrogen, or if one uses a complete fertilizer on muckland. 
Cultivation of onions.

"Tillage is manure" is an old and true saying, but in cultivating onions one must be careful that it is done properly. There are just two points to be kept in mind; to keep the weeds down, and to conserve the moisture in the soil. The former is well understood by all gardeners, and needs but to be mentioned; the second, however, is usually overlooked; many persons recognize the value of working land during dry times, but do not know why it has the desired effect on the crops. At least an inch of loose soil should be kept on the ground as a mulch during dry times.

For hand cultivation, the single-wheel hoe is undoubtedly the best machine now on the market. Whatever tool is used, it should not penetrate the ground more than an inch, and in no case touch the bulbs of the plants.

If the field is to be cultivated by horse power, it will require a cultivator made especially for that purpose; there is no difficulty in training a horse or mule to do the work well, and a great deal of hard work can be avoided by so doing. In the onion-growing sections, the land is too costly to permit the use of a horse, and the wheel hoes are used exclusively.

The workers in the field carry a bag with them to receive any purslane or other weed that may have been missed or allowed to grow to flowering size. All these large weeds are carried to the edge of the field and thrown in heaps to rot. There are very few fields that are free enough of weed seed to grow a crop without some hand weeding; this 
should be done with a knife, that is, large weeds should not be pulled when growing in the row. For this purpose there are knives made, which may be obtained from most supply stores, but an old case-knife may be bent into good shape without costing as much. The point is turned up to lessen the danger of hacking into the onion plants as the knife is being used. The ordinary garden-hoes do not work well in the fields; a worn-out one that has been cut down to half its width, so as to leave the corners acute, will work fairly well. A sharp Dutch or thrust-hoe is also useful for weeding onions. All tools should be kept as sharp as the steel will permit; a dull hoe will soon use up more time than would pay for a new one.

The large-scale method of onion-growing.

The large-scale method of raising onions, where labor is expensive, is to sow the seed in the field where the crop is to grow. This method is followed in many oniongrowing sections. The land is prepared in the same way as for setting out. Sowing is best done by a seed drill. The drill is set so it will sow from 12 to 36 seeds to the linear foot, according to the variety and the germinating quality of the seed. The rows should be made from 15 to 20 inches apart for hand culture, and 2 to 3 feet for horse culture. In dry weather, the seed is very slow to germinate. It has been known to lie in the ground for six weeks without a perceptible change. To anticipate such a condition, one should mix radish or rape seed with the onion seed in such proportion that one of these seeds will be dropped about every foot. Radish and rape seeds spring up quickly and are easily seen. They will mark the 
rows, so that cultivation can be carried on before the onions are up. If a beating rain occurs before the onions are showing or as they are just appearing, it is liable to smother the young and tender seedlings; but by cultivating after a heavy rain, the water draws off rapidly and does less damage. Of course, this cannot be practiced on strong clay soil.

It is only in an exceptional year that onions can be grown with profit in this way on weedy land. All weeds in the middle should be kept down by the use of a hoe or a wheel hoe. The weeding, or removing of weeds from the row, is at best a slow and expensive task; often the workmen have to get down on their knees and elbows. Only competent laborers should be employed; incompetent ones are likely to disturb the seedlings, or simply pull the tops off the weeds; either of which might go without detection for a week.

\section{Curing the onion crop.}

When the larger part of the tops fall, it is a sign of their being ripe. The crop should be pulled and allowed to dry, which will take about a week of dry weather. If a rain occurs, it will be necessary to turn the bulbs, which can be done by using a garden rake with dull teeth; but rain is apt to bleach the crop and so damage the sale. This is best prevented by taking the onions to a curing shed; which simply needs a roof to keep the rain off, and possibly some movable sides for rainbreaks, to prevent a driving rain from beating in.

The tops should not be removed until they are dry, when they break easily and can be stripped off without difficulty. 
It is usually better to push the crop forward as early as possible. The maturing may be hastened somewhat by knocking the tops over.

As soon as the roots loosen their hold on the ground, the onions may be pulled, as there is some danger of their making a second start if the season is rainy. In such a case they must be drawn out and cured quickly. In a dry storing room, onions may be kept for a long time, in order to await a favorable market.

\section{Crating onions.}

It is not necessary to use a fine material to make onion crates; the poorer quality left from sorting tomato crates will be found to bring as good a price as the finer ones. In packing, the crates should be well filled to prevent the onions from being bruised, as they rot down very quickly. All culls should be removed from the field, and composted, to prevent them from drawing insects and growing fungi.

Raising onions from sets.

The earliest onions to mature in the North are those raised from sets or small bulbs. The operation differs from the transplanting of young onions only in that the sets are in a dormant state and are handled more easily. The general directions remain the same.

\section{Varieties.}

The only onion mentioned in the previous pages is the Bermuda, but it should not be understood that this is the only one worthy of trial. It grows to a very large size 
and develops early. Its mild flavor and clear white color make it a favorite on the table. The seed is high priced, and much spurious material is on the market every year; therefore, one should buy only of reliable seedsmen. It should not be understood that all true Bermudas are white, as there is also a red kind on the market. The Bermudas have given the best results in Florida. When the seed is sown late in the fall in northern climates, the tops die down while the bulbs are still small. In this way sets are obtained. These sets may be used in place of seed, but will be found much more expensive, and will probably not pay, except for home use.

The varieties recommended for subtropical culture are: White Bermuda, Crystal Wax, and Red Bermuda.

Yellow Danvers is an excellent variety which grows well from seed; of good quality and a fair shipper. The bulb is nearly round and of a brownish yellow color.

White Portugal is the leading white variety, and on account of its color, flavor, and shape, it usually commands a good price. It is not a good keeper; it will stand marketing, however.

Giant Rocca is an Italian onion which grows well in the southern United States. Red Creole (Plate VII) has been long grown in Louisiana, and is well suited to the cool season of subtropical countries. The Top or Tree onion bears bulbils in place of the seed. These bulbils are planted to produce young onions for bunching. White Multiplier is used largely for pickling. It is highly prized, because of its white color and small, plump bulbs. It is reproduced by small offsets or bulbs forming at the base of the one planted. (See Plate VII.) 
Costs in onion-growing.

The Bermuda onion is a staple vegetable, and hence never brings a fancy price, but southern vegetable-growing will not be on a settled foundation until those engaged in it are prepared to produce crops on narrow margins that will compete with other sections that are near the market. This crop brings on an average eighty cents in the field for a bushel crate. If one can be certain of a profit of ten cents a crate, the investment will be a profitable one. The expense of raising an acre of Bermuda onions is about as follows in Texas:

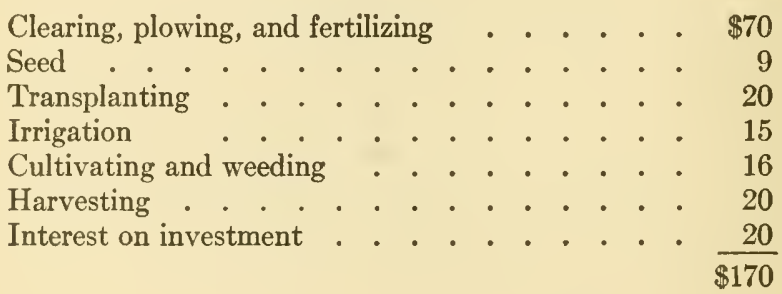

An acre should raise from 200 to 300 bushels. If, then, one is certain of eighty cents a bushel, one will have a net profit of $\$ 70$. This is 40 per cent on the money invested.

In Florida the labor is probably more expensive than in Texas.

Bulletins.

Onions and Bunch Crops, Tex. Bulletin 77, 1904.

Fertilizer Tests with Onions, Tex. Bulletin 115, 1908.

Onion Culture, Farmers' Bulletin 354, 1909. 


\section{LEEK}

The leek is very tolerant of differences of temperature. Like some other biennials, it is fitted to endure both the heat of summer and the cold of winter. Hence it may be grown with success as far north as Scotland and as far south as the outer tropics. When large and blanched it retains but little of the strong onion flavor, and has even attained the position of a national vegetable in Wales. The leek is not so popular as the onion, because it cannot be stored like onion bulbs, but for a vegetable-garden in temperate regions during the summer, or in subtropical and tropical countries during the cool season it is well worth growing. The allyl sulfide found in the onion and leek is a nerve stimulant. Leeks are cooked in the same way as onions, and the leaves are often stewed along with the blanched lower part of the plant. Leeks have been grown well in Florida, the West Indies, and India.

Leek has not been grown in the southern United States for distant markets, though it stands shipping well. There has not been a demand for it excepting at the season when the northern markets supplied it. If it is known that a certain vegetable is not in the market, persons will not demand it, but as soon as it is available, there will be a market for it.

During September, or early in October, a bed should be prepared to receive the seed. Care should be exercised not to allow the soil to become dry, as the seed may fail under such treatment. The weeds should be kept down and if the days become unusually warm, the seedlings shaded. When the plants are about 6 inches high, they 
should be taken up carefully and transplanted to the field. In taking up leeks, it is a good practice to run a spade under the row and lift the plants; then, as the soil separates, they will be removed without injury. If the leaves happen to be long, cut them back a third.

The soil should be a strong loam; if a clayey loam, it must have good drainage. The land should be fertilized heavily, and plowed thoroughly, but not deeply. Before plowing, all rubbish should have been removed from the ground. The soil should be pulverized well, and the rows laid off 18 inches or 2 feet apart, and the plants set 6 inches or a foot apart in the row.

The fertilizer material prepared for onions will also be good for this crop. Leeks can stand more nitrogenous matter and grow more slowly, hence it is advisable to use more nitrogen and to use it in a form that will not dissipate readily; such materials as barnyard manure and compost are better than the commercial forms. If commercial fertilizers are relied upon, it will be better to make several applications.

Transplanting may be done during any moist time; usually watering is not necessary; in other respects, the manipulation of transplanting is like that of onions. The plants are set 3 to 6 inches deep. They may be blanched by earthing up or boarding.

In preparing for market, the plants are dug and the outer dry leaves peeled off. If the shipment is for a near market, the plants may be washed; but if they will be four or five days in transit, it is not advisable to use water at all. They are tied in bunches of six or eight and packed in crates. 
The variety known as Large Flag has a strong lead. Mussellburgh, Carantan and Rouen are other good varieties.

The seed of leeks may be collected in the same way as that of onions.

\section{SHALLOT}

Shallot is a close relative of the onion. It is but little grown in the United States. The bulbs are like mild onions, and are used like onions for flavoring and for pickling. The shallot is not grown from seeds, but from young bulbs which arise as in the multiplier onion. It grows well in subtropical countries, and in the cool season of the tropics, and is worth growing where good onions cannot be raised. The bulbs may be obtained from European seedsmen. The culture is the same as for onion sets.

\section{CHIVE}

The chive is a native of the northern hemisphere, closely related to the onion, and is grown mainly for its leaves. They are milder and more tender than those of the onion, and are used for salads and for seasoning soups. It may be multiplied by division, from the bulblets, or from seed. Chive is not cultivated to the extent of making a crop, but it is frequently sold in northern markets as an early spring vegetable. It may be grown in tropical gardens, where it is a useful ingredient of salads. The rows are made about 18 inches apart and the plants set about 2 inches apart in the row. The leaves grow again after being cut to the ground. 


\section{GARLIC}

This strong smelling bulb is a close relative of the onion, but has flat leaves like the leek. It is used in cookery by some of the Mediterranean people, by the natives of India and of other warm countries. It is probable that it is used for the stimulating effect of the allyl sulfide, but most persons are averse to the use of such highly-odored food. Garlic was once employed as a medicine. The crop is grown from the bulblets which form around the main bulb. These can be planted out at the beginning of the cool season about 2 inches deep and 7 to 9 inches apart. When ripe, the bulbs are dried and stored like onions. In some tropical American countries, the bulbs are sold in strands made by braiding the partially dried leaves with the bulbs attached. 


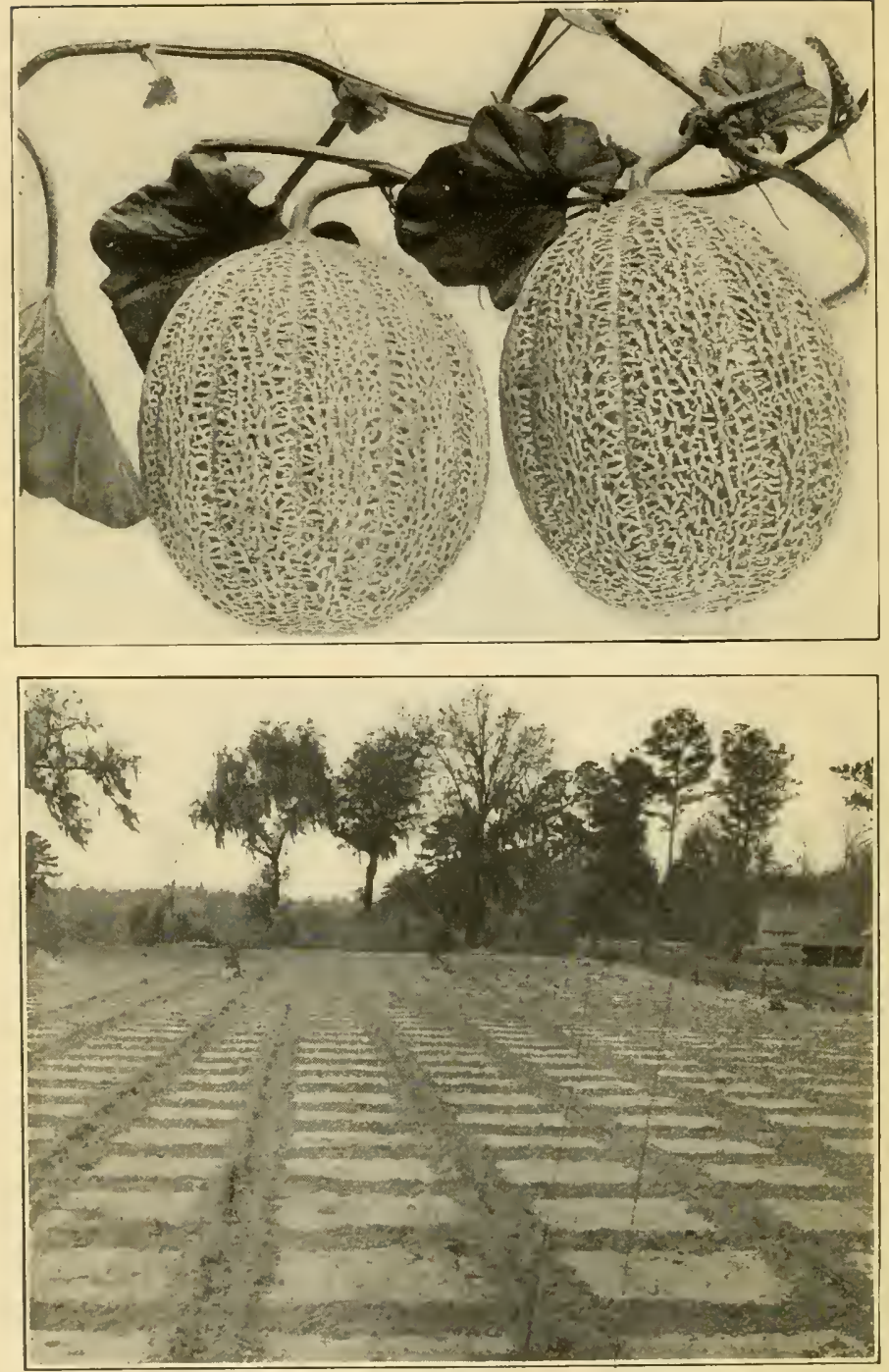

Plate VIII.- Melons.

Top, Rocky Ford muskmelon; bottom, field marked off for muskmelons. 


\section{CHAPTER XIII}

\section{VEGETABLES WITH EDIBLE FRUITS-THE CUCURBITS}

A FRUIT is a direct product of a flower. Many of the crops that we class as vegetables are really fruits. Of such are those discussed in this chapter, which are frequently called cucurbits because they belong to the Cucurbitaceæ or squash family. These are the muskmelon and cucumber, belonging to the genus Cucumis; the watermelon, of the genus Citrullus; the squash and pumpkin, of the genus Cucurbita; and the chayote, belonging to the genus Sechium. They are all warm-country plants, and will not withstand frost. The seeds are large and flat and germinate quickly.

\section{CANTALOUPE}

The muskmelon, usually called cantaloupe in the southern United States, is grown in most subtropical countries, and acclimated varieties are cultivated in the East and West Indies, and in other tropical lands. The melon succeeds very well in dry climates with irrigation. The cultivated melons came from South Asia, but many varieties have originated in the United States, where the muskmelon is now a staple crop from Florida to Illinois and Colorado. 
Soil and preparation.

The soil used for ordinary gardening will be found well adapted to this crop. While muskmelons grow well in a stiff clay soil, they are later in maturing than in warm loam.

The ordinary preparation will give good results. The land should be plowed shallow, but all turned. If it is a light, sandy loam, four furrows turned together will make a sufficient bed to plant on.

Fertilizer.

The proportions of fertilizer ingredients for cantaloupes should be as follows: ammonia, $3 \frac{1}{2}$ per cent; available phosphoric acid, 8 per cent; potash, 8 per cent. Use 1000 to 1500 pounds of the above formula to an acre. If the soil is poor in nitrogenous matter, the ammonia should be increased to 5 per cent.

The following table gives the amounts of different fertilizers that may be used to obtain as much of each element as the formula calls for:

Potnds to the ACre

Ammonia . . $\left\{\begin{array}{l}500 \text { to } 750 \text { cottonseed meal; or } \\ 300 \text { to } 450 \text { dried blood; or } \\ 225 \text { to } 350 \text { nitrate of soda; or } \\ 200 \text { to } 300 \text { sulfate of ammonia. }\end{array}\right.$

Phosphoric acid . . 800 to 1200 acid phosphate.

Potash . . $\left\{\begin{array}{l}1000 \text { to } 1500 \text { kainit; or } \\ 160 \text { to } 225 \text { muriate of potash; or } \\ 160 \text { to } 225 \text { high-grade sulfate of potash; or } \\ 300 \text { to } 450 \text { low-grade sulfate of potash. }\end{array}\right.$ 
Planting and cultivating muskmelons.

Muskmelons may be treated like cucumbers, and planted in paper pots, or veneer baskets, and then set out in the field; or the seed may be planted in the field. The rows are made 6 feet apart (Plate VIII), and the hills put from 3 to 6 feet apart in the row, according to the variety. If the land is rich, or a liberal amount of fertilizer has been used, the plants may be allowed to grow as close as a foot in the row. From four to eight seeds are dropped where a plant is desired, and when the vines begin to run they should be thinned out to one or two in a hill.

The cultivation must be shallow, but kept up constantly, and the weeds kept down.

Marketing muskmelons.

The smaller kinds are ready to pick when the stalk begins to crack. If picked too green, they never ripen. Rocky Ford melons are usually packed in standard crates 20 by 12 by 12 inches, holding 45 melons, and shipped by a refrigerator car. They may be graded according to the degree of netting, which has been found to correspond with the quality of the fruit.

Saving melon seed.

No difficulty will arise from planting muskmelons and watermelons in the same field. There is no danger of hybridizing these two species, but seed should not be saved where different varieties of muskmelons have been planted in the same field. 
The seed is saved in the same way as directed for cucumbers. It has been claimed that muskmelon seed saved in the South for several seasons is superior in more than one way to northern-grown seed.

The seed may be kept for several years under proper conditions without losing its vitality.

\section{Enemies.}

The rust of muskmelons which injures the quality of the fruit can be obviated by proper selection of varieties, and by rotation. It is readily prevented by spraying with fungicide.

The insect enemies are much the same as those of the cucumber.

Varieties of melons.

The Rocky Ford (Plate VIII) strain of Netted Gem, which is extensively grown in Colorado, is the staple variety in the northern markets. A rust-resisting race of this has been developed. Other shipping varieties are Osage, Hackensack, and Montreal Market. New Orleans Market and Augusta Market are varieties much grown in the South for local use.

\section{Bulletins.}

The Rocky Ford Cantaloupe Industry, Colo. Bulletin 108, 1906. Melon Culture, N. Mex. Bulletin 63, 1907.

Cantaloupe Breeding, Colo. Bulletin 126, 1908

Commercial Melon-Growing, Ind. Bulletin 123, 1908.

Marketing the Muskmelon, Ill. Bulletin 124, 1908.

Growing Better Gems, Ind. Bulletin 135, 1909. 


\section{WATERMELON}

The watermelon is a tropical plant, and grows well in tropical and even equatorial lands. They are grown in the southern United States to a greater extent than anywhere else in the world, and the best varieties have originated there.

Soil.

Watermelons will flourish and make an excellent crop on warm sandy soils. Heavy or soggy land should not be chosen, nor will thirsty soil produce a good crop; however, this plant has a wider range of soil than any other raised for market in the South. The profits an acre from raising watermelons are usually so small that from inferior soil they are practically nothing. Also, the early shipments, as a rule, bring good returns, while the later ones are liable to go at a loss.

The plowing should be shallow but thorough. While the roots do not penetrate deeply, they grow out for a long distance from the hill, and in no case should the fertilizer be so deeply placed as to coax the roots to an unnatural stratum.

Fertilizer for watermelons.

For watermelons, the fertilizer proportion should be as follows: ammonia, $3 \frac{1}{2}$ per cent; available phosphoric acid, 8 per cent; potash, 8 per cent. Use from 800 to 1200 pounds of this formula to the acre. If the soil is rich with nitrogenous matter, ammonia may be omitted altogether. Too much nitrogen makes overgrown melons, 
poor shippers, and an insipid product. From the foregoing, it should not be considered that fertilizer can produce a fine crop from a poor variety, but by properly balancing the fertilizer a fine crop can often be raised when otherwise it would fail.

The following table gives approximate fertilizer formulæ:

Pounds to THE ACRE

Ammonia . $\begin{cases}400 \text { to } & 600 \text { cottonseed meal; or } \\ 250 \text { to } & 350 \text { dried blood; or } \\ 175 \text { to } & 250 \text { nitrate of soda; or } \\ 150 \text { to } & 200 \text { sulfate of ammonia. }\end{cases}$

Phosphoric acid . . 650 to 900 acid phosphate.

Potash . . . $\left\{\begin{array}{l}800 \text { to } 1200 \text { kainit; or } \\ 125 \text { to } 200 \text { muriate of potash; or } \\ 125 \text { to } 200 \text { high-grade sulfate of potash; or } \\ 250 \text { to } 300 \text { low-grade sulfate of potash. }\end{array}\right.$

Planting watermelons.

The land should be laid off in checks about 6 by 6 feet and the fertilizer put in the hill. One should not deceive himself into the belief that it is sufficient to run a plow through the hill once or twice to mix the fertilizer with the soil. The melon-grower who uses commercial fertilizer must, sooner or later, learn that to mix the fertilizer thoroughly with the soil means about three times as much work as most growers usually put into it. The fertilizer should be scattered in a circle about three feet in diameter about the place where the hill is to stand, and applied a week or ten days before planting. Some successful growers now work the fertilizer in the furrow, and then turn up beds instead of hilling. 
A crop may be brought in early by using paper flowerpots and potting soil as described for cucumbers, but the pots should be a size larger than for cucumbers.

When seeds are sown in the field, they may be sown in a shorter time after fertilizing than when plants are set out. Six to twelve seeds are dropped in a hill. Insects and vermin will destroy so many that but few will have to be thinned out. Thinning to one plant is claimed to give larger melons. If cottonseed meal has been used as a source of nitrogen - and this is advisable - a teaspoonful of nitrate of soda may be scattered in the hill just after the seedlings have appeared above the ground, or when the plants are set out. This will stimulate the plants to a rapid growth, and get them out of the way of insects.

\section{Cultivating.}

All cultivation of watermelons should be shallow, merely to keep the surface mellow and free from weeds. As soon as practicable after heavy rains, the field should be cultivated; and when no rains occur, it should be cultivated every week or ten days, depending upon the kind of land. It is not necessary to till all the middles while the plants are small, though weeds should not be allowed to go to seed; but if the weather is dry, the middles must be worked to conserve the moisture in the soil, and all weeds kept down, as each one of these is a leak to so much soil moisture. The horse weeder will be very useful at this time. As the plants grow larger, the cultivation has to be pushed farther to the middles until finally the plants meet across the rows, when tillage must be discontinued. If tall weeds grow in the field after this, they should be cut off, 
not pulled, as the vines are fastened to these by their tendrils and must not be disturbed. Cowpeas may be sown broadcast at the last cultivation so as to fix the vines against wind.

\section{Marketing watermelons.}

Marketing is a simple operation, and yet many fail from various causes. Experience alone can guide one as to how ripe the crop must be to reach the market in time. In loading the car, care must be exercised to have all the product of uniform size and ripeness. The melons are then placed regularly and carefully, the long diameter being placed lengthwise of the car.

Saving seed.

Only the finest watermelon specimens, and those on vines free from disease, should be selected for seed. Melons intended for seed may be marked by scratching the rind; and as soon as the marked fruit is full grown, the other melons on those vines should be removed, so as to throw as much vitality into the seeds as possible. The melons should be allowed to become completely ripe, and then removed to the packing house. They are cut in two lengthwise and the flesh and seeds removed. The flesh is dropped into a tub, and mashed well without injuring the seeds, and placed in a warm spot. The pulp is turned into a barrel. In about forty-eight hours the material will have fermented enough to macerate the flesh; the seeds may then be removed, by washing in a No. 2 sieve. The seeds must not be allowed to remain in the barrel longer than about sixty hours, as the heat 
generated is liable to make them sprout. As soon as the seeds are washed they should be drained and dried quickly without any heat. Melon seeds have been kept for twelve years without losing vitality.

Diseases and insects.

The watermelon is subject to practically the same pests as the cucumber and the muskmelon. The profit an acre on a crop of watermelons is so small, however, that the ordinary methods of combating insects and diseases are unprofitable. On this account the grower rarely plants a crop of watermelons on the same land in successive years. The aphis may be successfully combated by using finely ground tobacco dust. The campaign must be begun immediately on discovery of the aphis, and it is best to destroy the hills in which the first attack is discovered.

Varieties of watermelon.

In choosing a variety to raise, one should be sure that the meat is solid and the rind hard and strong, if wanted for a distant market. The following varieties will be found good: Tom Watson, Kolb Gem, Florida Favorite, Augusta Rattlesnake, Lord Bacon, and Duke Jones.

For home use and local markets, much will depend on the local demands: usually, these want a small, or medium-sized melon, very sweet, with thin rind and redfleshed. The following varieties will be found to be useful: Seminole, Ice Cream, and Mountain Sweet. If the last-mentioned is desired, be sure that seed from a good strain is obtained. 
Bulletins and papers.

Watermelons, Ga. Bulletin 38, 1897.

Growing Watermelons, N. H. Bulletin 86, 1901.

Watermelon Culture in Georgia, Cyclopedia of American Horticulture, 1904.

Melon Culture, N. Mex. Bulletin 63, March, 1907.

\section{CUCUMBER}

Local kinds of cucumbers are grown in India and the West Indies. The varieties from temperate regions often suffer greatly from the attacks of beetles, but can be grown, with care, in the cool season, or on the mountains.

The cucumber has become one of the leading vegetables for the Lower South. It stands shipping to distant markets remarkably well. Where killing frosts occur, the seedlings should be started in a coldframe or in a hotbed. For every acre to be planted, 12002 -inch paper flowerpots should be procured; the same number of 4 -inch, and if very early cucumbers are wanted, the same number of 6-inch pots. Only the best seed should be used and four planted in each pot. These pots should be filled with good potting soil to within a half-inch of the top; this should be done six weeks earlier than the last frost usually occurs, if it is intended to use only the two smaller sizes of pots, but about nine weeks, if the three sizes are to be used. The cost of the pots in the former case will be less than $\$ 9$; in the latter, about $\$ 25$. There is is no doubt that one could obtain a liberal discount on these pots if a large quantity were bought at one time. If the pots are not sunk into the sand, they will last for two crops. During their growth, the plants should be 
examined frequently to see that they do not become potbound. They should be shifted to a larger pot as soon as the soil is permeated by the roots. This may be tested by removing the soil from one of the pots, which may be done easily as follows: Hold a pot upside down and press on the bottom; the soil will come out and the condition of the roots can be examined without difficulty. As soon as the roots have taken up most of the space in the pot, the plant should be shifted to a larger one.

The seeds may also be sown at once in 4-inch pots, or in strawberry baskets, and set out from these in the field. In Louisiana the early plants are often protected by single panes of glass. Soaking the seeds twenty-four hours before sowing causes quicker germination.

If the plants show any signs of yellowing, they may be restored to health by a light application of liquid manure. They should not be transferred to the field until two weeks after danger of frost is past; and if the spring is cold and backward, it is better to keep the plants under the protecting cloth. Some vegetable-raisers may object to this method as being expensive. However, it does away with the first two plowings, and the plants are further advanced, and so less subject to insect and fungus attacks. The striped cucumber beetle and aphis rarely get a start on pot-grown plants. The amount of seed required will be reduced to a minimum. The most important consideration, however, is that the first pickings will be two weeks or a month earlier than they would have been had the seed been planted in the field.

Another very successful method, and one that is employed a great deal, but is somewhat more crude, is to 
prepare a coldframe with fibrous soil and to transplant the seedlings from this. When the plants have arrived at the proper stage for setting out, they may be successfully removed from the coldframe in the following manner : Prepare from fifty to a hundred two-pound tomato or vegetable cans by throwing them in a fire to remove the top and bottom and also to unsolder the side. When one is ready to begin the operation of transplanting, this cylinder of tin is pressed firmly into the soil in such a manner as to leave the cucumber plant in the center. If the soil is fibrous and moist, the plant can now be readily lifted from the seed-bed in the cylinder of tin and transferred to the field with only slight injury. If the soil is not sufficiently fibrous to be held in the cylinder readily, a trowel may be inserted under it and thus aid in transferring the plant. Several boards large enough to hold from a dozen to two dozen such cylinders may be used to good advantage. A board should be placed so that the cylinder holding a plant can be slipped on to it readily. When the board contains a convenient number of plants, it may be removed to a cart. In the field the cylinders containing the plants are set out in the proper places, the soil firmed around them, and the cylinders drawn out; then the watering and further firming of the soil completes the operation.

Protecting cucumbers from frosts.

In some parts of the South, large areas, sometimes ten acres in extent, are put under canvas for growing lettuce during the colder part of the year. When the warmer season approaches, the canvas is no longer needed for 
protecting the lettuce. As soon as the crop of lettuce matures, cucumber seeds are planted at proper intervals in these beds. When light frosts occur in the late spring, the canvas can be readily spread to protect the cucumbers from frosts that would not injure lettuce. In this way the beds may be made to serve the double purpose of growing crops of lettuce during the colder part of the year, and when the warmer weather approaches, large yields of cucumbers will mature early in such beds. (See Plate V.)

Another way of protecting cucumbers against late frosts is illustrated in Plate I. In this V-shaped troughs are made, the primary object of these being to distribute water to the cucumber field. The sluice way and $\mathrm{V}$-shaped troughs are illustrated in Plate $I$, the sluice way to the right carrying an abundance of water, the V-shaped troughs lying beside the young cucumber plants. When a frost may be expected, it is easy to overturn the $\mathrm{V}$-shaped troughs on to the young cucumber plants and thus cause them to escape from a destructive cold spell.

Soil and preparation of the cucumber field.

A light sandy loam on a southern slope will be found admirable for cucumbers. The low flat lands or bottoms should be avoided. If a warm sandy loam is not accessible, an upland clay may be used ; this will raise as large a crop as a sandy loam, or larger, but will not be quite so early. The field should be plowed to a medium depth, turning it over well. While the cucumber is partial to the finer grades of fertilizer, it will thrive on coarser material than many other plants. Any form of decaying organic material may be utilized to advantage. The field is laid 
off in rows 6 feet apart, and the hills from 4 to 6 feet apart in the row. Two weeks before the field is to be planted, the rows and checks are laid off, and the amount of fertilizer desired is dropped and worked in the hills. If commercial or other concentrated fertilizer is to be used, it must be worked in thoroughly. The crop rarely suffers from over-fertilizing in the field, but frequently is ruined by improper fertilization.

Two weeks after fertilizing a field, it is usually safe to plant the seed or set out plants. If the seed is planted, about half a dozen should be dropped in a hill. When the plants begin to run, the hill should be reduced to two to four plants. Some of the missing hills may be supplied by lifting a part of a full hill on a hoe and setting it in place. If plants are set out, the pots are removed and the ball of earth set an inch below the surface of the ground.

\section{Fertilizer for cucumbers.}

The first application of fertilizer should be made about two weeks before the seed is sown or plants set out. Five hundred pounds of the following formula may be used on ordinary sandy loam: ammonia, 6 per cent; available phosphoric acid, 4 per cent; potash, 5 per cent.

It will be found advisable to employ a chemical in which the nitrogen is quickly available to supply one half of the ammonia. The following combination is largely used by the commercial cucumber-growers in Florida:

100 pounds nitrate of soda,

100 pounds dried blood, 17 per cent ammonia,

150 pounds acid phosphate, 14 per cent available,

50 pounds muriate of potash. 
As soon as the vines are beginning to produce the fruiting bloom and to produce runners, a second application of the following formula is made: ammonia, 3 per cent; available phosphoric acid, 4 per cent; potash, 8 per cent.

The following ingredients will give approximately the amount of plant-food contained in 500 pounds of the above formula: this is the amount to an acre usually employed.

50 pounds nitrate of soda,

50 pounds dried blood, 17 per cent ammonia,

150 pounds acid phosphate, 14 per cent available,

80 pounds muriate of potash.

This fertilizer should be applied a short distance away from the hill and scattered evenly on the ground out to a distance of three or four feet from the hill. It is worked in either by hand implements or cultivators.

If the vines are showing a lack of vigor, or a lack of healthy color, much good can be done frequently by applying from 50 to 100 pounds of nitrate of soda or nitrate of potash. This material should be applied broadcast at a time when the leaves are perfectly dry, otherwise scalding of the leaves will occur to a greater or lesser degree. If the conditions are such as to permit any of the chemical to remain lodged in the leaves, scalding is almost certain to follow.

\section{Cultivating cucumbers.}

Where the seed is sown in the field or plants from a coldframe set out, the land must be in the best of tilth. If warm dry weather follows the time of sowing, the first 
plowing may be delayed ten days; but by this time the cultivator should be used on each side of the row, and a week after this plowing the rows should be cross-plowed. If plants have been set out, the plowing should not be delayed so long. This plowing is not so much to kill out young weeds as to get air into the soil, and to conserve the moisture. If rains occur soon after planting, no time should be lost in loosening the soil; this will help to let off the surplus water besides aërating and warming the soil.

It is usually not necessary to cultivate the middles deeply oftener than twice a month, just often enough to keep the land in good condition. An implement known as a weeder and drawn by one or two horses is excellent for keeping the middles in proper tilth. As the vines grow out from the hills, the "middles" will decrease in width until finally the vines meet and plowing must be suspended. In case the vines begin to run too much, their tips should be cut off ; this will cause new laterals to be formed and the hill to grow compact. It is not good to disturb a vine, as this loosens its hold and gives the wind a chance to mutilate it. If the hill is kept compact by heading in the runners, the vines will cling to one another, and prevent any damage from their being blown about.

\section{Picking and packing.}

Cucumbers are "ripe" when the blossom end has filled out well. It is best to allow them to get as large as possible without letting the seed harden. As soon as the shell around the seed begins to harden they are no longer salable; this can be learned by testing a few. One will find 
that this will differ with the variety. If by chance some have been left too long on the vine, they should be pulled as soon as possible. A ripening cucumber saps the vitality of a vine to a remarkable degree. Culls and wormy fruits should also be removed and destroyed immediately. Sometimes culls can be sold in the local market to advantage, but it will not pay to ship them.

Cucumbers are usually shipped in special carriers. (Plate XI.) They should be picked while dry, taken to the packing house, sorted and crated. They are laid in quickly and evenly, pressed down with a lever, and the top fastened. The product should not be bruised or loose enough to shake in the crate in transit. It is necessary to pick a field three times a week. The amount that an acre will produce seems incredible to those who have not raised a full crop; while 200 or 300 crates may be considered a fair crop, yields of 600,800 , and even 900 crates to the acre, have been reported.

Saving cucumber seed.

The seed may be kept some years without serious loss of vitality, though fresh seed is preferred. If the shipping season should be short, the remainder of the crop may be allowed to ripen. Saving seed is simple, easy and profitable. The ripe cucumbers are gathered, of course only the perfectly formed ones being selected. The fruit is cut into halves lengthways, and the seed and pulp scraped out into a barrel, which may be filled half or three-fourths full but not more, as otherwise the fermenting would cause it to run over. The material is allowed to remain in the barrel from two to five days to ferment, when the 
mucilage will have disappeared from the seeds. It should be stirred once or twice a day to mix the whole thoroughly, so that the fermentation will go on evenly. As soon as the seed will wash clean, it should be removed from the barrel.

If one has a hydrant or force-pump, the work of cleaning seed can be greatly facilitated. A number 3 and a number 10 sieve should be provided beforehand for this work; these can be obtained from most hardware stores. A large tub should also be provided. This tub should be filled with water and the number 3 sieve filled with some of the pulp from the barrel immersed. While the sieve is under water, the pulp is worked about to separate the seeds; these being heavier pass through the sieve, while most of the pulp and pieces of rind are caught. When nearly all the seeds have passed through, the sieve is rinsed out and the pulp removed. The operation is repeated until a barrel of material has been worked through. Some of the pieces of pulp that passed through the sieve can be floated off by forcing water among the seed. The seed is poured into the number 10 sieve and set aside to drain. Protecting cloth will be found excellent to dry the seeds on. They may be spread out to the sun for an hour or two, and the drying completed in the shade. When the seed is thoroughly dry, the remaining heavy particles are winnowed and finally sifted out through the number 10 sieve. The seeds are then wrapped and labeled securely. It will be advisable to look out for mice and roaches as well as moisture. The seeds are wrapped in glazed paper or parchment paper and placed in a tight box. 
As stated before, this seed has great vitality; consequently it can be kept for two or three years.

Varieties.

There are many varieties of cucumber that are commendable for forcing, but for field culture none exceeds in popularity the Improved White Spine. For home use an earlier variety, such as Early Russian or Early Cluster, may be raised ; and Japanese Climbing or Telegraph are good varieties for trellising.

\section{SQUASH}

The squashes belong to at least three species. The summer squashes (of the crookneck and scallop type) are forms of Cucurbita Pepo; the field pumpkin of the North, used for stock feed and for pies, is a form of the same species. The large field squashes of the Hubbard and turban types are Cucurbita maxima. The winter squashes are mostly of the species $C$. moschata, although forms of C. maxima are good keepers. The summer squashes are probably native to America. These do not intercross with the winter squashes. Large squashes of any of the three species are usually called pumplins. Squashes of some kind are grown in several parts of the tropics, and when acclimated often give better results than the first sowing of seed grown in a colder climate.

It is thought by some persons that when watermelons and squashes, watermelons and muskmelons, watermelons and cucumbers, or any other combination of these vegetables, are planted together, they will produce hybrids, 
bees and other insects carrying the pollen. While this belief is firmly impressed on some gardeners, no botanist or horticulturist has yet been able to produce these hybrids. In no case has fruit set, but the blossoms have fallen as though not fertilized. Different varieties of squashes, however, will cross with one another freely.

Choosing the soil for squashes.

A good cucumber soil is also a good squash soil. Very rich land with but little sand in the soil is not adapted for squashes; there will be an abundance of fruit, but it will be insipid and will rot easily. A piece of well-drained sandy muckland raises heavy crops of good fruit. For shipping, the early varieties are about the only ones that pay.

Squashes have one advantage over melons and cucumbers, in that they can be grown on freshly-broken land. All that is necessary is to keep the land in a well-worked condition. It does not pay to neglect this crop.

Fertilizers.

Almost any kind of decaying organic matter will make a good manure for squashes. They respond to good treatment, however. The plants should not be allowed to exhaust the fertilizer which is in the soil in an available form, before more is applied. If the fertilizer is well balanced, there will be no trouble arising from too much being used; but care must be exercised not to use too much nitrogen. J. J. H. Gregory, who is the best authority on squash-raising in the country, applies an amount of manure that seems very large indeed, and at the close of his discussion on fertilizers he makes this pointed state- 
ment: "Catch a farmer of that class (one who fertilizes heavily) going backwards and putting on less and less manure on his ground, what a phenomenon he would be. No; the progress of all enterprising farmers is in one direction. By extra manuring, the possibilities of receiving extra paying returns are far greater in agricultural than in commercial life, as figures will readily show, though the popular belief is directly the contrary."

Of all the plants that have been discussed, squashes can best stand top-dressing in fertilizing and are best adapted to hill fertilization. A plan that has long been followed, is to dig a circle about 2 feet in diameter and a foot deep, and fill in with fertilizer together with the earth taken out; this will make a mole-hill-shaped mound when finished. The seeds are then planted on the top. This involves much unnecessary work with no advantage. A better way is to make the hills where wanted, fertilize heavily and mix well with the soil, but not stir more than 6 or 8 inches deep, as the roots are surface feeders and should not be coaxed into the soil. The second application should be made when the vines begin to run, and must be placed some distance from the hill.

Fertilizers for squashes.

The fertilizer ingredients should be in the following proportions: ammonia, 5 per cent; available phosphoric acid, 6 per cent; potash, 8 per cent. Use 1000 to 1500 pounds of the above formula to the acre. If nitrate of soda is used to supply the nitrogen, several applications will have to be given. It will be better, however, to use some less soluble form. 
The following amounts of fertilizers will give the probable desired amount of each element:

Podnds to THE ACRE

Ammonia . . $\left\{\begin{array}{l}400 \text { to } 600 \text { dried blood; or } \\ 300 \text { to } 400 \text { nitrate of soda; or } \\ 200 \text { to } 300 \text { sulfate of ammonia. }\end{array}\right.$

Phosphoric acid . 600 to 750 acid phosphate.

Potash . . $\left\{\begin{array}{l}160 \text { to } 225 \text { muriate of potash; or } \\ 160 \text { to } 225 \text { high-grade sulfate of potash; or } \\ 300 \text { to } 450 \text { low-grade sulfate of potash. }\end{array}\right.$

Planting squashes.

The hills are planted 4 by 4 or 8 by 8 feet apart, according as the plants are of the bush or running class, and the seed dropped directly in the field, about $2 \frac{1}{2}$ pounds being required for an acre. There is less danger from insects than in the case of cucumbers. It is well to drop about six seeds to the hill and when the danger from insects is past, thin out to one or two plants.

When a crop is wanted early, it can be obtained by following the directions given under the discussion of cucumbers. One should begin with a 4-inch pot, however. Some gardeners cut sods, turn them upside down, and plant seed on these in a coldframe or hotbed. This practice works very well with those who give careful attention to the growing of squashes, but with the novice, it fails oftener than it succeeds. The one important point to be kept in mind is, that the plant should never be checked in growth. 


\section{Cultivating.}

Soon after the earlier leaves appear, the squash plant seems to become weak near the ground, and is easily tossed about from one side to another by the wind, and often is broken off or at least severely bruised. This can be remedied by drawing the earth up to the plants with a hoe, but this should not be carried on so far as to make a hill for them to stand on; just enough should be drawn up to hold the plant in place.

As soon as the plants are set in the field, or as soon as the seedlings appear above the ground, the horse and plow should be set to work in the field. If the field is in good cultivation, there is not much use for a hoe; the filling referred to before can be done with a cultivator. If the season is dry, the top of the soil should be stirred often to conserve the moisture. During drought the weeds should be zealously kept down, as they cause great loss of moisture in the soil.

When the vines begin to "run" they should grow very rapidly - some have been ascertained to grow fourteen inches in twenty-four hours. Therefore the field should be kept in the best condition before this time. It is a bad practice to pick the vines up and turn them from their course; they are subsequently so easily broken by the wind that little or no fruit sets.

When land is high-priced, squashes are planted as a second crop, or at the edge of some other crop, as corn.

Marketing.

Squashes are usually marketed in barrels or boxes. While many acres of squash have been grown in the 
South, it is not a crop to be relied upon for profit. The gardeners in the North are able to store and keep their fall crop over winter, so it is late in the spring before there is a great demand for the southern-grown produce. It is a good crop, however, to raise for home markets, and is so easily grown that every farmer or gardener can have squashes for family use.

The seed does not keep its vitality as long as that of cucumbers; the best way is to test it before planting.

\section{Varieties.}

For the northern market, the summer or bush class of squashes can be planted. Early White Bush, Scallop, and early Summer Crookneck are the best sellers. The Straightneck is easier to pack than the Crookneck. Golden Custard, English Marrow, and Italian Marrow are good varieties.

For home use and home markets, the fall sorts will be the more profitable. Early Orange Marrow, Boston Marrow, Winter Crookneck, Marblehead, and Hubbard are desirable varieties.

\section{CHAYOTE}

The chayote is a Mexican relative of the squash, and is grown throughout the West Indies and the adjoining tropical mainland. It is perennial and forms a large starchy tuberous root. The vines climb many feet, and may bear each year a hundred or more fruits, weighing from a few ounces to two pounds. These fruits are pearshaped or rounded, and deeply grooved. Some varieties have a few soft spines. The color is white or green. The 


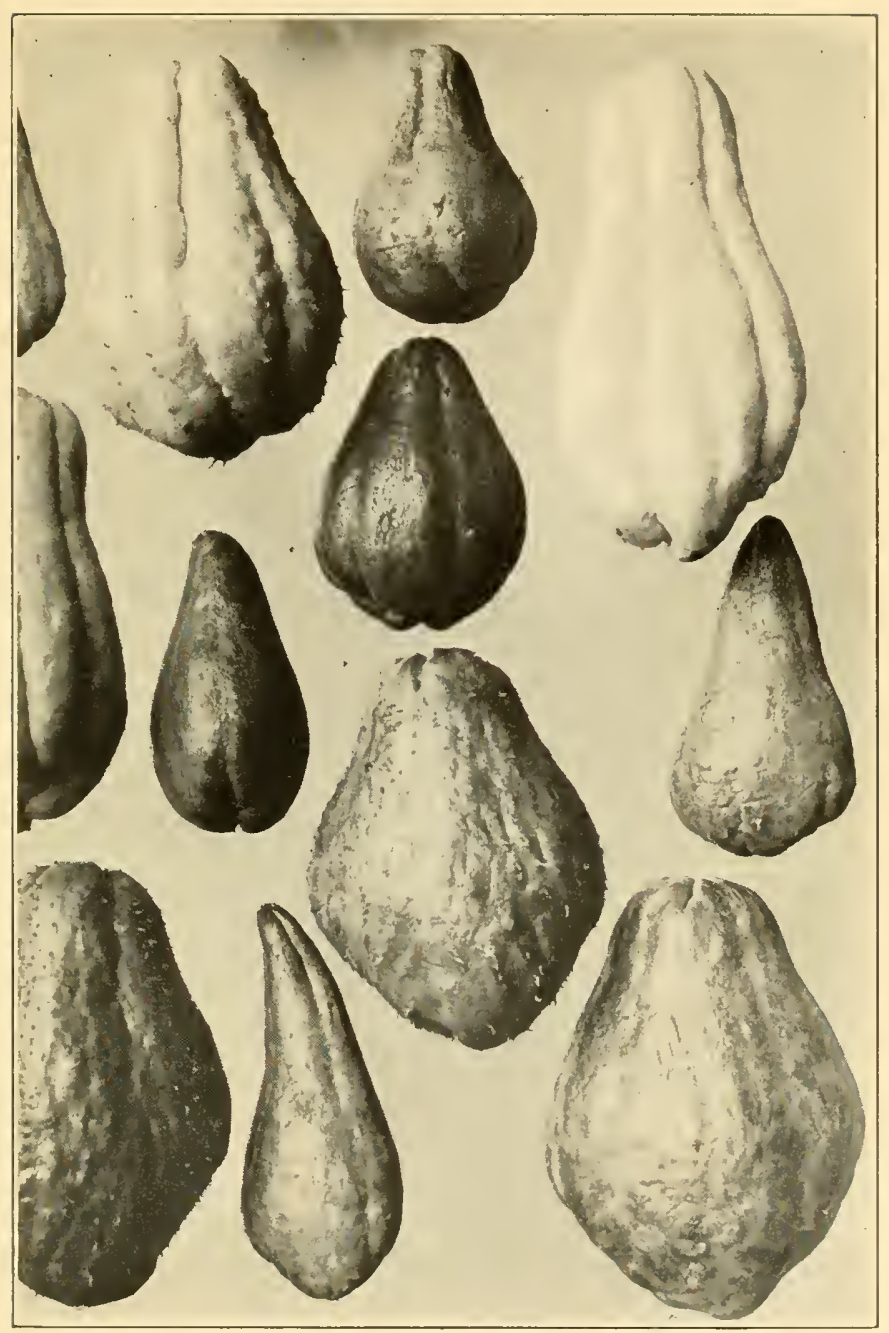

Plate IX. - Twelve Varieties of Chayote (Sechium edule). One-third Natural Size. 

flesh is firmer than that of the eggplant or squash, and is usually cooked or fried, or stewed with sugar. The chayote and the eggplant are the two green vegetables that are nearly always obtainable in the West Indies. From its perennial nature, this plant seems especially suited to the tropics, and to those parts of the subtropics where frosts are quite or nearly absent. It is one of the $\mathrm{Cu}$ curbitaceæ; the botanical name is Sechium edule. It is native to tropical America. The fruit differs from all the squash and melon tribes in having but a single seed, and this is very large. (See Plate IX.)

The chayote is indispensable in the tropical vegetable garden ; since, once planted, it requires no further care, and for several years will bear a heavy crop. It is grown for the market in several subtropical countries. Each fruit contains but one large seed, and the whole fruit is always planted in the soil, on its side and partly covered. The fruits may be planted near a trellis or fence, up which the vines can climb. They may be set out 10 or more feet apart. The plants begin to bear in three or four months. The young shoots make a good green vegetable, and the stems and leaves have been used for fodder. The white ivory-looking varieties have the best appearance in the market, though the green kinds are most frequently grown for domestic use. This vegetable stands shipping remarkably well, and is found more or less regularly in the New Orleans market. It is usually picked for home consumption before it is quite ripe.

In South Florida, where the climatic conditions appear to be favorable, the chayote is usually killed by the downy mildew before maturing a crop. By giving special atten- 
tion to protect the roots against freezing, however, fruits have been grown even as far north as Georgia.

Bulletin.

The Chayote; A Tropical Vegetable, U. S. D. A., Div. of Botany, Bulletin 28, 1901. 


\section{CHAPTER XIV}

VEGETABLES WITH EDIBLE FRUITS-SOLANACEOUS PLANTS

The plants included in this chapter all belong to the Solanaceæ or potato family. They are tomatoes, eggplants, and capsicums or peppers. All of them are warm-country plants, very susceptible to frost or cold. The seeds are rather small, and are commonly started in pots, flats, or frames. Other plants belonging to the Solanaceæ are all the nicotianas, including tobacco; also belladonna, strawberry tomato or ground cherry, pepino, tree tomato, henbane, jimson-weed, petunia.

\section{TOMATO}

This tropical American plant has been known to us for only three hundred years. The large smooth varieties have originated within the last forty years. The tomato, whose home was, apparently, on the dry west coast of South or Central America, suffers in damp weather from many fungous enemies. Hence in a moist climate, like that of Florida, the use of a spray of bordeaux mixture is often a necessity for successful tomato-growing. To produce abundant fruits, however, this plant must have a 
fair supply of water. Hence it grows well in a dry climate under irrigation. The original tomatoes had small fruits and grew upright like the Irish potato, their relative. But the larger fruits, which have been produced by selection and cultivation, weigh the branches down to the ground and necessitate the staking of the plant to keep it in an erect position.

The tomato is to-day one of the most popular of vegetables. It is grown in the open all over the world where the summer is long enough to allow the three months or more free from frost which it requires for its growth. Where the summers are too short and cool, as in England, it is grown extensively in greenhouses. It is remarkably well fitted for growth in subtropical countries during the spring and early summer and late fall. It may be easily grown in tropical lands during the cool season, especially with the help of occasional irrigation.

By planting under a slat shed, or at an elevation of a few thousand feet, it may be possible to obtain good tomatoes in many tropical localities throughout the year. This wholesome vegetable is indispensable for the tropical garden, and will, with a little care, yield fruit equal to that produced in a more temperate climate. It has sometimes been noticed, however, that the seed saved in hot countries, especially from volunteer plants, is degenerate; but this may be the result of careless selection. To avoid such degeneration, the tomato has been reproduced in the West Indies from year to year by cuttings only. A well-drained soil, judicious irrigation, and mulching in dry weather, trellising and pruning, will give the best results in hot climates. For the tropical garden, the larger 
fruited varieties, such as Ponderosa, seem to be preferred for local use; though when, as in Cuba, tomatoes are grown for northern markets, the medium-sized shipping varieties have the preference.

In the United States, more and more attention is given to placing this vegetable in the market all the year round. The crop of the North is usually cut off by frosts in September or October, while that of the states farther south, such as North and South Carolina, is not usually cut off until November or December. During December the crop from south Florida is brought forward to the market, and the Florida crop continues to be shipped as long as it will pay for transportation. Under favorable conditions, by the first of May the crop as far north as Georgia begins to ripen, and is pushed forward to the market, crowding the Florida crop out.

\section{Tomato seed.}

There are very many seedsmen from whom one can obtain tomato seed, but not all of these grow their own seed. If the seed of a new variety is offered for sale, and it is thought that it will be profitable in a certain section, a package of seed and one year's test will greatly help to decide the question. When a vegetable-grower has once found a well-established variety which gives good success, he should not readily discard it for something else that he has not tried. Money saved by buying inferior seed is lost over and over again in the crop. In selecting seedsmen from whom to procure seed, one should first find out whether they make tomato-seed-growing a specialty, or whether it is merely a secondary matter. Whenever 
possible, one should procure seed from those who make a specialty of tomato-growing.

Seed-beds.

In regions where there are slight frosts in winter, the seed-beds may be protected by boarding round and covering with protecting cloth, so as to make a coldframe. This cloth is waterproof and may be rolled up during the day.

The coldframe will be found profitable at any place where the coldest part of the winter is about $24^{\circ} \mathrm{F}$. If, however, there is an occasional winter that gets colder than this, one can make preparations for it. The plants in the coldframe can be covered with litter or leaves, and the protecting cloth rolled over this; should the cold continue for several days, there will be no danger in leaving the bed in this way.

In south Florida, where the temperature rarely gets to the freezing point during winter, tomatoes may be planted in an uncovered seed-bed. There should, however, be some protection against the hot sun and against frosty nights and even cold winds. A warm location should be chosen. If it has not a natural wind-break, one may be prepared on the east, north, and west sides, leaving the south open. Even when the crop is wanted for late fall shipments, seed-beds will be found useful. The seed should be sown about $\frac{3}{4}$ inch deep, about two to the inch, in drills about $\frac{3}{4}$ inch apart, the seed covered carefully, the ground smoothed off, and the soil thoroughly moistened.

In tropical countries the seed-beds can be shaded by 
cheese-cloth or cotton cloth until the plants are fairly large; and in case of ground free from weeds, and where the land is fairly moist, the seed may be sown in the field, if there is no likelihood of heavy washing from rains.

For commercial growing, the seed is sown thinly and the plants left in the seed-bed, with perhaps some thinning, until they can be set out in the field. But if it is found to pay, the seeds may be sown thickly in part of the coldframe, and picked out when they are an inch or less high. In temperate latitudes more transplanting is sometimes done, but it has been found by experiment to lessen the crop and delay the maturing of the fruits, and also involves extra cost.

\section{Soil for tomatoes.}

For the winter crop, the soil should be a warm sandy loam with a gentle slope to the south. While this is not always obtainable, it is very desirable to have at least a general slope to the south. By careful tests it has been proven that soil that has a southern slope may be five or six degrees warmer than that which has a northern slope. For this reason a clay or marl loam should be avoided, except where the crop is wanted for the late market; in such a case a clay or marl soil will be found well adapted. Another important point in locating a tomato field is to have a good wind-break to the north, east, and west. Many cold winds that are not severe enough to freeze will be harmful to the plants. In fact, any temperature below $45^{\circ}$ will be found detrimental to the plants, and will be all the more so if accompanied by high winds, as 
these carry the warmth away from the plants and soil rapidly. It is not uncommon to find that the only tomato plants which have survived a cold spell are those that were sheltered from the wind by a dense hammock or grove.

Fertilizer.

The fertilizer used should contain the following ingredients: ammonia, 5 per cent; available phosphoric acid, 6 per cent; potash, 7 per cent. Use from 1000 to 2000 pounds to the acre, depending upon the fertility of the soil and the distance apart that the plants are set. If the soil is rich in humus or nitrogenous matter, a part of the nitrogen should be withheld, as too much of this element makes tomatoes soft and liable to have hollow places in their interior.

When the fruit is maturing, an abundance of available potash in the soil is desirable to make it firm and solid.

\section{Pounds to THE ACre}

Ammonia . . $\left\{\begin{array}{l}275 \text { to } 550 \text { nitrate of soda; or } \\ 200 \text { to } 400 \text { sulfate of ammonia. }\end{array}\right.$

Phosphoric acid . . 600 to 1200 acid phosphate.

Potash . . . $\left\{\begin{array}{l}900 \text { to } 1800 \text { kainit; or } \\ 140 \text { to } 280 \text { muriate of potash; or } \\ 140 \text { to } 280 \text { high-grade sulfate of potash; or } \\ 300 \text { to } 600 \text { low-grade sulfate of potash. }\end{array}\right.$

Preparing the tomato field.

A sandy loam needs little preparation. In fact, it is usually sufficient to plow the land deeply and work down with a cutaway harrow. All dead roots, brush, or débris 
should be removed so as not to interfere with later cultivation. A one-horse plow may then be used to open out a double furrow where the row is to stand, and the fertilizer worked in this furrow, a portion of it being scattered in the bottom and some of the soil worked on to this, then another portion of the fertilizer applied and more soil worked into the furrow, and so on until all the fertilizer has been used.

In a sandy soil or a sandy loam, it is preferable to use the fertilizer in two or more applications. The first application is made before the plants are set and should contain a high percentage of ammonia in a quickly available form. The second may be made just as the first bloom appears and may contain only a small percentage of ammonia. If at any time during the growth or fruiting period the plants are showing a lack of thrift, an application of 75 or 150 pounds of nitrate of soda or nitrate of potash may be made to good advantage. The latter will give firmer and better shipping fruit. If the early bloom is being cast off, this can frequently be corrected by making an application of fifty to a hundred pounds of high-grade sulfate of potash. But if the casting of bloom is due to cold winds or too much moisture, the fertilizer is not likely to correct it.

Experiments have indicated that where the soil is retentive, for example stiff clay, nothing is gained, and indeed, something is lost by applying the fertilizer at different times. If the season is very moist, the ground will be ready to receive the plants in a week after fertilizing. If, however, the soil remains unusually dry, it may be much longer. 
Setting out tomato plants.

Before the plants are set out in the field, they should be hardened off, but this must be done very carefully. It is not a good practice to withhold the moisture all at once, but it should be done gradually. In this way the plants adapt themselves to the conditions and are thus better able to stand the shock which they receive at setting out. A week before the time the plants are ready to be set out in the field, just enough moisture should be applied to keep the plants in the seed-bed from becoming wilted. It will be found, treating them thus from day to day, that the plants will be in a much better condition to be set out than they were at the time when hardening off was begun.

The distance at which tomatoes should be set varies with the fertility of the field and with the varieties used. If one has an ordinary field that produces about thirty bushels of corn to the acre, and wishes to use about 1000 pounds of fertilizer to the acre, it will be well to plant in checks, 4 by 4 feet. If, however, the land is very fertile, the tomatoes may be planted as close as 3 by 3 feet, or the rows may be planted 4 feet apart, and the plants set at 2 feet or even less in the row. In hot climates when tomato plants are inclined to be short lived, they are placed about a foot apart in the row. Many devices for transplanting purposes have been invented, but none seems to meet the demands fully. Some machines are drawn by horse power and others worked by hand. The greatest objection against some of these is the cost of the implement. Therefore, for various reasons, up to the present time the 
bulk of the crop is still transplanted by hand, and as this is not an especially expensive operation, it will be continued for many years. A man or strong boy can set out an acre of tomatoes in a day. Consequently, it should not cost more than $\$ 1$ to $\$ 2$ to set out an acre of tomatoes, including the sets. Various labor-saving devices, or socalled short cuts, have been resorted to by tomato-growers. One that has been recommended is to plow out a furrow with a one-horse plow and drop tomato plants along this furrow at proper intervals. The plants are so dropped that the heads project to one side of the furrow. The soil from a small furrow is then throw upon their roots, care being exercised not to cover them too far. The plow is then run down the outer side of the row, which will set the plants more or less erect. For such an operation it will be necessary to have plants that are more or less drawn out, and usually considered too large for transplanting.

A convenient setting-out tray may be made cheaply by using an ordinary soap box that is 6 inches deep, 12 or 14 inches wide, and 10 inches long. One end of this is knocked out and a bail fastened from one side to the other. The plants may be carried in this to the field, and, as they are wanted, taken out of the open end to place in position.

\section{Cultivating.}

Cultivating tomatoes is simple and not laborious. Most of it is performed by a one-horse cultivator. As soon as the tomatoes begin to show bloom or set fruit, much care should be taken not to disturb the roots, as this is liable to shock the plants and cause the bloom to fall. 


\section{Pruning tomato vines.}

Whether it will pay to prune or trellis a commercial crop of tomatoes can only be determined by trial. Many fungous diseases may be thus kept off or lessened.

There are two reasons for pruning tomatoes. The first is to bring the earliest fruit in earlier than it would ripen without pruning. The second is to develop the fruit to its fullest extent. The earliest form of pruning was to remove all the side shoots, and thus train the plant to one main stem, or vine, as it is usually called; this being either tied to a stake or fastened to a trellis. While this does much toward producing a good crop, it does little in the way of bringing the crop in earlier. From experience, it has been proved that the earliest tomatoes can be forced to ripen a week or even two weeks earlier by topping than those which have not been topped. By topping or cutting out the terminal bud just below the second cluster of blossoms before the first cluster has begun to open, the growing force is thrown into the first cluster. It is not at all uncommon, under such treatment, to have this cluster produce from five to seven tomatoes, and all of these to ripen at nearly the same time. While the crop is much smaller than it would have been as a whole if no topping had occurred, the early crop comes in so much earlier that it more than compensates for the loss in quantity. Staked plants are usually topped after they have set three or four clusters.

Pruning should not be carried too far, however, as the leaf surface of the plant must be sufficient to assimilate the crude material that is absorbed by the roots. If 
the leaf surface is too small, so much absorbed matter will be sent to them that the tissues and cells become swollen and unable to perform their functions. It should always be kept in mind that one wants to check the growth of the stem and further the formation of fruit, but not to interfere with the production of leaf surface; so the mere removing of buds and flower-clusters will be the pruning desired. The extent to which pruning can be carried will depend largely upon the variety, condition of the weather, and kind of land. A dwarf variety, during dry weather and on poor, dry soil, can be pruned much more severely than a large-growing variety, during a rainy season, on fertile lands; in fact, the latter will scarcely permit any pruning.

Staking tomatoes.

The usual varieties of tomatoes that are grown for northern markets have not a strong enough stem to carry the weight of the fruit. Consequently they fall over and the fruit comes in contact with the soil ; this renders it unsightly and also very accessible to attack from insects and fungi. Thus many tomatoes are lost when the vines are not staked and tied. Stakes used for this purpose are about one-and-one-half inches square and three feet long. One of these is driven down by each tomato plant, and the plant tied firmly to this. Some soft wrapping cord is employed. The cord should be wrapped twice around the stake at the proper height and a hard knot tied. Then the string is passed around the tomato plant and the knot tied so as to hold the plant loosely. Staking and tying tomatoes will not be found profitable where land is cheap and labor high priced. (See Plate XII.) 


\section{Trellising.}

The trellising of tomatoes is carried on in parts of the United States where tomatoes are selling at a low figure, and yet it is found profitable to do this work. In preparing the trellis, posts are placed in the ground at proper distances and two or three wires attached to these, much as in vineyards. The tomatoes are then tied to the wires, or if the wires have been placed close enough together, the plants are simply trained to them.

Either staking or trellising should be practiced in the South, where a late summer or early fall crop is wanted for home use. For a small garden it pays to prune and trellis.

\section{Picking tomatoes.}

The picking season is the busiest of the year for the tomato-grower. If his crop is ready to go forward, it must be put on the market without delay. The loss of twenty-four hours may often work a damage of $\$ 100$ on a single car-load; consequently everything should be in readiness, and all the necessary hands ready to go to work. During the cool winter months, the tomatoes must be allowed to assume a light color or even a slight tinge of red before picking, otherwise they will arrive in the market too green. During the warm summer months these same tomatoes would have arrived in the market overripe; therefore, the tomatoes must be allowed to become riper on the vines in cold weather than in the warm part of the year. In the warm spring months, it is sufficient to allow the tomatoes to become full-grown and 
change slightly from green to whitish; but it will require considerable experience before one is able to pick just at the right time.

The picking is usually done in ordinary market baskets. Hands for this purpose must be selected with some degree of caution, as only those who can discriminate well and who are not rough with the vegetables should be employed. At convenient places in the field, boxes are placed; these boxes are about ten inches wide, fourteen deep, and thirty long; they hold about two crates. In making such boxes it will be found best not to leave any cracks open, and to make them of whole boards; this lessens the danger of injuring the fruit. Strips are nailed across the ends, which serve as handles and at the same time give additional strength. It is desirable to make the box large enough to hold two crates, as this weight usually requires the attention of the person handling it, and there will be less danger of carelessness.

Packing-house.

It is very desirable to have the tomato packing-house located at a depot or railway switch, so that the crated vegetables can be loaded directly on the car; this will save one handling, and consequently compensate for a considerable haul. If, however, the packing-house is so far from the railroad that the crated fruit must be handled, it should then be placed as near the center of the field as possible. There are many reasons why a packing-house should not be near dwellings.

The interior of the packing-house should be arranged so that the boxes are received from the wagon and set on 
the floor without any high lifting; they should be on a level with the sorter's bench. After the tomatoes are received, they should be sorted immediately, and the different kinds placed in separate.places to be packed. 'The person placed at the sorter's bench must be quick at discriminating and active with his hands. Chutes can be arranged to carry the fruit to the different tables, or it can be made to run into different boxes, which when full may be put in place for wrapping. The wrapper's bench should not be higher than the boxes that receive the fruit from the sorters. After the fruit has been packed, it should continue to be carried downward and in no case should there be any lifted upward. The packed fruit may then be delivered to the other side of the packinghouse, and carted to the station.

Sorting tomatoes.

The successful tomato-growers usually sort their tomatoes into various grades, depending largely upon the tastes of the growers and the market for which they prepare. There are two general grades that are recognized by all tomato-growers, and they are usually observed even by persons who make no pretense of grading their tomatoes; these are usually spoken of as "ripes" and "greens." These two grades give the grower a chance to distribute the fruit to different markets and have them all arrive in suitable condition. More advanced tomatogrowers make, besides these, other divisions, as "large ripes," "small ripes," "large greens," and "small greens." While it seems like a great deal of work to separate the fruit into grades, it is found to be very profitable. The 
tomatoes are then wrapped in different kinds of paper to suit the grower, and packed in carriers. By sorting the fruit into various sizes or grades, one will be able better to meet the desires of different markets and the different desires of the same market.

Few tomato-growers pay sufficient attention to local or near-by markets, so it may happen that tomatoes are being shipped to New York at a loss, when near-by towns and cities have to depend on northern canned goods.

The usual tomato crate holds about twenty-four quarts, and should be made of first-grade material; no pains should be spared to make the crate and the material in the crate look as attractive as possible. The better shippers are using colored designs and other tasty means of distinguishing their products.

Summer and fall crop.

In preparing for the fall tomato crop, a frame should be prepared, as for the spring crop. The protecting cloth in this case is used for an entirely different purpose, however. At this time of the year it is wanted to keep off the sun and to keep the rain out, also to ward off such insect pests as grasshoppers.

All the watering had better be done by hand. In setting the tomatoes out, care should be taken to provide for them a shelter by using slats, or leaves of palms. The construction of a slat shade for a field is discussed on page 57.

Saving tomato seed.

The seed that is offered on the general market is so excellent and so cheap that it scarcely seems worth while to 
save any ; but one will never have varieties better adapted to his own conditions until there is some seed-grower who will select tomatoes with special wants in view. The very best plants should be selected, not the best individual fruits, from the variety that has done well, and these allowed to ripen their fruits. These may then be gathered and broken into pomace, or may be cut and the seed, together with the parts that contain the seed, taken out and placed in a barrel to macerate for a day or so. In the meantime it should be stirred several times to make the rotting as even as possible. To separate the seed from the pomace, the directions given under eggplant should be followed.

Canning.

All tomato-growing districts or communities should have one or more canning factories to preserve the surplus as well as the fruit that becomes too ripe for shipping in the fresh state. The greatest difficulty seems to be in having a sufficient amount of labor at hand to carry the work on successfully. In tropical and subtropical regions many other vegetables as well as fruits might be grown especially for canning purposes.

In several places, coöperative canneries have been established which are giving returns satisfactory to those interested. Such a corporation does business just as if it were a private enterprise. The advantage in this plan is that many are working for a common cause. The expense of erecting a canning factory is by no means the most important consideration. An establishment that 
would cost from $\$ 500$ to $\$ 5000$ would be able to do the work that would be required of it for a very large tomatogrowing district.

The operation of canning is simple, yet it requires an expert to do the work well, so that when it is done the material will not degenerate in the cans. The principle involved is simply to place the material to be canned under a temperature sufficient to kill all living organisms contained therein, and in this condition it is sealed. Under these circumstances there can be no degenerating, no fermenting, and no rotting.

With a small home outfit, costing $\$ 10,300$ two-pound cans may be put up each day. This affords a good method of disposing of surplus tomatoes.

Enemies of the tomato in Florida.

Damping-off may occur in the seed-beds, the seedlings being cut off near the ground. It does not usually happen unless the plants are too close together and too damp. Spraying the soil with ammoniacal copper carbonate is advantageous.

Root-knot often starts from the young plants in the seed-beds. It may be combated by careful choice of seed-beds, by sowing the seeds in the open field, and by rotation.

Cutworms, which attack the young plants, are best destroyed by poisoned bait.

Rust begins as brown spots, which spread over the leaves. It can be prevented by spraying the plants in the seed-bed with bordeaux mixture; and when found in the field, several sprayings will save the crop. 
Fungus blight attacks the plant from the soil. The leaves turn yellow and die from below upwards. Rotation is the only remedy.

Sclerotium blight also lives in the soil, and the first symptom is the wilting of the top of the plant. This disease may be prevented by spraying around the stem with ammoniacal copper carbonate.

Bacterial blight spreads from an infected leaf and soon kills the plant. Infected plants should be immediately destroyed.

White mold is due to an invisible mite and can be promptly cured by spraying with sulfur or one of the sulfur solutions.

The tomato fruit-worm may be controlled by destroying all wormy tomatoes; especially by destroying those that appear during the time when the earliest tomatoes are being picked.

Varieties of tomatoes.

The varieties which are the most grown for the market in the southern states and the West Indies are Earliana, Beauty, Stone, Perfection, and Acme. Perfection, Matchless, Favorite, and Quarter Century have given good results in tests. Success has been grown for the late summer crop. Ponderosa is one of the best of the largefruited kinds, but is better suited for private gardens than for the market. Some markets prefer red, some pink varieties. The yellow-fruited sorts are not of much value. For canning, a medium large red tomato, that colors well right through, is preferred, if it is smooth and solid. 


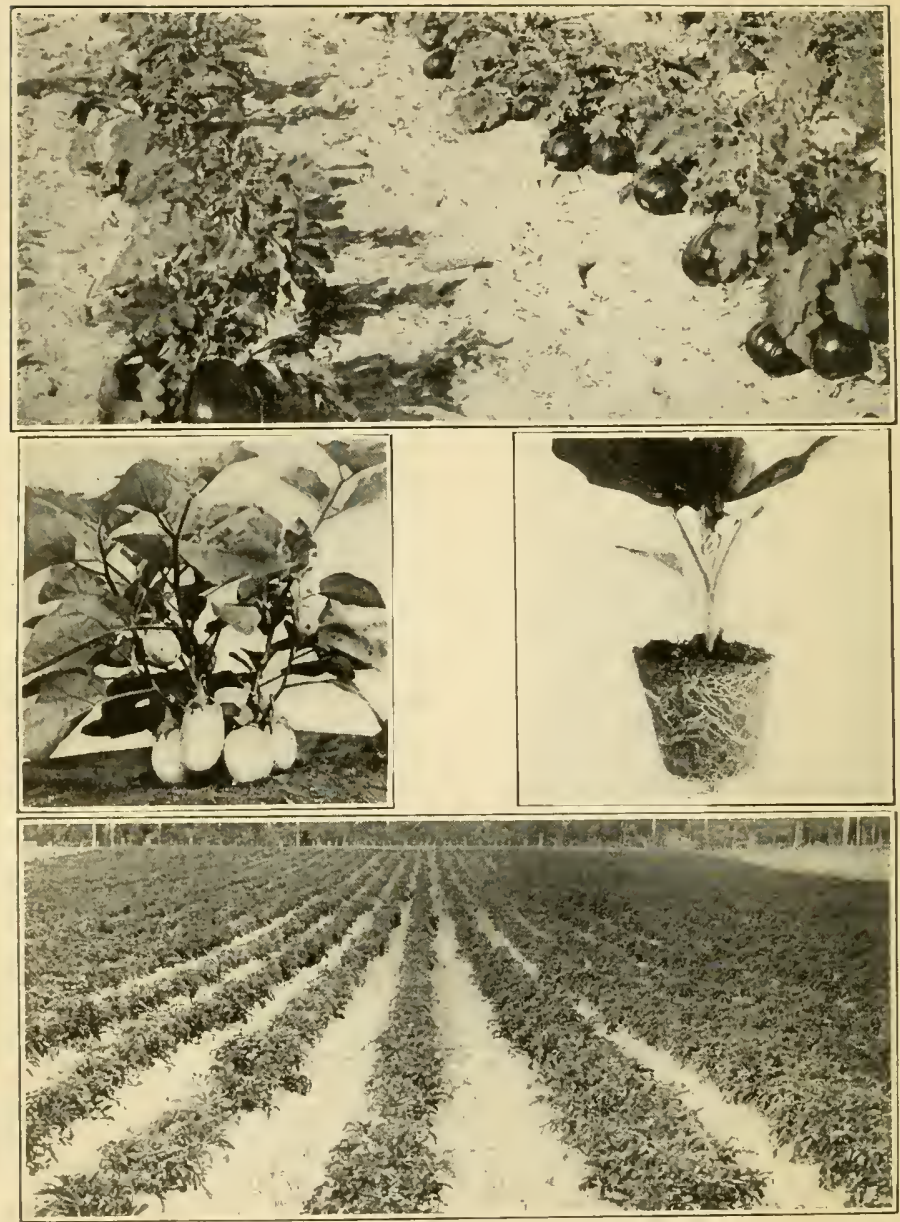

Plate X. - Eggrlants and Peppers.

Top, eggplant plantation; center left, white eggplant; center right, eggplant ready for transplanting to the field; bottom, peppers in field. 


\section{Literature}

Livingston and the Tomato, Columbus, Ohio, 1893, pp. 172.

Tomato Culture (in Cuba), Bulletin 4, Estacion central agronomica de Cuba, 1905.

'Tomatoes, U. S. D. A., Farmers' Bulletin 220, 1905.

Tomato Diseases, Fla. Bulletin 91, 1907.

Tomato Culture, by W. W. Tracy, New York, 1907, pp. 150.

\section{EGGPLANT}

The eggplant has been cultivated by the natives of India for thousands of years. It is now one of the commonest of green vegetables in almost all tropical countries, especially in the East Indies.

This vegetable is a money crop for the southern United States; although it can be grown in gardens of the North, it does not flourish so well there since the seasons are short. The greatest obstacle in the way of success for this crop is that gardeners rarely supply sufficient fertilizer to the soil. A successful grower in Florida began by raising ten acres, but did not make a profit on the crop; he then reduced his acreage to five, and used the same amount of fertilizer that he put on the ten acres. Later, he again cut down the acreage to two and one-half acres, but kept the amount of fertilizer at the original figure, and also bestowed as much attention on the two-and-one-half as he did formerly on the ten acres. The two-and-one-half acres then gave him more fruit of better quality and better size, than the original ten acres, and at the same time the field became more profitable. This instance illustrates what has been insisted upon before, that one should resort to intensive, rather than extensive, vegetable-growing. 


\section{Hotbeds and coldframes for eggplants.}

For early fruit, and the northern parts of the subtropics, it will be necessary to use a hotbed and later a coldframe. A hotbed properly prepared will save these plants through frosts of $14^{\circ} \mathrm{F}$. Of course such extreme cold is by no means healthful to the plants, but they may be saved from destruction. For eggplant seedlings, the manure is placed in the hotbed about a foot thick, and banked up on the outside of the frame to the rim. Two sheets of protecting cloth are used, with some space between them; the outer edges are covered to keep the wind from getting under them. During cold weather, the plants will make very little progress, however, but the gentle bottom heat causes them to make a good root system.

As soon as all danger from further frosts is past, the seedlings may be thinned out; and if any empty places occur, these may be filled in from places where the plants are too thick in the row. The plants should have about an inch space in the row, and the rows should be about 3 inches apart. As soon as the plants begin to crowd one another, they should be transplanted to another frame; this time each plant should be given about 2 inches in the row, the rows being 4 inches apart. Inexperienced persons are somewhat timid in removing eggplant seedlings, or transplanting them, because they fear they will be injured in the operation; but experience has taught that they may be removed, or re-set, when small, without any disadvantage to the plant. The time to sow the seed depends upon the time when the last killing frost occurs in the section. 
The seed may be sown in coldframes in warm sections, but the plants will not come along so rapidly as they would in a hotbed. They will, however, mature much earlier than the northern-grown product, and consequently be marketable when the prices are still very good. The same precaution as for hotbeds should be observed for coldframes. In regions where killing frosts are not likely to occur, the seed-beds should be established about the first of August to have the vegetable about the first of January. The treatment of a seed-bed is similar to that of a coldframe. The young plants need some screening to protect them from the direct rays of the summer sun. A slat screen or a covering of cheese-cloth fixed about a foot above the surface of the bed will be found sufficient.

\section{Using flower-pots.}

Eggplant seedlings are somewhat sensitive about having their roots disturbed, consequently some gardeners have used several sizes of flower-pots to prevent this injury. For this operation they secure paper ones of various sizes, beginning usually with two-and-one-half inch. These cost about $\$ 2.50$ a thousand. The pots are filled about four-fifths full of potting soil, to which has been added a liberal supply of fertilizer. Six or eight seeds are dropped into each, and the pots are then placed in the hotbed or the coldframe. Some growers plunge the pots into the soil, while others do not; the former way requires less attention, but destroys the pots in one year. 'The seedlings grow in these pots just as though they were in the hotbed, but from time to time the gardener should examine the plants to see that they do not become pot-bound, or do not 
send their roots through the bottom of the pot. As soon as either of these occurs, the plants are shifted to a largersized pot, which is usually a 3 -inch one. The increased space is filled up with soil similar to that formerly used, and the pots are then placed where the other size stood; of course they require more room. As soon as the fertilizer in the 3-inch pots has been fairly well appropriated by the plants, they are transferred to a larger size, say 4 -inch; some prefer 6-inch pots. The treatment in these pots is similar to that given in the first. It should have been mentioned, however, that before shifting the plants from the smallest pots to the larger, the smaller plants should be pinched off, leaving one plant in the pot. Under proper manipulation, plants may grow to bearing size in 6-inch pots, but this is not profitable. Plants should not be removed to the field until the soil is warm and all danger of cold spells is past, as the seedlings are very sensitive. (See middle figure, Plate X.)

In using flower-pots for propagating eggplants, care must be taken that at no time do the plants become checked in their growth, as this will materially reduce their productive powers. There are two points always to be borne in mind: first, that fresh fertilizer is applied as soon as the earlier supply has been used; second, plants should not become pot-bound. Under proper manipulation plants may be grown from seed in 3-inch pots, from which marketable fruit can be obtained in sixty days after setting out. In tropical countries, sections of bamboo, and the so-called "bamboo flower-pots," are used. The seed is sown in them, the seedlings thinned to one in each, and the pots split when setting out. 
Soil and preparation.

Eggplant requires good rich loam that is very deep. It is a deep feeder, consequently it cannot stand moist or soggy land. The plowing should be deep and thorough. Any refuse material or decaying vegetable matter should be removed from the field.

The field should be laid off in rows 3 to 4 feet apart, and the plants set from 2 to 4 feet apart in the row, depending upon the variety and the fertility of the soil. In setting plants in the field, they should be placed an inch or so below the level at which they stood in the hotbed or coldframe.

Fertilizer for eggplants.

The fertilizer should be made up of the following ingredients: ammonia, 5 per cent; available phosphoric acid, 5 per cent; potash, 9 per cent. Use 1500 to 2500 pounds to the acre of this formula. This plant is very sensitive to improper use of fertilizer, shedding its fruit or failing to set it at all if improperly fertilized or set in badly prepared soil. Consequently, there are many cases of failure, and it is very difficult to tell what is the matter with the plant, as the symptoms of many ailments are so similar that they cannot be distinguished. A successful way of applying the fertilizer is to make a double furrow where the row is to be. A portion of the fertilizer should be applied down the row and a part of the soil that has been thrown out mixed in; then more of the fertilizer applied and more soil worked in. This should be continued until the fertilizer has been deposited evenly 
throughout the entire furrow. If the plants are to be set in checks 4 by 4 feet, it will be sufficient to fertilize the ground for about a foot on each side of the plant. In sandy soils or sandy loams, a portion of the fertilizer may be withheld until the first fruits are about an inch diameter. The earlier application may have more ammonia than the formula calls for. One half of it should be in a quickly available form. The later application should about follow the above formula. In case the plants show a lack of vigor, much good can be done by making a separate application of nitrate of soda or nitrate of potash at the rate of about a hundred pounds to the acre.

The following table of fertilizers will give the desired amounts of each element for an acre :

Ammonia . . $\left\{\begin{array}{l}1000 \text { to } 1600 \text { cottonseed meal; or } \\ 600 \text { to } 1000 \text { dried blood; or } \\ 400 \text { to } 650 \text { nitrate of soda; or } \\ 325 \text { to } 525 \text { sulfate of ammonia. }\end{array}\right.$

Phosphoric acid . 750 to 1200 acid phosphate.

Potash . . $\left\{\begin{array}{l}1600 \text { to } 2000 \text { kainit; or } \\ 275 \text { to } 450 \text { muriate of potash; or } \\ 275 \text { to } 450 \text { high-grade sulfate of potash; or } \\ 500 \text { to } 800 \text { low-grade sulfate of potash. }\end{array}\right.$

Cultivation of eggplants.

The field cultivation of eggplants is very simple. The soil should be well stirred. The cultivation should not be carried to the extent of tearing the roots, hnwever. Those who are not acquainted with the root system of this plant will find it profitable to dig into the soil frequently and find out how near the top and how far the 
roots extend. During rainy weather, it will be necessary to cultivate the field deeply as often as twice a week. This cannot, of course, be done when the field is on strong clay soil. During dry weather, merely stirring the upper stratum to the depth of three or four inches every week or ten days will be sufficient.

Gathering eggplants.

It is very important to be able to tell just when the fruit is ready for market. While the early crop brings the best price usually, the fruit is liable to be too small and green for the market. Fruit that is too ripe is worthless. As soon as the berry turns from a lustrous purple to a dull color, you may suspect that the shipping stage has arrived. The best way is to test a few eggs by cutting through the center; if the seeds are well formed, the time for gathering has arrived. They should, however, not be allowed to remain on the plant until the seed-coat begins to harden. In case of Black Pekin or Improved New York Purple, the fruits are about seven inches long. The fruit should be cut with a stem about $\frac{3}{4}$ inch long.

Marketing.

Eggplant is usually marketed in barrel-crates and for distant markets each fruit is wrapped in heavy paper.

Seed saving.

Eggplants that bear exceptional crops of good fruit may be set aside for choice seed. Considerable time elapses between the marketing time and the ripening of the seed. Usually the fruits intended for seed may be left on the 
plants until they are fully ripe, but this is not necessary, as the seed can be gathered and saved for planting as soon as the fruit becomes tough and fibrous. The fruits are gathered as for shipping, and taken to the packinghouse. Here they may be left for several days, or for a week if the pile is not too large. When a considerable lot is on hand, a time may be set aside for taking the seed out. By examining the fruit it will be noticed that about onethird of the meat may be cut away from the stem without harming the seeds. After paring this away, the central part is quartered with a dull knife and sliced thinly. This material is put in a barrel for maceration in water, not having the barrel more than two-thirds full. The barrel should be set out of the hot sun, but kept in some warm place. In twenty-four hours it should be stirred up thoroughly, so as to have all parts mixed evenly. The pomace may be left to ferment for two or three days, depending upon the temperature in the meantime. A number 3 sieve that will go conveniently into the inside of the barrel should be secured. A half-barrel is filled with water and the sieve placed in the water, but not on the bottom of the half-barrel. The sieve may be held in place by wires stretched across the half-barrel. The seeds are dipped out of the barrel and put into the sieve, working the pomace around so as to break it into small pieces. Some of the pomace and the seed will go through the sieve and fall to the bottom, while the larger pieces will be taken out and thrown away, then a fresh lot will be taken from the barrel and the work continued as before until three or four inches of the material have collected in the bottom of the barrel. This may be turned out into 
a barrel and a sieve of number 6 mesh used for the second preparation. The meshes of this sieve are just large enough to let all the seed pass through and screen out all the pomace that is left. As soon as all the seed has been worked through the second sieve, it may be placed on a third sieve with number 12 wire mesh. This sieve permits all fine pomace to get through and screens out all seed. As soon as a large quantity has collected in the sieve it may be put aside for an hour or so to drain, then spread out on canvas, or other suitable place to dry; but this should not be done in the hot sun, as the high temperature is liable to injure its vitality. The seed should be dried as quickly as possible, as there is danger of its beginning to sprout. If the fruit has been allowed to decay or the pomace allowed to remain in the barrel too long, there is danger of the seed germinating during this time. When the seed has been thoroughly dried, it should be winnowed or run through a fanning mill to get rid of the chaff. The seed is tied up in suitable packages and placed where they are safe from attacks of mice and roaches. It is preferable to tie the seed in parchment paper or paraffin paper to keep it from getting moist. In this way seed may be kept for two or three years without losing its vitality.

In a moist tropical climate the well-dried seeds may be preserved in bottles or tins sealed with paraffin, and kept dry inside by a lump of good quicklime wrapped in paper.

Varieties of eggplants.

The early varieties are not usually so productive as later ones. The New York Improved Spineless will 
mature several weeks later than the Black Pekin, but the latter is much more productive. The New York Purple and Black Pekin are excellent varieties for shipping or for home use, but the New York Spineless and Early Long Purple mature earlier. (See Plate X.)

The New Orleans Market is a variety which has long been grown in Louisiana and gives good results in the hotter parts of the United States. The Florida Highbush is an excellent variety as it carries the fruit free from the soil, - an important consideration in a moist climate. The white eggplant has not become a favorite with the market, but for home use it is excellent, as its flavor is superior to that of the colored varieties.

\section{PEPPER}

The "pepper" grown in vegetable gardens is the fruit of species of Capsicum; they are sometimes called "chillies," particularly the small, very pungènt kinds. The fruits are also known as "red peppers" and "Cayenne peppers," to distinguish them from the true pepper (of the genus Piper) from which the black and white table pepper of commerce is made.

The red peppers were among the vegetables found by Columbus in the New World four hundred years ago. They are now cultivated in most tropical and subtropical countries. They grow well in the warmest parts of the earth. Within the tropics the hot peppers especially are used as seasoning, while the large sweet peppers are preferred as vegetables in temperate lands. The sweet peppers are sometimes canned. The hot peppers are used 
in the manufacture of chile con carne, paprika, curry powder, tabasco sauce, and cayenne pepper; and may be readily preserved by drying in the sun.

There is an increasing demand for peppers during the winter months in the United States. While shipments of large size cannot be disposed of very well, the demand in small lots is often above the supply. Much of the product for the northern and eastern markets has come in the past from Bermuda, the Bahamas, and Cuba. Peppers are being more grown now in the southernmost states.

Hotbeds and coldframes for peppers.

For the regions in which freezing weather occurs, it will be necessary to provide hotbeds to grow peppers, but where frosts do not occur, or only occasionally, coldframes will be sufficient. If located in a clay country the soil should be composed of about one-fourth clay, one-half vegetable mold, and one-fourth coarse sand, to which is added the necessary fertilizer. The soil of the hotbed may be tested by wetting it down thoroughly; if, after two or three hours, the soil can be squeezed into a more or less solid mass, there is not enough sand and too much clay in the mixture. If, however, the mass does not remain in a body but breaks up readily, the soil will be about right. On the other hand, if the water drains off immediately, and the soil becomes dry to the depth of one-half inch in the course of four or five hours, in the sunshine or a gentle wind, too much sand has been used and a little more clay should be introduced.

The rows should be made about 3 inches apart, and the seeds dropped about three to the inch, and covered to the 
depth of about $\frac{3}{4}$ inch. Before the seedlings begin to be spindling, they should be transferred to another bed, this time planting the seedlings 3 by 3 inches.

A successful and convenient way is to make use of $2 \frac{1}{2}-$ inch, 3-inch, and 4-inch flower-pots in respective order. When these flower-pots are used, the soil should be the same as in hotbeds without flower-pots.

The seed should be sown from forty to sixty days before the average time of the last frost. The rapidity with which the seedlings come along will depend upon the amount of sunshine and warm weather, and also upon the attention of the gardener; consequently a statement as to the time required for the seedlings to grow to planting-out size cannot be made more definitely. In frostless countries the seeds are sown thinly in shaded seed-beds, and the seedlings thinned out before setting out. Or they may be sown like eggplants, in bamboo pots. About eight weeks should be allowed from the time of sowing to the time of setting out.

Soil and preparation for the pepper.

A warm sandy loam that retains moisture in the subsoil will be found excellent. In preparing land for peppers, care should be taken to remove all decaying matter and rubbish from the field. The rows are laid off 2 or $2 \frac{1}{2}$ feet apart and the plants set from 1 to $1 \frac{1}{2}$ feet distant in the row. The variation in the distances in which they are planted should depend on the conditions of the land and the varieties which are being fruited. The larger or sweet kinds require more room than the small hot ones. 
Fertilizer for peppers.

Ammonia, 5 per cent, available phosphoric acid, 5 per cent, and potash, 9 per cent, should be used as a fertilizer, applying 750 to 1250 pounds to the acre. The same precautions should be used in applying the material as directed for eggplant.

Cultivation of peppers.

Cultivation should be carried on thoroughly and deeply, but never to the extent of injuring or destroying the roots of the plants. This must be ascertained by observation. An easy and satisfactory way is to remove the soil from beside a thrifty plant and follow the roots to the ends. Before the plants have reached their bearing size, it is well to discontinue the deep cultivation, but to continue the cultivation of the upper stratum of the soil, until the shipping season is over. When the plants are no longer wanted, they should be destroyed at once; especially should this be done if another crop of peppers is to be grown on the same land the following year. (See Plate X.)

Marketing.

As soon as the large varieties have reached two inches in diameter, they are usually considered ready for marketing, but one must be guided by experience in the matter. The earliest shipments are usually the most remunerative.

It is not usually necessary to wait for the fruit to become slightly wilted before packing, but sometimes this may be done to advantage. The fruit is packed in the 
usual vegetable crate, with the top pressed down firmly, to prevent the peppers from shaking about.

Saving seed.

Experiments have shown that selected home-grown pepper seed may be better in the South than that grown farther north, hence after the shipping season is over, it may be an advantage to save one's own seed, or to sell it to neighbors. The matter of saving seed is simple and easy. The fruit is allowed to become ripe, then picked, allowed to dry, and the seed removed. It will be necessary to protect this from mice, rats, or other vermin. Under ordinary circumstances the seeds will retain their vitality for a number of years.

Varieties of peppers.

Among the large sweet varieties are the large Bell, or Bull Nose, and the County Fair. The first-named and those that grow similarly are to be preferred for shipping purposes. The County Fair has several advantages, however, for home use and the local market. Among the hot varieties is the Small Chili. The Celestial is also excellent, besides being highly remunerative. If one desires to raise hot varieties for market, Small Chili Tabasco, and Bird's eye may be tried. 


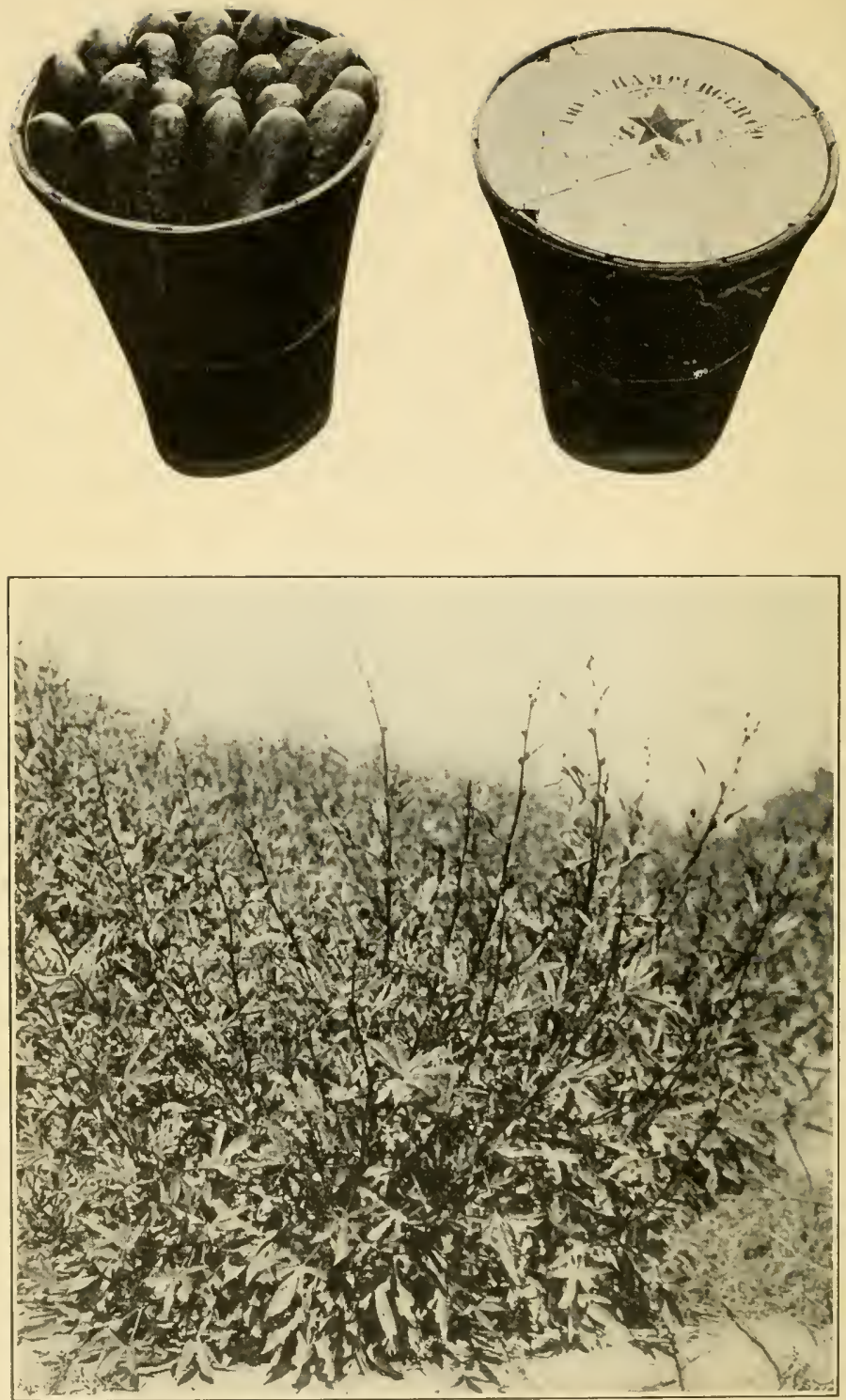

Plate Xi. - Cucumber Hampers; and a Plant of Roselle (VicTOR VARIETY). 


\section{CHAPTER XV}

\section{VEGETABLES WITH EDIBLE FRUITS - OTHER CROPS}

There remain other edible-fruited vegetables, that do not classify with those in the two preceding chapters, nor do they classify with themselves. For convenience, they may be placed together here. Some of them, as the plantain, papaya, and bread-fruit, are usually classed as fruits rather than as vegetables, but many readers will expect to find them here.

\section{ROSELLE}

The roselle, or Jamaica sorrel (Hibiscus Sabdariffa), is a tropical plant producing its fruit in the cool season and then perishing. As it will stand drought, it may be cultivated throughout the tropics and subtropics during the hot and rainy seasons. It is killed by a slight frost, and can be grown with profit only where there are no frosts during its time of fruiting, which, in Florida, is usually between November and December.

In regions like Florida, where neither the red currant nor the cranberry grow, the roselle offers a palatable substitute for the acid jellies or jams made from these two fruits. Its products are regarded, by those who have 
employed them, as nearly or quite equal to the currant or cranberry preserves of more northern regions. It is not an unusual occurrence for visitors in Florida to mistake roselle fruits, when prepared for the table, for cranberries. This plant has long been grown for similar purposes in India, Egypt, and other hot eastern countries.

\section{Propagation.}

The roselle is regularly propagated by seeds, but it can be readily grown from cuttings. To secure the best results, the seed should be carefully selected from the earliest ripening bolls, growing on the most prolific plants. As a whole, the plants are rather more vigorous than need be; consequently, no attention need be paid in the direction of vigor.

The seed should be sown in a hard seed-bed, such as is prepared for eggplants, tomatoes, or peppers. The month of April is found to be the most favorable for the larger part of Florida. The seeds are sown in drills about 6 inches apart, dropping enough seed so that the plants may be thinned out to an inch apart in the drill. The thinning out should be done as soon as the plants begin crowding one another. By the first of July they will be large enough to set out in the field. At this time abundant rains may be expected, and thus one avoids the necessity of having to water the plants, excepting at the time of setting out.

If the seed is sown early in the year, the plants grow much more vigorously and produce a larger stalk than with late sowing. It is a question, however, whether the increase in size of stalk produces an increase 
in the quantity of roselle that is produced in the field as a whole.

Cultivation of roselle.

A sandy loam suits roselle best. The fields are prepared just as in the case of eggplants, tomatoes, or peppers. The rows are laid off about 4 feet apart. The fertilizer should be spread down the row, having the field in thorough tilth and cultivation before setting out the plants.

No definite experiments have been made to show the exact fertilizer needs of this crop. Heavy crops have been produced by the use of ordinary vegetable fertilizers. It is quite probable, therefore, that the formula ordinarily used for vegetables will be found approximately correct. The amount used to the acre should be about one-half or one-fourth of what is ordinarily used. If the quantity ordinarily used for vegetables be applied, the plants grow exceedingly rank and are apt to shed many of the early bolls.

The plants are set 18 inches or 2 feet apart in the row. The cultivation is carried on just as for garden or other vegetable crops. By plowing the field frequently and close to the plants, all necessity for hoeing is avoided. If, however, the field happens to be unusually foul, it may be necessary to hoe between the plants. As soon as the plants have reached a size of eighteen inches or two feet in height, the abundant leafage will shade the ground so completely that no more hoeing will be needed. Four or five plowings in ordinary good vegetable land will be found sufficient cultivation. 
Gathering.

The fruits should be gathered before any woody matter forms in the pods, or in the calyxes. This can usually be determined by breaking them open by hand. If any woody fibers have formed, a certain amount of stringiness will be observed. The bolls with stringy fibres running through them have matured too far.

Crops that are grown under good cultural conditions may be picked without the use of a knife. The bolls will be tender, crisp, and plump, and by taking hold of the boll with the fingers and thumb and giving it a sharp kink just below, the stalk will break. This characteristic may also be used as an index of the ripeness. If the bolls fail to break off readily, they have matured too far. It will be found that they break off more readily in the morning than towards night.

Shipping roselle.

For shipping purposes, the bolls should be gathered just as for home.use. Care should be taken to keep them free from leaves and other trashy material that may get mixed in. By handling the bolls carefully, they may be dropped as picked into a container, such as an eight to ten-quart pail. For shipping purposes, the six-carrier tomato crate has been used. Before putting the bolls in, paper wraps are placed in the carrier so as to prevent the bolls from coming in contact with it, and also to give a wide enough lap to cover them completely after the carrier has been filled. This protects them from injury by rubbing against the wood in transit, and also from 
spilling out of the carrier. Each carrier should be filled so as to require only a slight pressure on the lid of the box at the time of nailing up. In this way roselle was shipped from Florida to Washington. After reaching its destination it was found to be in excellent condition for making retail sales in that city. Roselle, when carefully packed, may be sent by express from Florida to any point east of the Mississippi river.

Productivity.

At one of the trials in California, three pounds of fruit of roselle are said to have been produced by each plant. It has been stated that a quarter of a bushel to a plant can well be counted on in south Florida. The yield in Porto Rico was estimated at four pounds of fruit to a plant, and at double this amount in good sandy loam. Sixteen pounds to a plant have been gathered in south Florida.

Uses of roselle.

The part used as a fruit consists of the red, juicy, swollen calyx and involucel. This may contain about 87 per cent of water, nearly 3 per cent of acids, and only 1 per cent or less of sugars. The acids are said to consist of malic and tartaric, with no citric. A cooling summer drink is made from an infusion of the fruits of the roselle, its natural bright-red color giving it an attractive appearance. This drink is bottled in the West Indies. It keeps well if no sugar is added, and if the bottles are sterilized by heat, and sealed while hot. The abundant acid, the bright cherry-red color, together with a plentiful supply of pectins, render this plant a good jelly-maker. Roselle 
jelly is nearly or quite as good as red currant or cranberry jellies. The fruits are at their best soon after the flower has fallen. It is preferable to remove the capsules when making roselle sauce, jam, or marmalade. For jelly, only three-fourths of a pound of sugar is needed to a pint of the juice got by cooking and straining the fruits. To make roselle jam or marmalade, the calyxes are cooked in strong sirup.

The fruits of this hibiscus may be used for making jelly, even after the seed has ripened in the capsules. The fruits may also be dried without losing their acidity or their capacity for jelly-making. The young, tender shoots may be used for greens and for jelly-making.

Diseases.

The roselle plants in Florida are usually attacked late in the year by a mildew which destroys the leaves. Dry sulfur dusted over the plants has been found a good preventive.

Varieties of roselle.

In India and the West Indies a yellowish variety, without the bright red of the calyx, is sometimes met with. This yields a greenish-yellow jelly, or marmalade; but it does not seem desirable. In south Florida there has arisen a variety of roselle, Victor, that produces much larger bolls than that usually grown. The plants are smaller and more prolific than the common kind. (See Plate XI.)

Bulletin.

Roselle; its Culture \& Uses, U. S. D. A., Farmers' Bulletin 307. 


\section{OKRA}

This tropical annual or biennial (also called gumbo) is cultivated in most tropical and subtropical countries, where it often furnishes a welcome green vegetable when no other can be obtained. Like the roselle, to which it is related, it stands drought well, and hence suits the native or negro inhabitants of the tropics, who prefer vegetables which give them no trouble to raise. Its desirable qualities lie in the mucilaginous pods. The taste for this vegetable is more or less an acquired one, however; when used in small quantities in soups, only a few persons object to it. Besides its use in soup, it may be pickled, and also cooked as a dish by itself.

Any good agricultural land will produce okra. Like cotton, it is partial to a warm sandy loam. To produce okra for shipping purposes, a warm sandy loam should be chosen, and highly fertilized, unless it is already rich. When grown on poor soil, okra is stringy and wanting in mucilage. The land should be prepared thoroughly and deeply. The roots of this plant descend below any ordinary plowing, so that it can stand an unusual drought without apparently suffering.

The rows should be made $2 \frac{1}{2}$ or 3 feet apart, and a seed dropped about every 3 inches. The seed is planted an inch deep. When the plants are about 6 inches high, they should be thinned to a foot in the row for dwarf varieties, and to about $1 \frac{1}{2}$ feet for the half dwarf varieties. If the large varieties are planted, the rows may be made 4 feet apart and the plants thinned out to 2 feet in the row.

The cultivation should be deep and thorough. The 
plants are so strong that there is rarely any occasion for the use of a hoe, since the work may be done with a plow.

In gathering okra for a distant market, the stems are cut close to the pod. Okra is shipped in an ordinary vegetable crate, and packed down firmly, so that the product will not shake about on the way. There is little demand for this vegetable in the markets of the Northwest, so it must be shipped to some neighboring market or to the East.

The seed is easily saved. When the pods are ripe, they should be removed from the plant. They will break easily, and the seed comes out readily.

The taller-growing varieties of okra are not so profitable nor so desirable as the smaller or dwarf. Little Gem and White Velvet are among the favorite dwarf varieties. Improved Green is a good medium-sized variety.

Bulletin.

Okra : Its Culture \& Uses, U. S. D. A., Farmers' Bulletin 232.

\section{PLANTAIN}

Plantains are those varieties of banana that are not suited for eating raw, but require to be cooked. It is difficult to tell the difference between the many varieties of plantain and banana before the fruit appears. The common plantain has fewer and larger fruits, more loosely set in the bunch, and more three-angled than the common bananas. It is an important tropical vegetable. Boiled or baked green plantains, or fried ripe plantains, are common table vegetables throughout the West and East Indies. 
It is decidedly worth growing in all tropical (and some subtropical) gardens, and with proper care in choosing the suckers to be allowed to fruit, a supply may be procured from a small field throughout the year. It is propagated exclusively by suckers, which are produced in abundance. A length of about two feet is usually best for the sucker, which is cut off from the parent plant beneath the soil. Some of the leaves may be removed, and the suckers planted out, 15 feet or more apart. The soil should contain much humus. In the trade-wind belts, a wind-break of dense trees, such as mangoes, on the east of the plantains, is of use. Irrigation during dry weather is very beneficial. In the absence of irrigation, the beginning of the rainy season is the best time to set out suckers. They will produce their first bunch in a year or less, and then there will be almost continuous fruiting from new suckers. Some of these should be cut out, and by doing this with proper judgment, bunches of plantains may be obtained in quantity at almost any desired season of the year. The field will not need replanting for several years, but will require manuring.

The plantain can doubtless be grown to advantage in regions where the winter temperature, as a rule, does not go below $32^{\circ} \mathrm{F}$., but if cut down by frost every year, it will hardly pay to grow it, though some fruit might be obtained.

\section{PAPAYA}

The papaya, or melon papaw, is a cultivated plant of the American tropics, which has been spread throughout the tropical belt. Almost wherever it is grown, the young 
green fruits are cooked as a vegetable, and much resemble summer squashes. Since the tree sets a larger amount of fruit than it can properly carry to maturity, this removal of many young fruits allows those which remain to increase greatly in size. The unripe papayas thus furnish an agreeable vegetable when properly cooked and seasoned, and one which can be procured at almost any time of the year; whereas squashes cannot be raised in the hot season, and are not much grown even in the cool season between the tropics. The fruits are peeled and cut into pieces, after the removal of the seeds. They are usually soaked for some hours in cold water to extract the rather acrid latex, and then boiled until soft. If they are cooked with tough meat of any kind, they soften it remarkably. Since the meat in tropical countries must, in the absence of an ice-house, be eaten the same day that it is killed, this digestive property of the papaya is of decided value. The green fruits cooked with sugar make excellent preserves.

Papayas are grown only from seeds, of which each fruit produces a large number. The seeds germinate easily and rapidly. The plants should be set out when they are about 6 inches high, in a well-drained soil, at distances of 10 feet or more.

The tree may be grafted by inarching, and cuttings may be rooted, but these processes are slow and require so much attention that neither has come into practice. Budding may also be successfully employed. For this purpose a plant two feet or more tall should be selected, the top cut off in the tender portion, split as for cleft grafting; and a wedge-shaped bud two to four inches long 
inserted. This should be tied firmly and in a week to ten days a union will have been made. The bud may be shielded against sun and rain until the union is made.

Papayas are benefited by irrigation during the dry season. About half the trees will bear staminate or barren flowers only, and nearly all such trees (which may be recognized by the long thin sprays of tubular flowers), should be cut out as soon as noted. The fruiting plants are distinguished by bearing their flowers mostly in clusters of three. One or two staminate trees to the plantation will insure sufficient pollination of the flowers on the pistillate trees. The papaya very seldom branches at all. It may bear sixty or more large fruits each year. When grown for the ripe fruit, the long-fruited or the cantaloupeshaped varieties are much better than the common oval form. The first fruits usually appear in less than a year, and the tree will continue bearing for several years. The papaya will only endure a very light frost. Hence it is adapted only to countries where freezing weather rarely occurs, though it can be grown farther north if protected during the winter. The potent digestive properties of its ripe fruit render its best varieties important members of tropical or subtropical gardens. The digestible ferment (papain) is destroyed by heating to the boiling point, and hence would not be present in cooked fruit.

A space 8 by $\delta$ feet is usually sufficient for a thrifty plant. The older ones usually become less productive; it is therefore advisable to start with fresh plants every three or four years. The small seedlings transplant with more or less difficulty, but after the stem has become woody and about an inch in diameter, no difficulty is 
experienced in transplanting during the rainy season. The seed from the best fruits only should be sown. These may be sown in rows several feet apart and several inches apart in the row.

\section{BREAD-FRUIT}

The seedless variety of this tree of the Pacific Islands would seem to provide a vegetable which, in all but one particular, fulfills the ideal of the ordinary tropical native; that is, to have a food plant which only requires the two operations of planting and gathering. Unfortunately, however, for the inactive basker in the sun, the bread-fruit yields its crop only in the late summer and early fall, and its fruits cannot readily be kept through the remainder of the year, although in some islands they are sliced and dried over the fire to be stored like biscuits.

The value of the bread-fruit has been over-rated. No wonder that when the adventurous English captain first came to Hawaii he should admire a vegetable which kept alive a swarming native population, and afforded him and his seamen an agreeable change from the wormy shipbiscuit of those old times! Although the bread-fruit might keep savage tribes from starvation, yet when it was introduced into the West Indies, and extensively propagated there, it was not found to be as digestible and nourishing as food which, like yams, cassava, or sweet potatoes, requires more labor to raise. Nevertheless the bread-fruit on the very numerous trees in the Lesser Antilles appears to be appreciated by the negroes, for it is difficult to find one fruit left to ripen out of the abundant crops produced each year. Sliced boiled bread-fruit 
appears as a vegetable at times on the tables of Europeans in the tropies, but it does not seem to be particularly in favor. Its taste is rather agreeable, and it is either baked whole, or cut up and boiled or fried.

The bread-fruit is usually picked while still green. It is about the size of a muskmelon, but solid throughout, without seeds, and with a slight core in the middle. It is increased by planting large root-suckers. Like the coconut, it is a strictly tropical plant, and seems to flourish best near the sea. It does not seem worth planting, except as a curiosity, where potatoes and fresh bread can be secured easily. 


\section{CHAPTER XVI}

\section{VEGETABLES WITH EDIBLE SEEDS}

The edible-seeded vegetables include mainly leguminous plants, such as peas and beans. Of all ordinary vegetables, these supply the most concentrated form of food, especially of protein food.

\section{PEA}

Garden or English peas are generally cultivated in the warmer regions for winter and early spring market. They form a staple crop, which requires little attention, and so is a favorite with many vegetable-growers. This crop will stand a light frost and grow even in very cold weather. A temperature of $24^{\circ} \mathrm{F}$. will injure open flowers and pods, but will not hurt the vines unless in an actively growing state.

Peas may be grown in the cool season between the tropics outside the equatorial belt. They usually require a fair supply of nitrogenous manure, such as nitrate of soda or nitrate of potash, since the nitrogen-gathering bacteria peculiar to the pea plant are not usually present in such soils. It would be advisable in many localities to use a slat shed. In India acclimated seed is preferred for the hotter regions. 
Soil and cultivation.

A light warm soil is very desirable for winter crops of peas. The land should be well prepared, though not deeply, about the last of October or in November; and the fertilizer scattered along the row and mixed with the soil. If one uses a seed-drill, a row should be made up of three or four drills about 2 or more inches apart. This will give the plants a chance to hold to and support one another. The ordinary practice is to make a row about 6 inches wide, by scattering the seeds along a furrow, and covering about an inch deep. The rows may be 20 inches or more apart.

Cultivation is needed to get air into the soil and to conserve the moisture. During cultivation the soil should be gradually worked up to the row so as to leave the plants hilled up at the last.

Fertilizer for peas.

The best fertilizer formula for peas is: ammonia, $\frac{3}{4}$ per cent; available phosphoric acid, 7 per cent; potash, 7 per cent. Use 600 to 1000 pounds to the acre.

For this crop it will be found desirable to use mineral fertilizer rather than compost. If nitrate of soda is used, it will require two applications - one at the time of sowing, and the second just as the first flower-buds begin to show. Cottonseed meal can be used as a source of nitrogen before planting, as a part of a compost fertilizer. Nitrate of soda will cause the vines to make a vigorous growth, so it should not be applied when a frost is looked for.

The following amounts of fertilizing materials may be 
used to obtain the amounts of each of the fertilizer elements called for in the formula :

Pounds TO THE ACRE

Ammonia . . $\left\{\begin{array}{l}300 \text { to } 500 \text { cottonseed meal; or } \\ 180 \text { to } 300 \text { dried blood; or } \\ 120 \text { to } 200 \text { nitrate of soda; or } \\ 100 \text { to } 150 \text { sulfate of ammonia. }\end{array}\right.$

Phosphoric acid . . 420 to 700 acid phosphate.

Potash. . . . $\left\{\begin{array}{l}500 \text { to } 900 \text { of kainit; or } \\ 80 \text { to } 140 \text { muriate of potash; or } \\ 90 \text { to } 150 \text { high-grade sulfate of potash; or } \\ 160 \text { to } 240 \text { low-grade sulfate of potash. }\end{array}\right.$

Enemies.

The pea weevil which attacks the young peas in the pod can be killed in the dry seed by the use of carbon bisulfide.

The powdery mildew, which spreads over late pea vines, can be checked entirely by bordeaux mixture, and probably by the use of sulfur.

Varieties of peas.

The garden peas may be divided into those with round seed, with wrinkled seed, and with edible pods. Those with wrinkled seed are better, but they are not so hardy as the round-seeded varieties. The sugar peas with edible pods are worth growing in the garden.

For shipping purposes, the dwarf varieties should be chosen. American Wonder and Blue Beauty do well. 
McNeil is a local variety grown extensively in Florida. The large number of varieties offered for sale often leads to confusion, but those named above may be regarded as trustworthy.

For home use, it is often desirable to sow the tall-growing varieties; these are later but usually more prolific. Telephone, Marrowfat, and Champion of England have been recommended. The land is prepared in the same way as for the dwarf varieties. If it becomes necessary to plant peas in a body - that is, to plant more than two rows alongside of one another - alternate rows should be farther apart, so as to have them by twos. When the peas have reached a height of 10 to 14 inches, it will be time to stake them. The two near rows should be staked so that they will mat together, leaving an abundance of space to pass between the alternate rows. As nearly all the peas will form on the outside or towards the light, the picking will be easy.

\section{BEAN}

The common snap or green shell beans are also known as kidney or haricot beans. There are over 180 distinct varieties in the United States. These beans grow well in spring or fall in subtropical climates and can be grown during the cool season in tropical lands, especially if shaded (as by a slat shed). They are not quite so tolerant of heat as the lima bean.

Seedsmen divide beans into two classes - the bush beans and the pole beans. These classes require different treatment. 


\section{BUSH BEANS}

Bush beans are the kind used for shipping purposes, as string-beans, snap-beans, or snaps. In some sections of the South the growing of snap-beans is a lucrative class of gardening. All beans are tender and sensitive to cold, even when it is not severe enough to freeze. Some peculiarly protected situations on the east coast of Florida are so favorably located for growing this crop for early spring markets that the lands bring an annual rental of $\$ 20$ to $\$ 100$ an acre and are valued correspondingly high, while only a score of miles distant equally good land not protected from the frosts is not worth possessing. Only those parts of the South that are free from frosts and long cold spells can grow beans for midwinter market; in other parts, late fall and early spring crops pay well.

Soil for bush beans.

For the early winter crop a light sandy soil is most valuable, while for a fall crop a heavier soil may be used to advantage. The land should be prepared moderately deep, and need not be in a high state of tilth. Any decaying vegetable matter that happens to be on the field may be left there.

\section{Fertilizer.}

'The proportion of fertilizer ingredients should be as follows : ammonia, $3 \frac{1}{2}$ per cent ; available phosphoric acid, 7 per cent; potash, 7 per cent. On poor land, 1000 to 1500 pounds of the above formula should be used to the acre. If the land is rich in vegetable matter, the ammonia 
may be omitted. While beans are able to assimilate atmospheric nitrogen when they have grown to a certain size, they are not able to grow well, cspecially when young, in a soil devoid of this element. It is, therefore, frequently necessary to supply an additional amount of nitrogen in the form of nitrate of soda, which is quickly available. This is frequently done at as late a period as when the plants are in bloom.

To obtain the amounts of different fertilizer elements called for in the above formula, the following materials may be used :

Pounds to the Acre

Ammonia . . $\begin{cases}300 \text { to } & 400 \text { dried blood; or } \\ 200 \text { to } & 300 \text { nitrate of soda; or } \\ 500 \text { to } & 750 \text { cottonseed meal; or } \\ 150 \text { to } & 200 \text { sulfate ammonia. }\end{cases}$

Phosphoric acid . . 700 to 1000 acid phosphate.

Potash . . . $\left\{\begin{array}{l}900 \text { to } 1200 \text { kainit; or } \\ 150 \text { to } 200 \text { muriate of potash; or } \\ 150 \text { to } 200 \text { high-grade sulfate of potash; or } \\ 300 \text { to } 450 \text { low-grade sulfate of potash. }\end{array}\right.$

Planting and cultivating bush beans.

When the crop is intended for snaps, the rows should be made $2 \frac{1}{2}$ feet apart, and the beans scattered thickly in the row, at least 10 seeds to the foot, making the row about 6 inches broad. The row should be made as straight as possible as this will save much labor in cultivating.

In sections where artesian wells may be employed to irrigate, the rows should be run on contours. When such contour lines have been established, they will serve as guides by which the irrigating system is laid out. A 
very simple and effective method has been employed with good success by some vegetable-growers in south Florida. The field, after the contour lines have been located, is thrown up in beds wide enough to hold but two rows. These beds are made by using a large two-horse plow and throwing up a head-land for every two rows of the crop to be planted. This leaves a double open furrow for every two rows. When the water is turned into such an open furrow, it moistens the land thoroughly. Such work requires a large amount of water, and is not practicable where the supply is limited. Under such a plan, the two rows on a bed are made only 18 or 20 inches apart, while the distance between those on separate beds is correspondingly greater.

In regions where frosts may be expected, a second sowing may be made two weeks after the first. The rows of the second sowing should be made as near as possible alongside of the rows of the first sowing. If a frost occurs, the first sowing will protect the plants of the second sowing. If no frost occurs, the second sowing may be destroyed by using a cultivator when it begins to injure the first sowing.

All cultivating in a bean field should be shallow, unless the crop is planted in a heavy soil ; but it should be frequent, especially in rainy weather (this of course does not refer to clay soil). As soon as the bloom appears abundantly, it is time to stop cultivating, at least near the plants.

Preparing bush beans for market.

Snaps are picked any time during the day when the dew is off and they are not wet from rain. They should be 
picked as soon as the beans in the pod areabout half grown, or before the pods begin to harden.

They are taken to the packing house and allowed to stand exposed to the air for an hour or so to lose their brittleness. The packing is simple. The pile is worked over more or less closely and all culls removed, at the same time they are straightened more or less and placed in special bean crates. The crates are pressed down just enough to keep the product from shaking about.

In warm climates the product of ten suffers severe loss from anthracnose, which causes peculiar red sunken spots on the pods. This disease often destroys entire shipments in transit. It can be prevented by spraying the picked pods while in the packing house with potassium sulfide or with sulfur spray. The snaps must be thoroughly dried before placing in the crate.

Harvesting bush beans.

If the crop is to ripen, it will be found more convenient to plant in hills; but these should be proportionately farther apart in the row. As soon as nearly all the pods are ripe, the plants may be cut off with a scythe or a grass-mower. The gathering is usually best accomplished by collecting the vines on forks and placing them in small piles at convenient distances. When thoroughly dry, they are stacked, and later threshed either by machine or by hand. The hand-threshed beans usually contain fewer broken ones, and hence sell for a higher price. Often the pods are picked as they ripen, but this process is too expensive for any but beans saved for seed. 
Varieties of bush beans.

W. W. Tracy, after a thorough study of all the varieties, gives the following list of desirable kinds :

Green Snaps :- Earliest: Warwick, Bountiful, Taylor's Green Pod, Ne Plus Ultra, Grenell's Stringless Green Pod.

Market:- Hudson Green Pod, Late Refugee, Black Valentine, Extra Early, Refugee, Giant Stringless Green Pod, Red Valentine.

Home :- Giant Stringless Green Pod, Red Valentine, Late Refugee, Warren Bush.

Yellow Snaps:-Earliest: Challenge Black Wax, Valentine Wax, Golden Wax, Improved Golden Wax, Currie's Rust-proof Wax.

Market:- Hudson Wax, Kenney's Rustless Golden Wax, Golden Wax, Davis Wax, Refugee Wax, Bismarck Black Wax.

Home:- Maule's nameless Wax of 1906, Pencil Pod Black Wax, Kenney's Rustless Golden Wax, Refugee Wax, Burpee's Kidney Wax.

Kidney Green Shell :- Improved Goddard, Ruby Horticultural Bush, Tennessee Green Pod.

The green-podded varieties are more popular among gardeners because of a general belief that they are hardier than the yellow-podded ones. There is less danger of getting poor varieties in beans than in many other vegetables.

\section{POLE BEANS}

The pole beans requires a richer soil than the bush beans, and are rarely used for shipping purposes. These 
beans are desirable for family use, but are somewhat later in maturing than the dwarf beans, so that both kinds should be planted for home use.

The early preparation of the soil is the same as for the low-growing forms. The land should be laid off 4 by 4 or 6 by 6 feet, the checks thoroughly fertilized, and after the fertilizer is well incorporated, the seed planted. From one to four beans should be planted to the hill, varying the number of plants to suit the strength of the land. Such ordinary care as is given garden crops will be sufficient. As soon as the vines begin to run, they should be staked. It is best to set the stakes so the tops of four will come together, and tie them; in this way, they will support one another. When staking them in this way, the space between the rows arched together must be cultivated by hand, but the vines will soon shade the ground, thus preventing further growth of weeds. When poles are not procurable, two wires may be set, 5 feet apart, along each row and twine run between.

Varieties of pole beans.

W. W. Tracy enumerates the following desirable varieties for home use :

Green Snaps:-Black Kentucky Wonder, Burger's Stringless, Kentucky Wonder, Lazy Wife Pole.

Yellow Snaps :- Golden Carmine, Podded Horticultural, Golden Cluster Wax, Indian Chief.

Green Shell : - Lazy Wife, Child's Horticultural, London Horticultural, Golden Carmine, Podded Horticultural. 


\section{LIMA BEANS}

The large-seeded varieties of the lima or butter bean provide, in the opinion of many, one of the choicest of vegetables. Shelled from the green pod, or when ripe and dry, these beans are alike acceptable if cooked for two hours or so. Lima beans are grown in many tropical countries and the best varieties should be in every tropical garden where the conditions allow of their thriving. They usually grow well in the dry or cool season or at an elevation of 1000 feet or more.

Culture.

The culture of the limas is the same as for the snap beans, except that they are more sensitive to cold, and require some weeks longer to mature.

Varieties of lima beans.

Some of the best varieties of lima beans are as follows:

Carolina or small-seeded:- Wood's Prolific Bush, Wood's Improved Polc.

Large-seeded:- Wonder Bush, Dreer's Bush, Henderson's Ideal (pole), Leviathan (pole), Challenger (pole).

\section{RUNNER BEANS}

Runner beans grow well in many tropical climates at the proper season. Their large pods are sliced and cooked green, or the seeds used as green shell beans. For the latter purpose, they are somewhat inferior to the lima beans. They are chiefly grown in California. 
Varieties.

Some of the best varieties of the runner bean are: Aroostook Bush (called Lima), Scarlet Runner Pole, White Dutch Runner Pole. Other varieties may be obtained from European seedsmen.

Enemies of beans in general.

The bean weevil injures the green pods and also the stored seed. It may be destroyed in the latter by treatment with carbon bisulfide.

Cutworms often destroy seedling beans and are best kept under by the use of poisoned bait.

Anthracnose appears as brown sunken blotches on the leaves and pods. It can be checked by spraying the seedlings with bordeaux mixture and by rotation. It is infectious and is frequently carried by the seed.

Sclerotium blight, which produces wilting and death, may be prevented by spraying the soil around the stems with ammoniacal copper carbonate.

Bacterial blight occurs as brown watery patches, which dry up. It spreads quickly. All diseased plants should be destroyed and rotation practiced. Downy mildew of lima beans pods may be checked by bordeaux mixture.

\section{Bulletins.}

Beans, U. S. D. A., Farmers' Bulletin 289.

American Varieties of Garden Beans, U. S. Bureau of Plant Industry, Bulletin 109, September, 1907.

American Varieties of Beans, N. Y. Agr. Expt. Station, Builetin 260, November, 1908 . 


\section{BROAD BEAN}

The broad bean (Vicia Faba) does not belong to the same genus as the other common beans, and is very different in appearance. It is much grown in Europe in the spring and summer. Its large flat seeds, an inch or so across, when young and tender, are almost as good as English peas, and are prepared in the same way. In subtropical countries, this bean may be grown in the winter season, as, unlike the lima bean, it will stand some degree of frost. It will not endure much heat, and the summer of most of the United States is too hot for it, though it is raised in Canada. It has been grown in India and in Louisiana, during the cool season, but does not produce a crop of good quality in the hotter parts. In England the seeds of the broad bean are often planted in double rows, consisting of two lines 9 inches apart, the rows being 2 to 3 feet asunder. The seeds are set about 2 inches deep. The plants are upright and the varieties vary from fourteen inches to five feet in height. The pods are picked when the seeds have attained their full size but are still very tender. They are in considerable demand in the countries where they are grown, both for the soups and as cooked vegetables. The Long-pod varieties are the most productive, while the Windsor group are the best for eating. Seeds of the broad bean can readily be obtained from some American and most European seedsmen. In dry weather it is sometimes advisable to soak the seeds for twelve hours before sowing. On the whole, the broad bean seems a promising winter vegetable for the subtropical regions of the western hemisphere. 
COWPEA

Cowpeas, often called field peas in the southern United States, besides being used as a soil-improver in a rotation, and as a valuable hay crop, are grown in the South, especially in Louisiana and Florida, for use as shell peas, as snaps, or for the dry peas which are cooked like beans. After conducting experiments on their digestibility, C. E. Wait said: "The cowpea has a distinctive and pleasing flavor, and can be prepared for the table in a great many appetizing ways, and compares favorably with other legumes in respect to both nutritive value and digestibility. Its wholesomeness and possible place in the diet are attested by its long and general use in the Southern States." The Lady cowpea was found to be somewhat more digestible than kidney beans, 83 per cent of the protein, and 95 per cent of the carbohydrates being digested. The varieties most used for table purposes are Sugar Crowder (an early pea), Blackeye, Lady (a small white pea), and Wonderful (a late variety). Bush Conch is a Florida table pea. These varieties can be obtained from seedsmen in Louisiana or Florida. For the sandy regions of the coastal plain, the Iron or the Brabham should be planted. Cowpeas will grow well in the hot season in subtropical countries, and as they stand heat better than the English pea or even than many kinds of beans, they can be grown in the tradewind belts. Cowpeas should be planted in drills 2 to 3 feet apart, with 6 inches or so between the plants. They may be fertilized and cultivated like beans. Bulletin.

Cowpeas, U. S. D. A., Farmers' Bulletin 318, 1908. 


\section{PEANUT}

The peanut is becoming one of the staple products of nearly all subtropical regions. The trade with the United States amounts to millions of dollars annually. The smallpodded kinds are grown in most warm countries. The kernels are regarded as valuable food for man and the lower animals, and as forming a more nearly complete food than any other single crop raised. The oil has been much used instead of olive oil, and is nearly colorless, with a slight odor that is not unpleasant, and a taste resembling that of olive oil. It is used in soap-making, and can also be employed for lubricating and for burning. One bushel of unhulled peanuts yields about a gallon of oil. The residue, after expressing the oil, makes a good oil-cake for stock, and also a good fertilizer; but it is too valuable to use for the latter purpose. Pigs fatten rapidly when turned into a peanut field, and peanut hay or straw is a useful stock feed. Besides this, millions of pounds are converted into confections or eaten as "nuts."

Soil and preparation.

Peanuts require a light-colored sandy soil, well drained but not dry. Loamy soils containing clay and lime produce heavier nuts and greater yields than more sandy soils. A warm location is preferred. The preparation of the field is similar to that for the usual field crops, except that it should be more thorough. Deep plowing is essential in localities where drought is likely to occur during the growing season. 
Fertilizer.

Peanuts require the following proportions of fertilizer ingredients : ammonin, $3 \frac{1}{2}$ per cent; available phosphoric acid, 5 per cent; potash, 10 per cent. Use 600 to 1000 pounds of the above formula to an acre. Most of our land will not require nitrogenous fertilizer for this crop. Dressings of lime are very beneficial, especially on sour soils. The following table gives the amounts of different fertilizer materials that may be used to supply the desired amounts of each element:

Podnds to the Acre

Ammonia . . $\begin{cases}300 \text { to } & 500 \text { cottonseed meal; or } \\ 180 \text { to } & 300 \text { dried blood; or } \\ 120 \text { to } & 200 \text { nitrate of soda; or } \\ 100 \text { to } & 150 \text { sulfate of ammonia. }\end{cases}$

Phosphoric acid . . 300 to 500 acid phosphate.

Potash . . . $\left\{\begin{array}{l}800 \text { to } 1200 \text { kainit; or } \\ 120 \text { to } 200 \text { muriate of potash; or } \\ 125 \text { to } 210 \text { high-grade sulfate of potash; or } \\ 250 \text { to } 400 \text { low-grade sulfate of potash. }\end{array}\right.$

Planting peanuts.

Before planting the best kinds, the pods are shelled, by breaking between the thumb and fingers, care being taken not to injure the kernels. After the seed has been shelled, it must be stored in small lots to keep it from heating, but must not become too dry. When many acres are to be planted by one person, it becomes quite a task and also a risk to keep the seed after it is prepared, if a planter is not used. While the seed is being hulled it is at the same time selected, all the poorly formed and bad kernels 
or pods being thrown out. It will pay to have a breeding plot, and select seed from the best plants, as with corn and Sea Island cotton. Two bushels in the pod will give seed enough to plant an acre.

In Virginia and the Carolinas, it is necessary to be careful about the time of planting; if a cold spell follows the planting, the seed is liable to fail ; if the planter waits until the possibility of cold weather is past, the greater part of the crop is likely to be frozen in the fall. The expense of replanting in those states is a doubtful investment. In the lower South there is no disadvantage in waiting until the weather and soil are warm enough to ensure speedy germination. The seeds should be tested, however, before they are committed to the ground. This can be done easily in a coldframe, or in a large shallow box which can be protected from the cold.

The rows are made about 3 feet apart, and the seeds planted 1 or 2 feet apart in the row. When the land is in a good state of cultivation, it is not difficult to lay off the rows and then make dots in which to drop the seeds. On clay soils the row must be raised slightly above the general level, so that the seeds will be about on the level of the land. The seeds should be planted about an inch deep; if the soil is sandy or light, it will be better to plant deeper. Peanuts, however, are usually planted with a one-horse planter, similar to a cotton planter, and costing about $\$ 15$. In about two weeks after planting, the field may be examined and any missing hills replanted. The time of planting depends on the weather, but is usually between the middle of April and the middle of May or even later near the tropics. 
Cultivation of peanuts.

The field is put into thorough tilth before planting, and is kept in good tilth so as not to give the weeds a chance to get the crop under. A week or ten days after the field has been planted, it should be cultivated. It does not matter what kind of implement is used, so long as the surface is kept mellow, and weeds not allowed to grow. In some sections it is better to plant the field in checks. One thing should be kept in mind constantly, that weeds are very difficult to clear out after the vines have begun to bush. In general, level or flat culture will be found better in light sandy soil. Under this form of cultivation, the soil does not dry out as much as with hill culture. A second cultivation is given within ten days or two weeks after the first, the interval being gauged more by the necessity of the case than by the time elapsed. After the second cultivation, the hoe and the fingers may have to be used considerably; the hills have begun to spread so that it is difficult to cultivate up to the plants. Care must be taken not to disturb them as they are preparing to produce flower-buds, and any interference is liable to be detrimental to the yield. All grass and weeds coming up in the hill have to be pulled out by hand. The third and fourth cultivations have to be carried on with still greater care than the second; the weedings need more care also, on account of the crop setting at that time. After this, shallow cultivation may be kept up until the vines meet across the row. If the land is quite level, the cultivation should be carried on so that when the plants are "laid by," the rows will stand on 
slight mounds, the trough between which will carry off the water during a rainy season and keep the crop dry. After a field is well established there is little danger from drought.

\section{Harvesting peanuts.}

About two months after the last plowing, the earlier nuts begin to ripen. In a dry season, the vines may be left in the field until the greater part of the crop is ripe, if there is little danger from frost; but in Virginia the crop has to be harvested before the first frost, as the nuts and vines are severely damaged by it. During a rainy autumn it is necessary to watch the erop, and harvest it before the earlier ripened nuts begin to sprout.

For removing the vines, a plow with a long sweep is often used. This share or blade passes along on each side of the row under the nuts and cuts off the roots. This implement may be likened to a stirring plow with the moldboard removed. The share is regulated to such a depth as to work as near the surface as possible without cutting any of the nuts. A machine potato-digger will do the work well, and special peanut diggers are also used which dig, clean, and bunch the vines.

When the plow is used, laborers follow it and raise the vines with a pitchfork, at the same time shaking off all the dirt. Two rows of vines are tossed together into a windrow. These are allowed to dry for a few hours and then stacked. A pole about seven feet long is put into the ground firmly and the vines piled around this. Before stacking, some sticks of wood are laid down around the pole to keep the vines off the ground. The stacks are made as narrow as possible, to give them a good chance 
to dry out. In about two or three weeks from the time of stacking, the crop will be ready to be picked. This is usually done by women or children, and is paid for by the bushel. The picking is an expensive operation, and it may be delayed; but if the hay is wanted, it is best not to leave this out any longer than necessary. It is also well to have the nuts where they cannot be destroyed by insects and other animals, and when one has room in the barn it will be found cheaper to dry the crop and then house it at once. The smaller kinds of peanuts fill the shell more completely, and so can be more readily picked by machine. There has been some objection raised by the retail dealers to buying the nuts that have been picked by machine, but this will soon disappear when more perfect separators are used, and when the nuts become so cheap that they cannot be picked by hand.

After the nuts have been picked they should be cleaned. This is done in cleaning and grading factories. The process throws out all "pops and snaps," and also removes the dirt and sand. It would pay to have one of these cleaning and grading factories in every neighborhood where many of the large-podded peanuts are grown, so as to be able to put the product on the market in the best shape possible. As soon as the crop is cleaned, it should be sacked in bags holding about 100 pounds or four bushels. It ean be stored in this way, and put on the market at any time.

The usual yield is from thirty to fifty bushels an acre, but many crops are greater than this, some as high as a hundred bushels. Besides the nuts, from one to two tons of excellent hay may usually be obtained. 
After the crop has been removed, hogs should be pastured on the field to feed on the nuts that were not gathered.

Varieties of peanuts.

Virginia Bunch and Virginia Runner are large-podded varieties. Dixie Giant has a larger pod, and is grown on the Gulf Coast. Spanish and Tennessee Red are mostly grown for stock feed.

Literature.

Peanut, Cyclopedia of Amer. Agriculture, Vol. II, pp. 514-519, 1907. Peanut, U. S. D. A., Farmers' Bulletin 431.

\section{GOOBER}

The goober looks like a large one-seeded peanut. In some parts of our country the name goober is applied to the peanut. Botanically, the peanut is Arachis hypogoea, while the goober is Voandzeia subterranea. The cultivation and general manipulation are the same as for the peanut. The crop has not been grown extensively.

Either the peanut or the goober makes a good soiling plant, and one that is worth careful attention from this standpoint, as well as from that of an economic crop.

\section{SWEET CORN}

The varieties of sweet corn grown for cooking when nearly ripe have the starch in the grain more or less replaced by sugar, and the grains in consequence wrinkle when dried. It might be called wrinkled corn, just as 
the sweet kinds of English pea are called wrinkled peas. Sweet corn is not grown in the southern United States to such a large extent as in some parts of the North. It has been found that properly cured and selected home-grown seed is superior to that from more northern states. Sweet corn should be planted earlier than field corn so that it will blossom first, or it should be grown in an isolated place where it will not be liable to mix with the field corn. Pollen from field corn makes every grain of sweet corn it fertilizes starchy, and so injures the quality of the ears.

The varieties Crosby, Black Mexican, Hickox, Country Gentlemen, Stowell's Fvergreen, and Iate Mammoth have been recommended for a succession in Louisiana. In north Florida, Black Mexican was found to do well, and this would probably be one of the best sugar corns for tropical countries. There are several points requiring attention in the growing of sweet corn for seed. If there is any field corn tasseling at the same time within even a quarter of a mile, the pollen from this will often cause mixing in the ear. But these mixed ears can readily be detected, and thrown out altogether, or the blended grains only removed. As sweet corn usually ripens in the rainy season, the ears will require drying under cover in thin layers, or with the help of a fan. Fire heat has not proved satisfactory. Early Adams and Extra Early Adams are often grown as garden corn; but they are not sugar corns, and so will spoil any sweet corn which blossoms at the same time. 


\section{CHAPTER XVII}

\section{VEGETABLES WITH EDIBLE TUBERS OR ROOTS}

Several of the root crops, such as the potato, the sweet potato, and cassava, are important food crops. Others, as the radish and carrot, form agreeable adjuncts to the staple foods. Their food value is mostly due to starch, or, in the case of the sweet potato and beet, to sugar also.

\section{IRISH POTATO}

The potato, or as it is often called the Irish potato, was cultivated by the ancient inhabitants of South America on the tropical mountains of Peru and Colombia. It seems to have still some of the characteristics of a tropical mountain plant in its poor endurance of frost, drought, or heat. In subtropical countries where frosts occur, the potato is grown only in the spring and fall. In frostless regions it may be cultivated in the cool season, but in several tropical countries it will only grow well at elevations of some thousands of feet.

To raise Irish potatoes profitably in the South, it will be well to watch the crop in the potato-growing sections of the North. If the yield of the late crop has been good, the demand for new potatoes will be small and the market 

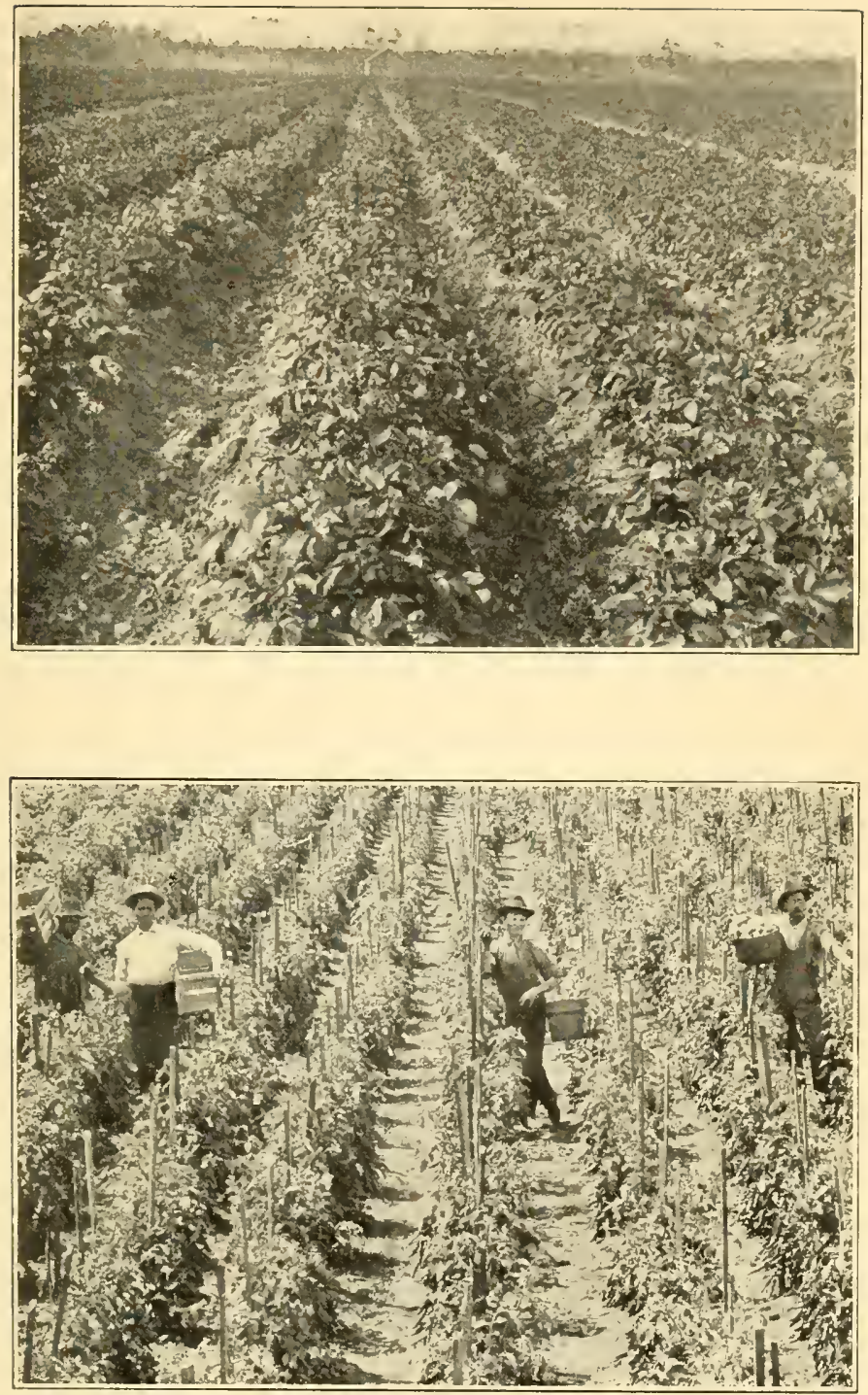

Plate XII. - Potatoes and Tonatoes.

Irish potato field above; below, tomatoes properly staked. 

easily stocked; but if the yield of the late crop has been poor, there will be a steady demand for all the potatoes which can be raised.

The large yields that one reads about are produced by persons who have served their apprenticeship at this kind of gardening. One should not expect to raise a heavy crop until he is well acquainted with the fields to be used, and familiar with many kinds of potatoes. Over the greater portion of the South it is necessary to use insecticides and fungicides to raise the largest crop.

Soil and preparation for potatoes.

Potatoes can stand heavier land than the usual vegetables, but the soil must be fertile and deep. A bay head or muckland that has been drained and freed of sourness will be found exceedingly well adapted to this crop. A cold, stiff, clayey soil usually fails to give a profitable return. If the land is not naturally moist, water will have to be supplied; it is useless to try to raise this crop on dry land, but it will stand a long drought if the substratum is not dry. Heavy soggy land will not produce a good crop until it is drained. On this point we can do no better than to quote Dr. Lawes, of the Rothamsted Experiment Station, England: "If you want to grow large crops of potatoes, you must be liberal in your supply of water as well as food. The following will give you some idea of the importance of rainfall, even when the potatoes have an abundance of food. We grow potatoes continually upon the same land, using the same manures. The potash and phosphate are in excess of the requirements of the largest crop grown, so they are an accumulation in the soil. The 
nitrogen is also largely in excess of what the crop takes up, but this does not accumulate. Rainfall in inches:

May to October, $1881,13 \frac{1}{2}$ in., yield 482 bu. per acre.

May to October, 1882, $12 \frac{1}{2}$ in., yield 397 bul. per acre.

May to October, 1883, 13 in., yield 401 bu. per acre.

May to October, 1884, 9 in., yield 222 bu. per acre.

In 1881 the rainfall was better distributed over the season than in 1883."

In preparing the land, all débris and rubbish should be removed. The plowing should be deep and thorough, so there will be no difficulty for the plants to find moisture. Thorough plowing will partly compensate for a lack of fertilizer.

If the field is to be irrigated (and this should be done where it is possible), it may be thrown up in beds wide enough to hold from two to ten rows. The trenches between the rows are to guide the water. During a very wet season, these trenches of about nine inches in depth are excellent for drainage, as they keep the water from standing on the land. By this method the plants are fed from the bottom, and keep sending their roots downward to the stratum of moisture. Plate XII shows deep furrow in left foreground.

Fertilizer for potatoes.

The following fertilizer ingredients should be used: ammonia, 5 per cent; available phosphoric acid, 6 per cent; potash, 9 per cent. Use from 800 to 1200 pounds of the above formula. When potatoes sell for a high price and the land is near market, it will be found profitable to use as much as 2000 pounds. 
Chlorides are regarded as detrimental to the quality of the potatoes. On sand lands and sandy loams, organic ammonias are usually employed.

The following quantities of fertilizers will give the desired amounts of the elements :

Pounds to THE ACRE

Ammonia . . . $\left\{\begin{array}{l}500 \text { to } 800 \text { cottonseed meal } 500 \text { dried blood; or } \\ 3500 \text { to } 300 \text { nitrate of soda; }\end{array}\right.$

200 to 300 nitrate of soda; or

150 to 250 sulfate of ammonia.

Phosphoric acid . . 500 to 700 acid phosphate.

Potash . . . $\left\{\begin{array}{l}200 \text { to } 300 \text { nitrate of potash ; }{ }^{1} \text { or } \\ 150 \text { to } 225 \text { sulfate of potash, high-grade. }\end{array}\right.$

The roots of the potatoes do not penetrate the soil as deeply as those of some other crops, so the fertilizer should be in the furrow or in the hill. In whatever way the fertilizer be applied, no effort should be spared to have it well mixed with the soil.

Seed potatoes.

Several series of careful experiments have been undertaken, which appear to show that the use of small tubers for planting decreases the yield. On the whole the evidence is against the use of small tubers for propagation, and these are also more likely to be immature. Mediumsized tubers will give satisfactory yields.

${ }^{1}$ When nitrate of potash is used, only one-third of the amount of materials used for nitrogen need be employed. By referring to the table of approximate amounts of different fertilizers, it will be seen that the nitrate of potash contains 13 to 14 per cent of nitrogen. 
With regard to home-grown seed potatoes, the difficulty is chiefly with properly ripening and storing the tubers. If this can be done, it has been claimed that the fallgrown tubers in the South are equal to northern-grown potatoes as seed for the spring crop. However, many growers who raise early potatoes use northern seed. Even with good home-grown seed, experience in both Europe and America has shown that a change to seed potatoes from another locality is often necessary every few years to keep up the yield.

It is usually best to cut the tubers before planting. There are machines that cut, drop the pieces, and fertilize the ground at the same time; such machines are used with a profit in regions where potato-growing is carried on extensively. On well-cleared land, and where large areas are to be planted, it will pay to use them.

\section{Planting potatoes.}

For the fall crop, the seed potatoes are often sprouted before planting and cut to one or two eyes. If the planting is to be done by hand, care should be taken not to cut the tubers and leave them lying in a pile; even as small a heap as a bushel is liable to heat and partly to lose its germinating power in twenty-four hours. If the tubers are cut several days beforehand, scatter them to dry; the moisture lost by evaporation is soon regained when planted, and without perceptible loss in vigor of growth. Some growers advise the use of lime or land plaster on the cut tubers when they are not used immediately. The tubers should be cut so as to give the eyes as much "meat" as possible; if the conditions are proper, only one or two 
eyes in each piece will start, the rest remaining dormant. The pieces are dropped about a foot apart in the row and covered by means of a plow, and if the land is loose, rolled. When irrigation is used, it is impossible to cultivate across the rows and they should then be made as straight as possible so that the cultivator can run very near the row. It is possible to raise good crops of potatoes without hoeing at all.

For fields that cannot be irrigated, the rows may be made $2 \frac{1}{2}$ or 3 feet apart. Two by 2 feet is too close for good cultivation. When labor is hard to obtain, it will be found cheaper to raise the crop in checks. In such a case, the rows may be marked out $2 \frac{1}{2}$ feet apart with the crossmarks 2 feet apart. If labor is cheap, the rows may be marked out 3 feet apart, and the potatoes dropped about a foot apart in the row. Such fields usually have to be hoed once or twice. Cover the pieces with 4 or 5 inches of soil.

While potatoes like decaying vegetable matter, barnyard manure is rarely used on account of its tendency to induce scab. It is difficult to make the soil too rich, but whether it will pay to use large quantities of commercial fertilizer depends on the conditions of the markets. Lime or other corrective of acidity should not be used.

\section{Cultivation of potatoes.}

The cultivation is much the same as for tomatoes, and should be carried on in the same way. When the potatoes are about to come through the ground, a good harrowing with a smoothing harrow or horse weeder will destroy many weeds and will take the place of the first hoeing.

The cultivation should be thorough, and the first cul- 
tivation may be deep. If the field is not irrigated, it will be safer to employ level culture. Hill culture is good in a rainy year, but is disastrous in a very dry one. In case of a rainy season, trenches can be made in various parts of the field to relieve it from surplus water. By the time the tubers begin to form, the field should be "laid away." Towards the end the cultivation should be rather shallow. (See upper figure, Plate XII.)

\section{Harvesting.}

The time to harvest potatoes depends on the condition of the market. Usually the earliest crop brings the best returns; very early potatoes never fail to sell well. The marketing is done in ordinary barrels. This is a staple crop, so it is not necessary to pay much attention to fine stencils and nice finish of containers. The buyers pay more attention to the product offered for sale than to the style in which it comes.

It is not profitable to raise large quantities for the local market, unless one is engaged in the general vegetable business. The hotels throughout the South consume a considerable quantity, and their trade is worth soliciting. The time of harvesting is determined by the condition of the tubers; if the skin peels off easily, they will not carry to a distant market, and be in a presentable condition. For midwinter delivery the market expects a certain amount of peel to be knocked off ; this insures the product as new.

During the time that the crop brings a fancy price, it will pay to dig the potatoes by hand with a fork, but when the profits are small and the crops are large it will be 
found more profitable to use horse power. A favorite way is to plow them out with a common two-horse turning plow, and then have the hands gather those in sight and work the hills over till they are found. A more successful method is to use a potato digger. A cheap form is simply a large bull-tongue plow with iron rods projecting back to separate the potatoes and the soil. The machine is simple, but saves much labor and does efficient work. There are also much more elaborate machines, that dig and elevate the potatoes to a wagon, thus reducing the labor to a minimum; but these are not operated easily unless the land has been well cleared.

\section{Storing potatoes.}

In colder climates, all that is necessary is to keep the potatoes from freezing, and usually they will remain sound until spring. As soon as warm weather approaches, they begin to sprout. This may be prevented by keeping the cellar cool. In the South the matter of storing is not quite so simple, as the tempcrature is usually so high that germination begins soon after ripening. A successful way of keeping potatoes for family use is to kill the buds, and then barrel the tubers to prevent excessive evaporation. One-half to one per cent sulfuric acid will accomplish this. The potatoes are placed in the liquid for an hour and then removed to dry. Of course this will remove all vitality from the buds, and the potatoes can only be used for food. The operation kills many germs of decay at the same time, and so acts as a preservative. Another excellent way is to keep the tubers in thoroughly dried sand, to which one part in four of air-slaked lime has 
been added. This method has the advantage of not destroying their germinating power.

Varieties of potatoes.

The earlier potato varieties are preferable for market, as the early part of the crop pays best. The later varieties will be found good for home use, and give potatoes after the early ones have been exhausted. There are many disadvantages in raising the early varieties, however, and often they fail to produce a crop at all; but as the vegetable-grower learns more about the requirements of the crop this becomes easier. Rose No. 4, Early Rose, Bliss Triumph, Early Ohio, Beauty of Hebron, and Burbank are good early varieties. Carman No. 1 and Rural New York No. 2 are good later varieties.

Second crop of potatoes.

It is a common practice to import potatoes for fall and winter use, but this has been proved unnecessary by the production of a second crop. The first crop does not keep well without special care later than September. In July or August tubers are spread out to the light under an arbor or on a barn floor where the sun will not hurt them. This is not necessary, but it will hasten their sprouting, and it is easier to take care of them here than when planted in a field. When the tubers have sprouted well they may be cut and planted, care being taken, of course, not to knock the sprouts off. Sometimes the long sprouts are taken off as "draws" and planted.

The field may be planted any time, even as late as September, with a reasonable hope of securing a small 
crop. It will, however, be found difficult to keep the vines healthy and the field free from weeds. It is also necessary to have the field well prepared as to drainage, for while potatoes like a moist soil they cannot stand a soggy one.

The second crop is simply intended for home use and for local markets. It is well worth the time and trouble to raise this fall crop when one has to pay $\$ 1.50$ to $\$ 2$ a bushel at retail for potatoes grown in the North. This second crop is sometimes used to supply seed tubers for the spring.

Diseases of potatoes.

Scab is often carried by the seed potatoes. It may be lessened or prevented by treating the seed with a dilute solution of corrosive sublimate or of formalin.

Early blight is caused by a fungus which spreads on the leaves in ring-shaped areas, and decreases the yield. It may be prevented by repeated spraying with bordeaux mixture.

Late blight destroys the leaves and rots the tubers. It may be prevented or checked by thorough spraying with bordeaux mixture.

Rhizoctonia (Corticium) causes rotting of the base of the stem and rosetting. It is often carried by the seed potatoes, and the remedy is to plant healthy seed.

Bacterial blight causes the leaves and stems to wilt and is contagious.

Bulletins.

Growing Irish Potatoes, Fla. Exp. Sta. Bulletin 82, 1905.

The Cultivation of Potatoes, Va. Exp. Sta. Bulletin 174, 1907. 
Potato Diseases, Maine Exp. Sta. Bulletin 149, 1907.

The Improvement of the Potato, Ill. Exp. Sta. Bulletin 127, 1908.

Potato Growing, Minn. Exp. Sta. Bulletin 114, 1909.

The Potato as a Truck Crop, U. S. D. A., Farmers' Bulletin 407, 1910.

\section{SWEET POTATO}

The sweet potato is a tropical plant which is cultivated in most tropical and subtropical countries, and especially in the southern United States. In warm countries, it commonly produces some fertile seed, and new varieties can be obtained from these, as is done with the Irish potato. There has not been much systematic work done in this direction, though a beginning has been made in some tropical countries. The plant is remarkable for the ease with which cuttings of the green vines take root, and this is the commonest method of propagation. Its tuberous roots contain about the same percentage of starch as the Irish potato, together with a variable amount of sugar.

This crop is cultivated extensively in the southern states. It may be grown successfully as far north as Nebraska and New York, but in these sections it cannot be regarded as more than a garden product.

Soil for the sweet potato.

Nearly all land in the South is adapted to this crop, but clay soil is not as good as loam. The opinion that rich land is not suitable is a mistake. Some of the very best crops have been raised on drained muckland. The sweet potato is so tolerant that it is difficult to find land that will not produce a fair crop. To produce a large crop, warm 
sandy soil should be chosen, well fertilized and plowed deeply. A finer grade of sweet potato for table use may be produced by plowing shallow and using less fertilizer or none at all.

Fertilizer.

The proportion of fertilizer ingredients should be as follows: ammonia, 5 per cent; available phosphoric acid, 7 per cent; potash, 9 per cent. Use 800 to 1200 pounds to the acre. If the soil is rich in nitrogenous matter, less of this element should be used, or if very rich, it should be omitted altogether. If the potatoes are intended for table use, the amount of fertilizer should be less than when grown for stock feed or for shipping. Sulfate of potash is preferred as a source of potash.

The following quantities of fertilizers will give the amounts of each element called for in the formula :

Pounds to the Acre

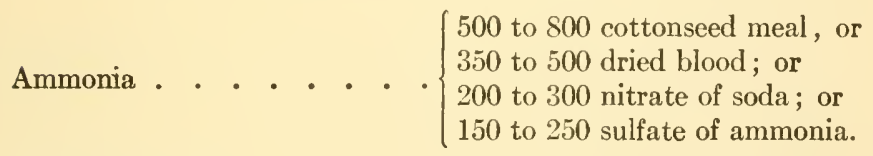

Phosphoric acid . . . . 550 to 800 acid phosphate.

Potash . . . . $\left\{\begin{array}{l}150 \text { to } 225 \text { sulfate of potash; or } \\ 200 \text { to } 300 \text { nitrate of potash; or } \\ 500 \text { to } 700 \text { cottonseed hull ashes. }\end{array}\right.$

Propagation of the sweet potato.

To obtain early sets, or "draws," in subtropical climates, the whole potatoes should be placed in a hotbed or coldframe and covered with an inch of soil, six or seven weeks 
before the young plants are wanted. By pushing the sets ahead in a hotbed, one will have new potatoes at least a month earlier than by waiting for them to sprout in the field. The early crop will be found to be among the most profitable for shipping; if the crop is wanted for home consumption, it will be sufficient to make a bed in the open from which to obtain sets. The amount of space required in a hotbed for a bushel of potatoes varies from 9 to 32 square feet, depending on the size of the potatoes used. The number of these plants required for an acre is from 5000 to 12,000 , varying with the locality and the character of the soil.

For repeated "drawing," $1 \frac{1}{2}$ to 2 bushels of small potatoes, or 4 to 10 bushels of large ones are required to give sets enough to plant an acre. Double that quantity will give enough sets at one drawing to plant an acre.

The main crop of sweet potatoes is grown by vine cuttings from an early patch planted by "sets."

Preparation of the land for sweet potato, and transplanting.

Nearly all of the crop is planted out on ridges to allow of drainage, but it is a question whether this is the most desirable method on sandy land. For an extensive crop the plants may be set in checks ; this requires fewer plants to an acre and gives a smaller yield, but it does away with most or all of the hoeing, which is an expensive operation.

The labor of transplanting is an important item of expense, and if this could be reduced it would largely increase the acreage. The transplanting machine is sometimes used for this crop. 


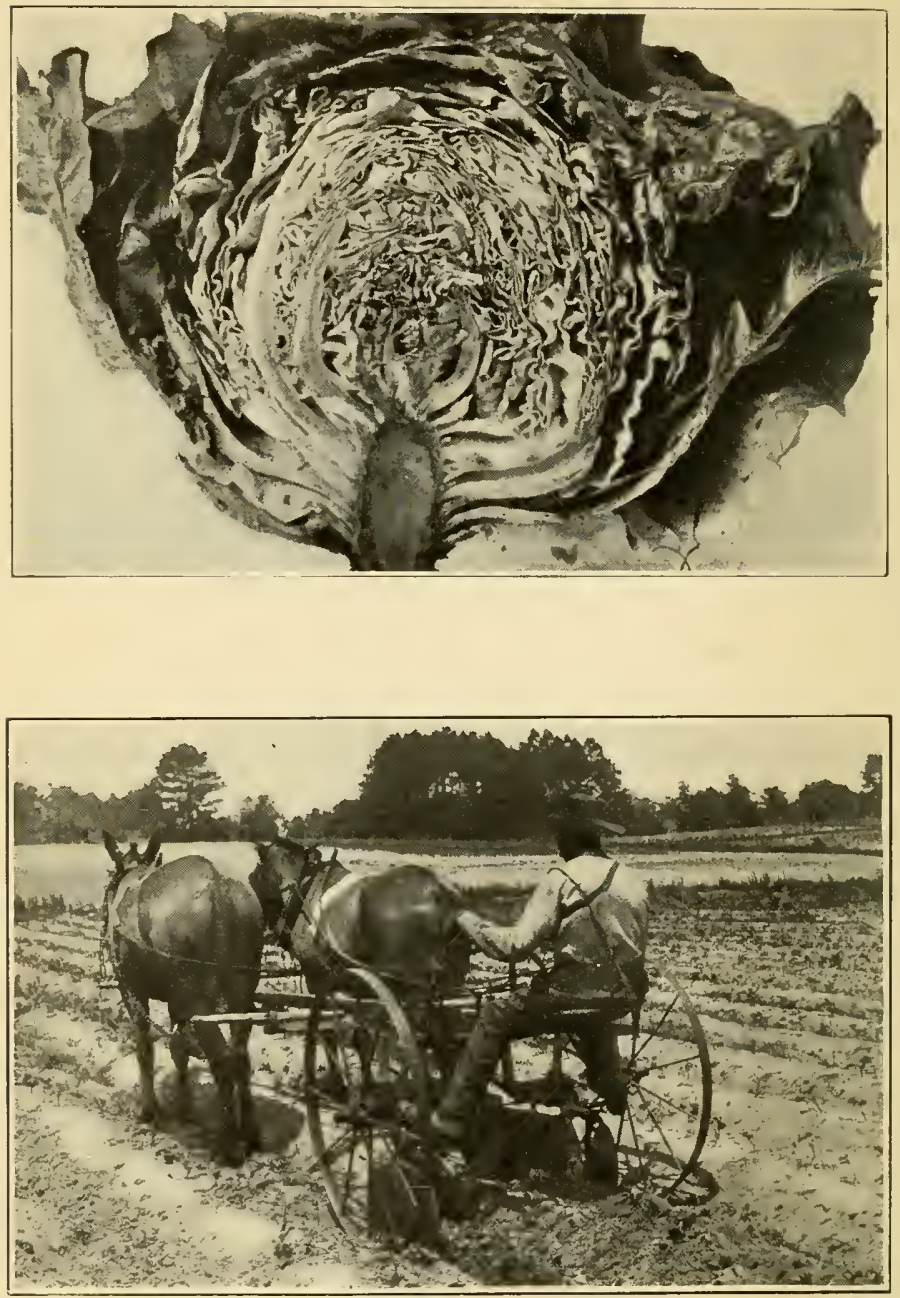

Plate XiII. - Big Boston Head Lettuce in Longitude Section, above; below, Disc Cultivator in Sweet Potato Field. 
An inexpensive and efficient way of preparing the land is shown in the illustration (Plate XIII). The beds are thrown up with a two-horse disk cultivator. The vine cuttings are dropped at proper intervals. The vines are then pushed three or four inches deep into the loose soil. A flat stick three or four feet long will be found convenient for this purpose. Either an end or the middle of the vine is pushed in the soil, according to the wishes of the planter. The rows should be made $3 \frac{1}{2}$ to 4 feet apart and the plants set 15 to 18 inches in the row. If the crop is to be checked, the plants should be placed $3 \frac{1}{2}$ by $3 \frac{1}{2}$ feet, or for the smaller kinds $2 \frac{1}{2}$ by $2 \frac{1}{2}$ feet.

\section{Cultivation.}

The soil should be stirred often enough to keep it loose and free from weeds. If many and heavy rains fall, it will be necessary to cultivate oftener than when there is only a moderate amount of rain. All cultivation should be shallow and no vines covered. After the vines begin to run, it may be necessary to raise them with a pronged hook, or an attachment to the cultivator. Such a device may be made of $\frac{1}{2}$-inch round iron about 4 feet long; this iron is bent into the shape of a letter $J$ and a loop or eye made at the end of the long arm. It is attached to the cultivator by passing a half-inch bolt through the eye and through the beam. The short arm of the bent iron is placed down, and by varying the amounts of curvature, and having the point more or less sharp, it will run under the vines and raise them out of the way. Some adjusting is necessary to adapt it to the particular implement and to the particular field. (See lower figure, Plate XIII.) 


\section{Storing.}

The harvesting of sweet potatoes is a simple operation; the vines being removed, a man plows the crop out with a large two-horse plow. It is necessary to set the plow deep enough and to have one wide enough to turn the hills out completely; a small plow and a shallow furrow will cause too many potatoes to be cut. In a sandy loam there is little else left to do than to pick up the crop.

The storing may be done in houses or banks. A sweet potato house may be built of planks covered with sod and the cracks filled with clay. The temperature should remain as low as possible without freezing; there are only occasional days when it will be cold enough to freeze, but as they are liable to occur every winter, one must prepare for them as though they occurred more frequently.

A dry place should be selected, as convenient and as safe as possible. If the spot does not shed water, a bed of corn-stalks about 8 feet wide and as long as desired should be made. The potatoes are piled on this bed in an A-shaped pile about six feet high. This pile is packed with corn-stalks, rice straw, or boards, and covered with loam to the depth of 4 to 6 inches. If straw is used, a layer should be packed around the base of the pile, then another higher up, and so on; this will cause it to turn water out. In banking the soil, the same method should be followed. A number of ventilators should be made of boards. These should be perforated with auger-holes, and run through the central part of the heap. They should be so fixed that the rain cannot enter through them.

A small quantity of sweet potatoes may be kept by 
placing them in dry sand or dry cottonseed hulls and keeping in a cool place. These methods may be used to keep them over from the time of taking out of the bank until new ones come on. The cooler the storage of sweet potatoes without freezing, the better they will keep. Just after they are put into piles, there will be a period of sweating; during this time the temperature is liable to run up to $80^{\circ} \mathrm{F}$, but no trouble need be anticipated from this source.

\section{Marketing.}

Sweet potatoes for shipping should be graded into two or three grades. They are shipped in double-headed ventilated barrels, holding eleven pecks. The yam varieties of sugary sweet potato are becoming somewhat more popular in the northern markets in the spring.

\section{Uses.}

Sweet potatoes can be easily dried in an evaporator after boiling and slicing, and there is some demand for the canned article.

One of the mot promising uses is to feed to stock. The vines may also be used as hay.

\section{Enemies.}

The worst insect enemy of the sweet potato is the rootborer or weevil. This is found throughout the tropics and is spreading in some of the Gulf states. It may be checked by the destruction of all infested potatoes and by change of land.

The black-rot is one of the worst fungous diseases. It attacks the young shoots and forms brownish patches on 
the potatoes. It is spread by using sets from diseased potatoes.

The liability to fungous diseases is lessened by using only cuttings from healthy vines to plant the fields, and by practicing rotation.

\section{Varieties of sweet potatoes.}

The varieties that give a very large yield do not make, as a rule, good table potatoes, and are generally grown for stock-feeding.

In the North the sweet potato is usually boiled and a dry starchy one is preferred; in the South the potato is usually baked and a sugary moist-fleshed one is in demand. Big-stem Jersey, Yellow Jersey, and Red Jersey are the most extensively grown varieties of the floury type. The moist sugary potatoes are usually known as yam potatoes, and among those grown for table use are Georgia Yam, Pumpkin Yam, Southern Queen, and Vineless. Triumph and Providence are favorites in Florida. Nancy Hall is also grown extensively there.

There are about a hundred varieties, or about that many different names occur for varieties. The term yam should be omitted whenever practicable, as this refers to an entirely different vegetable. It pays to raise some mealy early varieties for shipping north. These always bring a good price, but are usually a home-grown product, because southern varieties are not shipped in.

\section{Bulletins.}

Fungus Diseases of Sweet Potatoes, N. J. Exp. Sta. Bulletin 76, 1890. 
New Method of Preserving Sweet Potatoes, S. C. Exp. Sta. Bulletin 71, 1902.

Sweet Potato Experiments, Ark. Exp. Sta. Bulletin 72, 1902.

Diseases of Sweet Potatoes, Ala. Exp. Sta. Bulletin 135, 1906.

Sweet Potato Borer, Tex. Exp. Sta. Bulletin 93, 1907.

Sweet Potatoes, U. S. D. A., Farmers' Bulletin 324, 1908.

\section{JERUSALEII ARTICHOKE}

This vegetable is not an artichoke, nor does it come from Jerusalem. It is an underground tuber belonging to the sunflower family (Helianthus tuberosus) and is a native of the United States, where it was grown by the Indians. In its own country it has not met with much favor, and is disliked as a vegetable by some. But the varieties which are grown in Europe, when properly cooked, are liked by many, as an agreeable change from potatoes. It is grown successfully in most gardens of India in the hot season, and is appreciated there. From its early culture, large returns, and resistance to cold or heat, it well deserves a place in the subtropical or tropical garden.

It is propagated from the tubers, which may be cut up like Irish potatoes. In English gardens, with rich soil, it is usually planted early in the spring in rows about 3 feet apart, the sets being put about 6 inches deep and a foot or so apart. Its flowers rarely appear in England, probably from the shortness of the summer. In India the tubers are planted in May and the crop is ready in November. The flowers should be removed before they form seed. As soon as the tubers become firm and large in the fall they may be used for cooking, and will be in 
good condition until they begin to sprout in the spring. The harvesting may be done by plowing out the row and then picking up the tubers that are in sight. A harrow is then run over the furrow to drag out as many more as is practicable. Hogs may be turned into the field to gather what is left. If the hogs are not left in the field too long, tubers enough will be left to produce plants for another year, but these will not be in rows, so they cannot be cultivated as before. This difficulty may be avoided by saving tubers enough to plant the field again. The tubers may be stored in dry earth.

\section{YAM}

Different species of yam (genus Dioscorea) grow wild or are cultivated throughout the tropical belt, and even in the subtropical regions of China and Japan. They have large perennial rootstocks containing much starch (seldom sugar). From these arise long twining vines with heartshaped leaves. Some varieties of sweet potato are called "yams" in the southern United States, but the real yams have no resemblance to the sweet potatoes. Yams form an important article of food for the laboring classes in the West and East Indies, and the best varieties are served at the table in all houses where the potato cannot be obtained, as is often the case.

As a table vegetable, even the best yams are inferior to the potato, although when properly cooked they make a passable substitute. It does not seem likely that the yam will come in favor at any northern market where the potato can be obtained, except perhaps as a curiosity. 
But in tropical countries, where the Irish potato can only be raised on the mountains, or during the cool season, the best kind of yams should find a place in the vegetable garden. Several varieties of yam have the advantage over the sweet potato as a staple food in that they can be kept for a much longer period out of ground without damage. Yams are also easy to grow, and may be planted at all seasons of the year and taken up from the ground almost at any time when they are wanted, so that a constant supply may be had. They form the staff of life of the negro population of the Antilles.

The yams are propagated by cutting off the top of the rootstock and planting it again with the attached vines; or after this has grown for a few months, the yam it produces is cut up into pieces with buds on each, and these pieces used for a new crop; or the top of the yam may be cut at once into "sets." The "sets" are planted several in a hill with a stake to climb on, at 6 to 8 feet apart, or are allowed to trail on the ground. They have been found to give better returns when staked. The yams are ready in seven to, eleven months. Several yams may be produced by one plant, and according to the species or variety may weigh from a few ounces to a hundred pounds each. The produce may be a dozen tons to the acre.

The white or square-stemmed yam is the most extensively grown, and there are many varieties of it, some with purple flesh.

The small yam from South America, called cushcush, with three-lobed leaves, is one of the best to use as a table vegetable. There are a hundred or more other species 
and varieties cultivated, or dug in the forests, throughout the tropics.

The Chinese yam will endure a severe winter and is grown as an ornamental in the United States under the name of "cinnamon vine." This, like the Japanese yam, bears tubers above-ground in the leaf-axils, by which it may be propagated.

It is possible that the coarser kinds of yam might be used as food for stock in tropical and subtropical regions where the cost of labor in digging them was not too high.

\section{RADISH}

Radishes can be grown well in the cool season in the tropical belt, if they can be provided with sufficient water. In the hottest weather they soon become acrid and woody. They may be grown under slat sheds.

The radish is one of the most easily grown vegetables known. The early varieties mature in a remarkably short time and under a low temperature. In fact, it is so easily grown that there is usually no profit in raising it for distant markets. A bed 6 by 12 feet can keep a family supplied throughout the entire season for the crop. For local markets, the radish is a favorite crop with the market-gardeners; it grows rapidly, costs little, and sells well. The quickly maturing varieties require only twenty to thirty days and remain good for only four to eight days.

Soil and preparation.

A light, warm, and rich soil should be chosen for radishes. Water is needed in abundance, but the land must not be 

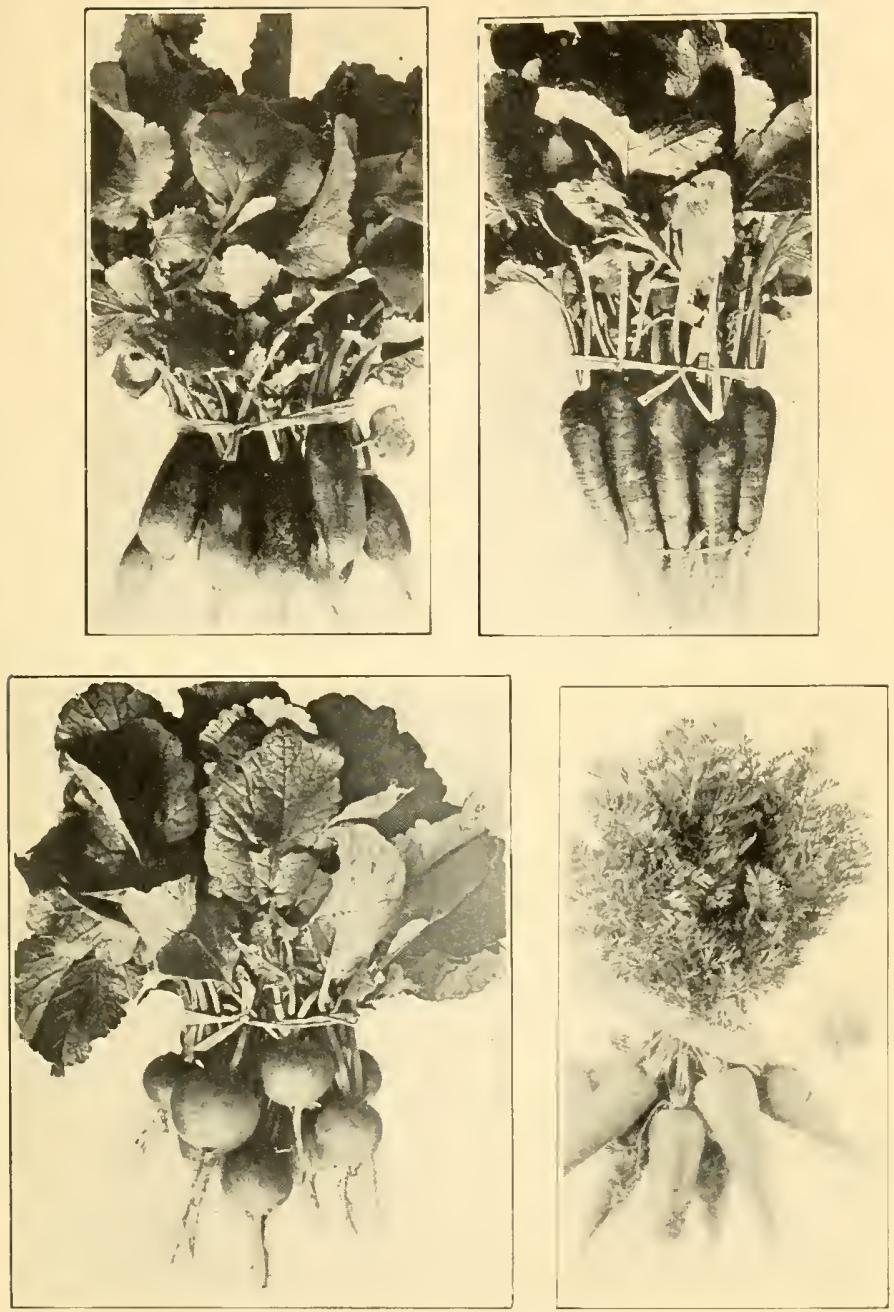

Plate XIV. - Root Vegetables.

Left top, French Breakfast radish; right top, Long Scarlet radish; left bottom, Rose Turnip radish; right bottom, Chantenay carrot. 

soggy. The particles that go to make up the soil should be rather coarser than for the average garden crop.

All rubbish should be removed and the soil stirred to a moderate depth. The land should be raked off smoothly and no rough and undecomposed material should remain on the plot.

\section{Fertilizer for radishes.}

The proportion of fertilizer ingredients should be as follows: ammonia, $3 \frac{1}{2}$ per cent; available phosphoric acid, 7 per cent; potash, 9 per cent. Use 1000 pounds of the above formula to the acre. This fertilizer should be applied in the drill, and worked in shallowly for the early spring radish, but deeply for the summer or winter radish.

The following will give the amounts of fertilizer to apply to secure the desired quantity of each element :

Ammonia . . . $\left\{\begin{array}{l}350 \text { to } 500 \text { cottonseed meal; or } \\ 200 \text { to } 300 \text { dried blood; or } \\ 130 \text { to } 200 \text { nitrate of soda; or } \\ 100 \text { to } 150 \text { sulfate of ammonia. }\end{array}\right.$

Phosphoric acid . . 500 to 700 acid phosphate.

Potash . . . $\left\{\begin{array}{l}900 \text { to } 1300 \text { kainit; or } \\ 120 \text { to } 180 \text { muriate of potash; or } \\ 125 \text { to } 200 \text { high-grade sulfate of potash; or } \\ 230 \text { to } 340 \text { low-grade sulfate of potash. }\end{array}\right.$

Sowing and cultivation.

The early varieties should be sown in very rich warm loam, three or four weeks before they are wanted. A seed- 
bed or coldframe is to be recommended. The seed should be sown in drills about 3 inches apart, dropped an inch apart in the row and covered about half an inch deep. The soil should not be allowed to become dry from the time the seed is sown as it is liable to make the radishes pithy.

Only a slight amount of cultivation is required. Weeds may be kept down by pulling as they appear.

The summer varieties should be sowed in drills 12 to 18 inches apart, and about 1 inch apart in the row, and the seed covered about an inch deep. The soil requires stirring about twice as often as for ordinary crops. It sometimes happens that the plants come to a standstill in growth; in such a case, some liquid manure or nitrate of soda should be applied along the row.

The winter varieties should be sown in rows about 18 inches apart, and thinned out to about 2 inches in the row. These varieties require a long time to mature, and therefore should be sown in November or December, or some may be sown as early as October. The cultivation is the same as for summer radish.

\section{Marketing radishes.}

For marketing radishes, the bunches are made about four inches in diameter. The roots are washed clean of all adhering soil, and are turned up so as to show the clear scarlet and white color. Radishes make a fine display for marketing. For distant market they are packed in bunches of about a dozen each, most of the leaves being removed, in half-barrel veneer baskets, or in barrels with ice. 
Seed raising.

A variety of radish that grows well on a particular soil and sells well in the market ought to be grown to seed by the gardener. The finest radishes should be selected and allowed to remain in the place where they were grown. As soon as the flowering stalk has reached a height of eighteen inches, a strong stake should be driven down beside the radish and the seed-stalk tied to this. Care is necessary to remove the stalks as they ripen, or birds are liable to become troublesome. The stalks must be hung up away from mice and rats, and when all are dry the seed may be beaten out. After beating, the seed may be winnowed and packed in dry bottles for seeding time.

Varieties of radishes.

There are numerous varieties, or so-called varieties, of radishes, many of which differ imperceptibly from one another. The favorite shipping variety in south Texas is the Scarlet White-Tipped. Among the early spring forms are French Breakfast, Scarlet Globe, and Early Scarlet, as good varieties. For the South, the varieties that grow larger and for which more time is required are better. Among this class are Long Scarlet, Chartier, Glass, Large White Summer, and Large Yellow Summer, as good varieties. (See Plate XIV.)

The scarlet varieties usually sell better than the white or yellow ones, but for home use there is probably no choice.

The winter varieties grow larger and require more time for growth. These are favorites in the South, especially the scarlet varieties. For marketing, the following are 
good: White Spanish, Scarlet Chinese, and Celestial. The Long Black Spanish and Round Black Spanish are good in some markets and for home use.

Comparison of Varieties of Radish grown in the Open GARDEN

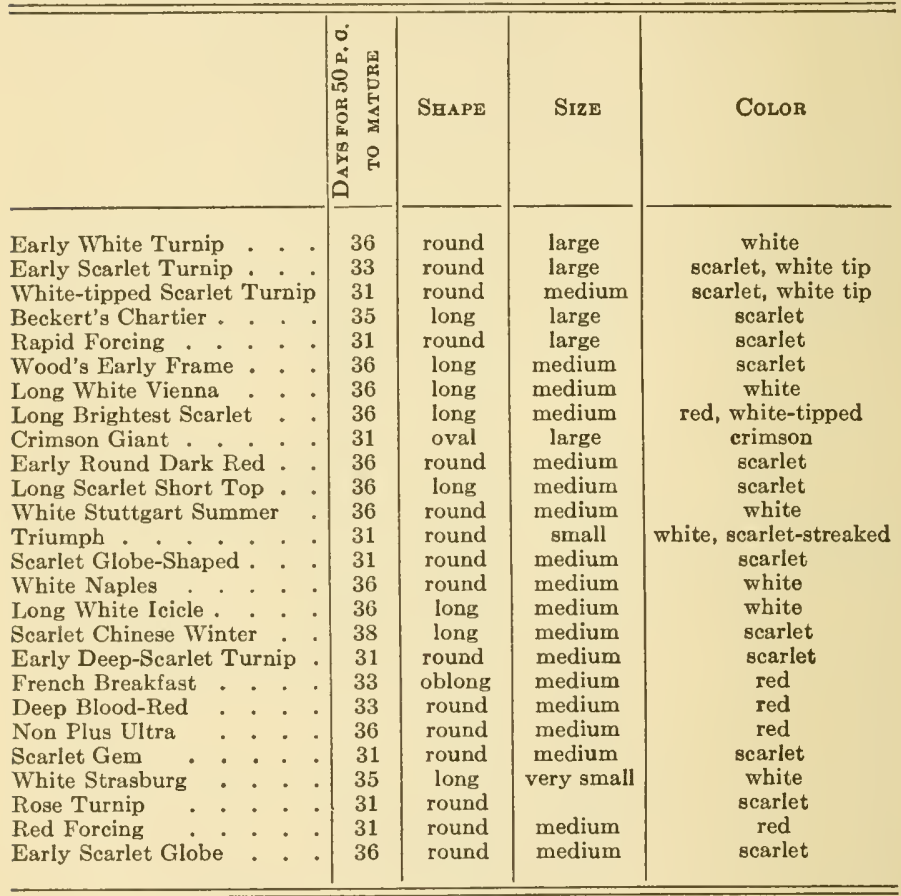

\section{TURNIP}

Turnips can be grown for the table in the intertropical belt in the cool season, if regularly supplied with water. 
In a hot climate they often become strong-tasting. The varieties used in Europe for forcing under glass in winter are said to do well in tropical climates, and plants grown from acclimated seed have been found to give best results. In subtropical countries turnips are grown in the fall, winter, and spring.

This crop is so easily grown that it is scarcely necessary to discuss it from that point of view, yet it is not appreciated as it ought to be. Turnips cannot be recommended as a crop to be shipped to distant markets in large quantities, but the local markets and southern cities will use a considerable quantity, and the northern markets take bunched turnips packed with ice in the winter.

Soil and preparation.

Newly prepared, or what is often called raw land, will raise a crop, if it is not too badly stocked with weeds. Muckland, or land containing much nitrogenous matter, should be avoided, except in cases where the product is to be used for stock feed. Wet or soggy land will not raise a crop, but on the whole this crop has a much wider range in the matter of soil and moisture than most of the cultivated plants.

About the same amounts and kind of fertilizer that are recommended for radish should be used for turnips.

If the land is heavy or inclined to be hard, it should be plowed deeply, but a light loam will need only a slight amount of stirring.

Planting and cultivating.

Turnip seeds are best sown with a seed drill. They may be sown by hand, but this is not satisfactory. A tin 
can, with a hole punched in the bottom, may be used as a make-shift on a small scale. The rows should be made 18 inches to 2 feet apart, and the seed sown about twice as thick as the plants are wanted to stand. The seed should be covered $\frac{1}{2}$ inch to 1 inch deep. When the plants are 4 or 5 inches high, thin out, so as to give them from 4 to 8 inches each. The cultivation needs to be sufficient to keep the ground mellow and the weeds from growing.

Marketing.

Turnips that can be marketed in October and November meet with ready sale in local markets, in bunches containing five to eight turnips with "greens." Later, the greens are not wanted, and the turnips are marketed like potatoes. In the winter and spring they are sent to the northern markets bunched, with ice in the barrel.

Varieties of turnip.

The field varieties may be used in the kitchen if taken before they mature. After they are full grown they become too coarse-grained; this may be changed somewhat by withholding the nitrogen in the fertilizer. Early White Flat Dutch is an old and standard variety. Scarlet Kashmyr is a good early variety for quick growing. Early White Egg is good for an early crop. Early Milan and Purple Top White Globe are also favorites.

RUTABAGA

Rutabaga is also called the Swedish turnip. There are only a few points in which it differs from the turnip. It 
usually has denser yellow flesh and takes longer to mature. The roots can stand the long summer heat without becoming acrid or woody, and while they cannot be considered a delicate dish, they fill an important gap that would otherwise occur in the kitchen garden of the South. A good kind is the Purple Top rutabaga. For a summer crop, the seed should be sown in winter or spring. For other points regarding this vegetable, the reader is referred to the account of the turnip. The rutabaga is more grown as a stock feed than as a vegetable.

\section{BEET}

Beets can readily be grown for table use in the cool season in tropical and even in equatorial regions, if sufficient water is provided to insure continuous growth. Beets are grown, for shipping to northern markets, during the winter, in the Gulf states. They ship well, and are in fairly constant demand in the winter months. Two crops are sometimes raised on the same land between October and May.

Soil and preparation.

Beets require a moist soil. One that would be considered too damp for the usual garden crops will raise a good crop of beets; of course, a cold, clammy soil should be avoided. They grow well under irrigation. Drained land makes an excellent beet field, provided the amount of nitrogen in it is comparatively small.

The land should be plowed deeply and harrowed to a level. 
Fertilizer for beets.

Fertilizer ingredients in the following proportions should be applied to beet land: ammonia, 5 per cent; available phosphoric acid, 6 per cent; potash, 9 per cent. Use at the rate of 600 to 1000 pounds of the above formula to an acre. When beets are raised for sugar, sulfate of potash, free from chlorine, is used as a source of potash.

The following ingredients will give the desired amounts for one acre:

Pounds to the Acre

Ammonia . . $\begin{cases}400 \text { to } & 650 \text { cottonseed meal; or } \\ 250 \text { to } & 400 \text { dried blood; or } \\ 160 \text { to } 275 \text { nitrate of soda ; or } \\ 130 \text { to } 200 \text { sulfate of ammonia. }\end{cases}$

Phosphoric acid . . 360 to 600 acid phosphate.

Potash . . . $\left\{\begin{array}{l}800 \text { to } 1300 \text { kainit; or } \\ 100 \text { to } 180 \text { muriate of potash; or } \\ 110 \text { to } 190 \text { high-grade sulfate of potash; or } \\ 200 \text { to } 350 \text { low-grade sulfate of potash. }\end{array}\right.$

The fertilizer should be applied along the row, and worked in thoroughly a week or ten days before the seed is planted.

Seeding and cultivating beets.

The rows should be made 18 inches or 2 feet apart, and the seed sown about three times as thick as the seedlings are wanted to stand. While the seed rarely fails altogether, it does not come up evenly; so it should be sown thickly, and cut out to make a good stand. Seeding is best done by a seed drill. When the plants are about an 
inch high, they should be thinned out to about 3 inches apart in the row. If the land is strong, two rows may be drilled, about 4 inches apart in place of one row; or if the seed is sown by hand, a drill about 5 inches wide may be made and the seed scattered along this. The seed should be covered from $\frac{1}{2}$ to 1 inch deep, depending on the soil and amount of moisture.

Soon after the seedlings are up, there is a period during which they make no apparent progress, especially if the weather is unfavorable. If the temperature is at the freezing point, it is well not to force the plantlets; but during warm weather an application of liquid manure or a solution of nitrate of soda will hasten them over this stage.

Cultivating should all be done with a wheel-hoe or a horse cultivator; avoid using a hand hoe as it is slow and expensive. The soil should be kept loose, so that the fleshy roots have room to form in the ground. As the tap-root goes down straight and deep, there is no danger of disturbing it while cultivating.

It is usually unprofitable to transplant beets for the market; therefore it should not be practiced, except when it is known that the product will sell well, or for home use.

Marketing.

Beets may be marketed as soon as they are two or more inches across. They should be pulled, and the leaves cut an inch or more from the fleshy root. If the leaves are cut too close, the roots lose more moisture than they otherwise would, and hence appear in the market wilted. 
If the beets are to be bunched, the tops are left on, the outer leaves only being removed; or the tops are cut to six inches and the beets tied in bunches of three to six.

The ordinary vegetable crate or even a barrel will be found desirable for use for marketing, although ventilated barrels and veneer baskets are often used.

In the vicinity of a pickling establishment small varieties of beets may be raised, or the thinning out may be delayed until the roots can be used for pickling.

Varieties of beets.

Fxtra Early Eclipse, and Extra Early Egyptian are good varieties for shipping. Extra Early Bastian is a good early beet. Electric is also a favorite shipping sort. As a rule, the turnip-shaped varieties are preferred in the northern markets; as to color, the market prefers a deep red. There are other varieties worthy of mention and desirable for home use.

The varieties used for making sugar and for feeding to stock are large and coarse-grained, and, consequently, not valuable for a garden crop.

\section{CARROT}

Carrots may be grown as rearlily as turnips in the cool season of most tropical and subtropical countries. They take three, four, or five months to mature.

This root crop may be shipped to a distant market without danger of loss. Vegetable-growers should raise and ship a few crates, bunched with leaves, and refrigerated during April and May. The carrot is also an 
excellent crop to raise for home use. The nutritive ratio is high for vegetables and the taste pleasant. If one has planted more carrots than are needed, they may be fed to horses, cows, or hogs to good advantage.

The vegetable is a good keeper and the northern markets are stocked with the old crop until growing season in the spring - April or May. New carrots are to be found in the New York markets, however, during the late winter months.

Soil and preparation.

A deep, rich, dark-colored loam is usually chosen for this crop, when grown extensively. It will make good roots on sandy loam or even on a light clay soil, but the ground must be mellow. It is not necessary that the land should be rich in nitrogenous matter, but it should contain a good supply of phosphoric acid and potash. A wet soil will not raise a good crop.

The land should be plowed deeply and all rubbish removed, especially undecomposed vegetable matter.

Fertilizer for carrots.

The following fertilizer proportions should be used: ammonia, 3 per cent; available phosphoric acid, 7 per cent; potash, 8 per cent. Use from 600 to 900 pounds of the above formula on ordinary land. If the land is rich in nitrogenous matter, less nitrogen can be used or it may be omitted altogether.

The fertilizer should be mixed thoroughly with the soil and worked in more deeply than usual. 
Sowing and cultivation of carrots.

The seed should be sown with a drill, in rows about 18 inches apart, and covered about $\frac{1}{2}$ inch deep. About three times as many seeds should be sown as plants are wanted, and when the plants are an inch high, the inferior ones should be trimmed out, leaving the others to stand from two to four inches in the row.

The time of sowing will depend upon the variety in hand. The later and longer ones should be sown in October, the earlier ones in November, and the very earliest ones about the first of December. The seed is rather slow to germinate, so a few seeds of cabbage, radish, or turnips should be mixed with it to indicate the rows before the carrot seedlings are visible.

The soil should be kept in a high state of cultivation, and plowing should begin before the seed is up. The plowing should be deep and close to the rows, except during dry weather, when plowing should be shallow and frequent enough to keep the land mellow.

\section{Marketing.}

The young or spring crop is marketed with the leaves on, as it thus brings a higher price. The carrots are washed, the large and dry leaves removed, and about six tied in a bunch. Marketing is usually done in boxes or barrels, but good crates would be preferable. Refrigeration may be required for long distance shipping in the spring. Varieties of carrots.

Early Scarlet Horn, Oxheart, and Half Long Nantes are favorite varieties of orange-colored and early carrots; 
Danvers and Chantenay (Plate XIV) are also recommended. Long Orange and Large White Belgian will prove more vigorous, and are generally grown for stock feed; therefore they should not be sown in the market-garden except when there are facilities for marketing the half-grown crop.

\section{PARSNIP}

The parsnip can be raised in the cool season in subtropical and the cooler tropical countries, although beets or carrots are usually preferred since they can be grown in less time.

Many persons enjoy the taste of parsnips from the first trial. Others acquire a liking for them, while only a few do not relish them. It is not advisable to use them for stock feed, although it is sometimes done. The parsnip is not a good vegetable to be grown for distant markets, but should be raised for home use and local markets.

Soil and preparation.

The native habitat of the parsnip is in moist or swampy places, and here it grows "all to top" and produces only a small root; but with the transfer to dry uplands comes an increased size of root. A dry, deep loam should be selected and prepared as deeply as the implements and soil will permit and the fertilizer worked in deeply.

Fertilizer for parsnips.

Fertilizer in the following proportions should be applied : ammonia, $3 \frac{1}{2}$ per cent; available phosphoric acid, 9 per cent; potash, 8 per cent. Use from 600 to 900 pounds of 
the above formula in the drills. One should be sure that it is worked in deeply and thoroughly. A good way will be to run out a deep double furrow where the row is to be, apply a portion of the fertilizer, and mix thoroughly with enough soil to fill about one-third of the furrow; then add some more fertilizer and mix in more soil; continue this mixing until all the fertilizer has been used, when the row should be a little above the general level. If the flat or turnip-shaped varieties are planted, the preparation and fertilizer need not be so deep.

Sowing and cultivating parsnips.

Seed should be sown during September, October and November. The earliest sowing will allow the plants to mature by the first of January. The summer crop has not met with so much success. There is no danger of the young plants being frozen. The rows should be made 18 inches or 2 feet apart and thinned to 4 inches in the row. The seed is a little slow to germinate, so it will be well to add some radish or turnip seed to mark the row.

The cultivation is best carried on by horse implements after the plants are about four or five inches high. When the roots are about a foot long and an inch in diameter, they will be found sufficiently mature to use. Parsnips are marketed in barrels, very much as potatoes. The preparation for table use is quite similar to that of potatoes. Varieties.

The improved Hollow Crown, or Sugar, and Student are good long varieties of parsnip ; the first named is the larger and longer. 


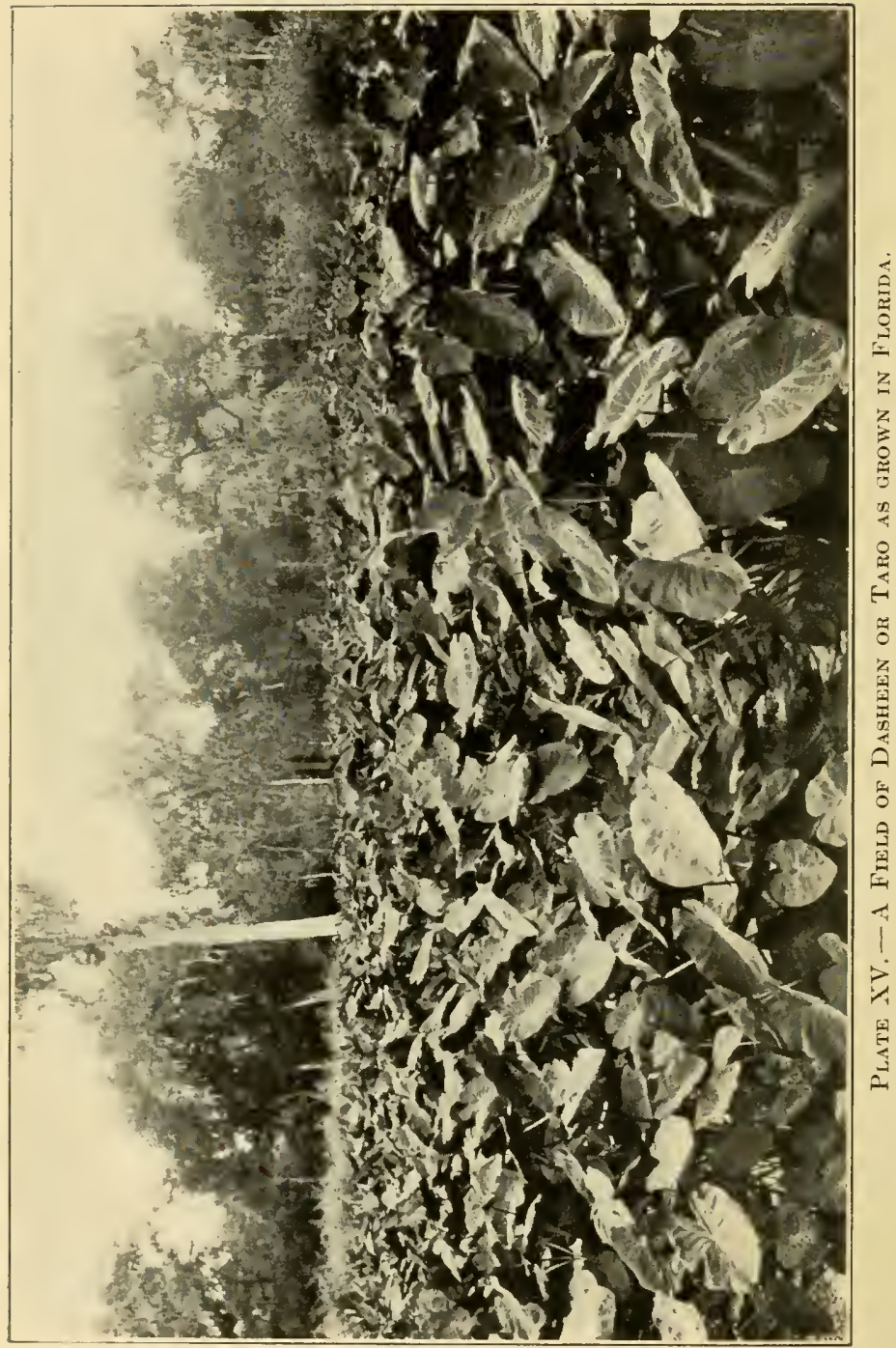




\section{SALSIFY OR OYSTER PLANT}

Salsify can be raised in the outer parts of the tropical belt. The demand for this, the vegetable oyster, is continually increasing. While it will not be in great demand for home consumption, it is still a good plant to raise, as it sells readily and can stand shipping. The seed is difficult to save on account of birds destroying it.

This seed should be sown in the fall or during the winter. The cultivation and preparation of the soil are much the same as for the usual root crops. A sandy loam is preferred. The rows are about 2 feet apart, and the plants thinned to 4 or 6 inches in the row.

For market the large tap-root is dug up, and, with the leaves, is washed and trimmed. Six or eight usually make a bunch. It is used mostly in the North during the winter and early spring. A good market for this vegetable can be opened by growing it in the South so that it can be offered for sale during May and June, after the fresh oyster can no longer be obtained. Sandwich Island Mammoth is one of the best varieties.

\section{DASHEEN OR TARO}

The taro, frequently called tanyah in Florida (Colocasia antiquorum var. esculentum), is cultivated in most tropical countries, being a staple food in the Pacific Islands. Varieties of it are grown in India, China, and Japan. It may readily be distinguished from tanier by the leaf-stalk being attached near the middle, not at the base, of the 
blade. In some varieties, such as the dasheens, the root-stock forms many side-tubers. The usual method of propagation in the Pacific Islands and in some parts of the West Indies is to cut off the top of the root with about six inches of the leaf-stalks, and plant this. In India the small tubers are planted. In Florida the smaller tubers are usually used for planting.

The distance apart varies from 1 to 4 feet, in rows 4 to 6 feet apart, according to variety. The crop may require nine months or more to ripen, according to the variety. The roots can be left for some time in the ground, and may also be kept in a dry place for a considerable time after digging. On irrigated land between the tropics, up to fifteen tons to an acre are grown by native methods. The plant, however, may be grown without irrigation; although it requires abundant moisture to do well, it does not do well in swampy lands. The general methods of cultivation and fertilization applied to potatoes will be found applicable. After the leaves shade the ground completely, which usually occurs in summer, no further cultural attention will be requried. Taro has been grown successfully in southern California and in Florida, and it is a useful garden vegetable in tropical and subtropical regions. In the tropies it may be planted at almost any time, and in the subtropical regions at the end of the cool season. (See Plate XV.)

In parts of Florida one variety commonly called tanyah has escaped from cultivation. In earlier times it was used as food by the Indians, and later collected for shipment to the North, where the tubers commanded a good price for use as ornamentals. 



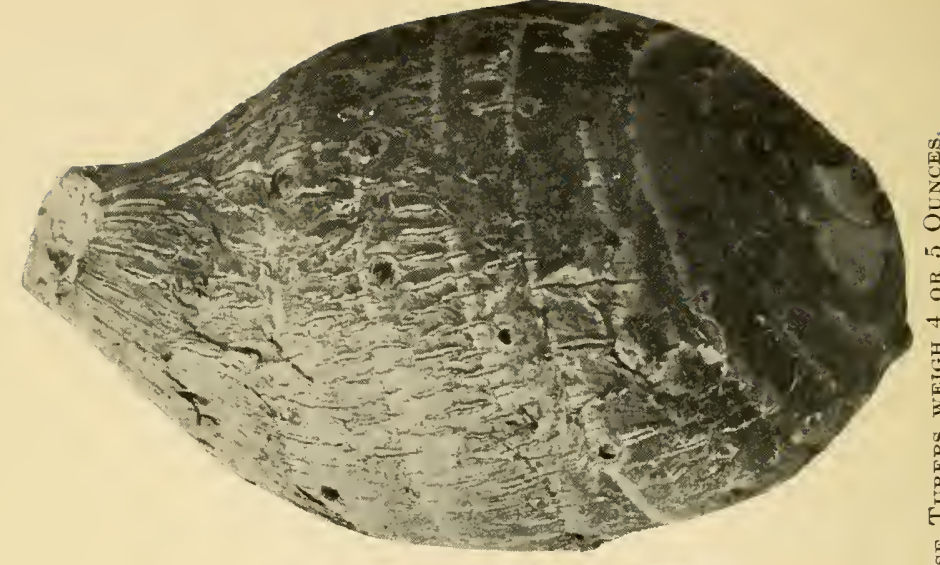

覓

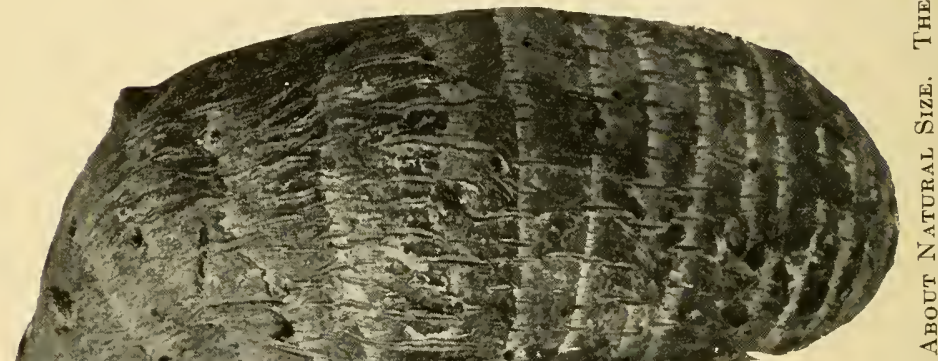

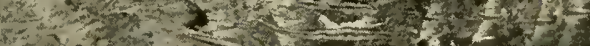

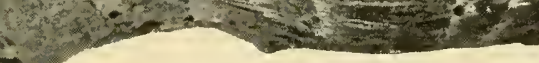

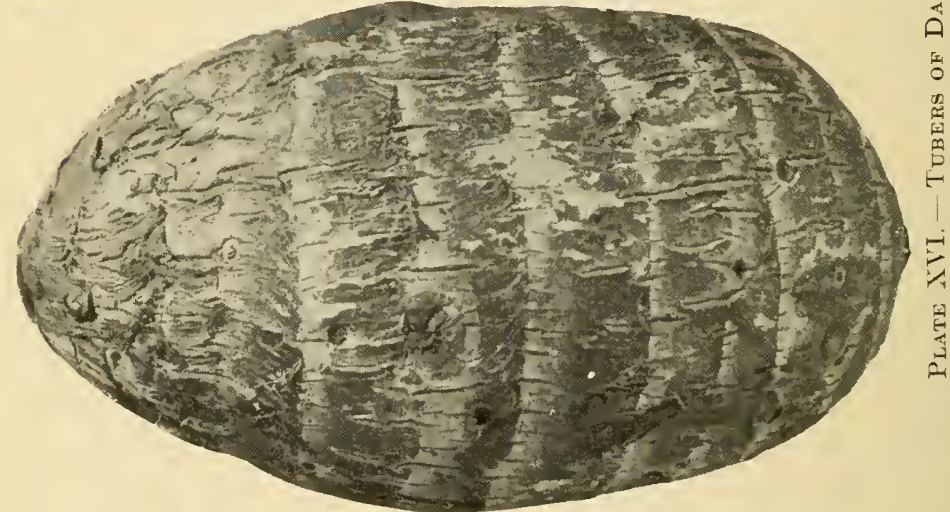


Uses of dasheen.

Much attention has been given to dasheens by the United States Department of Agriculture. Different varieties have been extensively introduced throughout the southern states. The tubers, when cooked like potatoes, form a very appetizing dish. (See Plate XVI.) They may be prepared in almost all ways that potatoes are prepared. In preparing for use, it should be remembered that the tubers and leaves are decidedly acrid. To prevent irritation to the hands, the tubers should be handled in water to which a teaspoonful of salsoda to a quart has been added.

The young leaves when well cooked make a good vegetable for greens.

In Hawaii, taro has been in cultivation since before the discovery of the islands by the Caucasian race. Poi is a favorite dish prepared from this crop and may in a general way be likened to oatmeal or grits as used in the United States.

\section{Bulletins.}

Yautias, Taros, Dasheens, Bur. Plant Ind. Bulletin 164, 1910.

The Dasheen, a Root Crop for the Southern States, Bur. Plant Ind. Circular 127, 1913.

\section{TANIER (Xanthosoma)}

Tanier is a staple vegetable in the West Indies and the neighboring parts of Central and South America. It is one of the aroid family, and is allied to dasheen. It is called yautia in Porto Rico. It is sometimes confused with the taro, but can be easily distinguished by its 
leafstalk joining the leaf blade at the base instead of near the middle. Most varieties have no stem above ground, and the height of leaves and leaf-stalks varies from one to eight feet. Most taniers produce many white, yellow, or pink tubers on the sides of the main root-stock, and it is these tubers which are chiefly used for food. A tuber may weigh up to two pounds or more, and one plant may yield over four pounds of tubers. Many varieties also produce abundant suckers. The tanier is preferable to the taro as a starch-producer, and rivals the cassava in this respect. It contains about the same amount of carbohydrates as the sweet potato, but mainly starch. One of the best varieties is the tanier with white tubers, called Rolliza in Porto Rico. This matures its crop in about eight months and would probably be valuable for south Florida, and other subtropical countries. The tubers keep well in the ground, but dry up in the air. They are eaten boiled or baked, like Irish potatoes. The young leaves are cooked as greens.

The tanier is usually propagated by cutting off the head of the rootstock with a few inches of the leaf-stalks, and using these as sets. It may also be reproduced by planting small tubers, or by cutting up the main root-stock into pieces. The sets may be planted in rows 4 to 6 feet apart and at distances of $1 \frac{1}{2}$ to 3 feet in the row, according to the variety. This would give from 2400 to 7000 plants approximately to the acre. The yield may be as much as seven to fifteen tons to the acre in good soil.

\section{Bulletin.}

The Yautias or Taniers, Porto Rico Exp. Sta. Bulletin 6, 1905. 


\section{HORSE-RADISH}

Horse-radish has been grown in the cool season or at an elevation in tropical lands. It has not been grown to a large extent in the southern United States. It requires a deep, rich, sandy soil, and is usually planted as a by-crop. It is worthy of a test in each locality, but no one should invest in this crop without knowing that it will succeed.

The soil should be prepared as for cabbage. The sets will be found to be small straight roots, about $\frac{1}{2}$ inch in diameter and 6 inches long. The rows should be made about 2 feet apart and the sets planted 18 inches in the row. A deep hole should be made with a dibber, or other suitable implement, and the set dropped in it in an upright position. The crown of the set should go from 2 to 4 inches below the surface of the soil. The cultivation need not be frequent, but had best be rleep.

The roots are the only marketable parts; these should be removed from the soil, washed, and trimmed. They will remain in a marketable condition for several weeks after digging, and may be shipped as freight.

\section{CASSAVA}

There are two classes of varieties of this tropical American plant, the bitter and the sweet. Only the sweet varieties seem to be cultivated in Florida and Colombia. In Florida a considerable area was grown during the late nineties for the production of starch, and two large factories were established for preparing the starch for market. In the West Indies and Brazil, both kinds are grown. It 
is often difficult to distinguish between the two. The characters that are marks of distinction in one locality do not seem to apply in another place.

The bitter varieties contain so much hydrocyanic (prussic) acid in the substance of their roots, that they are poisonous, and cannot be fed to animals ; neither can they be used as food until the roots have been grated to meal and the juice squeezed out. The meal must be well dried on hot iron plates, and it then forms the staff of life in much of South America. Pressed into large thin biscuits and cooked on hot iron plates, it forms cassava bread, which has a peculiar appetizing flavor of its own. The starch which settles from the juice is also heated on iron plates, and is then well known as tapioca.

The roots of the sweet varieties of cassava, on the other hand, contain hydrocyanic acid, in quantity, only in the rind. The roots, stems, and leaves may be fed raw to farm animals. The peeled roots may be cooked and used hot as a vegetable, forming a cheap food in tropical countries. However, cases of poisoning sometimes arise from mistaking the bitter for the sweet cassava.

The sweet cassava roots are used to a considerable extent as a vegetable in the West Indies and other tropical American countries. The bitter cassava is well worth raising for the sake of the biscuits, which are most wholesome and appetizing.

Cassava is grown from short pieces of the thick stems, which are planted 4 to 6 feet apart each way in a welldrained soil. The planting is done in subtropical regions as early in the year as possible, and in the tropics during the cool season. In eight to twelve months the roots are 
ready for use, but they may be left in the ground for a considerable time without injury. They do not keep well after being removed from the ground. In regions where light freezing weather occurs during the winter, the canes may be stored in a bank. They should be cut early, just before frost may be expected. After cutting, they should be placed in large compact piles and covered with soil. One should choose a place that is well drained and one that will keep quite dry. The object of the banking is to keep the canes from drying out and being frosted.

\section{Bulletins.}

Sweet Cassava, U. S. D. A., Bur. of Chem. Bulletin 44, 1894.

Cassava, Farmers' Bulletin 167, 1903.

\section{LLEREN}

Lleren has been long cultivated in the West Indies, and especially in Porto Rico. It was described in 1904, by $\mathrm{O}$. W. Barrett, in the "Plant World." It grows about three feet high, and like the banana, increases by offsets or "heads." It bears many ovoid root-tubers, an inch or two long. These are boiled, and after removing the skins, are eaten as a vegetable. The flavor is said to resemble sweet corn, and is liked by most persons. It is a good shipper. In Porto Rico the "heads" are planted in rows 4 feet apart, with 2 feet between the plants. It requires a year or more to produce a crop of large-sized tubers. These root-tubers cannot be used for propagation. The plant is Calathea Alluia, allied to Maranta and Canna. 


\section{CHAPTER XVIII}

\section{OTHER VEGETABLES; PLANTING LIST}

HERE are brought together short accounts of several tropical or subtropical vegetables that are cultivated more or less in those regions, and that offer a promising field for improvement by selection and the discovery of useful sports. They are not yet grown commercially in Florida, and apparently not elsewhere in adjacent tropical regions.

\section{CHENOPODIUM QUINOA}

This annual vegetable has been grown in the high regions of Colombia, Peru, and Chile for hundreds of years. There are several varieties. The seeds are cooked with soups or fish, or used as a porridge. They must first be boiled to get rid of acridity. The leaves are eaten like spinach. This plant could be grown on tropical or subtropical mountains.

\section{ULLUCUS TUBEROSUS}

This vegetable has long been cultivated in the mountains of Peru and Bolivia at 3000 feet or more high. Its creeping rhizome bears fleshy tubers like potatoes but smaller, and containing sugar as well as starch. Several varieties are known. It is said to be propagated both by the tubers and by cuttings. It will endure some frost. 
ARRACACIA XANTHORRHIZA (A. ESCULENTA)

This excellent vegetable of the mountain regions of Venezuela and Colombia resembles the carrot or parsnip, to which it is related, and to which its flavor is said to be superior. It is grown in Porto Rico on the mountains. It is well suited for culture on all tropical mountains at elevations of a few thousand feet. It is grown like carrots or celery (without blanching); but seed is not used (and is rarely produced). The crop is grown from small "heads" which form at the bases of the leaf-stalks. It is said to mature in four months sufficiently to be of use; and a longer period, up to eleven months, allows the roots to grow larger. There are several varieties. It is eaten boiled, fried in slices, or in soups.

\section{YAM-BEAN (Pachyrhizus erosus and P. tuberosus)}

There are two or three kinds of this tropical plant. The one grown in Mexico has two varieties at least. It is grown on ridges in irrigated fields. The roots, which resemble turnips in shape, are eaten raw or cooked. They are dug up before they get large and woody, and the plants are not allowed to mature seed. A yam-bean is much cultivated in Indo-China and the Malay archipelago for its roots, of which it yields under a ton an acre in three or four months. The roots are eaten raw or boiled, and contain 22 per cent of starch, 11 per cent of sugar, and 12 per cent of proteid. The yam-bean is worth cultivating in tropical and subtropical countries. The pods of one kind are eaten like string beans. 


\section{GOA BEAN (Psophocarpus tetragonolobus)}

This leguminous plant, of which there are several varieties, is much grown in India, where its young tuberous roots are eaten raw or cooked, being dug before any seeds ripen. The young green pods form an excellent vegetable when cooked like string beans. It is called in Australia the asparagus pea. It has large light-blue flowers, and is well worth growing in tropical vegetable-gardens.

\section{NEW ZEALAND SPINACH (Tetragonia expansa)}

This annual herb is not related to the ordinary spinach, and forms an excellent substitute for it during hot weather, when spinach will not thrive. It may be grown in tropical countries, and stands sun and drought. It forms a good green pot-herb in summer. Sow the seed in a well prepared cold frame about January first and protect the bed during cool weather. When the plants have reached a height of one or two inches in the seed-bed, they may be transplanted to the field, placing them in rows about 3 feet apart and about one foot apart in the row. These plants are likely to continue to grow throughout the summer and into the late fall. Another sowing may be made in the late spring or early summer in similar beds, protected from the sun by means of cheesecloth. The plants can then be set out in September and make a fair growth before the cool weather of the fall retards further development.

\section{BASELLA (Basella rubra)}

This annual or biennial tropical herb has a vigorous growth and is a good pot-herb and also an excellent salad. 
It is usually grown from seeds, and being a twiner may be supported on a low trellis. There are several varieties from India, China, and Japan. The best kind is said to be grown from cuttings. This vegetable has been well recommended in several tropical and subtropical countries.

EDIBLE JUTE (Corchorus olitorius var. edulis)

This large tropical annual is much grown in Egypt and India for the use of its tender shoots and leaves as a potherb. The young leaves are also eaten in salads. It is ready in forty to fifty days (Egypt), and may be cut twice. It is one of the garden vegetables that should be grown in tropical lands where green vegetables are often scarce.

Edible amaranth (Amaranthus oleraceus, A. gangeticus, and $A$. viridis)

Several forms of amaranth are cultivated as pot-herbs in India, China, and tropical countries. The young shoots are used in the place of asparagus. The best kinds seem worthy of a place in the tropical vegetable-garden.

\section{PARA CRESS (Spilanthes oleracea)}

This tropical composite hardly takes the place of a cress. It is a creeping yellow-flowered annual. Its leaves are used for a pungent medicinal salad, which, presumably from some narcotic quality, is often eaten in tropical countries as a remedy against toothache. The true watercress can usually be grown in tropical mountain streams. 


\section{PIGEON PEA (Cajanus indicus)}

There are several varieties of this tropical legume. It may grow for several years, forming a tall woody shrub; but is perhaps best cultivated as an annual. It is halfhardy, grows vigorously even if neglected, and yields a heavy crop. Its unripe peas are eaten in tropical countries to replace English peas, to which they are not so much inferior. It seems a promising plant to use as a starting point for improvement as a tropical garden pea.

\section{SWORD BEANS AND JACK BEANS (Canavalia)}

Some kinds of this tropical legume are worth cultivating. One $(C$.gladiata) is a perennial climber in India, where it is said to be the finest of all the native vegetables. The young pods, sliced and boiled, are little if anything inferior to French beans, and are extensively used by Europeans in India. The young pods of the Jack bean, when less than six inches long, are used as string beans, in Japan, Demerara, and elsewhere.

\section{Chinese Cabbage (Brassica Pe-tsai)}

This relative of the cabbage has been recommended as a substitute for the latter in hot climates. In Louisiana it is used in salads instead of the cabbage, and somewhat resembles a large lettuce. In two or three months, plants have been obtained weighing more than six pounds. It may be grown in tropical countries, especially on the mountains, and is much cultivated in Indo-China. 


\section{CHINESE MUSTARD (Brassica juncea)}

This is a good pot-herb which can be grown in hot climates. There are several varieties cultivated in Japan, and the plant is also grown in India and in other tropical countries. 'The half-pungent flavor is very agreeable. The Chinese mustard should be sown in rows 14 to 18 inches apart. The soil must be well prepared, a light sandy loam being preferred. Sow the seed the same as for ordinary mustard; give same culture as for turnips or radishes. It is prepared for food in the same way as ordinary mustard.

\section{ROQUETTE (Eruca sativa)}

Roquette is a cruciferous annual whose young leaves are used in salads or as a pot-herb. 'The flavor somewhat resembles horse-radish. The vegetable is grown in France and Egypt. Seed of roquette may be obtained from some of the seedsmen in southern United States. The first seeding should be early in the spring. Treat in about the same way as for turnips or mustard, sowing the seed in shallow drills about one foot apart. The soil should be rich and well supplied with moisture. If dry weather occurs it may be necessary to irrigate. With the approach of warm summer weather, the plants are likely to run to seed. For fall greens, sow late in the summer or early in the fall.

WeSt INDIA CUCUMber (Cucumis Anguria)

This small prickly cucumber or gherkin grows well in tropical countries, where it is difficult to grow other cu- 
cumbers. It is usually eaten cooked or pickled. The vine of this plant resembles the watermelon vine to a considerable degree and may be mistaken for it. This plant can be grown as a curiosity, or allowed to grow wild, and in some places has become established as a weed. The fruits are usually one or two inches long and more or less prickly, though some tend to be quite smooth. It is supposed to be a native of the American tropics. Not much attention has been given to its cultivation.

\section{GINGER (Zingiber officinale)}

This plant can be grown successfully in most subtropical gardens, as in south Florida, and up to elevations of several thousand feet in tropical countries. In India it is usually planted just before the rainy season, small pieces of the rhizomes being set in rich soil one foot apart each way. The ginger is ripe at the end of the year. When grown for a preserve, the youngest tubers only are taken, peeled, and preserved in cold sirup.

\section{DANDELION (Taraxacum officinale)}

This plant forms a favorite salad, and the large-leaved garden varieties are the better for being blanched. The Improved Thick-Leaved has done well in Cuba and Porto Rico.

ASPARAGUS BEAN (Dolichos, or Vigna, sesquipedalis)

This bean is grown in China and South America, and its long pods are eaten as snap beans. It is a pole 
bean with few-seeded pods two or three feet or more long. It has been long grown in the tropics and there developed to its greatest perfection. Numerous attempts have been made to introduce it into the cooler regions, but it has not proven as successful there as in the subtropical regions, although the vegetable has been produced as far north as New York state.

Planting and general treatment should be about the same as in the case of cowpeas. A longer time is usually required for the vegetable to mature. The succulent green pods make a desirable vegetable when prepared like snap beans or cowpeas. The dried beans are also used at times for food. A considerable number of variations in this species occur.

\section{HYACINTH BEAN (Dolichos Lablab)}

This is a climbing bean, the young pods being eaten as string beans. There are several varieties. It is much grown within the tropics, especially in India. Some of the varieties generally known under this name are drought resistant, thus forming a favorite vegetable in regions where it is difficult to produce cowpeas and the legumes belonging to this group. Owing to the fact that it has been long in cultivation, it has led to so many varieties that the name may be applied to a variety of plants.

The general cultural methods employed for cowpeas or string beans will be found useful for this crop and methods of preparation for the table are the same. In the cooler temperate regions this plant is often grown for ornamental purposes, being attractive because of its splendid racemes of flowers. 


\section{SNAKE GOURD (Trichosanthes Anguina)}

This plant bears a cucumber-like fruit, three feet or more in length. It is eaten sliced and cooked in India and China. This should be planted and treated very much the same as the gourd.

\section{TREE TOMATO (Cyphomandra betacea)}

This relative of the tomato grows into a shrub. It fruits in the second season from seed, and bears its eggshaped fruits abundantly most of the year. They taste somewhat like tomatoes, and are eaten raw with salt or sugar, and in salads; or used for pastries, jellies, and preserves. An analysis in Java showed about 4 per cent of sugar in the pulp. This plant grows in subtropical countries and does best on the hills in the tropics. It is grown from seeds or cuttings, and may be a promising subject for improvement.

\section{CHARD (Beta vulgaris var.)}

This is a vegetable closely related to the garden beet, but has a small woody root, and large, white, thick leaf stalks and mid-ribs, which are the parts cooked for use, though the leaf-blades may also be eaten. The plant is easy of cultivation and yields well in Cuba and Porto Rico. It is a useful vegetable for the subtropical and tropical garden.

\section{PEPINO (Solanum muricatum)}

Pepino is a seedless vegetable, propagated by suckers and cuttings. It bears in a few months striped fruits 
which taste something like cantaloupes, and are four to six inches long. It will stand a little frost and sprouts up next year from the root. The fruit, which is a product of cultivation in Peru, will grow well in subtropical countries, and on tropical mountains, and is said to ship well. The plant itself bears a remote resemblance to the eggplant. The bush is not as sturdy a grower, or as hardy in the northern regions. It has fruited as far north as New Jersey but produces only a very small crop. In the tropics it needs special care. It should be given the same attention as eggplant in the preparation of the soil and cultivation. Owing to the fact that seed is not producer, there is some difficulty in getting a start with pepino. Cuttings root readily in a moist loam but should be protected from the sun. Make the cuttings in the summer.

\section{WAX GOURD (Benincasa cerifera)}

The wax gourd or China preserving melon is grown in China and in many subtropical and tropical countries. Its fruits are about a foot long, with small seeds, and are cooked like a summer squash, or preserved in sirup. This plant may be cultivated like a muskmelon or allowed to grow up a trellis. In India the seed is sown in the rainy season. The fruit matures in about four months. It is well worth growing in a tropical garden for making preserves or sweet pickles. 


\section{PLANTING-LIST OF VEGETABLES BY MONTHS}

The following list is a suggestion to those in Florida who desire to know what vegetables may prove successful under average conditions if planted in the different months.

\section{NORTH AND CENTRAL FLORIDA}

\section{January}

Asparagus seed, Brussels Sprouts, Cabbage seed and plants, Cauliflower seed, Collards, Eggplant seed, Leeks, Lettuce, Mustard, Onion sets, Radishes, Rape, Spanish Onion seed, Tomato seed, Turnips.

\section{February}

Asparagus seed, Adam's Early Corn, Beans, Brussels Sprouts, Cabbage, Cantaloupes, Carrots, Collards, Cucumbers, Eggplant seed, English Peas, Irish Potatoes, Kale, Leeks, Lettuce, Onions, Parsley, Parsnips, Pepper seed, Rutabagas, Salsify, Spinach, Windsor Beans.

\section{March}

Beans, Beets, Brussels Sprouts, Cantaloupes, Carrots, Cauliflower, Collards, Corpeas, Cucumbers, Early Corn, Eggplants, English Peas, Irish Potatoes, Kale, Kohlrabi, Leeks, Okra, Onions, Parsley, Parsnip, Pepper, Pumpkin, Radishes, Rape, Rutabagas, Salsify, Squash, Sugar Corn, Tomatoes, Turnips, Watermelons. 296 


\section{April}

Beans, Cantaloupes, Collards, Cowpeas, Cucumbers, Eggplant, English Peas, Irish Potatoes, Kohlrabi, Lettuce, Okra, Onion plants, Parsley, Parsnip, Peppers, Pumpkins, Radishes, Rutabagas, Squash, Sugar Corn, Sweet Potatoes, Tomatoes, Turnips, Watermelons.

\section{May}

Beans, Butter Beans, Cantaloupes, Collards, Cowpeas, Cucumbers, Eggplant, Okra, Peppers, Pumpkin, Squash, Sugar Corn, Sweet Potatoes, Tomato plants and seed, Watermelons.

\section{June}

Butter Beans, Cabbage seed, Cauliflower seed, Celery seed, Cowpeas, Eggplant, Peppers, Squash, Sweet Potatoes, Tomatoes, Watermelons.

\section{July}

Cabbage seed, Cantaloupes, Cauliflower seed, Celery seed, Cowpeas, Eggplant, Parsley, Peppers, Pumpkin, Rutabagas, Squash, Sweet Potatoes, Tomato plants and seed, Watermelons.

\section{August}

Beans, Beets, Cabbage seed, Cantaloupes, Cauliflower seed, Carrots, Cowpeas, Cress, Cucumbers, Collards, Eggplant, Irish Potatoes, Kale, Kohlrabi, Okra, Onions, Parsnip, Peppers, Pumpkin, Radishes, Rape, Rutabagas, Salsify, Spinach, Squash, Tomatoes, Turnips, Windsor Beans.

\section{September}

Beets, Brussels Sprouts, Cabbage, Carrots, Cauliflower plants, Celery plants, Collards, Cowpeas, Cucumbers, English Peas, Irish Potatoes, Kale, Leeks, Mustard, Onion sets, Parsnip, Radishes, Rape, Rutabagas, Salsify, Spinach, Squash, Turnips. 


\section{October}

Beets, Bermuda Onion sets, Brussels Sprouts, Cabbage, Carrots, Cauliflower plants, Celery plants, Collards, Kale, Leeks, Lettuce seed and plants, Mustard, Onion sets, Parsnip, Radishes, Rape, Spinach, Turnips.

\section{November}

Beets, Brussels Sprouts, Cabbage seed and plants, Carrots, Collards, Kale, Lettuce, Mustard, Onion sets, Parsnip, Radishes, Rape, Spinach, Turnips.

\section{December}

Cabbage plants and seed, Collards, Leeks, Lettuce plants and seed, Mustard, Onions, Radishes, Rape.

\section{TAMPA AND SOUTHWARD}

\section{January}

Beans, Beets, Brussels Sprouts, Cabbage seed and plants, Cauliflower seed, Collards, Eggplant seed, Irish Potatoes, Kale, Kohlrabi, Lettuce, Mustard, Radishes, Rape, Spanish Onion seed, Spinach, Tomato seed, Turnips.

\section{February}

Adam's Early Corn, Beets, Beans, Brussels Sprouts, Cabbage, Cantaloupes, Carrots, Cucumbers, Eggplant seed, Irish Potatoes, Kale, Lettuce, Okra, Onions, Pepper seed, Spinach, Squash, Windsor Beans.

\section{March}

Beans, Beets, Brussels Sprouts, Cantaloupes, Carrots, Cauliflower, Cowpeas, Cucumbers, Early Corn, Eggplants, Irish Potatoes, Lettuce, Mustard, Okra, Onions, Pepper, Pumpkin, Radishes, Squash, Sugar Corn, Tomatoes, Watermelons. 


\section{April}

Beans, Collards, Cowpeas, Cucumbers, Eggplant, Kohlrabi, Okra, Onion plants, Peppers, Pumpkins, Radishes, Squash, Sugar Corn, Sweet Potatoes, Tomatoes.

\section{May}

Beans, Butter Beans, Cowpeas, Eggplant, Okra, Peppers, Pumpkin, Squash, Sugar Corn, Sweet Potatoes, Tomatoes.

\section{June}

Butter Beans, Cabbage seed, Celery seed, Cowpeas, Eggplant seed, Peppers, Squash, Sweet Potatoes, Tomato plants and seed, Watermelon.

\section{July}

Cabbage seed, Cantaloupes, Celery seed, Cowpeas, Eggplant and seed, Peppers, Pumpkin, Squash, Sweet Potatoes, Tomato plants and seed, Watermelons.

\section{August}

Beans (Snap), Cabbage seed, Cantaloupes, Cauliflower seed, Carrots, Cowpeas, Collards, Cucumbers, Eggplant, English Peas, Irish Potatoes, Kale, Kohlrabi, Lettuce, Mustard, Onions, Peppers, Pumpkin, Radishes, Rape, Rutabagas, Spinach, Squash, Swiss Chard, Tomatoes, Turnips, Windsor Beans.

\section{September}

Beets, Brussels Sprouts, Cabbage plants and seed, Carrots, Collards, Cowpeas, Cucumbers, English Peas, Irish Potatoes, Kale, Lettuce, Mustard, Onion sets, Radishes, Rape, Rutabagas, Spinach, Squash, Swiss Chard, Turnips. 


\section{October}

Beets, Bermuda Onion seed, Brussels Sprouts, Cabbage plants and seed, Carrots, Collards, Kale, Lettuce seed and plants, Mustard, Onion sets, Radishes, Rape, Rutabagas, Spinach, Swiss Chard, Turnips.

\section{November}

Beets, Brussels Sprouts, Cabbage seed and plants, Carrots, Collards, Kale, Lettuce, Mustard, Onion sets, Radishes, Rape, Rutabagas, Spinach, Swiss Chard, Turnips.

\section{December}

Cabbage plants and seed, Collards, Lettuce plants and seed, Mustard, Onion sets and plants, Radishes, Rape, Spanish Onion seed, Swiss Chard. 


\section{INDEX}

Acidity, how to test soils for, 20. $\mid$ Basella, 288.

Acidity of Florida soils, 20.

Acid phosphate, 11.

Amaranth, edible, 289.

Amaranthus gangeticus, 289.

Amaranthus oleraceus, 289.

Amaranthus viridis, 289.

Ammonia (see nitrogen, 7).

Ammoniacal solution of copper carbonate, 75 .

Amount, formula, how to compute, 13.

Arachis hypogca, 242.

Arracacia esculenta, 287.

Arsenate of lead, 67.

Arsenite of zinc, 68 .

Artichoke, globe, 132.

Artichoke, Jerusalem, 261.

Ashes, cottonseed hull, 10.

Ashes, saw palmetto, 11 .

Ashes, wood, 11.

Asparagus, 124.

Asparagus bean, 291.

Asparagus, blanching, 129.

Asparagus, bulletins on, 131 .

Asparagus, bunching and crating, 128.

Asparagus, canning, 130.

Asparagus, cutting, 127.

Asparagus, enemies of, 130 .

Asparagus, fertilizer for, 126 .

Asparagus, marketing, 128.

Asparagus, planting, 127.

Asparagus, preparation of plot, 125 .

Asparagus, seed per acre, 45.

Asparagus, varieties of, 131 .

Bait, poison, 72.

Barbarea, 123.

Basella rubra, 288.

Basic slag, 11.

Bean, asparagus, 291.

Bean, broad, 234.

Bean, goa, 288.

Bean, hyacinth, 292.

Bean, Jack, 290.

Beans, 225.

Beans, bulletins on, 233.

Beans, bush, 226.

Beans, bush, fertilizer for, 226.

Beans, bush, green snaps, 230 .

Beans, bush, harvesting, 229.

Beans, bush, kidney green shell, 231.

Beans, bush, planting and cultivating, 227.

Beans, bush, preparing for market, 228.

Beans, bush, soils for, 226 .

Beans, bush sorts, seed per acre, 45.

Beans, bush, varieties of, 230 .

Beans, bush, yellow snaps, 230 .

Beans, enemies of, 233.

Beans, lima, 232.

Beans, lima, Carolina or smallseeded, 232.

Beans, lima, culture, 232.

Beans, lima, large-seeded, 232.

Beans, lima, varieties, 232.

Beans, pole, 230.

Beans, pole, green shell, 231.

Beans, pole, green snaps, 231.

Beans, pole sorts, seed per acre, 45 .

Beans, pole, varieties of, 231.

Beans, pole, yellow snaps, 231.

Bean spray, 71. 
Beans, runner, 232.

Beans, runner, varieties, 233.

Bean, sword, 290.

Beds, seed and plant, 58.

Beet, 271.

Beet, fertilizer for, 272.

Beet, marketing, 273.

Beet, seeding and cultivating, 272.

Beet, seed per acre, 45.

Beet, soil and preparation, 271.

Beet, varieties of, 274.

Belladonna 177.

Benincasa cerifera, 293.

Beta vulgaris, 292.

Bisulfide of carbon, 72.

Blood, dried, 10.

Bone meal, 11.

Bone phosphate, 9.

Bordeaux mixture, 73.

Borecole, kale or, 87 .

Brassica juncea, 290.

Brassica Pe-tsai, 290.

Bread-fruit, 220.

Broad bean, 234.

Broccoli, 95.

Brussels sprouts, 87.

Bulbs, edible, vegetables with, 134.

Cabbage, 81 .

Cabbage, bulletins on, 86 .

Cabbage, Chinese, 290.

Cabbage, enemies of, 86 .

Cabbage, fertilizers for, 84 .

Cabbage, marketing, 85 .

Cabbage, planting and cultivating, 84.

Cabbage, preparing for market, 85 .

Cabbage, seed bed, 82 .

Cabbage, seed per acre, 45 .

Cabbage, soils for, 83 .

Cabbage, sowing seed of, 82 .

Cabbage, varieties of, 86 .

Cajanus indicus, 289.

Calathea Alluia, 285.

Canavalia gladiata, 290.

Canna, mentioned, 285.
Cantaloupes, 151.

Cantaloupes, bulletins on, 154 .

Cantaloupes, enemies of, 154 .

Cantaloupes, fertilizer for, 152.

Cantaloupes, marketing, 153.

Cantaloupes, planting and cultivating, 153.

Cantaloupes, saving the seed, 153.

Cantaloupes (see muskmelon), 45.

Cantaloupes, soil and preparation, 152.

Cantaloupes, varieties of, 154 .

Carbon bisulfide, 72 .

Carrot, 274.

Carrot, fertilizer for, 275 .

Carrot, marketing, 276.

Carrot, soil and preparation, 275.

Carrot, sowing and cultivation of, 276.

Carrot, varieties of, 276.

Cassava, 283.

Cassava, bitter, 284.

Cassava, bulletins, 285.

Cassava, propagation, 284.

Cassava, sweet, 284.

Cauliflower, 89.

Cauliflower, books and bulletins on, 95.

Cauliflower, crating heads, 93.

Cauliflower, cultivation of, 93 .

Cauliflower, cutting, 93.

Cauliflower, enemies of, 95 .

Cauliflower, preparation of land for, 91.

Cauliflower, seed per acre, 45.

Cauliflower, seed production, 94 .

Cauliflower, setting out plants, 92.

Cauliflower, soil and fertilizer for, 92.

Cauliflower, sowing seed of, 90 .

Cauliflower, varieties of, 94 .

Celery, 109.

Celery, blanching, 116.

Celery, bulletins on, 119 .

Celery, cultivation of, 115 .

Celery diseases, 118. 
Celery, distance of planting, 114 .

Celery, fertilizer for, 111.

Celery, irrigation of, 116.

Celery, overhead irrigation, 117.

Celery, preparation of soil for, 110.

Celery, preparing for market, 118.

Celery, seed per acre, 45.

Celery, seed-sowing, 112 .

Celery, soil for, 109.

Celery, sub-irrigation, 117.

Celery, transplanting, 113.

Celery, varieties of, 119 .

Chard, 292.

Chayote, 174.

Chayote, bulletin, 176 .

Chayote, methods of handling, 175 .

Chenopodium Quinoa, 286.

Cherry, ground, 117.

Chicory, 119.

Chicory, cultivation of, 120 .

Chinese cabbage, 290.

Chinese mustard, 290.

Chive, 149.

Citrullus, 151.

Clay, 2.

Clay loam, 2.

Clay, strong, 2.

Coldframes, construction, 52 .

Coldframes, selection and location, 52.

Cole crops, 81 .

Collards, 88.

Collards, seed per acre, 45 .

Colocasia antiquorum, var. esculentum, 279.

Composition of soils, 3 .

Compost, 25.

Compost, how to prepare, 25.

Continuous cropping, 30 .

Copper carbonate, ammoniacal solution of, 75 .

Corchorus olitorius var. edulis, 288.

Corn (sweet), seed per acre, 45.

Cottonseed hull ashes, 10.

Cottonseed meal, 10.
Cover-crops, rotation of legumes used for, 31 .

Cowpea, 235.

Cowpea, bulletin on, 235 .

Cress, 122.

Cress, cultivation of, 123 .

Cress, garden, 123.

Cress, para, 289.

Cress, upland, 123.

Cress, water, 123.

Cucumber field, soil and preparation of, 163.

Cucumbers, 160.

Cucumbers, cultivation, 165 .

Cucumbers, fertilizer for, 164 .

Cucumbers, picking and packing, 166.

Cucumbers, protection from frost, 162.

Cucumbers, seed per acre, 45 .

Cucumbers, seed saving, 167.

Cucumbers, varieties, 169 .

Cucumber, West India, 291.

Cucumis, 151.

Cucumis Anguria, 291.

Cucurbita maxima, 169.

Cucurbita moschata, 169.

Cucurbita Pepo, 169.

Cucurbits, 151.

Cyanamid, 10.

Cynara Scolymus, 132.

Cyphomandra betacea, 292.

Dandelion, 291.

Dasheen, 279.

Dasheen, bulletins, 281.

Dasheen, planting, 280.

Dasheen, uses of, 281.

Deterioration of seed in tropics, 50 .

Dioscorea, 262.

Diseases, and pests, 66 .

Dolichos Lablab, 292.

Dolichos sesquipedalis, 291.

Drain, tile, 40.

Dried blood, 10.

Dry materials, machines for, 76 . 
Edible amaranth, 289.

Edible jute, 288.

Eggplant, 195.

Eggplant, cultivation of, 200.

Eggplant, fertilizer for, 199.

Eggplant, gathering, 201.

Eggplant, hotbeds and coldframes for, 196.

Eggplant, marketing, 201.

Eggplant, seed per acre, 45.

Eggplant, seed saving, 201.

Eggplant, soil and preparation, 199.

Eggplant, using flower pots, 197.

Eggplant, varieties of, 203.

Emulsion, kerosene, 68.

Endive, 106.

Eruca sativa, 290.

Fertilizer, complete, 6 .

Fertilizer elements, percentage of, 10.

Fertilizer formulæ tentative, 7 .

Fertilizer, how to test a field for, 21.

Fertilizer, incomplete, 6 .

Fertilizer table for making up formulæ, 16.

Fertilizers, 5.

Fertilizers, mixing, 11.

Fertilizing elements deficient, 5 .

Fish-oil soap, 69.

Fish scrap, 9.

Fish scraps, 10.

Florida soils, acidity of, 20.

Formalin, 72.

Formula, how to compute amount, 12.

Formulæ compared, 14.

Fungicides, 73.

Garlic, 150.

Gaseous insecticides, 72 .

Ginger, 291.

Globe artichoke, 132.

Goa bean, 288.

Goober, 242.
Gourd, snake, 292.

Gourd, wax, 293.

Ground limestone, 18.

Guano, 10, 11.

Gumbo, 215.

Helianthus tuberosus, 261.

Henbane, 177.

Hibiscus Sabdariffa, 209.

High grade fertilizer cheaper, 15.

Honest packing, 80.

Horse-radish, 283.

Hotbeds, 55.

House, packing, 78.

Hull ashes, cottonseed, 10.

Humus, 1.

Hyacinth bean, 292.

Hydraulic ram, 35.

Insecticides, contact, 68 .

Insecticides, gaseous, 72 .

Insecticides, poisonous, 67 .

Irish potato, 244.

Irrigation, 36 .

Irrigation, overhead, 37 .

Irrigation, sub-, 40.

Irrigation, surface, 40.

Jack bean, 290 .

Jerusalem artichoke, 261.

Jimson-weed, 177.

Jute, edible, 288.

Kainit, 10.

Kale or borecole, 87.

Kerosene emulsion, 68.

Kohlrabi, 97.

Kohlrabi, soil and preparation, 97.

Kohlrabi, varieties of, 98 .

Land becomes poor, why, 4 .

Land, clearing, 61.

Land, plowing, 61.

Land, preparation of, 59 .

Land, "tired," 4.

Land, well drained, 60. 
Lead arsenate, 67.

Leek, 147.

Leek, preparation for market, 148. Leek, transplanting, 148 .

Legumes used as cover crops, rotation of, 31 .

Leguminous plants, 222 .

Lepidium, 122.

Lettuce, 99.

Lettuce, bulletins on, 106.

Lettuce, cultivation of, 102 .

Lettuce, diseases of, 105.

Lettuce, fertilizer for, 102.

Lettuce, field preparation for, 102 .

Lettuce, irrigation for, 103.

Lettuce, marketing, 104.

Lettuce, seed-bed for, 100.

Lettuce, seed per acre, 45 .

Lettuce, seed raising, 104.

Lettuce, setting out, 101.

Lettuce, varieties of, 105.

Lima beans, 232 .

Lime, 18.

Lime, nitrate of, 10 .

Limestone, coarse ground preferred, 19.

Limestone, ground, 18.

Lime sulfur solution, 70 .

Lime sulfur solution, commercial, 70.

Liquids, machines for, 76 .

Lleren, 285.

Loam, 2.

Machines for dry materials, 76 .

Machines for liquids, 76.

Machines, how to test, 43.

Machines, spraying, 75 .

Magnesia, sulfate of potash and, 11.

Manures, fertilizer ingredients, 24.

Manures for vegetable gardening, 24.

Maranta, mentioned, 285.

Marketing, 78 .

Marl, 3.
Meal, bone, 11.

Meal, cottonseed, 10.

Melon (musk), seed per acre, 45.

Melon pawpaw, 217.

Melon, water, 155.

Melon (water), seed per acre, 45.

Miscible oils, 71 .

Mixture, bordeaux, 73 .

Muck, 28.

Muck, composition of, 3 .

Muck, good, 10.

Muck soils acid, 20 .

Muskmelon (see cantaloupe), 151154.

Mustard, Chinese, 290.

New Zealand spinach, 288.

Nicotianas, 177.

Nitrate, materials used for, 10.

Nitrate of lime, 10.

Nitrate of soda, 10.

Nitrogen, cheapest, 8 .

Nitrogen, forms of, 7 .

Nitrogen gathering plants, 32 .

Nitrogen, plants as a source of, 31 .

Nitrogen, sources of, 7 .

Nitrogen, substances used as sources of, 7 .

Oils, miscible, 71.

Okra, 215.

Okra, bulletin on, 216 .

Okra, seed per acre, 45.

Onion crop, curing the, 143.

Onion-growing, large scale method of, 142.

Onions, 134.

Onions, bulletins on, 146 .

Onions, costs in growing, 146.

Onions, crating, 144.

Onions, cultivation of, 141.

Onion seed, time to sow, 137.

Onion sets, quantity per acre, 45.

Onions, fertilizer for, 135.

Onions, how to set out, 140.

Onions, raising from sets, 144. 
Onions, seed-bed for, 137.

Onions, seed per acre, 45.

Onions, setting out, 138.

Onions, soil for, 135.

Onions, transplanting, 139.

Onions, varieties, 144.

Overhead irrigation, 37.

Oyster plant, 279.

Pachyrhizus erosus, 287.

Pachyrhizus tuberosus, 287.

Packing, honest, 80.

Packing-house, the, 78 .

Papaya, 217.

Papaya, distance to plant, 219.

Papaya, from seed, 218.

Papaya, grafting, 218.

Papaya, irrigation, 219.

Para cress, 289.

Paris green, 67.

Parsley, 121.

Parsley, planting, 121.

Parsley, varieties of, 122.

Parsnip, 277.

Parsnip, fertilizer for, 277.

Parsnip, soil and preparation, 277.

Parsnip, sowing and cultivation, 278.

Parsnip, varieties, 278.

Pawpaw melon, 217.

Peanut, 236.

Peanut, cleaning, 241.

Peanut, cultivation, 239.

Peanut, fertilizer, 237.

Peanut, grading, 241.

Peanut, harvesting, 240.

Peanut, literature on, 242.

Peanut, planting, 237.

Peanut, soil and preparation, 236.

Peanut, varieties of, 242.

Pea, pigeon, 289.

Peas, 222.

Peas (cow), seed per acre, 45.

Peas, enemies of, 224.

Peas (English), seed per acre, 45.

Peas, fertilizer for, 223.
Peas, soil and cultivation, 223.

Peas, varieties of, 224.

Peat, 28.

Pepino, 293.

Peppers, 204.

Peppers, cultivation of, 207.

Peppers, fertilizer for, 207.

Peppers, hotbeds and coldframes for, 205.

Peppers, marketing, 207.

Peppers, seed per acre, 45.

Peppers, seed saving, 208.

Peppers, soil and preparation for, 206.

Peppers, varieties of, 208.

Pests and diseases, 66.

Petunia, 177.

Phosphate, bone, 9.

Phosphate from fish, 9.

Phosphate rock, 8.

Phosphate, Thomas, 11.

Phosphoric acid, materials used for, 11.

Phosphoric acid, sources of, 8

Pigeon pea, 289.

Plantain, 216.

Plant-beds, seed-beds and, 58 .

Plant growth, elements necessary for, 3,5 .

Planting, 52.

Plants, acre, number of, 65.

Plants as a source of nitrogen, 31 .

Plant-sheds, 57.

Plants, how to select, 46.

Plants, number per acre (table), 64.

Plants transmit tendency to disease, 46.

Poison bait, 72 .

Poisonous insecticides, 67.

Potash, materials used for, 10 .

Potash, muriate of, 10.

Potash, nitrate of, 10 .

Potash, sources of, 9 .

Potash, sulfate of, and magnesia, 11. 
Potash, sulfate of (high grade), 11. Ram, hydraulic, 35.

Potato, Irish, 244.

Potato, Irish, bulletins, 253.

Potato, Irish, cultivation of, 249.

Potato, Irish, diseases of, 253.

Potato, Irish, fertilizer for, 246.

Potato, Irish, harvesting, 250.

Potato, Irish, planting, 248.

Potato, Irish, second crop of, 252.

Potato, Irish, seed, 247.

Potatoes (Irish), seed per acre, 45.

Potato, Irish, soil and preparation for, 245.

Potato, Irish, storing, 251.

Potato, Irish, varieties of, 252.

Potato, sweet, 254.

Potato, sweet, bulletins, 260.

Potato, sweet, cultivation, 257.

Potato, sweet, enemies of, 259.

Potato, sweet, fertilizer, 255.

Potato, sweet, marketing, 259.

Rock phosphate, 8, 11.

Rolliza, 282.

Roquette, 290.

Roselle, 209.

Roselle, bulletin on, 214.

Roselle, cultivation of, 211.

Roselle, diseases of, 214.

Roselle, gathering, 212.

Roselle, productivity, 213.

Roselle, propagation, 210.

Roselle, shipping, 212.

Roselle, uses of, 213.

Roselle, varieties of, 214.

Rotation of crops in vegetable gardening, 29.

Rotation of legumes used as cover crops, 31.

Rutabaga, 270.

Salsify, 279.

Salsify, seed per acre, 45.

Potato, sweet, preparation of land for and transplanting, 256.

Potato, sweet, propagation of, 255.

Potato, sweet, soil for, 254.

Potato, sweet, storing, 258.

Potato, sweet, varieties of, 260.

Psophocarpus tetragonolobus, 288.

Pumping plant, 38.

Quantity of seed for one acre (table), 45.

Radicula, 123.

Radish, 264.

Radish, comparison of varicties (table), 268.

Radish, fertilizer for, 265.

Radish, horse, 283.

Radish, marketing, 266.

Radish, seed per acre, 45.

Radish, seed raising, 267.

Radish, soil and preparation, 264.

Radish, sowing and cultivation, 265.

Radish, varieties of, 267.

Sand, light, 2.

Sandy loam, 2.

Saw palmetto ashes, 11.

Sechium edule, 175.

Seed-beds and plant-beds, 58 .

Seed-control laboratories, 48.

Seed for one acre, quantity of (table), 45.

Seed growing, 46.

Seed, in tropies, deterioration of, 50.

Seed, nearly all-important, 47 .

Seed, quantity to sow, 44.

Seeds and seed-sowing, 43.

Seed-storing, 49.

Seed testing, 48 .

Shallot, 149.

Sheds, plant, 57.

Slag, basic, 11.

Slag, Thomas, 8.

Snake gourd, 292.

Soap, fish-oil, 69.

Soap, whale-oil, 69.

Soda-sulfur spray, 69. 
Soft phosphate, 11.

Soil acidity, how to test for, 20 .

Soil, calcareous, 3 .

Soil, marly, 3.

Soils, acidity of Florida, 20.

Soils, composition of, 3.

Soils, for vegetable gardening in warm countries, 1.

Soils, mechanical classification of, 2.

Solanaceous plants, 177.

Solanum muricatum, 293.

Solution, lime sulfur, 70 .

Spilanthes oleracea, 289.

Spinach, 107.

Spinach, marketing, 108.

Spinach, seed per acre, 45.

Spinach, varieties of, 108.

Spray, bean, 71 .

Spray, soda-sulfur, 69.

Spray, tobacco-sulfur, 69.

Spraying machines, 75.

Sprouts, Brussels, 87.

Squash, 169.

Squash, choosing soil for, 170 .

Squash, cultivating, 173.

Squash, fertilizer for, 170 .

Squash, marketing, 173.

Squash planting, 172.

Squash (summer), seed per acre, 45.

Squash, varieties, 174.

Squash (winter), seed per acre, 45 .

Strawberry tomato, 177.

Sub-irrigation, 40.

Sub-irrigation, depth of tile, 40 .

Sulfate of ammonia, 10.

Sulfate of potash and magnesia, 11.

Sulfate of potash (high grade), 11.

Superphosphate, 8 .

Surface irrigation, 40.

Swedish turnip, 270.

Sweet corn, 242.

Sweet corn, varieties of, 243.

Sweet potato, 254.

Sword bean, 290.

Tanier, 281.

Tanier, bulletin, 282.

Tanier, propagation, 282.

Tankage, 10, 11.

Taraxacum officinale, 291.

Taro, 279.

Tetragonia expansa, 288.

Thomas phosphate, 11.

Thomas slag, 8 .

Tile, drain, 40.

Tobacco, 177.

Tobacco stems, 10, 11.

Tobacco-sulfur spray, 69.

Tomato, 177.

Tomato, cultivation, 185.

Tomato, fertilizer, 182.

Tomato, packing-house, 189.

Tomato, picking, 188.

Tomato plants, setting out, 184.

Tomato, preparing the field, 182.

Tomato seed, 179.

Tomato seed-beds, 180.

Tomato, seed per acre, 45 .

Tomato, soil for, 181 .

Tomato, strawberry, 177.

Tomato, tree, 292.

Tomato, trellising, 188.

Tomato vines, pruning, 186.

Tomatoes, canning, 192.

Tomatoes, enemies of in Florida, 193.

Tomatoes in the tropies, 178.

Tomatoes, literature on, 195.

Tomatoes, saving seed, 191.

Tomatoes, sorting, 190.

Tomatoes, staking, 187.

Tomatoes, summer and fall crop, 191.

Tomatoes, varieties of, 194.

Transplanting, 62.

Tree tomato, 292.

Trichosanthes Anguina, 292.

Tropical seeds, 50 .

Turnip, 268.

Turnip, marketing, 270.

Turnip, planting and cultivating, 269. 
Turnip, soil and preparation, 269. Watermelon, cultivating, 157.

Turnips, seed per acre, 45.

Turnip, varieties of, 270 .

Watermelon, diseases and insects of, 159 .

Watermelon, fertilizer for, 155 .

Ullucus tuberosus, 296.

Upland eress, 123.

Watermelon, marketing, 158 .

Watermelon, planting, 156 .

Watermelon, saving seed, 158.

Varieties, choosing the, 44 .

Watermelon, varieties of, 159 .

Vegetable gardening, rotation of erops in, 29.

Vegetables with edible bulbs, 134.

Vegetables with edible fruits, 151, $177,209$.

Vegetables with edible leaves or stems, 81, 99.

Vegetables with edible seeds, 222.

Vegetables with edible tubers or roots, 244.

Vicia Faba, 234.

Vigna, 291.

Voandzeia subterranea, 242.

Water, 35.

Water-cress, 123.

Watering, 35 .

Watermelon, 155.

Watermelon, bulletins and papers on, 160.

Wax gourd, 293.

Weeds, 32.

Weeds, sourees of plant diseases, 32.

West India cueumber, 291.

Whale-oil soap, 69.

Windmills, 36 .

Wood ashes, 11.

Xanthosoma, 281.

Yam, 262.

Yam-bean, 287.

Yam, kinds, 263.

Yam, preparation, 262.

Yam, propagation, 263.

Yam (sweet potato), 260.

Zine arsenite, 68.

Zingiber officinale, 291.

Printed in the United States of America. 



\title{
The Standard Cyclopedia of Horticulture
}

\author{
Edited by L. H. BAILEY
}

With the Assistance of over 500 Collaborators

New edition, entirely rewritten and enlarged, with many new features; with 24 plates in color, 96 full-page half-tones and over 4,000 text illustrations

To be complete in six volumes

Sold only in sets by subscription

The Country Gentleman's Companion

THe Amateur's Guide

THE BOTANIST'S TREASURE
The Gardener's Manual The Student's Textbook THE TEACHER'S LIBRARY

This, the fullest, the newest, the most authoritative of all works of its kind, supersedes the old Cyclopedia of American Horticulture first issued fourteen years ago. "The Standard Cyclopedia of Horticulture" is an entirely new work, freshly written throughout with the assistance of 500 collaborators. It represents the most recent research, labor and experience, and compresses the whole story of thought, learning, and achievement on the subject into one set of six large, handsome quarto volumes.

\section{TWO OPINIONS OF THE NEW CYCLOPEDIA}

"No one who knows anything at all about the literature of gardening needs to be told that the Cyclopedia is unique. It is the Bible and Britannica of the garden-folk, amateur and professional alike. And the remarkable thing is that while it is fundamentally a work of reference, it also contains limitless quantities of good reading of the sort dear to the heart of the garden enthusiast." - The Nation.

"It is no exaggeration to state that Bailey's new work is the best Cyclopedia obtainable for all who are connected, either remotely or intimately, as amateurs or professionals, with horticultural pursuits." - The Florists' Review.

\section{THE MACMILLAN COMPANY}




\section{Two Important Books Rewritten and Brought Up to Date}

\section{Principles of Fruit-Growing}

By L. H. BAILEY. New Edition, revised and rewritten

Illustrated, I2mo, $\$ 1.75$

Since the original publication of this book in 1897, it has gone through a total of nineteen editions. The progress of fruit-growing in the meantime has been very marked and it has now become necessary to rewrite this work. The present issue of it brings the accounts of the new practices and discoveries as they relate to fruit-growing up to date. It gives the latest information and points of view on fertilizers and different kinds of fruits, the heating of orchards to protect them from frost, the treatment of diseases and insects, full discussions with diagrams of the methods of laying out orchards and much other subject matter. This revision continues the text as standard. The illustrations represent new hand drawings, with the complete elimiuation of half-tones, thereby giving an artistic appearance to the volume.

\section{Plant-Breeding}

By L. H. BAILEY. New Edition

Revised by A. W. GILBERT, Professor of Plant-Breeding in the New York State College of Agriculture

Illustrated, cloth, I2mo, $\$ 2.00$

The original foundation for this book is Professor Bailey's standard text, Plant-Breeding, first published in 1895. As now issued the material in the old volume has been thoroughly revised and brought down to date. New discussions of mutations, Mendelism, heredity and the recent applications of the breeding of plants are all included. The work is now adapted to the classroom as well as to the needs of the general reader. Extensive laboratory exercises have been added; the bibliography, which has been a prominent feature of previous editions, except the first, has been retained and extended. A list of current books and periodicals and a glossary of plant-breeding terms are also contained in the book.

\section{THE MACMILLAN COMPANY}

Publishers

64-66 Fifth Avenue
New York 


\title{
Electricity for the Farm
}

LIGHT, HEAT, AND POWER BY INEXPENSIVE METHODS FROM THE WATER WHEEL OR FARM ENGINE

\author{
BY FREDERICK IRVING ANDERSON \\ Author of "The Farmer of To-morrow" \\ Cloth, Izmo, illustrated, $\$ I .25$
}

A year or so ago there was published an exceedingly practical little work entitled "The Farmer of To-morrow." Rarely has as much of genuine value been put into a book as was put into this one, and the author, Frederick Irving Anderson, was looked to for further contributions in the same field. The announcement, therefore, of the appearance of "Electricity for the Farm" will be welcomed by all farmers and students of agricultural matters.

Mr. Anderson believes that many farmers are not making the most of their opportunities. He shows how, with very little expense, a farmer may have all the benefits of electricity for light, heat, and power either by installing a simple gasoline engine or by using the neglected brook that runs through some part of the farm lands. As he points out, a mighty stream is not necessary to secure sufficient power, but a rivulet with only a little fall will quite answer the purpose. Realizing, however, that not every farm has even "a babbling brook," he considers other sources of power.

\section{THE MACMILLAN COMPANY \\ Publishers \\ 64-66 Fifth Avenue \\ New York}




\title{
TWO IMPORTANT NEW WORKS
}

\section{The Strawberry in North America}

\author{
By S. W. FLETCHER
}

Illustrated, cloth, I2mo

This work is not only a practical guide to strawberry growing but also a sketch of the evolution of the strawberry in North America, from the wilding of colonial days to its present position as the most cosmopolitan of American fruits, second only to the apple in commercial importance. The volume includes chapters on the early history of the strawberry in the old world and the new, the botany and origin of the cultivated strawberry, the rise of strawberry culture and the different ways in which it is practiced in different parts of the country, with something of an attempt to elucidate the principles that underlie these practices.

\section{Principles of Floriculture}

\section{BY EDWARD A. WHITE}

\section{Professor of Floriculture in the New York State College of Agriculture} at Cornell University

Cloth, I2mo, $\$ I .75$

The flower-growing business has become highly specialized. Science has, therefore, come to be an important factor in flower production, and there has arisen a demand for scientific information regarding all lines of floriculture. The purpose of the author of this book has been to consider the principles which underlie the successful culture of ornamental plants, and to present these in such a manner that the book may be useful in the class-room. It is believed that it will also be of service in a practical way to practical men. Among the topics discussed are: the importance of the plant and flower growing industry; principles and methods of constructing and heating glasshouses; factors which influence healthy plant growth; business principles in marketing flowers; glasshouse insects and their extermination; diseases of plants and their remedies, and the factors which underlie successful culture of standard florists' crops.

\section{THE MACMILLAN COMPANY}




\section{RURAL SCIENCE SERIES}

Edited by L. H. BAILEY

\section{Each volume illustrated. Cloth, $12 \mathrm{mo}$.}

A series of practical books for farmers and gardeners, sold as a set or separaiely. Each one is the work of a competent specialist, and is suitable for consultation alike by the amateur or professional tiller of the soil, the scientist or the student. Illustrations of marked beauty are freely used, and the books are clearly printed and well bound.

ON SELECTION OF LAND, ETC.

Isaac P. Roberts' The Farmstead . . . . . . . . . . \$1 50

T. F. Hunt's How to Choose a Farm . . . . 175

E. S. Cheyney and J. P. Wentling's The Farm Woodlot: $: 150$

Glenn W. Herrick's Insects Injurious to the Household . . 175

ON TILLAGE, ETC.

F. H. King's The Soil • • • . . 150

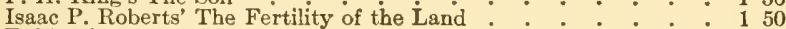

F. H. King's Irrigation and Drainage . . . . . . : . 150

Edward B. Voorhees' Fertilizers ? : : : : : : : 125

Edward B. Voorhees' Forage Crops ? . . . . . : . 150

J. A. Widtsoe's Dry Farming : : : : : 150

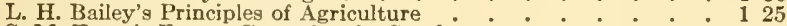

S. M. Tracy's Forage Crops for the South : : : : . : 150

ON PLANT DISEASES, ETC.

E. C. Lodeman's The Spraying of Plants . . . . . . . 125

ON GARDEN-MAKING

L. H. Bailey's Garden-Making . . . . . . . . . . . 150

L. H. Bailey's Vegetable-Gardening : : $: \div \quad: \quad$ : 150

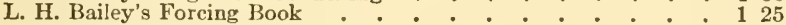

L. H. Bailey's Plant Breeding . • . • . . . . , 200

P. H. Rolfs' Subtropical Vegetable-gardening : $: \vdots \vdots \quad 000$

ON FRUIT-GROWING, ETC.

L. H. Bailey's Nursery Book . . . . . • . . . . 150

L. H. Bailey's Fruit-Growing (New Edition) : : : : : : 175

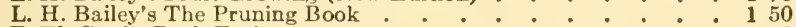

F. W. Card's Bush Fruits . 50

W. Paddock \& O. B. Whipple's Fruit-Growing in Arid Regions : 150

J. E. Coit's Citrus Fruits ․ 200

S. W. Fletcher's The Strawberry in North America. Preparing

ON THE CARE OF LIVE STOCK

Nelson S. Mayo's The Diseases of Animals . . . . . . . 150

W. H. Jordan's The Feeding of Animals . . . . 150

I. P. Roberts' The Hors?

M. W. Harper's Breaking and Trajning of Horses . . . . 175

George C. Watson's Farm Poultry. New edition : $: \vdots 150$

John A. Craig's Sheep Farming . • . • . . . • . 150

E. F. Phillips Beekeeping . : $: \div \quad: \quad 200$

ON DAIRY WORK, FARM CHEMISTRY, ETC.

Henry H. Wing's Milk and Its Products. New edition . . . . 150

J. G. Lipman's Bacteria and Country Ljfe . . : : : 150

ON ECONOMICS AND ORGANIZATION

William A. McKeever's Farm Boys and Girls • • . . . . 150

I. P. Roberts' The Farmer's Business Handbook ? . ․ . 125

George T. Fairchild's Rural Wealth and Welfare $: \vdots \vdots: \vdots 125$

H. N. Ogden's Rural Hygiene . . . . . . . . . . 150

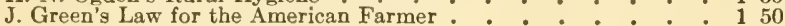

G. H. Powell's Coöperation in Agriculture : . . . . . 150

J. B. Morman's Principles of Rural Credits . . * . . . 125

\section{THE MACMILLAN COMPANY}




\section{RURAL TEXT-BOOK SERIES Edited by L. H. BAILEY}

\section{Each volume illustrated. Cloth, $12 \mathrm{mo}$.}

While the RURAL SCIENCE SERIES is designed primarily for popular reading and for general use, this related new series is designed for classroom work and for special use in consultation and reference. The RURAL TEXT-BOOK SERIES is planned to cover eventually the entire range of public school and college texts.

DUgGar, B. M.

Physiology of Plant Production . . . . . $\$ 160$ Duggar, John Frederick

Southern Field Crops. . . . . . . . . 175

Gay, C. Warren

Principles and Practice of Judging Live-Stock . 150 HARPER, M. W.

Animal Husbandry for Schools . . . . . . 140

Hiтснсоск, A. S.

Grasses . . . . . . . . . . . 150

Livingston, George

Field Crop Production . . . . . . . . . . 140

Lron, T. L. and Fippin, E. O.

Principles of Soil Management . . . . . 175

ManN, A. R.

Beginnings in Agriculture . . . . . . . 75

Montgomert, G. F.

Corn Crops

Piper, Charles V.

Forage Plants and Their Culture . . . . . 175

WARREN, G. F.

Elements of Agriculture . . . . . . . 110

Warren, G. F.

Farm Management . . . . . . . 175

WheELER, H. J.

Manures and Fertilizers . . . . . . 160

White, Edward A.

Principles of Floriculture. . . . . . . . 175

Widtsoe, Јонn A.

Principles of Irrigation Practice . . . . . . 175

\section{THE MACMILLAN COMPANY}

Publishers 



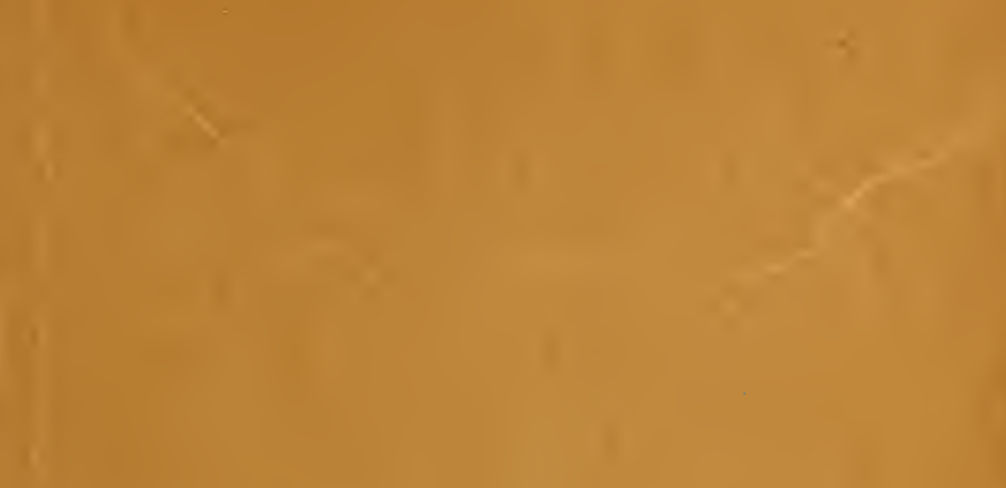

11

1

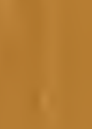

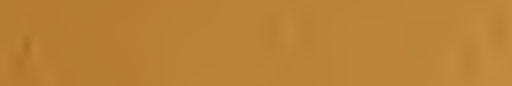

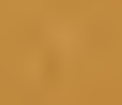

$x_{1}$

2
14.

4 i<smiles>CCCC</smiles>

$\sqrt{2}$
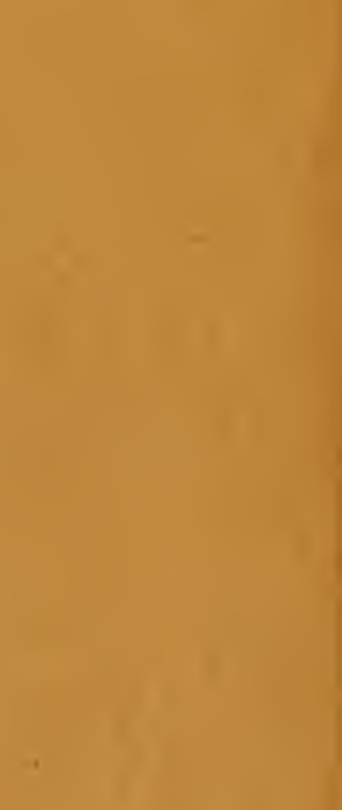

$-$<smiles>C1CCCC1</smiles> 


\section{LIBRARY OF CONGRESS

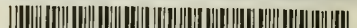

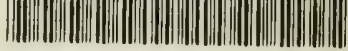 \\ 00009161508}

